\title{
JTEC Panel on \\ Electronic Manufacturing and Packaging in Japan
}

\author{
FINAL REPORT
}

February 1995

Michael J. Kelly, Chair

William R. Boulton

John A. Kukowski

Eugene S. Meieran

Michael Pecht

John W. Peeples

Rao R. Tummala

William R. Boulton, Editor

ISBN 1-883712-37-8

This document was sponsored by the National Science Foundation (NSF), the Advanced Research Projects Agency, the National Aeronautics and Space Administration, and the Department of Commerce of the United States Government under NSF Cooperative Agreement ENG-9217849, awarded to the International Technology Research Institute at Loyola College in Maryland. Any opinions, findings, and conclusions or recommendations expressed in this material are solely those of the authors and do not necessarily reflect the views of the United States Government, the authors' parent institutions, or Loyola College. 


\title{
ABSTRACT
}

This report summarizes the status of electronic manufacturing and packaging technology in Japan in comparison to that in the United States, and its impact on competition in electronic manufacturing in general. In addition to electronic manufacturing technologies, the report covers technology and manufacturing infrastructure, electronics manufacturing and assembly, quality assurance and reliability in the Japanese electronics industry, and successful product realization strategies. The panel found that Japan leads the United States in almost every electronics packaging technology. Japan clearly has achieved a strategic advantage in electronics production and process technologies. Panel members believe that Japanese competitors could be leading U.S. firms by as much as a decade in some electronics process technologies. Japan has established this marked competitive advantage in electronics as a consequence of developing low-cost, high-volume consumer products. Japan's infrastructure, and the remarkable cohesiveness of vision and purpose in government and industry, are key factors in the success of Japan's electronics industry. Although Japan will continue to dominate consumer electronics in the foreseeable future, opportunities exist for the United States and other industrial countries to capture an increasingly large part of the market. The JTEC panel has identified no insurmountable barriers that would prevent the United States from regaining a significant share of the consumer electronics market; in fact, there is ample evidence that the United States needs to aggressively pursue high-volume, low-cost electronic assembly, because it is a critical path leading to high-performance electronic systems.

\section{JTEC/WTEC}

Michael J. DeHaemer, Principal Investigator, Director

Geoffrey M. Holdridge, Staff Director and JTEC/WTEC Series Editor

Bobby A. Williams, Assistant Director

Catrina M. Foley, Secretary

Aminah Batta, Editorial Assistant

Patricia M.H. Johnson, Editor

Advance Work performed by M. Gene Lim of SEAM International

\section{International Technology Research Institute at Loyola College}

\author{
R. D. Shelton, Director
}

Copyright 1995 by Loyola College in Maryland except as otherwise noted. The U.S. Government retains a nonexclusive and nontransferable license to exercise all exclusive rights provided by copyright. The ISBN number for this report is 1-883712-37-8. This report is distributed by the National Technical Information Service (NTIS) of the U.S. Department of Commerce as NTIS Report \# PB95-188116. Information on ordering from NTIS and a list of JTEC/WTEC reports available from NTIS are included on the inside back cover of this report. 


\section{FOREWORD}

The National Science Foundation (NSF) has been involved in funding technology assessments comparing the United States and foreign countries since 1983. A sizable proportion of this activity has been in the Japanese Technology Evaluation Center (JTEC) and World Technology Evaluation Center (WTEC) programs. NSF has supported more than thirty JTEC and WTEC studies over a wide range of technical topics.

As U.S. technological leadership is challenged in areas of previous dominance such as aeronautics, space, and nuclear power, many governmental and private organizations seek to set policies that will help maintain U.S. strengths. To do this effectively requires an understanding of the relative position of the United States and its competitors. The purpose of the JTEC/WTEC program is to assess research and development efforts in other countries in specific areas of technology, to compare these efforts and their results to U.S. research in the same areas, and to identify opportunities for international collaboration in precompetitive

Many U.S. organizations support substantial data gathering and analysis efforts directed at nations such as Japan. But often the results of these studies are not widely available. At the same time, government and privately sponsored studies that are in the public domain tend to be "input" studies; that is, they provide enumeration of inputs to the research and development process, such as monetary expenditures, personnel data, and facilities, but do not provide an assessment of the quality or quantity of the outputs obtained.

Studies of the outputs of the research and development process are more difficult to perform because they require a subjective analysis performed by individuals who are experts in the relevant technical fields. The NSF staff includes professionals with expertise in a wide range of disciplines. These individuals provide the technical expertise needed to assemble panels of experts that can perform competent, unbiased, technical reviews of research and
development activities.

Specific technologies, such as telecommunications, biotechnology, microelectromechanical systems, and nuclear power, are selected for study by government agencies that have an interest in obtaining the results of an assessment and are able to contribute to its funding. A typical assessment is sponsored by two to four agencies. In the first few years of the program, most of the studies focused on Japan, reflecting concern over Japan's growing economic prowess. Studies were largely defined by a few federal mission agencies that contributed most of the funding, such as the Department of Commerce, the Department of Defense, and the Department of Energy.

The early JTEC methodology involved assembling a team of U.S. experts (usually six people from universities, industry, and government), reviewing the extant literature, and writing a 
final report. Within a few years, the program began to evolve. First we added site visits. Panels traveled to Japan for a week and visited twenty to thirty industrial and research sites. Then, as interest in Japan increased, a larger number of agencies became involved as cosponsors of studies. Over the ten-year history of the program, fifteen separate branches in six agencies of the federal government (including NSF) have supported JTEC and WTEC studies.

Beginning in 1990, we began to broaden the geographic focus of the studies. As interest in the European Community (now the European Union) grew, we added Europe as area of study. With the breakup of the former Soviet Union, we began organizing visits to previously restricted research sites opening up there. These most recent WTEC studies have focused on identifying opportunities for cooperation with researchers and institutes in Russia, the Ukraine, and Belarus, rather than on assessing them from a competitive viewpoint.

In the past four years, we also have begun to substantially expand our efforts to disseminate information. Attendance at JTEC/WTEC workshops (in which panels present preliminary findings) has increased, especially industry participation. Representatives of U.S. industry now routinely number 50 percent or more of the total attendance, with a broad cross section of government and academic representatives making up the remainder. JTEC and WTEC studies have also started to generate increased interest beyond the science and technology community, with more workshop participation by policymakers and better exposure in the general press (e.g., Wall Street Journal, New York Times). Publications by JTEC and WTEC panel members based on our studies have increased, as have the number of presentations by panelists at professional society meetings.

The JTEC/WTEC program will continue to evolve in response to changing conditions in the years to come. NSF is now considering new initiatives aimed at the following objectives:

- Expanding opportunities for the larger science and technology community to help define and organize studies.

- Increasing industry sponsorship of JTEC and WTEC studies. For example, NSF recently funded a team organized by the Polymer Science and Engineering Department at the University of Massachusetts (Amherst) for a two-week visit to Japan to study biodegradable plastics and polymers $R \& D$. Twelve industrial firms provided over half of the funds.

- Providing a broader policy and economic context to JTEC/WTEC studies. This is directed at the need to answer the question, "So what?" that is often raised in connection with the purely technical conclusions of many JTEC and WTEC panels. What are the implications of the technical results for U.S. industry and the economy in general? An economist has joined the current JTEC study on optoelectronics in Japan as part of a new effort to address these broader questions. 
In the end, all government-funded programs must answer the question, How has the program benefited the nation? A few of the benefits of the JTEC/WTEC program follow:

- JTEC studies have contributed significantly to U.S. benchmarking of the growing prowess of Japan's technological enterprise. Some have estimated that JTEC has been responsible for over half of the major Japanese technology benchmarking studies conducted in the United States in the past decade. JTEC reports have also been widely cited in various competitiveness studies.

- These studies have provided important input to policymakers in federal mission agencies. JTEC and WTEC panel chairs have given special briefings to senior officials of the Department of Energy, to the National Aeronautics and Space Administration (NASA) Administrator, and even to the President's Science Advisor.

- Studies have been of keen interest to U.S. industry, providing managers with a sense of the competitive environment internationally. Members of the recently completed study on satellite communications have been involved in preliminary discussions concerning the establishment of two separate industry/university consortia aimed at correcting the technological imbalances identified by the panel in its report.

- Information from JTEC and WTEC studies also has been valuable to both U.S. and foreign researchers, suggesting a potential for new research topics and approaches, as well as opportunities for international cooperation. One JTEC panelist was recently told by his Japanese hosts that, as a result of his observations and suggestions, they have recently made significant new advances in their research.

- Not the least important is the educational benefit of the studies. Since 1983 over 200 scientists and engineers from all walks of life have participated as panelists in the studies. As a result of their experiences, many have changed their viewpoints on the significance and originality of foreign research. Some have also developed lasting relationships and ongoing exchanges of information with their foreign hosts as a result of their participation
in these studies.

As we seek to refine the JTEC/WTEC program in the coming years, improving the methodology and enhancing the impact, program organizers and participants will continue to operate from the same basic premise that has been behind the program from its inception: the United States can benefit from a better understanding of cutting-edge research that is being conducted outside its borders. Improved awareness of international developments can significantly enhance the scope and effectiveness of international collaboration and thus benefit all of the United States' international partners in collaborative research and development efforts.

Paul J. Herer

National Science Foundation

Arlington, VA 


\section{TABLE OF CONTENTS}

Foreword

Contents

List of Figures

List of Tables ...

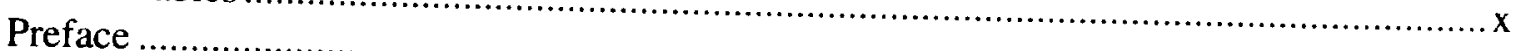

Executive Summary

1. -! Microelectronics in Japan

William R. Boulton

Introduction

The U.S. Electronics Industry

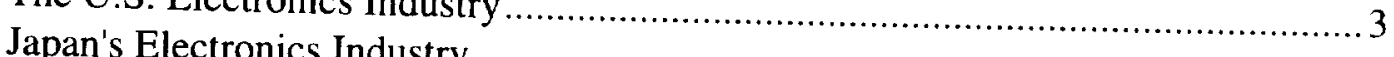

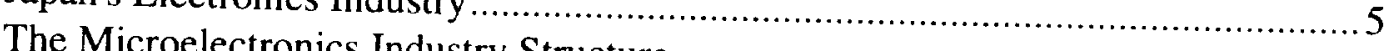

References $\ldots 16$

2. - 2 Building the Electronic Industry's Roadmaps

William R. Boulton

Dimensions of Product Development in Japan

Conclusions

References

3. - 3 Japan's Technology and Manufacturing Infrastructure

William R. Boulton

Eugene S. Meieran

Rao R. Tummala

Overview of Japan's Technology Infrastructure

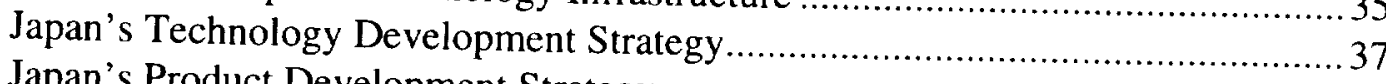

Industrial Computerizationent Strategy ........................................................ 42

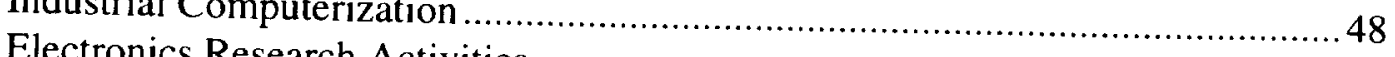

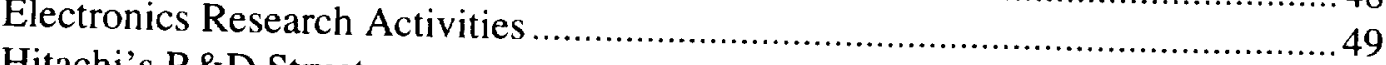

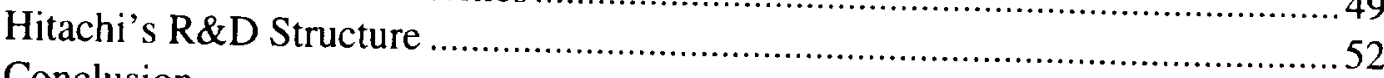

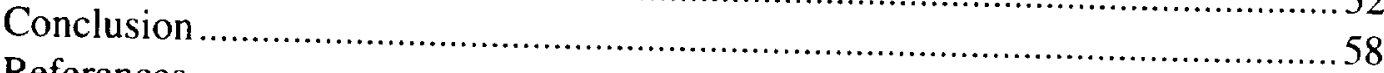

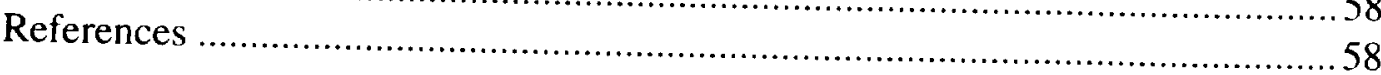


vi

4. Japan's Electronic Packaging Technologies

$4 \quad$ Rao R. Tummala

Michael Pecht

Introduction

Japan's Electronic Packaging Strategies

Plastic Packaging Technologies

Ceramic Packaging Technologies

Passive Component Technologies

Advanced Multichip Packaging Developments

Printed Wiring Board Technologies

Chip Assembly Technologies.

Package Assembly Technologies

Future Package Decisions.

Summary Of Japanese Packaging Trends

Conclusion.

References

5. Electronics Manufacturing and Assembly in Japan

5 John A. Kukowski

William R. Boulton

Japan's Distinctive Competence In Manufacturing

Enabling Technologies

Factory Automation (FA)

Japan's Automated Electronics Assembly Demonstrated

Summary

References

6. Quality Assurance and Reliability in the Japanese Electronics Industry

6 Michael Pecht

William R. Boulton

History of Japan's Quality Movement

Quality and Reliability Requirements

Summary

References

\section{Successful Product Realization Strategies}

1 John Peeples

William R. Boulton

Requirements Definition

Design for Excellence

Japanese Technology Commercialization Efforts

Summary

References 


\section{APPENDICES}

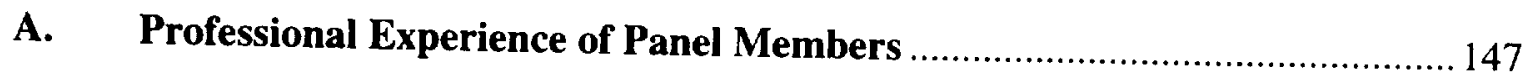

B. Professional Experience of Other Team Members................................ 152

C. Site Reports

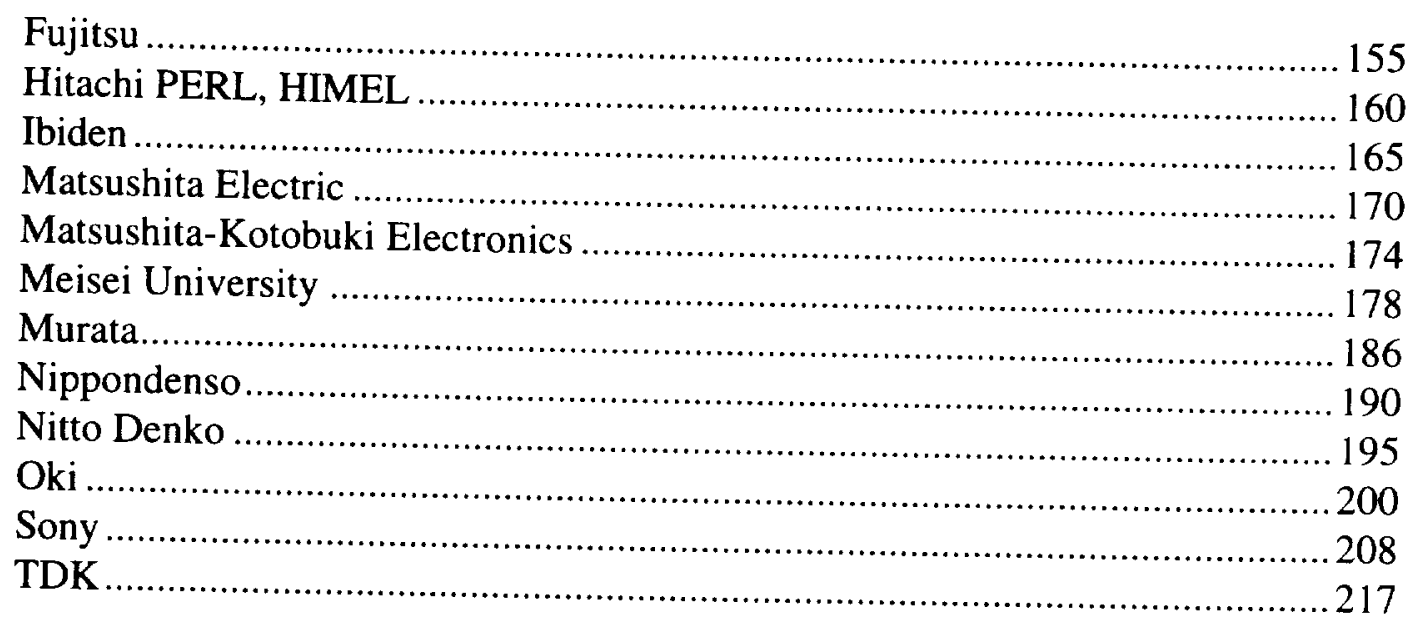

D. Sponsors of the JTEC Study on Electronic Packaging in Japan ............... 222

E. Attendees of the Industrial Representatives Meeting on April 19, $1993 \ldots . . .223$

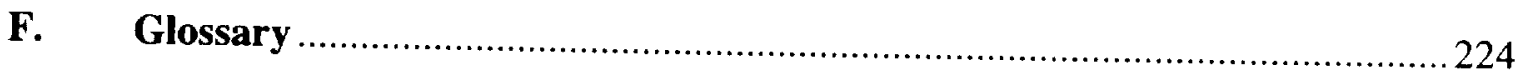


viii

\section{LiST OF FiguRES}

E.1 Mass production strategy for low-cost electronic products ..................................xiii

1.11991 global electronics production; the four largest electronics regions ...............6

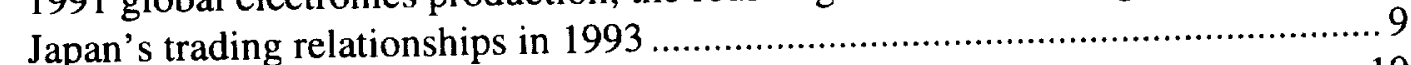

1.3 The movement of Japanese production facilities offshore ................................ 10

1.4 Japanese forecast of audiovisual production in 1995 and 2000 .......................... 14

$1.5 \quad$ Number of computer-related systems worldwide ........................................... 15

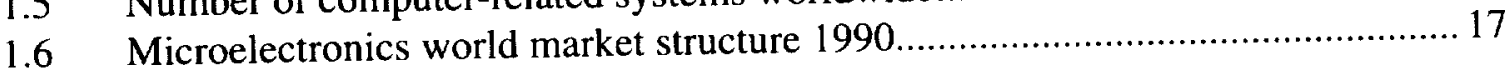

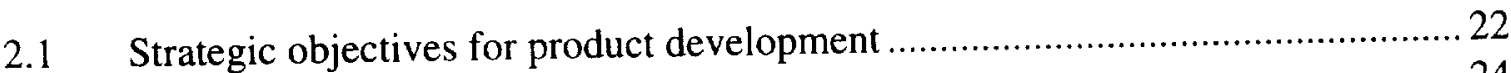

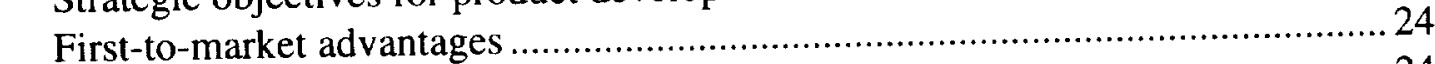

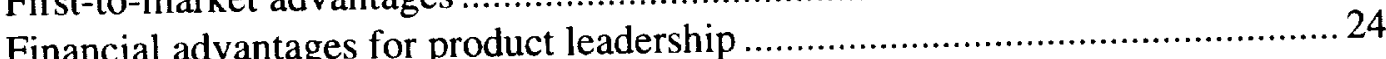

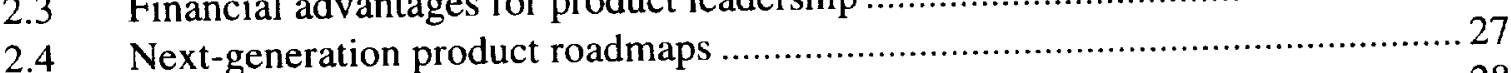

$2.5 \quad$ Market-driven demands for electronic packaging ......................................... 28

3.1 Japan's successful production development strategy ....................................... 38

3.2 Parallel product development strategies in Japan.......................................... 40

3.3 TDK's product development strategy.......................................................... 41

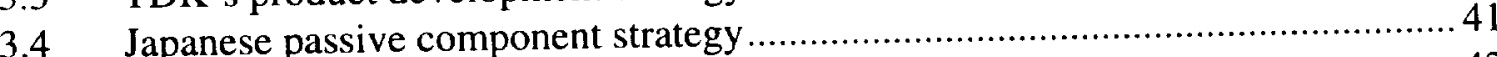

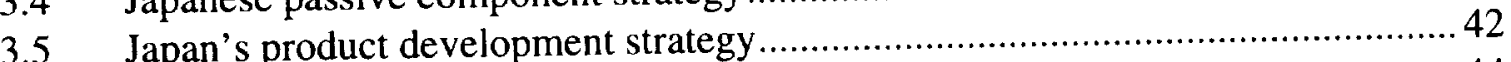

3.6 Moore's Law of Active Element Density ..................................................... 44

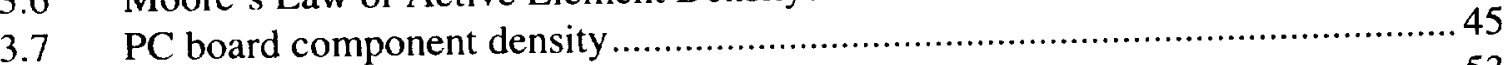

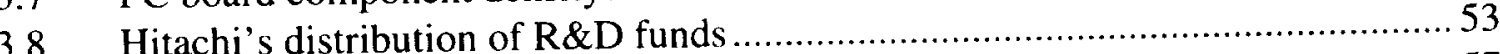

3.9 Hitachi's Strategic Business Projects system............................................... 57

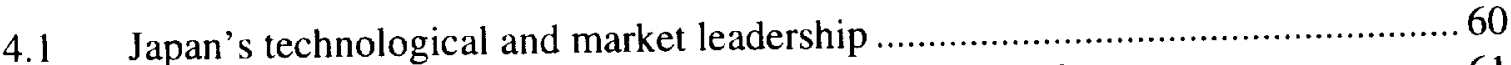

4.2 Japanese competitive advantage from breadth of technology ...........................61

4.3 Mass production strategy for low-cost electronic products .............................61

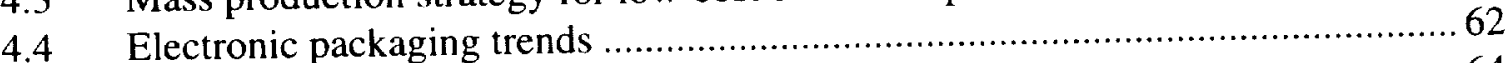

4.5 Single chip packaging costs

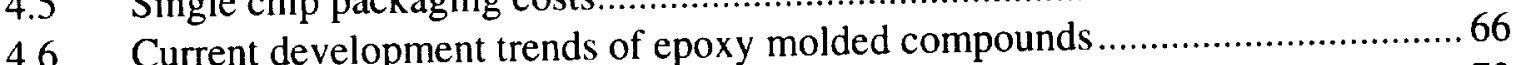

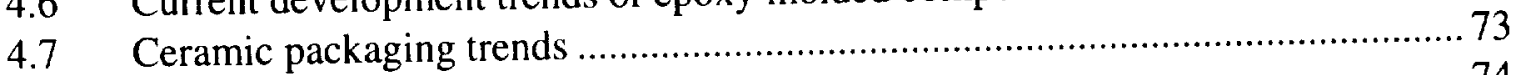

Consumer ceramic substrate.......................

4.9 Low-cost ceramic co-firing process with copper ...................................... 74

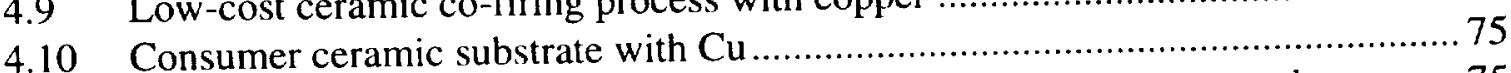

4.11 Multilayer ceramic (MLC) and printed wiring board (PWB) compared............. 75

4.12 Hollow structure in ceramic for improved dielectric constant ...........................76

Propagation delay versus dielectric constant

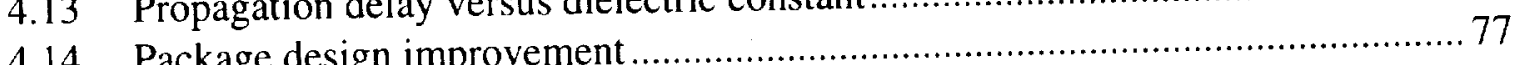

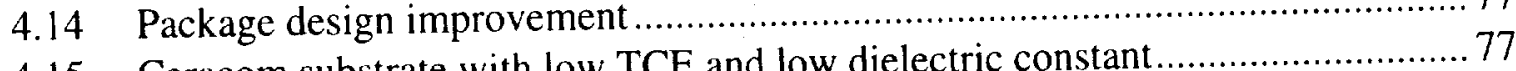

4.15 Ceracom substrate with low TCE and low dielectric constant .............................7 78

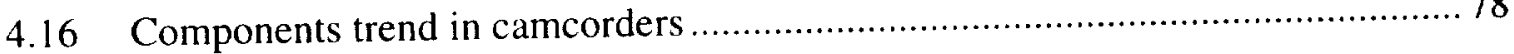


4.17 Overall Japanese packaging strategy

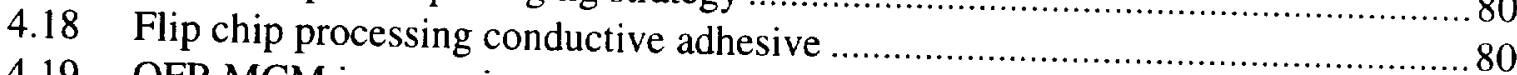

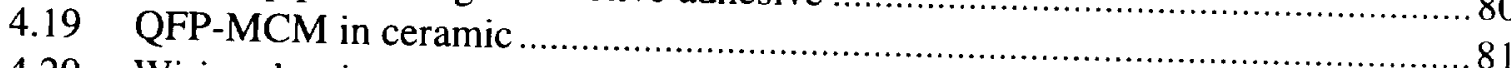

4.20 Wiring density comparison between PWB/ceramic ........................................ 81

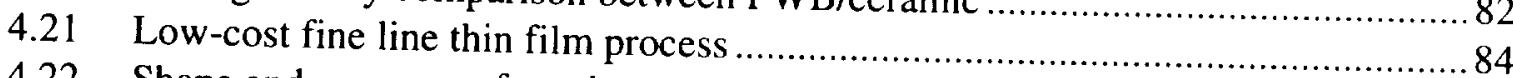

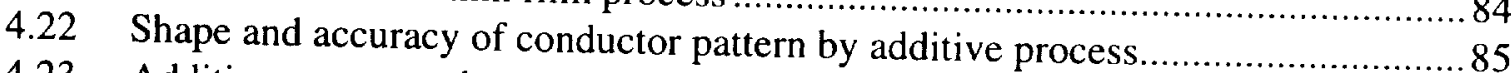

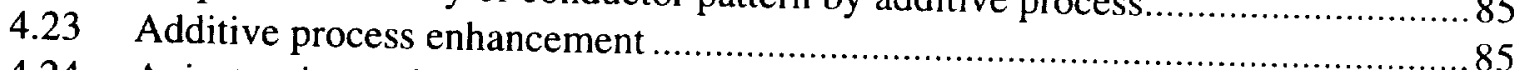

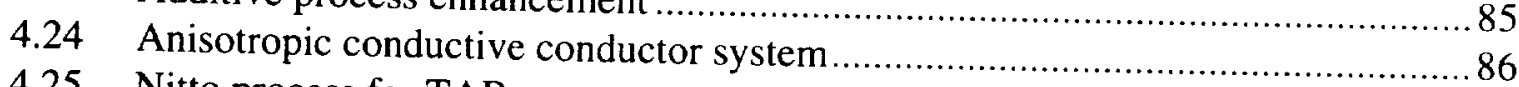

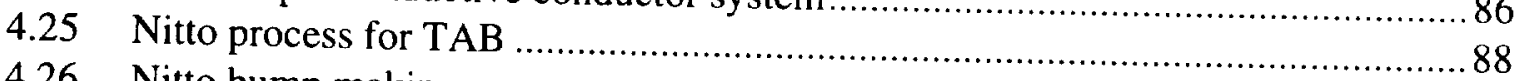

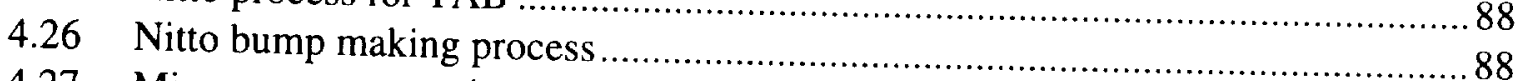

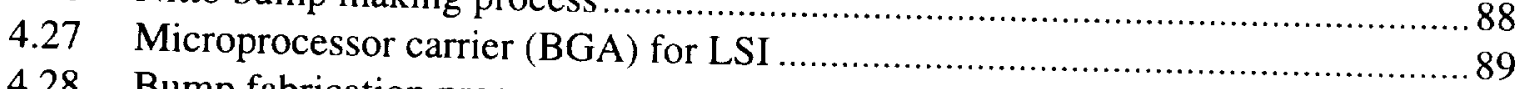

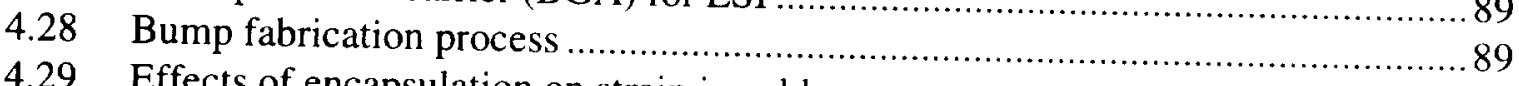

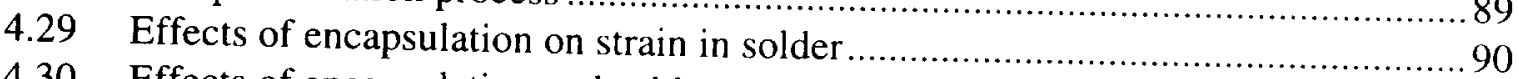

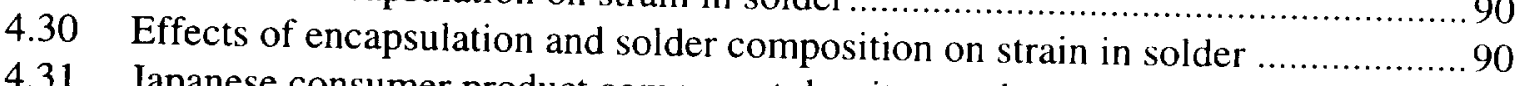

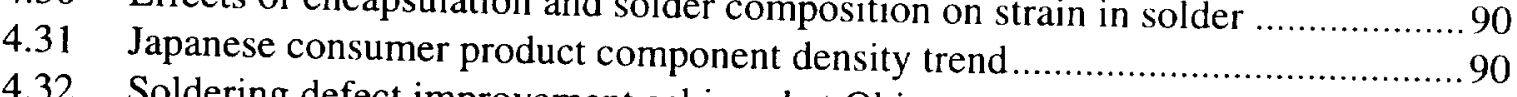

4.32 Soldering defect improvement achieved at Oki .................................................... 91

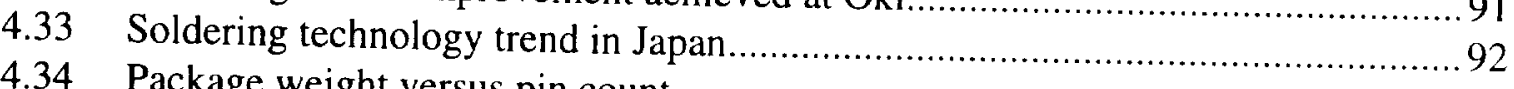

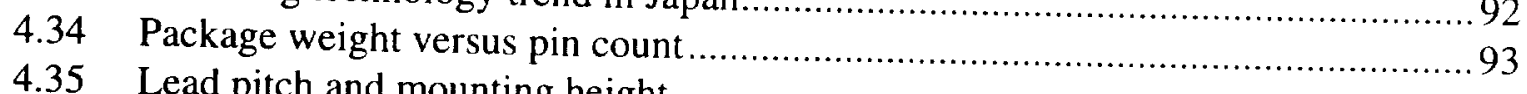

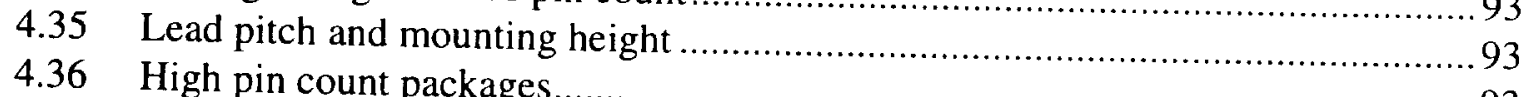

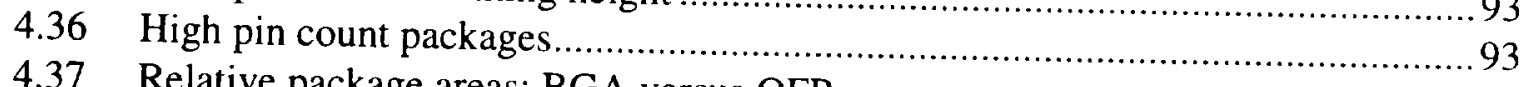

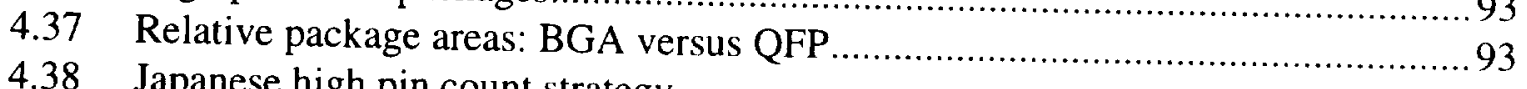

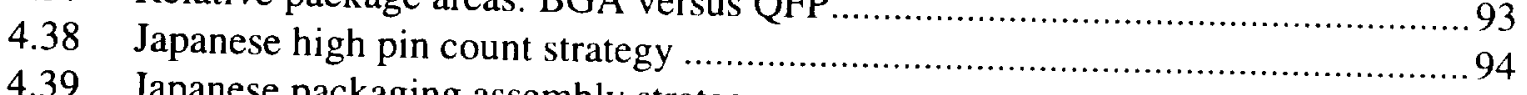

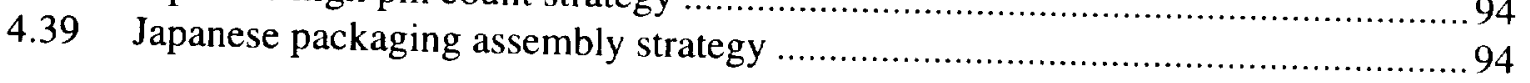

5.1 Japan's development of computer-integrated manufacturing ......................... 100

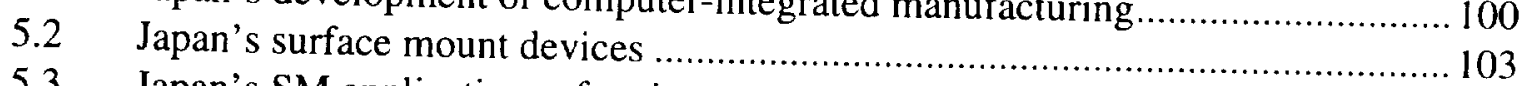

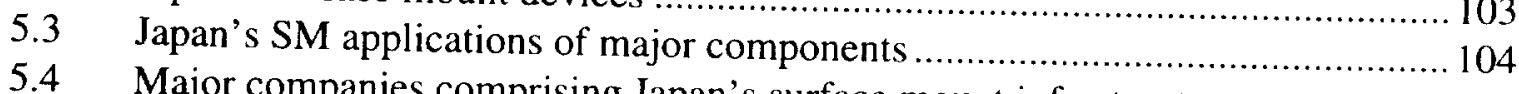

5.4 Major companies comprising Japan's surface mount infrastructure ...................... 105

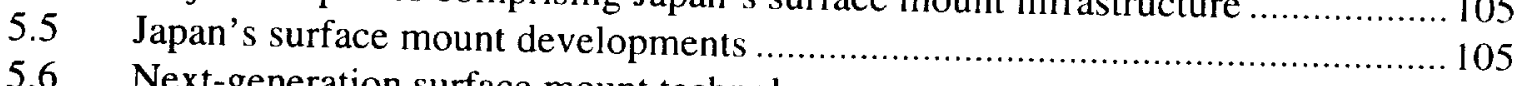

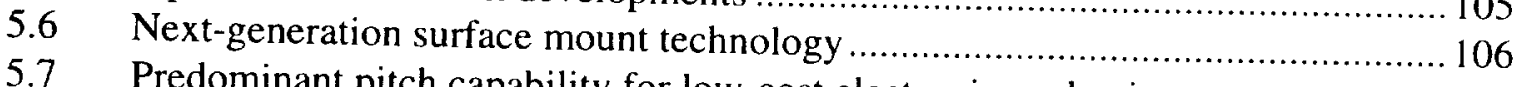

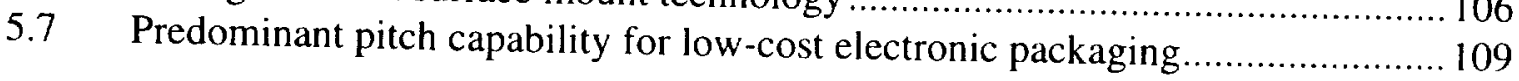

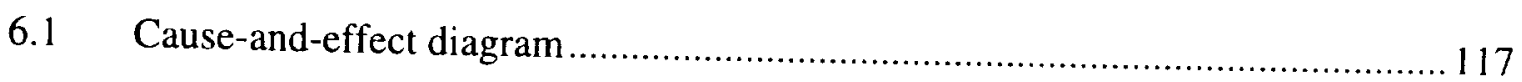

7.1 Japan's product development activities ................................................. 130

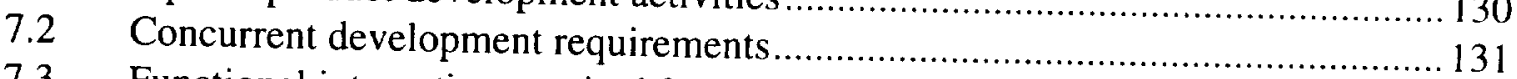

7.3 Functional integration required for technological innovations................................. 132

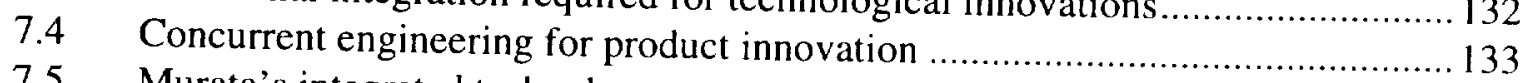

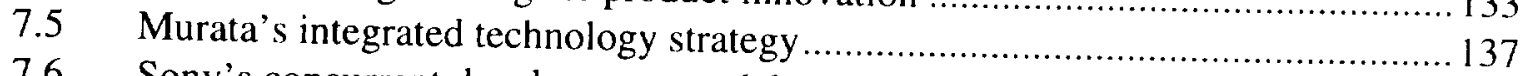

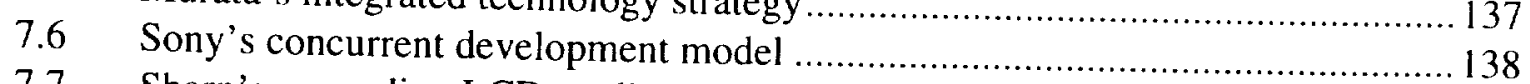

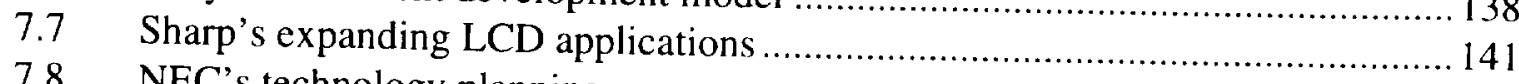

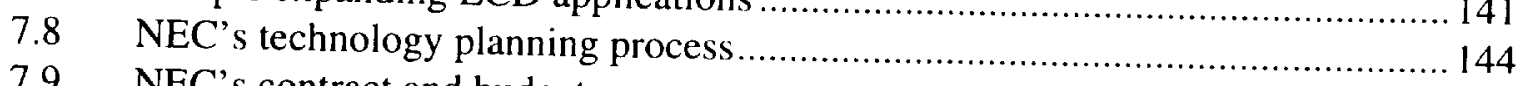

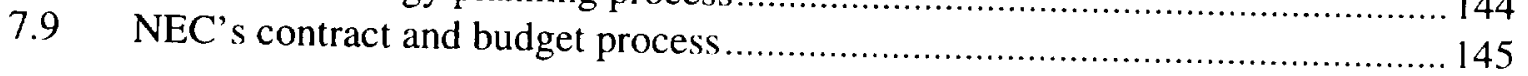




\section{List OF TABLES}

E.1 Packaging Technology Leadership (U.S. Compared to Japan) .......................... xvi

1.1 Japan's Electronics Industry Production 1992-3, Forecast for $1994 \ldots \ldots \ldots \ldots \ldots \ldots \ldots . . . . .7$

1.2 Japan's Consumer Electronics Production 1992-3, Forecast for 1994 ................. 7

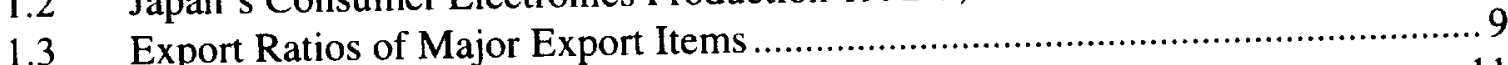

1.4 The Number of Offshore Japanese Production Bases in 1992 .......................... 11

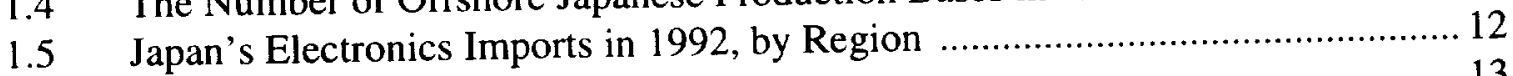

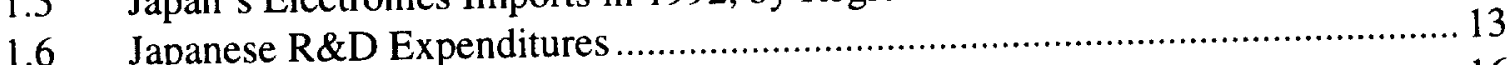

Electronic Devices and Parts Output........................................................... 16

2.1 1993 First-Half Performance of Japanese Electronics Companies ...................... 25

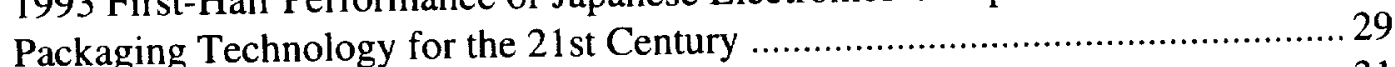

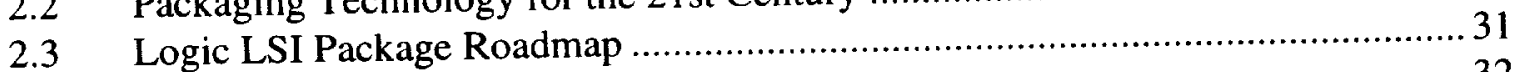

2.4 Matsushita Video Camera Board Designs..................................................... 32

3.1 Japanese Major Electronics Firms' Capital \& R\&D Investments ........................50

3.2 Hitachi Limited's Corporate Research Laboratories......................................... 54

3.3 Hitachi Corporate Research Funding ....................................................... 55

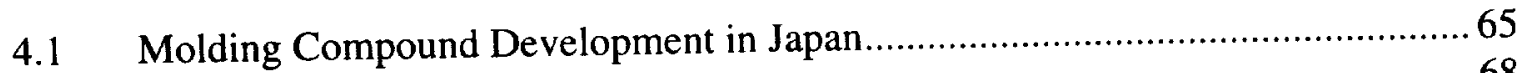

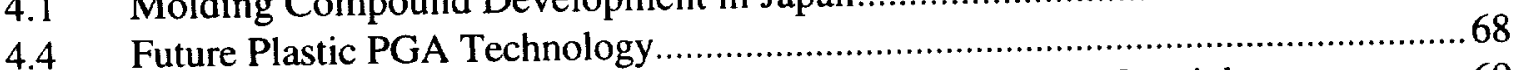

4.2 Development Roadmap of Semiconductor Encapsulating Material ....................69

4.3 Development Roadmap of Semiconductor Encapsulating Material (Part 2) ....... 70

4.5 Memory Package (TSOP) Technology Roadmap ......................................... 71

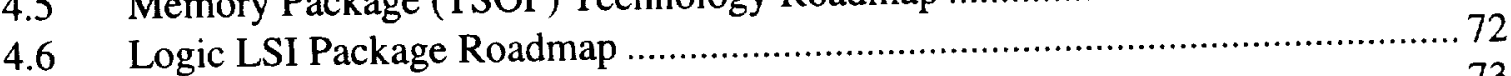

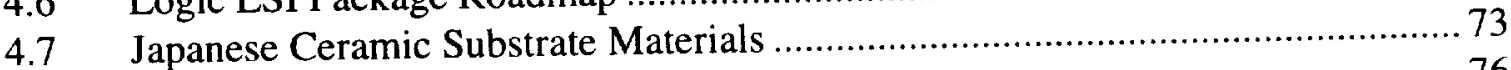

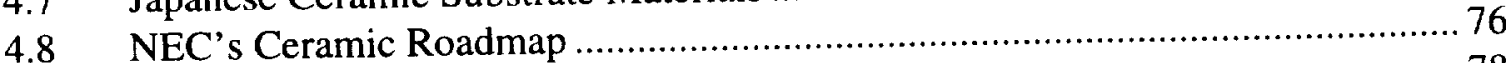

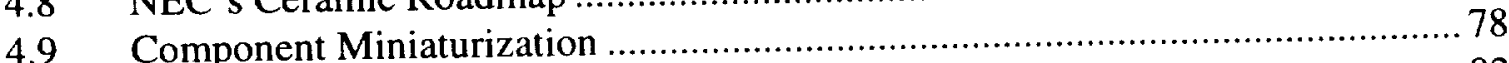

4.10 Nitto Denko's Blend Polymer Dielectric ..................................................... 82

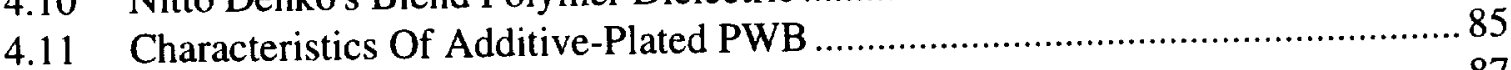

4.12 Japanese Chip Assembly Plan (Oki) .......................................................... 87

4.13 Japanese TAB Package (TCP) Characteristics (Oki) ....................................... 88

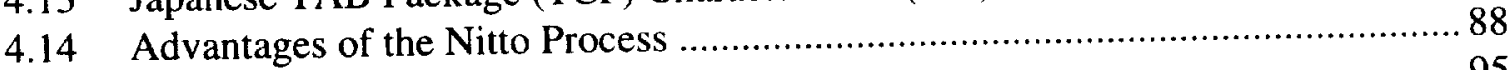

4.15 Japanese Packaging Technology Trends ..................................................... 95 


\section{Preface}

This report of the Japanese Technology Evaluation Center (JTEC) began in late 1992 when four agencies of the United States Government contacted JTEC to request a study of high-volume, low-cost electronic packaging in Japan. The four agencies that contracted this study were the Department of Commerce (DOC), the National Science Foundation (NSF), the National Aeronautics and Space Administration (NASA), and the Advanced Research Projects Agency (ARPA) of the Department of Defense (DOD). During a meeting held in Washington, DC, on January 8, 1993, representatives from the sponsoring agencies (listed in Appendix D) met with JTEC staff to identify their respective interests in the study. DOC through its charter to assess and report on Japanese technology, and NSF as the lead agency for JTEC, both were primarily interested in the technologies of electronics packaging in Japan; NASA was primarily interested in the reliability of electronics components for spacecraft; and ARPA was primarily interested in assessing the relative strengths of commercial industrial electronics products in the United States and Japan, because of DOD's commitment to increase procurements of affordable components in the commercial marketplace. The representatives from the four sponsoring agencies agreed that the basic goal for the study should be identification of the factors that have made Japan so successful in the field of high-volume electronics.

On request from the sponsors JTEC sought industrial input on the value of such a study to U.S. industry. Dr. Michael J. Kelly, Director of the Manufacturing Research Center at Georgia Tech, agreed to chair the JTEC Electronics Packaging Panel and to organize the meeting to solicit recommendations from the industrial sector. The meeting was held in Washington, D.C., on April 19, 1993. Attendees (listed in Appendix E) generally agreed that Japanese competitive advantages in electronics are based on more than technology. They argued for a study that also investigated the impact of infrastructure, management, investment, and government policies on Japan's dominance in the electronic marketplace. In response to these recommendations, JTEC selected a panel of experts with diverse backgrounds that would enable them to address multiple facets of electronics manufacturing and packaging in Japan. Following is a brief biography of each of the panel members. More detailed biographies of the panelists and of other participants in the Japanese site visits are included in this volume as Appendices A and B, respectively.

Dr. Michael Kelly, the panel chair, is Director of the Manufacturing Research Center at Georgia Tech. Prior to his present position he was Director of the Defense Manufacturing Office at the Advanced Research Projects Agency at the Department of Defense. He worked for IBM between 1969 and 1987.

Dr. William Boulton is a professor of strategic management and Director of the Center for International Commerce at Auburn University. Dr. Boulton has spent seven years in managerial and academic positions in Japan, including Visiting Scholar at Japan's Ministry 
of Finance's Institute for Fiscal and Financial Policy, and Visiting Professor at Keio University's Graduate School of Business Administration.

Mr. John Kukowski is a corporate fellow at Universal Instruments Corporation, where he also held the position of Vice President of Advanced Technology. Mr. Kukowski is presently on sabbatical at Rochester Institute of Technology, where he is assisting in the development of an interdisciplinary electronics design and manufacturing program.

Dr. Gene Meieran is an Intel Fellow whose knowledge of the electronic "food chain," beginning with materials, has established him as a leader in the electronics industry. In addition to his Intel responsibilities, Dr. Meieran is also Director of Research for the MIT Leaders for Manufacturing program.

Dr. Michael Pecht is a professor at the University of Maryland where he is also founder and director of the Computer Aided Life Cycle Engineering (CALCE) Electronic Packaging Research Center. Dr. Pecht is chief editor of IEEE's Transactions on Reliability.

Dr. John Peeples is an Assistant Vice President of Manufacturing for AT\&T Global Information Solutions (formerly NCR) and Director of the Manufacturing Technology Research Center. Dr. Peeples is also the leader of the Director of Engineering Peer Team for the General Purpose Product Group.

Dr. Rao Tummala is a recognized expert in high-performance electronic packaging who, as an IBM Fellow, was responsible for IBM's advanced electronic packaging program. Dr. Tummala is now a chaired professor in the Electrical Engineering Department at Georgia Tech.

On May 4, 1993, the JTEC electronics packaging (EP) panel met with its sponsors and JTEC staff in Washington, D.C., to clarify the objectives of the electronics packaging study. The attendees identified four primary areas for assessment:

1. Japanese technology priorities and roadmaps

2. Japanese product realization processes, with specific attention to notebooks, personal digital assistants, camcorders, and cellular telephones

3. Japan's competitive advantages related to manufacturing and production technology

4. Japan's competitive advantages related to infrastructure and management support systems

Dr. Gene Lim of SEAM International worked closely with the panel to arrange meetings with appropriate companies in Japan between October 1-9, 1993. The panel members were joined in Japan by Dr. Nick Naclerio of ARPA; Mr. Phil Barela of NASA; Mr. George Harman of DOC; Dr. Linton Salmon of NSF; Dr. Duane Shelton of JTEC; and Dr. Lim. 
Subsequent to the site visits, panelists and other team members generated a report on each site. These site reports are included in this report as Appendix C. JTEC held an open meeting in Washington, D.C., on January 12, 1994, during which the JTEC Electronic Packaging Panel reported its preliminary findings.

Following the workshop, the panel members prepared the first draft of the written report that is published in this volume. Both the site reports and the draft chapters were subjected to an extensive review process. During the course of this review, extensive new and updated information was added by both Japanese hosts and panel members. During proofing of the report prior to publication, more new information derived from recent publications was added. The end result that follows is the JTEC panel's final evaluation.

The content of the analytical chapters of this report, Electronic Manufacturing and Packaging in Japan, was contributed by the panel members. Michael Kelly prepared the Executive Summary; William Boulton edited the chapters in draft. The authors of the body of the report are as follows: William Boulton describes the importance of the electronics industry to global competition in Chapter 1, High-Volume Low-Cost Electronic Packaging. Dr. Boulton also provides a conceptual understanding of the product development problems for electronics as described in Chapter 2, Building the Electronic Industry's Roadmaps. Gene Meieran, William Boulton, and Rao Tummala developed Chapter 3, Japan's Technology and Manufacturing Infrastructure, to describe some of the underlying strengths of Japan's electronic industry. Rao Tummala and Michael Pecht provide the technological descriptions in Chapter 4, Japan's Electronic Packaging Technologies. John Kukowski and William Boulton offer a description of Japan's electronic manufacturing capabilities in Chapter 5, Electronic Manufacturing and Assembling in Japan. Michael Pecht and William Boulton are the authors of Chapter 6, Quality Assurance and Reliability in the Electronic Industry. John Peeples and William Boulton contributed the material for Chapter 7, Successful Product Realization Strategies.

The authors of this report are deeply indebted to the large number of people who contributed to its preparation. We extend our sincere thanks to our Japanese hosts who so graciously gave of their time in sharing information about their respective companies. We also appreciate the cooperation of the sponsoring agencies and the contributions of their representatives who accompanied the JTEC panel; these were major factors in the successful development of the report. We are greatly indebted to Dr. Gene Lim who made the excellent trip preparations to Japan and accompanied us during our visits to the Japanese companies. Finally, the panel members wish to express our appreciation to all the members of the JTEC staff, especially Geoff Holdridge, for their cheerfully given support in preparing for the study, executing it, and publishing the results. 
Preface 


\section{EXECUTIVE SumMARY}

This study of electronic manufacturing and packaging in Japan grew out of a widespread interest on the part of U.S. government and industry leaders to understand the strengths of Japan's electronics industry as a step towards improving the vitality of the U.S. electronics industry. The Japanese Technology Evaluation Center (JTEC) assembled the electronic packaging and manufacturing panel in 1993 at the request of four U.S. Government agencies: the Advanced Research Projects Agency of the Department of Defense, the Department of Commerce, the National Aeronautics and Space Administration, and the National Science Foundation. The purpose of the study was defined in consultation with industry advisors: to evaluate the technologies, processes, priorities, and supporting infrastructures that have allowed Japan to achieve dominance of the global electronics marketplace. The JTEC electronics packaging and manufacturing panel visited Japan from October 1-9, 1993, then reported its findings at an open meeting in Washington, D.C., on January 12, 1994. This written report is based on the panel's observations during site visits; on dialogues with colleagues in Japanese companies, universities, and professional associations; and on literature published subsequent to the panel's site visits.

\section{PRINCIPAL CONCLUSIONS}

The JTEC panel on electronic manufacturing and packaging confirmed its expectations: Japan has the most advanced electronic assembly manufacturing processes in the world. The United States must learn the lessons of Japan and become a world-class manufacturer.

1. Japan leads the United States in almost every electronics packaging technology. Comparisons of electronic packaging technologies in Japan and the United States (as in Table E.1) reveal that, while some U.S. companies lead in specific ceramic technologies and in the technologies of thin film multichip modules (MCMs), flip chip assembly, and package design, Japanese firms are the leaders in all other packaging categories.

2. Japan clearly has achieved a strategic advantage in electronics production and process technologies. Panel members believe that Japanese competitors could be leading U.S. firms by as much as a decade in some electronic process technologies.

- Because process technology improvements allow for quality improvements and cost reductions in end products, Japan's continuous perfection of its electronics manufacturing systems has enabled it to take market leadership away from technology innovators in the United States.

- Furthermore, it is apparent that due to its successes in process improvement, Japan will be a primary world supplier not only of electronics products and components, but also of electronics manufacturing equipment. 
Table E.1

Packaging Technology Leadership (U.S. Compared to Japan)

\begin{tabular}{|c|c|c|}
\hline & $\begin{array}{l}\text { Technology } \\
\text { Leadership } \\
\end{array}$ & $\begin{array}{c}\text { Manufacturing } \\
\text { Leadership }\end{array}$ \\
\hline $\begin{array}{c}\text { Single Chip } \\
\text { Plastic } \\
\text { Ceramic } \\
\end{array}$ & $\begin{array}{c}\text { Japan } \\
\text { U.S.* } \\
\end{array}$ & $\begin{array}{l}\text { Japan } \\
\text { Japan }\end{array}$ \\
\hline $\begin{array}{l}\text { Multichip } \\
\text { Thin Film } \\
\text { Ceramic } \\
\text { PWB } \\
\text { COB, COG } \\
\end{array}$ & $\begin{array}{l}\text { U.S. } \\
\text { U.S.* } \\
\text { Japan } \\
\text { Japan }\end{array}$ & $\begin{array}{l}\text { U.S. } \\
\text { Japan } \\
\text { Japan } \\
\text { Japan } \\
\end{array}$ \\
\hline $\begin{array}{l}\text { Chip Assembly } \\
\text { Flip Chip } \\
\text { TAB } \\
\text { Wire Bond } \\
\end{array}$ & $\begin{array}{l}\text { U.S. } \\
\text { Japan } \\
\text { Japan }\end{array}$ & $\begin{array}{l}\text { Japan } \\
\text { Japan } \\
\text { Japan } \\
\end{array}$ \\
\hline $\begin{array}{l}\text { Package Assembly } \\
\quad \text { Processes, Tools, Density } \\
\text { Passive Components } \\
\text { PWB } \\
\text { Flex } \\
\text { Connectors (Elastomeric, Anisotropic) } \\
\text { Package Design }\end{array}$ & $\begin{array}{c}\text { Japan } \\
\text { Japan } \\
\text { Japan } \\
\text { Japan } \\
\text { Japan } \\
\text { U.S. }\end{array}$ & $\begin{array}{c}\text { Japan } \\
\text { Japan } \\
\text { Japan } \\
\text { Japan } \\
\text { Japan } \\
\text { U.S. } \\
\end{array}$ \\
\hline
\end{tabular}

* Indicates status of IBM only in high-performance ceramics for single-chip and multichip applications; other U.S. companies are generally behind Japan in this area.

3. Japan has established this marked competitive advantage in electronics as a consequence of developing low-cost, high-volume consumer products.

- Japan's success is not a consequence of major technological breakthroughs, but rather a process of continuous and incremental improvements in the technologies of mass production - driven by products such as camcorders and cellular telephones, for which the emphasis has been on miniaturization, low cost, lighter weight, and portability. Those same features are now apparent in notebook and subnotebook computers and in personal and wearable digital assistants, which further demonstrate Japan's product "portability" strategy.

- This strategy permits Japanese industry to take full advantage of its existing infrastructure, capital investments, and skilled labor force as well as new production facilities in order to bring replaceable, lower-cost products to the marketplace in shorter and shorter intervals. 
4. Japan's infrastructure, and the remarkable cohesiveness of vision and purpose in government and industry, are key factors in the success of Japan's electronics industry.

- Long-term product development roadmaps provide the technology pull required to stimulate supplier investments in critical technologies and equipment essential for timely introduction of next-generation consumer electronic products.

- Overall industry structure and supporting institutions promote continuous, long-term technical and process improvements that sustain Japan's competitive position in low-cost consumer electronics and ensure the quality and reliability of products.

- Product development involves the highest levels of management to ensure that resources are available for concurrent engineering of new products.

- Weaknesses in these areas are major contributors to U.S. industry being unable to fully exploit technological innovations derived from extensive $R \& D$ investments, as occurred with integrated circuits and flat panel displays.

5. Although Japan will continue to dominate consumer electronics in the foreseeable future, opportunities exist for the United States and other industrial countries to capture an increasingly large share of the market.

- The United States in particular controls much of the technology that will drive future consumer electronics: telecommunications, computers, microprocessors, and software.

- The challenge for the United States is to exploit its technological advantages by becoming the low-cost producer of high-volume electronic products. Recent streamlining and restructuring of U.S. industry, combined with increased capital investments, have paid big dividends. The U.S. worker is now the most productive in the world. These developments provide the United States with major competitive advantages.

6. The JTEC panel identified no insurmountable barriers that would prevent the United States from regaining a significant share of the consumer electronics market; in fact, there was ample evidence that the United States needs to aggressively pursue high-volume, low-cost electronic assembly, because it is a critical path leading to highperformance electronic systems.

- The United States has the technological edge, as was demonstrated recently by its advances in high definition television. Japan has the edge in production technology, and it is expected to continue to be the world leader in high-precision electronic assembly. The country that excels in both new technology and production technology will lead the world in consumer electronics.

- Advanced technology continues to be the heritage of the United States; if a similar focus can be placed on production technology, the United States can capture a dominant share of the consumer market. Continuous corporate reengineering, an emphasis on concurrent 
development, partnering between suppliers and customers, and further commitment to enhancing the skills of the workforce are critical success factors that must be addressed. In the words of Robert Hayes $(1981,66)$, "We must compete with the Japanese as they do with us: by always putting our best resources and talent to work doing the basic things a little better, every day, over a long period of time. It is that simple - and that difficult."

The Japanese can do it; Americans can do it. The issue that separates the United States from Japan in high-volume, low-cost electronic assembly is neither technology nor manufacturing; it is primarily the will to take the measures necessary to compete and succeed.

\section{BACKGROUND}

The electronics industry is a vital part of the U.S. economy. It is "the largest manufacturing employer in the United States... [accounting] for nearly $11 \%$ of the U.S. gross domestic product. It is expected to grow at a rate of $4 \%$ per year throughout the remainder of the 1990s" (MCC 1992). The United States has developed or is developing many of the state-ofthe-art technologies on which the world electronics trade depends; also, the U.S. electronics industry has invested more money in $\mathrm{R} \& \mathrm{D}$ than have its foreign competitors. Despite these strengths, U.S. electronics manufacturers have steadily lost market share to foreign-owned or foreign-based manufacturers in practically every electronics sector. According to Ross (1992), "the U.S. electronics industry has been losing about $3 \%$ of world market share per year since the mid-1980s, a market that today is about three-quarters of a trillion dollars and is expected to be $\$ 2$ trillion by the beginning of the next century."

While the United States has lost ground in the world electronics marketplace, Japan has steadily improved its competitive position; it is now the recognized world leader in the production of consumer electronics products. U.S. firms have abandoned the markets for many consumer electronics products, and so there has been little incentive to keep up with Japanese firms in improving low-cost, high-volume electronic packaging and assembly equipment technologies. Without the incentives and profits of staying competitive in the consumer marketplace, however, there is much evidence that the U.S. electronics industry has lost its ability to efficiently produce top-notch, reasonably priced electronics components for the industrial and military - as well as the consumer - sectors. Furthermore, electronics products have come to represent a significant portion of the U.S.-Japan trade imbalance. In 1992 Japan's electronic exports to the United States were valued at $\$ 30.4$ billion, $32 \%$ of its total exports to the United States; in that year the United States had a negative trade balance with Japan of $\$ 7.3$ billion in consumer electronics and $\$ 7.8$ billion in computers and peripheral equipment (ITTRI 1994). These trends give U.S. policymakers and electronics manufacturers ample cause for concern.

The term "electronic packaging" today means the production and assembly of a great many types of increasingly tiny and complex electronic circuitry components and boards central to the design and low-cost assembly of electronic products. Japan's manufacture of products 
like camcorders, palmcorders, handycams, VCRs, and cellular phones has simultaneously driven the miniaturization of electronic packaging and a corresponding advancement of assembly technologies. These popular consumer electronic products utilize a relatively large amount of analog circuitry, which has pushed the Japanese to develop cost-effective processes for assembling high-density miniaturized passive components. The use of "1005" packages $(100 \mathrm{~mm} \times 50 \mathrm{~mm})$ and smaller formats requires both leading-edge surface mount process capabilities and ultrasmall component developments. That is, Japan's successes derive not only from production of advanced devices but also from development of new equipment and procedures to manufacture and emplace those devices. This study investigates both electronic packaging technologies per se and also related manufacturing technologies. In response to the widespread notion that the United States needs to better understand "the realities of Japanese industry," this study also investigates goal-setting and infrastructure in the electronics industry of Japan.

\section{CREATING A VISION OF THE FUTURE}

Chapter 2 provides a model of Japan's vision of future product development activities. The introduction of next-generation components and equipment corresponds to the introduction of next-generation products. At Sony, next-generation products are defined as half the size and half the weight at the same cost. Roadmaps signal industry suppliers about future customer requirements. The panel found that in Japan

- Long-term product planning accompanies a product-pull investment strategy. The Japanese will continue to make major R\&D investments that are product driven.

- The guiding principle for management is product planning, which leads to efficient investments in technology and production; the best technology is the most affordable technology.

- The focus on cost, size, and weight reduction drives the miniaturization process; however, there may be a limit to ultrasmall assembling.

The changes taking place in consumer electronics have significant implications for the future. Companies in the high-volume electronics business are on a steep learning curve that is providing continuous opportunities to fuse technologies to meet product objectives. This is most evident in the flat panel display technology that is merging traditional electronics with displays.

It appears that component vendors are moving toward supplying functional modules, and system integrators are becoming increasingly aware of the benefits of also manufacturing components. Sony, for example, now manufactures about $65 \%$ of the key components of the compact disc player. There is evidence that companies like Murata and Nippondenso are seeking increased independence through technology and component self-sufficiency. As vendors provide more of the subsystem integration and component costs increasingly dictate 
profits, the relationships between suppliers and end-product producers may change. At the time of the JTEC team's visit, however, there was no indication of any lessening of the traditional supplier-customer interdependencies. Subcontractors contribute to new product development, and technical information is widely shared among vendors and end-product integrators. This organizational structure lends itself to effective concurrent development, shorter development cycle times, and lower life-cycle costs.

As the fusion of technologies increases and semiconductors, electronic packages, displays, and peripheral devices become increasingly integrated, the electronics industry may undergo major restructuring; it is not evident who will have the major advantage. It is clear that advanced technology and flexible manufacturing will not, by themselves, provide the advantage; nor will excellence in design. Organizations capable of quickly responding to change, led by visionary and capable management, will hold the essential competitive advantage. The lesson from Japan is that teaming is a primary success factor.

\section{SUPPORTING INFRASTRUCTURES}

Chapter 3 provides an overview of the infrastructure that supports Japan's leadership in consumer electronics. The panel found that

- Japanese firms appoint a greater number of technically trained managers to head their companies than do U.S. firms.

- Corporate enterprises are structured and managed to operate effectively in the global marketplace.

- Firms have separated research on production technologies from other research and development activities.

- Enterprises invest heavily in the development of production automation technology.

- Japan's patent system functions to facilitate industry-wide transfer of technology rather than to protect intellectual property rights.

- Industrial research is given additional support through local municipal industrial research institutes (MIRIs).

- Japanese firms are constantly in pursuit of new technical knowledge and effective transfer of technology from global sources.

- Recent recessionary pressures are temporary and may actually strengthen the industry.

- People are the primary sustainable competitive advantage. Information technology can be employed to support continuous learning; it is not, however, a substitute for the kind of training and personal communication evidenced in Japan.

- The borderless manufacturing world is a continuing reality that justifies further investments in transportable manufacturing-enabling technologies. 
The existing infrastructure supports movement into advanced technologies and products. This is particularly evident in the electronics industries. Separation of production development focuses attention and resources on manufacturing advancements that ensure the rapid introduction of new, high-quality products at low costs. Without advanced equipment capabilities, it would take much longer for new component technologies to become part of next-generation product designs. The strategic importance of manufacturing is emphasized in the education of the workforce and in the priority that management gives to continuously improving the process in order to more rapidly and efficiently manufacture complex products.

The United States has lost the infrastructure necessary to be globally competitive in the production of high-volume, low-cost electronic products, despite the fact that U.S. industry may dominate certain sectors such as microprocessors. While the United States continues to invest heavily in $\mathrm{R} \& \mathrm{D}$, Asia is making major investments in manufacturing infrastructure. U.S. investments in $R \& D$ are now being exploited offshore, with associated negative effects on jobs, the balance of trade, and the general economic health of the country. Domestic suppliers have been abandoned in favor of low-cost offshore producers that frequently receive the latest technologies from their customers.

\section{PACKAGING TECHNOLOGIES}

Chapter 4 explores Japan's technology packaging strategy. It is important to understand not only what technology Japan is developing, but also how firms pursue their objectives. The JTEC panel's findings in this regard indicate that Japanese companies

- Seek to identify customer needs as the basis for developing next-generation products that establish the roadmaps for technological development.

- Make long-term commitments to component and equipment development that support future product innovations.

- Effectively utilize existing investments in the established supplier base and existing technological infrastructure; investments in new technologies are introduced only when competitive challenges require them.

Miniaturization is expected to continue to place pressure on packaging technologies and their assembly. In both the United States and Japan, the rate of silicon scale integration will continue to improve semiconductor cost and performance through the $1990 \mathrm{~s}$ as semiconductor suppliers develop systems on a chip. At the next level in the "food chain," the focus in the 1990s will be on high-density electronic assembly technologies. Many of the gains in the 1990s will be attained through continuous improvements in Japan's existing surface mount packaging and assembly technologies, leading to devices with improved functionality, input/outputs in excess of 1,000, lead pitches below $0.2 \mathrm{~mm}$, low-cost MCMs, and improvements in equipment technology to meet the requirements shown in Figure E.1. Specifics of the Japanese roadmaps for achieving these goals are provided in the report. 


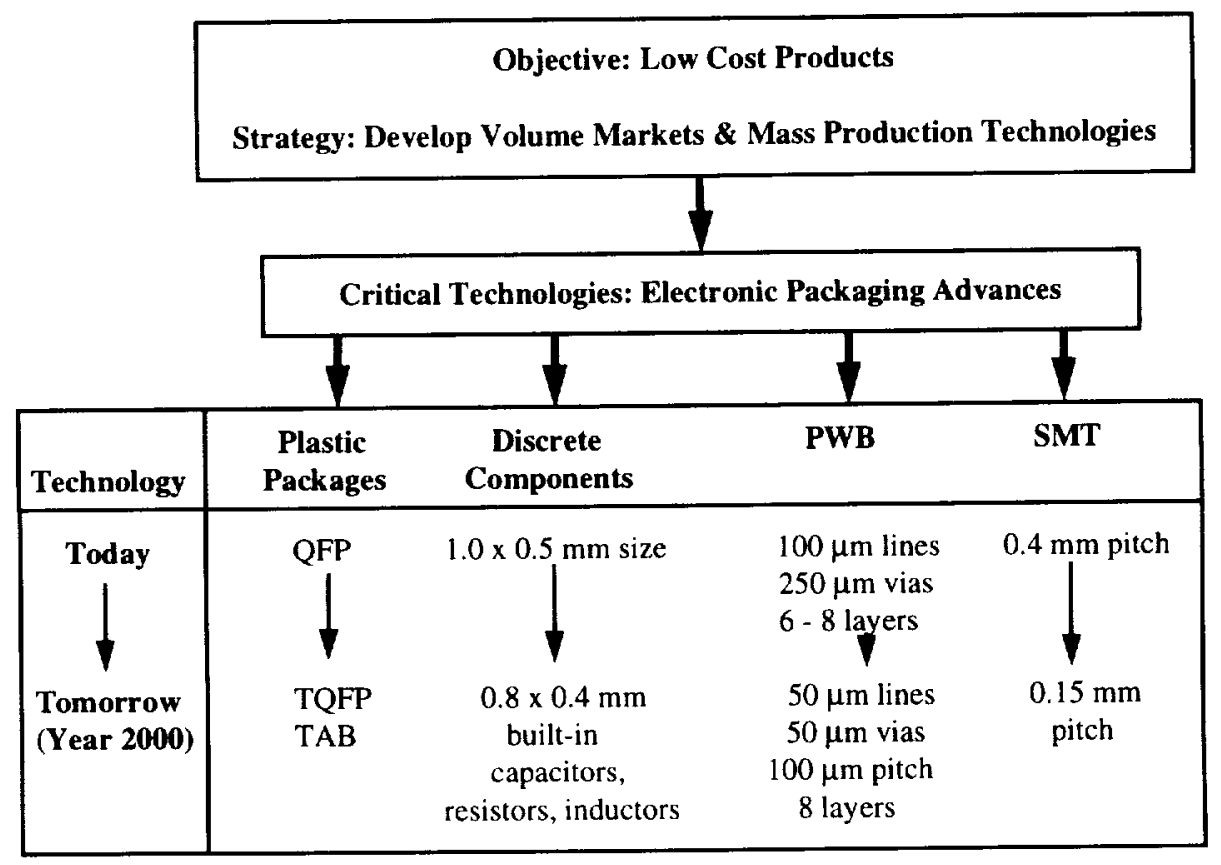

Figure E.1. Mass production strategy for low-cost electronic products.

The drive toward smaller, thinner, and lighter high-pin-count packages is expected to be satisfied initially through the employment of thin quad flat pack, tape automated bonding, and pin grid array. The ball grid array will be available for applications exceeding 600 pins. Flip chip technology is being extensively pursued by most Japanese companies. Of particular interest is direct bonding of a bumped chip to a printed wiring board (PWB) using a lowtemperature solder that is hot injection deposited onto the PWB through a mask. While there are continuing technical problems that need to be solved, such as the development of a thermally compatible encapsulant, success will permit Japanese investments in PWB to be incrementally improved over the next decade to meet consumer product requirements. There is evidence of merging technologies to meet new high-volume product demand: MCMs are appearing in both supercomputers and camcorders, and electronic drivers are fusing with flat panel displays.

\section{PRODUCTION TECHNOLOGIES}

Chapter 5 discusses production capabilities in electronic packaging. It was evident to the JTEC panel that Japanese manufacturing excellence is a consequence of the tight coupling of functions within each company and with respective suppliers. Major collaboration among industrial partners and between government and industry, as conclusively demonstrated in Japan, is required to sustain a competitive posture in the high-volume, low-cost electronics business. 
Japanese industry as a whole has focused a massive amount of resources on the design and development of complex automated equipment, and the range of equipment development expertise within individual companies is tremendous. That expertise covers all the technological areas required to be self-sufficient and dominant in this field. The consensus in Japan is that equipment provides a major competitive advantage and that equipment development technology is mandatory in order to lead in the introduction of new products. The panel also found that

- Equipment is the key to advanced manufacturing; it must be an integral part of technology development.

- Investments required for automation to achieve precision assembly, manpower reduction, and agility must be balanced against requirements based on modular product design and modular assembly.

- Continuous improvements in existing processes avoid capital investments, retraining, and risks associated with the introduction of new technology.

Component miniaturization, cost reduction, reduced development cycle times, and improvements in reliability and quality require continued advancement in production and process technologies. Production requirements will include more affordable and environmentally safe materials; flexible and automated equipment linked to affordable manufacturing processes; cost-effective and accurate testing; effective partnering with suppliers and enterprise teaming; continuous process improvements; and innovative, userfriendly designs. Increased demands for chip attach technologies will supplement current surface mount technology. Differences between technological alternatives will fade as technologies converge and hybrid electronic assemblies become commonplace in integrated systems.

The principal technologies that have provided competitive advantages include surface mount technology and flexible assembly technologies capable of responding to high-volume production with multiple product variations. While Japanese companies continue to do R\&D in advanced process technology, it appears evident that surface mount technologies will continue to dominate consumer products into the next century. Mounting methods will become more sophisticated and include greater levels of chips and direct bonding of bumped chips. Mounting densities will increase to 50 components per square centimeter. Passive components are expected to reach their size limitation at $0.8 \mathrm{~mm} \times 0.4 \mathrm{~mm}$ before they are integrated into modules. Pin pitches will be as low as $0.15 \mathrm{~mm}$. Low-cost resin board technologies will reach 50 micron lines and 50 micron vias with eight layers.

In the consumer electronics of the future, it will be increasingly difficult to separate integrated circuits, electronic packages, and flat panel displays. While continuous improvements can be expected in materials, equipment, and design tools, it will be the flexible, automated, adaptive manufacturing processes that will provide the primary competitive advantage. It is production technology that is making Japan the leader in high-volume, low-cost electronics, and it appears evident that this same strength will continue into the future. 


\section{QUALITY AND RELIABILITY}

Chapter 6 describes Japan's approach to quality and reliability. Japanese firms appear to seek out the root causes of quality and reliability problems. This has led Japanese producers to focus on continuous improvements in materials, equipment, and processes. Quality is considered the cost of entry; low product cost is considered the requirement for success.

Suppliers that are able to provide the required quality components at the appropriate time and cost will be the future market winners. To assure product quality, every Japanese supplier has had to resolve materials, equipment, and processes problems. Component suppliers often design future manufacturing processes in order to be "first to market" with new components. Next-generation production systems are developed for next-generation products. In order to fully exploit capital investments and to minimize variability and product defects in the manufacturing process, these new systems are only reluctantly changed once installed.

\section{PRODUCT REALIZATION}

Chapter 7 summarizes many of the comprehensive activities that make up Japanese firms' strategy of product development. The panel reached several conclusions about product realization in Japan:

- Product realization encompasses concurrent development, teaming, a supportive infrastructure, and a strategy of continuous improvement.

- Short development cycles, low cost, high volume, and innovative designs are responses to major customer requirements and competitive pressures.

- Major organizational commitments are being made and resources obligated to develop next-generation components and products.

- Continuous improvement of existing technology, in contrast to frequent introduction of new technology, appears to be a winning strategy. Anticipating technological discontinuities and planning for change are the main challenges for management.

Japan is investing to sustain its advantage through continuing to develop new materials, packaging, designs, equipment, and improvements to production processes. It was obvious that many companies had built competitive advantages by developing next-generation components, like charge-coupled devices for video cameras and liquid crystal displays for portable TVs and notebook computers. These components have given Sony a $75 \%$ market share in $8 \mathrm{~mm}$ video cameras and Sharp a major share in calculators and portable digital assistants. Today companies are seeking to use these component advantages to introduce innovative products like Sharp's new ViewCam. Cost pressures will accelerate global manufacturing partnerships, but Japan will continue to control many of the enabling production and component technologies used in next-generation packages. 
Once they have developed a market, Japanese firms have maintained market leadership through continuous improvement of existing products. Concurrent engineering allows for short product development cycles, as short as six months for Sony's Walkman products. Plans for next-generation products are managed by senior executives who have access to needed resources to push for rapid technological development. This next-generation productpull scenario is linked to a long-term product strategy for which the primary focus is affordability.

An industrial country cannot survive on technology alone. Unlike Japan, the United States has not fully understood that technology must be exploited through the manufacture of products in sufficient volume to generate the data - as well as profits - that are the basis of continuous improvement. Without the data generated by high-volume production, there are fundamental limits to improving manufacturing processes. The sought-after six-sigma process is directly dependent on the generation of significant data to evaluate a full production process.

The driver for electronics technologies has shifted from semiconductors to electronic assemblies, which are giving rise to new families of products that rival the integration of the camera and recorder. The telecomputer is the next high-volume consumer product. The word is a compound descriptive that links television and computer, telecommunications and computer, telephone and computer. Next will be the electromobile, with transportation increasingly dominated by the introduction of more and more electronics. There are those who are already referring to cars of the future as "chips on wheels." With more than fifty electric motors in some cars, the term "motor vehicle" is taking on a whole new meaning.

\section{CONCLUSIONS}

The JTEC study on electronic manufacturing and packaging in Japan, as described in this report, makes it very clear that Japan dominates electronic production technology. The report further demonstrates that Japan's success can be directly linked to a product-pull strategy that has the effect of exploiting new technology quickly. While Japan continues to invest in research and development of new technology, the dominant influence is in the process of continuous improvement of existing technologies to meet the cost, size, weight, and power requirements of the consumer market including portable electronic products. The strategy of continuous improvement is also considered the key to satisfying cycle-time reduction requirements.

When describing future consumer electronics there is a major focus on the multimedia units that will be found in seamless networks where data, voice, and graphical information are transmitted almost instantaneously. The cost of electronics is expected to continue decreasing at its present rate until, as Edward McCracken, CEO of Silicon Graphics, suggests, "We must make available $\$ 150$ to $\$ 300$ systems providing realtime audio and video

processing" (1994, 3). In the area of multimedia and networking technology, the United 
States continues to be in a very strong position; however, Japan and other Asian countries totally dominate consumer electronics. The JTEC panel is in full agreement that the United States must regain a prominent position in high-volume, low-cost electronics, and must do so quickly. As Peter Drucker has said, "A degenerative disease will not be cured by procrastination. It requires decisive action" $(1994,95)$. The decisive action is the commitment to exercise control over the enabling technologies which, when integrated, will produce the electronic systems that will be found at the nodes of the digital highways. It is an uphill struggle, but it is a challenge that must be accepted if the United States is to be globally competitive.

The competitors are not just the Japanese. In 1994, Taiwan was providing about $81 \%$ of the world's merchant motherboards; procurement by Japan of PC products in Taiwan is projected to reach $\$ 1.4$ billion in 1996 . South Korea is aggressively moving into consumer electronics with companies like Samsung expected to produce up to 90,000 AMLCD flat panel display units per month by the second quarter of 1995. China has become the country of choice for low-cost manufacturing, and it will continue to work with foreign countries to introduce hightech production capabilities. Japan is increasingly moving to offshore production in order to meet cost requirements. Haruo Tsuji, president of Sharp, has pointed out that, "The production cost in Japan has become the highest in the world." He goes on to say, "Japan is becoming a supplier of components and production machinery, like robots, to be used by other nations to assemble the final products" (1994, 3-1).

The JTEC panel did not see anything that would prevent U.S. companies from recapturing a significant share of future consumer products. However, as Drucker notes, "It requires decisive action." Certainly the United States' strong position in software can be used to its advantage, but even in that realm, Americans must be prepared for challenges from countries such as India.

Short product development cycles and product life cycles are causing companies like Compaq to produce more of their components locally because of the need for shorter delivery times. For many multinationals, however, "locally" means to "build where you sell." The United States is still the world's largest growth market and, therefore, can exploit the time parameter and build locally for its own market. There is a need, however, to prepare for the future when the Asia Pacific region will be the world's greatest growth market and "build where you sell" takes on new economies of scale.

We can be encouraged by some recent advances in manufacturing which have demonstrated that some U.S. companies have learned how to become low-cost producers. In some companies this has been done by applying their expertise in developing design tools that are effectively linked to production systems. In other cases the customer requirements are tightly coupled with production systems permitting product customization and fast turn-around. The people-free automated facilities that have characterized many high-volume production areas are giving way to skill-based, worker-enabling technologies that characterize agile production systems. 
While the JTEC panel is optimistic that the United States is making progress in improving its manufacturing capability, there is no doubt that Japan will continue to be the country to benchmark against. There is one major concern: the winners in the future will be those countries whose workforces are effectively educated and trained to meet the challenges of 21 st century production. In that regard the United States may be seriously at risk. The superior educational systems in some emerging nations, combined with decades of overseas enrollment and foreign students returning from American universities, is encouraging U.S. multinationals to be increasingly dependent on foreign sources for their required talent and is resulting in research and development following manufacturing offshore.

The semiconductor industry roadmap is targeting 0.07 micron geometry capabilities by the year 2010 (SIA 1994). During that period, electronic packaging will have to adapt to accommodate the more stringent semiconductor ground rules. The exploitation of these technologies to meet the demands of the consumer marketplace is what will differentiate the winners from the losers. The United States must regain its preeminence in consumer electronics to retain its position as a technology leader. As Oscar Wilde once said, "The one duty we owe to history is to rewrite it." The United States must rewrite history to regain consumer electronics, and it must improve its educational system to produce graduates that meet future workforce requirements.

In many respects, the JTEC panel conclusions are neither encouraging nor discouraging. The panel saw much to be concerned about when comparing Japanese packaging technology and manufacturing with similar efforts in the United States. It appears, however, that the race into the future has many competitors at the starting gate. The winners will be those who effectively exploit technology and manage global resources to reduce cycle time and meet product affordability criteria. The United States must commit to win; coming in second is being the first loser.

\section{REFERENCES}

Drucker, Peter. 1994. "The Theory of Business.” Harvard Business Review (Sept.-Oct.): 95.

Hayes, Robert H. 1981. "Why Japanese Factories Work." Harvard Business Review (July-August): 57-66.

ITT Research Institute (TTTRI). 1994. Manufacturing Competitiveness Frontiers. Vol. 18, Nos. 1 and 2 (January/February): 23.

MCC/Sandia National Laboratory. 1992 (September). "Industrial Competitiveness in the Balance: A Net Technical Assessment of North American vs. Offshore Electronics Packaging Technology" (report).

McCracken, Edward. 1994. Electronic Buyers' News. (Oct. 24): 3.

Ross, Ian. 1992. Star Ledger, 5.

Semiconductor Industry Association (SIA). 1994. The National Technology Roadmap for Semiconductors. San Jose, CA.

Tsuji, Haruo. 1994. New York Times (Oct. 23): 3-1. 


\title{
CHAPTER 1
}

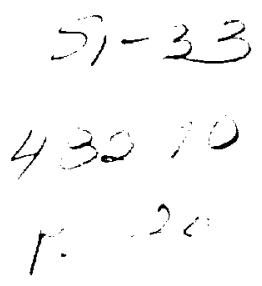

\section{MicroeleCtronics IN JAPAN}

\author{
William R. Boulton
}

The purpose of this JTEC study is to evaluate Japan's electronic manufacturing and packaging capabilities within the context of global economic competition. To carry out this study, the JTEC panel evaluated the framework of the Japanese consumer electronics industry and various technological and organizational factors that are likely to determine who will win and lose in the marketplace. This study begins with a brief overview of the electronics industry, especially as it operates in Japan today. Succeeding chapters examine the electronics infrastructure in Japan and take an in-depth look at the central issues of product development in order to identify those parameters that will determine future directions for electronic packaging technologies.

\section{INTRODUCTION}

Our lives are being revolutionized by electronics. The ways we work, communicate, shop, bank, travel, and learn are changing radically. And whereas natural resources, labor, and capital once determined a nation's wealth, today technology — in aerospace, computers, telecommunications, and consumer electronics - significantly affects a nation's wealth and security. Communications, computers, and control technologies are merging to create new multimedia capabilities for use in business, education, and entertainment. Advanced technologies like superconductivity promise a whole new range of capabilities in another decade. Miniaturization of existing products will put libraries and supercomputers into our briefcases. The range of future opportunities is bounded only by the ability of our industries to utilize these new capabilities in developing next-generation products. 
Production of high-quality, low-cost consumer electronics products is dependent on proficiency in electronic packaging technologies. Continuous improvement of packaging and related technologies has provided the impetus for development of new and improved consumer electronic products; likewise, consumer demand for new and improved electronic products at reasonable prices has provided the impetus for development of increasingly sophisticated electronic packaging. The most explosive improvements in lowcost, high-volume packaging for consumer products have been in Japan, precisely because Japan has been relentlessly pursuing the markets for consumer electronics. The United States is recognized for developing new technologies; Japan is recognized for continuously improving "old" technologies and pushing the technological limits of their applications in order to keep their costs down. In doing so, Japanese electronics firms have pushed electronic packaging into a whole new realm.

In the past, the term "electronic packaging" referred to a small number of formats for encasing electronic components, including integrated circuits, so they could readily and reliably be installed in electronic end-products. The principal packaging types were through hole, surface mount, tape automated bonding, single-chip, and multichip, and also packaging configurations like dual inline packages (DIP), small inline packages (SIP), and quad flat packages (QFP). Generally, the companies that specialized in manufacturing electronic packages did not participate in integrating them into the final products.

During several of the JTEC panel's site visits in Japan, it was evident that electronic packaging suppliers are integrating forward into both functional modules and integrated assemblies. TDK is making complex multichip modules with densities of 33 units per cubic centimeter. Murata is using its materials technology competence to develop and sell radio frequency (RF) components. Most suppliers now develop their own equipment and provide customers with the assembly equipment required to utilize their new components. At the same time, some of the major electronics companies are manufacturing more of their own electronic components based on in-house R\&D. Sony, for example, manufactures about $65 \%$ of the key components for its compact disc player and $45 \%$ of the components for its $8 \mathrm{~mm}$ camcorder. In-house advances in liquid crystal display (LCD), charge-couple device (CCD), and electronic packaging technologies were all needed to realize these products.

Consumer products that have been pulling the development of technological advances in electronic packaging include VCRs, cellular telephones, camcorders, personal digital assistants, and notebook computers. The goals that define the roadmaps for electronic packaging development for these products are miniaturization, portability, increased functionality, and cost reduction - in order to capture and retain consumer markets. These goals are being achieved through reduction of parts sizes and increased integration of technologies and functions. Electronic packaging technologies have seen increased pin counts, reduced pin pitch, and increased functional densities through the application of surface mounting techniques. Reduction in sizes of parts includes reductions in battery and display dimensions. For example, the reduction in the overall size of cellular phones from 
$500 \mathrm{cc}$ in 1987 to $150 \mathrm{cc}$ in 1991 was due to a variety of reductions in parts sizes that included the following:

- Power amp size was reduced by reducing part sizes and ICs.

- Filter size was reduced by reducing part sizes and using advanced designs.

- Controller size was reduced through development of special ASICs.

- Battery size was reduced after intermittent receiving methods cut power consumption.

- Board size was reduced by using smaller and thinner $0.5 \mathrm{~mm}$ pin pitch LSIs and $1.0 \mathrm{~mm} \times 0.5 \mathrm{~mm}$ passive parts in new circuit design.

Electronic packages now are becoming hybrid assemblies. Displays are being integrated with electronic drivers, flex cards are being designed for the flexibility to be manipulated to fit into restricted areas, and the form factor of power supplies is being designed to conform to available spaces within products. The rapid integration of functions within electronic products is likely to continue: Japanese firms are all working on merging technologies like integrated circuits, electronic packaging, and flat panel displays. At some point an "electronic package" will likely consist of all the electronic and electrical components of a product, ultrasmall in size and custom-configured for the product.

The technologies covered by the term "electronic packaging" are evolving rapidly. This report examines this process in terms of the goals, infrastructure, specific technological achievements, and dynamics of the electronics industry in Japan.

\section{THE U.S. ELECTRONICS INDUSTRY}

The United States is losing technological and market leadership in the world as its electronics companies drop out of consumer product markets. Today's global competitive environment requires that companies be first to introduce attractive products of the highest quality at the lowest price. Although the United States has long been both a technology innovator and a market leader, in the last decade it has been losing strength in the marketplace. According to the National Advisory Committee on Semiconductors $(1992,2)$,

At the beginning of a decade that promises unprecedented growth in global hightechnology markets, the U.S. firms competing in these markets are experiencing disturbing weaknesses. Many high-volume electronics products, from low-cost goods to highly complex merchandise, are already manufactured overseas. In addition, concern is growing about the ability of U.S. firms to remain competitive in markets where they traditionally have been strong, such as low-cost segments of the computer and office equipment markets. Across the entire world electronics markets, the share produced by U.S.-owned firms has fallen by 14 percentage points since 1985 . The market share loss translates to more than $\$ 100$ billion in lost revenues, given the size of the current world electronics markets. 
U.S. electronics manufacturers have lost market share to foreign-owned or foreign-based manufacturers in practically every electronics sector. This occurred while U.S. industry's R\&D investment exceeded that of foreign competitors, and while U.S. Government R\&D dwarfed that of foreign governments. The Commerce Department was concerned that Japan could surpass the United States in production of electronic goods by 1994 and emphasized that since 1984 (except for software and medical equipment) the United States lost market share in 35 of 37 electronics categories. There are many who believe that the problem is the U.S. R\&D structure's relative inattention to commercial applications, and that Americans must improve their focus on the basic problems of technology application and prototyping of new products. Bert Haskell of Kodak has stated the following:

North America must develop a...low cost, high technology manufacturing infrastructure. This can only be accomplished through a commitment to manufacturing consumer products, and in particular consumer electronics. North American companies must identify emerging high volume consumer electronics products, and must be determined to participate broadly in the manufacture of these systems (MCC/Sandia 1993).

The United States also lags behind Japan in flexible automated manufacturing. Japan operates over $68 \%$ of all installed industrial robots in the world, compared to only $12.5 \%$ operated by the United States. Japan also has over $40 \%$ of the world's installed flexible manufacturing systems. Driven by the shortening of product life cycles and the growing segmentation of markets, Japanese companies are committed to improving manufacturing system flexibility. While this is costly, it has the associated advantages of making possible rapid response to new product introductions. Continuous improvements in manufacturing as well as component technologies resulted in Sharp successfully introducing three new models of its $8 \mathrm{~mm}$ ViewCam within one year of introducing the original product. In sophisticated, flexible electronic assembly equipment, Japanese companies are dominant.

Proficiency in manufacturing high-technology consumer products is critical to maintenance of U.S. prosperity and leadership in a global marketplace; this is in turn dependent on electronic packaging proficiency. It is therefore likely that electronic packaging capabilities will play an increasingly important role in the future economic competitiveness of the United States. The MCC/Sandia report on electronic packaging (1993, 3-4) concluded the following:

- North American companies lead the world in several important segments of the Integrated Circuit [IC] market, but this lead is weakened by an ill-equipped low cost packaging infrastructure.

- Japanese IC packaging and assembling technology is significantly superior to North American capability in terms of miniaturization and cost effectiveness.

- The Japanese are the global leaders in manufacturing cost effective high density printed circuit boards [PCBs]. This leadership has resulted from a gradual improvement in high volume PCB fabrication processes for consumer electronics. 
- Japanese manufacturers' experience in consumer electronics has given them a significant edge over their global competitors in fabricating and deploying miniaturized connectors and passive chip components.

- Japanese market share in consumer electronics has created the "product pull" required to justify large investments in manufacturing processes.

- While cost effective multichip modules [MCMs] are only beginning to emerge, Japanese manufacturers find themselves with a large share of the critical consumer electronics applications which will require MCMs. Japanese manufacturers' dominance of consumer video and PC memory card markets gives them a strategic advantage over North American manufacturers in amortizing the cost of new MCM processes.

- Japanese leadership in flat panel display fabrication is well known. The packaging of display modules, however, also provides Japanese manufacturers with a high volume application with which to distribute the cost of innovative packaging process developments.

The latest generation of consumer products is being integrated to provide new products for home and office: camcorders, electronic still cameras, mini-compact disc players, digital compact cassettes, hand-held televisions, and computers. Other consumer products include portable facsimile machines, copiers and printers, electronic data books, laptop computers, optical disk mass storage systems, smart cards, and portable telephones. Such products grew from 5\% to more than $45 \%$ of Japanese electronics production between 1978 and 1988 , an average growth rate of over $20 \%$ per year, as compared to $10 \%$ for the electronics industry overall (Dataquest 1988, 4-7). Focusing on high-volume consumer electronics markets has been central to Japan's economic strategy. High-volume products have been estimated to account for at least one-third of global integrated chip consumption. U.S. companies have depended for $40-50 \%$ of the value added in their electronic products on foreign competitors, from whom they purchased large numbers of "upstream" electronic packages and components (IEEE 1989, 7). The majority of these imported products and technologies have come from Japan's electronics industry.

\section{JAPAN'S ELECTRONICS INDUSTRY}

Of the $\$ 652$ billion in global electronics production in 1991, Japan's production represented about 27\%, as shown in Figure 1.1. Japan's electrical and electronics industry as a whole produced $\$ 176$ billion in goods in 1991 , second only to the United States' $\$ 232$ billion. In consumer electronics, Japan produced $¥ 4.7$ trillion in goods, a $48 \%$ share of world production, as compared to shares of $12 \%$ for the United States, $22 \%$ for Western Europe, and $18 \%$ for newly industrialized economies (NIEs). In industrial electronics, Japan produced $¥ 11.7$ trillion in goods, a $22 \%$ share of world production, as compared to shares of $38 \%$ for the United States, $34 \%$ for Western Europe, and only $6 \%$ for the NIEs. In electronic components, Japan produced $¥ 8.8$ trillion in goods, a $37 \%$ share of world production, compared to shares of $32 \%$ for the United States, $18 \%$ for Western Europe, and 
$13 \%$ for the NIEs. Japan's share of worldwide electronic component production was stable from the previous year, the United States' share showed a decline, and the NIE share showed an increase. In 1991, Japan exported over $45 \%$ of its electrical/electronics production ( $¥ 11$ trillion of $¥ 25$ trillion in production), which accounted for $27 \%$ of Japan's total exports. In that year, Japan's electrical and electronics industry provided jobs for over two million workers, or $18 \%$ of Japan's manufacturing work force (Dodwell 1993, 4-6).

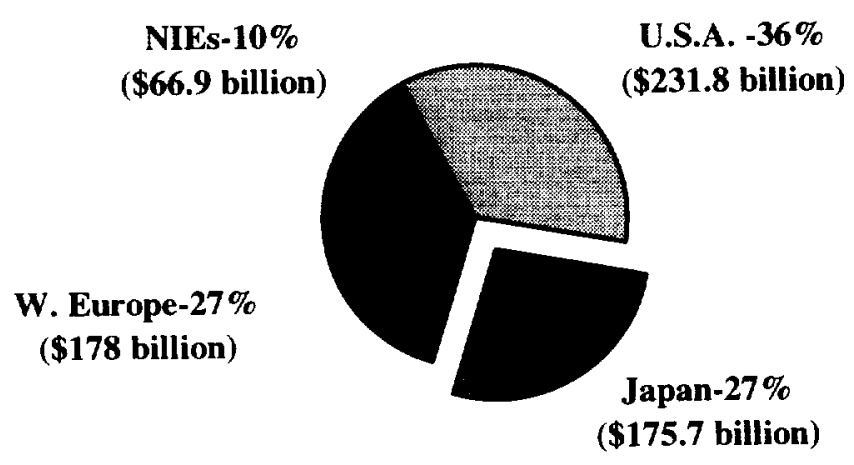

Figure 1.1. 1991 global electronics production, $\$ 652$ billion total: shares of the world's four largest electronics regions (Electronics Industry Association of Japan).

\section{Consumer Electronics in Recession}

Of Japan's total 1991 electronic production, consumer electronics represented 19\%, industrial electronic equipment represented $46 \%$, and electronic components represented $35 \%$. As shown in Table 1.1, both industrial electronics and components were expected to increase in 1993, to $47 \%$ and $37 \%$, respectively; however, as a result of the 1992-1993 recession, consumer electronics' market share fell to $16 \%$.

In 1991, Japan’s $¥ 4.7$ trillion in consumer electronics production consisted of $60 \%$ video equipment and $40 \%$ audio equipment. With Japan's burst bubble economy and ongoing recession, overall consumer sales were down $17 \%$ in 1992 and were projected to fall $3.5 \%$ in 1993 to below $¥ 3.7$ trillion. Sales of audio and video equipment had provided the basis for strong growth in the past, but were in severe stagnation, as shown in Table 1.2. By 1993, audio equipment went from $40 \%$ of the total market to around $36 \%$. Sony introduced its new MD (minidisc) Walkman in 1993 in hopes of stimulating future sales in this market. 
Table 1.1

Japan’s Electronics Industry Production 1992-3, with Forecast for 1994 (¥ million)

\begin{tabular}{||l|r|r|r||}
\hline & $\mathbf{1 9 9 2}$ results & $\mathbf{1 9 9 3}$ estimate & $\mathbf{1 9 9 4}$ forecast \\
\hline Consumer Electronics & $\mathbf{3 , 7 6 0 , 2 6 5}$ & $\mathbf{3 , 2 8 2 , 0 0 0}$ & $\mathbf{3 , 1 7 2 , 4 0 0}$ \\
Video equipment & $2,373,430$ & $2,042,100$ & $1,997,000$ \\
Sound equipment & $1,386,835$ & $1,239,900$ & $1,175,400$ \\
\hline Industrial Electronics & $\mathbf{1 0 , 5 2 7 , 3 6 4}$ & $\mathbf{9 , 8 0 4 , 4 0 0}$ & $\mathbf{9 , 8 6 0 , 1 0 0}$ \\
Radio communications equipment & $1,073,021$ & $1,062,400$ & $1,091,000$ \\
Wired communications equipment & $1,746,926$ & $1,735,000$ & $1,725,000$ \\
Applied electronics equipment & $6,175,651$ & $5,557,400$ & $5,587,400$ \\
Testing \& measuring instruments & 553,654 & 552,600 & 556,000 \\
Office equipment & 978,112 & 897,000 & 900,700 \\
\hline Electronic Components \& Devices & $\mathbf{7 , 9 6 5 , 9 6 9}$ & $\mathbf{7 , 8 5 3 , 7 5 8}$ & $\mathbf{8 , 0 5 6 , 6 3 3}$ \\
Electronic components & $3,518,810$ & $3,289,122$ & $3,208,204$ \\
Electronic devices & $\mathbf{4 , 4 4 7 , 1 5 9}$ & $\mathbf{4 , 5 6 4 , 6 3 6}$ & $4,848,429$ \\
\hline Total & $\mathbf{2 2 , 2 5 3 , 5 9 8}$ & $\mathbf{2 0 , 9 4 0 , 1 5 8}$ & $\mathbf{2 1 , 0 8 9 , 1 3 3}$ \\
\hline
\end{tabular}

Data from Japan Electronics Almanac 1994/1995, 26.

Table 1.2

Japan’s Consumer Electronics Production 1992-3, with Forecast for 1994 (¥ million)

\begin{tabular}{|c|c|c|c|c|c|c|}
\hline & \multicolumn{2}{|c|}{1992 results } & \multicolumn{2}{|c|}{1993 estimate } & \multicolumn{2}{|c|}{1994 forecast } \\
\hline & $\begin{array}{l}\text { Units } \\
(000) \\
\end{array}$ & $\begin{array}{c}\begin{array}{c}\text { Yen } \\
\text { (millions) }\end{array} \\
\end{array}$ & $\begin{array}{l}\text { Units } \\
(000) \\
\end{array}$ & $\begin{array}{c}\begin{array}{c}\text { Yen } \\
\text { (millions) }\end{array} \\
\end{array}$ & $\begin{array}{l}\text { Units } \\
(000) \\
\end{array}$ & $\begin{array}{c}\text { Yen } \\
\text { (millions) } \\
\end{array}$ \\
\hline $\begin{array}{l}\text { Visual Equipment } \\
\text { VCRs } \\
\text { Video movie cameras } \\
\text { Video disk players } \\
\text { TVs } \\
\text { Color TVs } \\
\text { LCD TVs } \\
\end{array}$ & $\begin{array}{r}23, \overline{-} \\
8,386 \\
1,747 \\
14,253 \\
12,024 \\
2,229 \\
\end{array}$ & $\begin{array}{r}\mathbf{2 , 3 7 3 , 4 3 0} \\
780,894 \\
614,007 \\
132,128 \\
846,402 \\
\mathbf{8 1 1 , 2 4 5} \\
35,157 \\
\end{array}$ & $\begin{array}{r}-\overline{2} \\
7,650 \\
2,790 \\
2,300 \\
12,900 \\
10,800 \\
2,100 \\
\end{array}$ & $\begin{array}{r}2,042,100 \\
624,700 \\
511,300 \\
131,900 \\
774,200 \\
748,000 \\
26,200 \\
\end{array}$ & $\begin{array}{r}- \\
19,600 \\
7,840 \\
2,750 \\
12,900 \\
10,600 \\
2,300 \\
\end{array}$ & $\begin{array}{r}1,997,000 \\
564,900 \\
509,400 \\
154,600 \\
768,100 \\
740,000 \\
28,100 \\
\end{array}$ \\
\hline $\begin{array}{l}\text { Sound Equipment } \\
\text { Tape recorders } \\
\text { Car stereos } \\
\text { Tape recorders for general use } \\
\text { Headphone stereos } \\
\text { Radio-cassette recorders } \\
\text { Other tape recorders }\end{array}$ & $\begin{array}{r}-\overline{1} \\
44,620 \\
18,380 \\
26,240 \\
9,711 \\
7,637 \\
8,892 \\
\end{array}$ & $\begin{array}{r}1,386,835 \\
682,284 \\
332,645 \\
349,639 \\
77,343 \\
165,587 \\
106,710 \\
\end{array}$ & $\begin{array}{r}- \\
42,330 \\
18,000 \\
24,330 \\
9,440 \\
6,600 \\
8,290 \\
\end{array}$ & $\begin{array}{r}1,239,900 \\
613,650 \\
309,550 \\
304,100 \\
71,300 \\
136,300 \\
96,500 \\
\end{array}$ & $\begin{array}{r}- \\
40,200 \\
17,200 \\
23,000 \\
9,000 \\
6,200 \\
7,800 \\
\end{array}$ & $\begin{array}{r}1,175,400 \\
573,400 \\
292,800 \\
280,600 \\
67,300 \\
125,500 \\
87,800 \\
\end{array}$ \\
\hline $\begin{array}{l}\text { Stereos } \\
\text { Stereo sets } \\
\text { Component stereos } \\
\text { Hi-Fi tuners } \\
\text { Hi-Fi amplifiers } \\
\text { Record players } \\
\text { CD players } \\
\text { Hi-Fi speaker systems }\end{array}$ & $\begin{array}{r}3,834 \\
1,136 \\
4,615 \\
944 \\
11,409 \\
2,182 \\
\end{array}$ & $\begin{array}{r}558,380 \\
197,875 \\
360,505 \\
11,170 \\
100,131 \\
9,982 \\
209,803 \\
29,420 \\
\end{array}$ & $\begin{array}{r}3,550 \\
1,005 \\
4,630 \\
650 \\
10,500 \\
1,770\end{array}$ & $\begin{array}{r}482,000 \\
163,400 \\
318,600 \\
9,900 \\
101,300 \\
7,000 \\
174,900 \\
25,500 \\
\end{array}$ & $\begin{array}{r}3,600 \\
- \\
970 \\
4,340 \\
560 \\
9,950 \\
1,680\end{array}$ & $\begin{array}{r}462,900 \\
163,200 \\
299,700 \\
9,450 \\
94,000 \\
6,500 \\
165,800 \\
23,950\end{array}$ \\
\hline $\begin{array}{l}\text { Radios } \\
\text { Radios for general use } \\
\text { Car radios }\end{array}$ & $\begin{array}{r}10,836 \\
6,693 \\
4,143 \\
\end{array}$ & $\begin{array}{l}58,818 \\
30,297 \\
28,521 \\
\end{array}$ & $\begin{array}{r}10,150 \\
6,650 \\
3,500\end{array}$ & $\begin{array}{l}55,350 \\
31,350 \\
24,000 \\
\end{array}$ & $\begin{array}{l}9,650 \\
6,550 \\
3,100 \\
\end{array}$ & $\begin{array}{l}51,850 \\
30,900 \\
20,950 \\
\end{array}$ \\
\hline Other & $=$ & 87,352 & - & 88,900 & 一 & 87,250 \\
\hline Total & - & $3,760,265$ & - & $3,282,000$ & - & $3,172,400$ \\
\hline
\end{tabular}

Items in shaded areas do not count separately in totals; they are subtotaled directly above shaded areas.

Data from Japan Electronics Almanac 1994/1995, 28. 


\section{Investments in the Electronics Industry}

A MITI survey in 1992 of 1,667 companies found total plant and equipment investments in Japan valued at $¥ 20.8$ trillion, as compared to $¥ 20.5$ trillion in 1991 . Of these totals, electronics equipment firms, including components firms, invested $¥ 1,399$ billion in 1991 and $¥ 1,030$ billion in 1992 . That is, with the ongoing recession, investment fell $26 \%$ in 1992. Electrical appliance makers held their investment ( $¥ 562$ billion and $¥ 569$ billion for 1991 and 1992, respectively).

Production-related investment accounted for $45 \%$ of overall outlays for new and highvalue-added products. R\&D-related investment represented $24 \%$ of overall outlays, with a priority on supplying competitive products. Investment related to cost cutting and labor savings represented $13 \%$ of overall investments. The most significant product-focused investments were in LCD production. Notebook-type personal computers received significant increases in investment. Investment in $4 \mathrm{M}$ and $16 \mathrm{M}$ DRAM (dynamic random access memory) semiconductor capacity was significantly reduced in 1992 . Investment in cordless and portable telephone capacity was heavy as demand continued to grow. Computer-related R\&D investment was also high.

\section{Moving Production Offshore}

Japan's success in global competition has created new political problems for the country. As shown in Figure 1.2, Japan's aggressive export strategy has allowed it to dominate its trade relationships with all of its major trading partners but China. Continuing imbalance in trade and current accounts has generated surpluses in Japan for 31 straight months. For 1993 , it was expected that Japan's account surplus would be $\$ 130$ billion. This heavy imbalance continues to put a damper on the economies of its trading partners at a time of global recession. A 20\% appreciation in the value of the yen in 1993 made it more difficult to maintain the low-cost requirement of Japanese consumer product strategy. This is part of the reason Japanese firms are moving operations, with the accompanying advanced production technologies, into countries where manufacturing costs are lower.

The yen's appreciation has had a significant impact on consumer product exports. Color TVs and VCRs have been among Japan's major export items, as shown in Table 1.3. According to Japan's Ministry of Finance, camcorders surpassed VCRs as the number one export from Japan in 1992, with $47 \%$ of exports going to European markets and $40 \%$ to North American markets. Until the recession, camcorders had been Japan's number one growth product. Video discs and CD players were among the only products that continued to grow during the recession.

As a consequence of the recession, Japan has had to adjust to the yen's continuing appreciation in value. To stay competitive in world markets, Japanese electronics manufacturers have cut back on their labor forces, downsized plants and facilities, and reduced product lines and frequency of product model changes. Moreover, manufacturers 


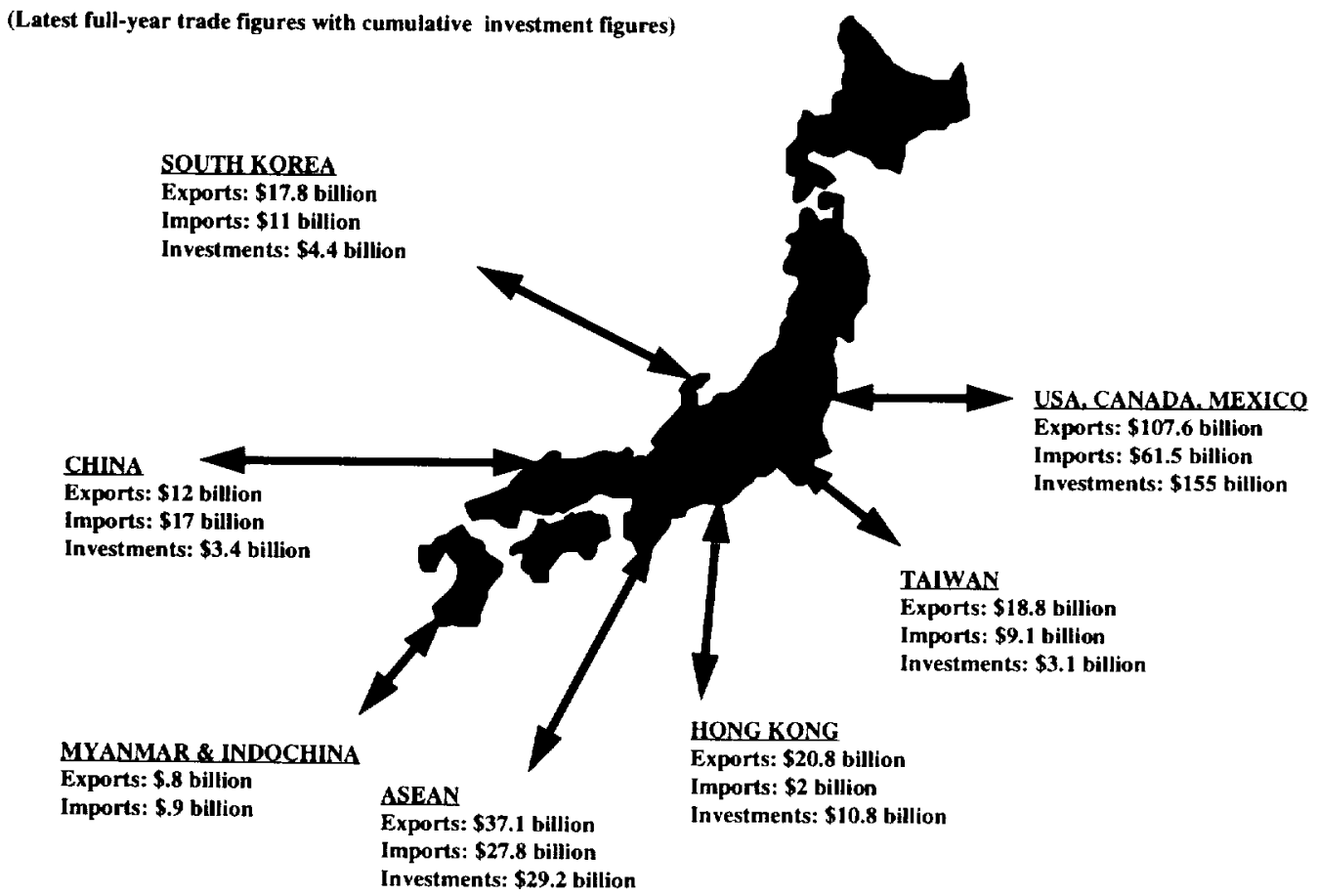

Figure 1.2. Japan's trading relationships in 1993 (Newsweek 1993, 15).

Table 1.3

Export Ratios of Major Export Items

(\% of Japanese industry production that is exported)

\begin{tabular}{||l|c|c|c||}
\hline & $\mathbf{1 9 8 0}$ & $\mathbf{1 9 8 5}$ & $\mathbf{1 9 9 1}$ \\
\hline \hline Color TV sets & $40 \%$ & $68 \%$ & $27 \%$ \\
VCRs & $79 \%$ & $84 \%$ & $71 \%$ \\
Communications equipment & $28 \%$ & $46 \%$ & $27 \%$ \\
Computers and peripherals & $15 \%$ & $31 \%$ & $30 \%$ \\
ICs & $32 \%$ & $32 \%$ & $36 \%$ \\
\hline
\end{tabular}

Source: Dodwell 1993, 3 
are continuing to move their production facilities overseas (Fig. 1.3). Of 400 overseas production bases owned by Japanese electronics makers, $60 \%$ are for consumer electronics plants and $40 \%$ for industrial products. The major shift in facilities began in 1985 with a move into Southeast Asia.

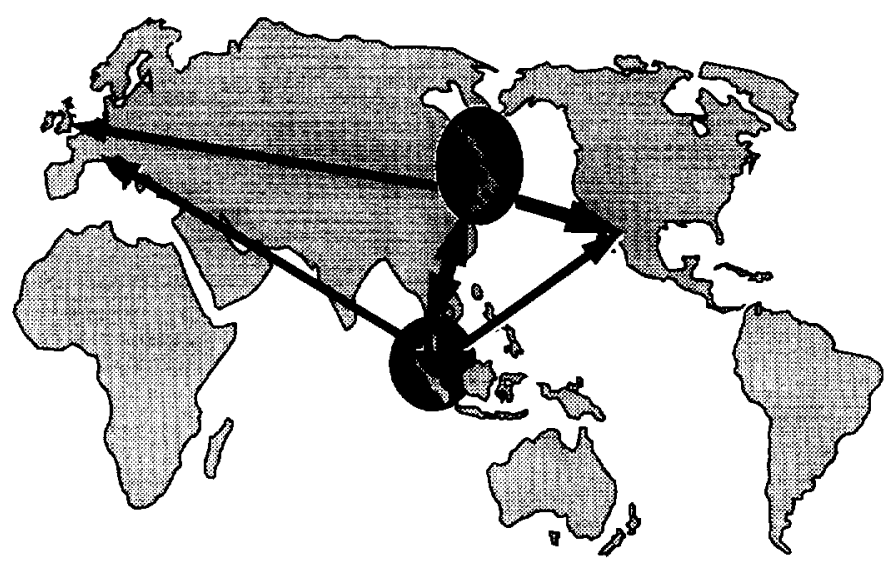

Figure 1.3. The movement of Japanese production facilities offshore (William R. Boulton \& Assoc.).

The largest number of Japan's Asian plants are located in the Association of Southeast Asian Nations (ASEAN) nations of Malaysia, Singapore, Thailand, and most recently, Indonesia. Japan's move to ASEAN countries is a result of its need to restructure global operations in light of declining production advantages in Japan, the yen's appreciation, trade friction, and unification of regional markets. These plants provide low- and mediumpriced electronics products and components. Of $¥ 136$ billion in consumer electronics goods imported by Japan in 1991, 86\% came from Asia, $8 \%$ from the United States, and 5\% from Europe. A number of Japanese companies continued to expand plants in Southeast Asia during 1993; however, the investment priority was shifting to China. After having invested a total of nearly $\$ 30$ billion in Malaysia, for example, Japanese firms invested only $\$ 1.5$ billion in 1992. The number of Japanese investment applications fell from 46 to 35 for the January to April periods of 1992 and 1993, respectively. Japanese investments in Singapore remained high, with nearly $\$ 3.5$ billion invested in 1993 (Newsweek 1993, 15).

As shown in Table 1.4, of 241 Japanese consumer electronics plants located offshore in 1992, 128 were located in Asia, 47 in Europe, 44 in North America, and 22 elsewhere in the world. Of 168 industrial electronics plants located offshore, 75 plants were in Asia, 38 in Europe, 48 in North America, and 7 elsewhere. 
Table 1.4

The Number of Offshore Japanese Production Bases in 1992

\begin{tabular}{|c|c|c|c|c|c|}
\hline & Total & Asia & Europe & $\begin{array}{c}\text { North } \\
\text { America } \\
\end{array}$ & Other \\
\hline $\begin{array}{l}\text { CONSUMER ELECTRONICS } \\
\text { Audio/Visual Equipment } \\
\text { TVs } \\
\text { VCRs } \\
\text { Radios } \\
\text { Head Phone Stereos } \\
\text { Cassette Tape Recorders } \\
\text { Other Tape Recorders } \\
\text { Stereos } \\
\text { CD Players } \\
\text { Hi-fi Speaker Systems } \\
\text { Car Audio } \\
\text { Others } \\
\text { Home Electrical Appliances } \\
\text { Microwave Ovens } \\
\text { Electric Fans } \\
\text { Refrigerators } \\
\text { Washing Machines } \\
\text { Air Conditioners } \\
\text { Compressors } \\
\text { Others }\end{array}$ & $\begin{array}{l}81 \\
47 \\
27 \\
12 \\
46 \\
23 \\
60 \\
31 \\
12 \\
38 \\
14 \\
17 \\
17 \\
21 \\
13 \\
24 \\
10 \\
79\end{array}$ & $\begin{array}{r}34 \\
18 \\
13 \\
11 \\
28 \\
18 \\
31 \\
19 \\
1 \\
19 \\
7 \\
\\
4 \\
14 \\
17 \\
12 \\
19 \\
8 \\
52\end{array}$ & $\begin{array}{r}14 \\
19 \\
0 \\
0 \\
0 \\
1 \\
10 \\
9 \\
2 \\
8 \\
4 \\
\\
6 \\
0 \\
0 \\
0 \\
1 \\
0 \\
3\end{array}$ & $\begin{array}{r}16 \\
2 \\
4 \\
0 \\
4 \\
0 \\
5 \\
1 \\
5 \\
6 \\
2 \\
\\
3 \\
2 \\
1 \\
0 \\
0 \\
2 \\
16\end{array}$ & $\begin{array}{r}17 \\
8 \\
10 \\
1 \\
14 \\
4 \\
14 \\
2 \\
4 \\
5 \\
1\end{array}$ \\
\hline Total* & 241 & 128 & 47 & 44 & 22 \\
\hline $\begin{array}{l}\text { INDUSTRIAL ELECTRONICS } \\
\text { Communications Equipment } \\
\text { Telephones } \\
\text { Cellular Phones } \\
\text { Pocket Pagers } \\
\text { Facsimiles } \\
\text { Others } \\
\text { Computers } \\
\text { Mainframes } \\
\text { Personal Computers } \\
\text { HDDs } \\
\text { Printers } \\
\text { Others } \\
\text { Other Applied Systems } \\
\text { Electronic Measurement Equipment } \\
\text { Office Equipment: } \\
\text { Calculators } \\
\text { Copiers } \\
\text { Other } \\
\end{array}$ & $\begin{array}{r}28 \\
12 \\
6 \\
13 \\
19 \\
\\
7 \\
6 \\
12 \\
16 \\
24 \\
21 \\
24 \\
\\
6 \\
18 \\
14 \\
\end{array}$ & $\begin{array}{r}20 \\
1 \\
3 \\
5 \\
8 \\
\\
1 \\
2 \\
5 \\
4 \\
10 \\
11 \\
13 \\
\\
5 \\
1 \\
1 \\
\end{array}$ & $\begin{array}{r}2 \\
3 \\
0 \\
5 \\
1 \\
\\
2 \\
2 \\
1 \\
10 \\
2 \\
4 \\
4 \\
\\
0 \\
11 \\
6 \\
\end{array}$ & $\begin{array}{r}5 \\
7 \\
3 \\
3 \\
7 \\
\\
4 \\
2 \\
6 \\
2 \\
12 \\
5 \\
5 \\
\\
0 \\
4 \\
7 \\
\end{array}$ & $\begin{array}{l}1 \\
1 \\
0 \\
0 \\
3 \\
0 \\
0 \\
0 \\
0 \\
0 \\
0 \\
1 \\
2 \\
\\
1 \\
2 \\
0\end{array}$ \\
\hline Total* & 168 & 75 & 38 & 48 & 7 \\
\hline
\end{tabular}

* As a company manufactures different kinds of products, the total figures do not equal the added number of manufacturers.

Source: Dodwell 1993, 27-28 
Table 1.5 shows the leading sources of Japan's electronics equipment and parts imports in 1992. Asia dominated Japan's consumer electronics imports with an $84 \%$ share. Asia also dominated Japan's import of passive devices and components and produced one-third of imported active devices. North America still dominated its industrial products imports and led in active devices, integrated circuits, and other parts and accessories. Only imports of U.S. microprocessors and memories continued to grow rapidly - up 23\% from 1990-91. Japan's 1991 imports of components from ASEAN nations, China, and Hong Kong grew significantly, while those from Europe, North America, Korea, and Taiwan decreased.

Table 1.5

Japan’s Electronics Imports in 1992, by Region (¥ million)

\begin{tabular}{||l|r|r|r|r|r||}
\hline & \multicolumn{1}{|c|}{ Asia } & \multicolumn{1}{|c|}{ Europe } & \multicolumn{1}{c|}{$\begin{array}{c}\text { North } \\
\text { America }\end{array}$} & \multicolumn{1}{c|}{$\begin{array}{c}\text { Other } \\
\text { Areas }\end{array}$} & \multicolumn{1}{c|}{ Total } \\
\hline \hline Consumer Electronics Equipment & $\mathbf{1 3 0 , 8 3 8}$ & $\mathbf{7 , 6 0 3}$ & $\mathbf{1 7 , 5 4 6}$ & $\mathbf{5 3}$ & $\mathbf{1 5 6 , 0 4 1}$ \\
\hline Industrial Electronic Equipment & & & & & \\
Wired communications equipment & 15,090 & 1,217 & 29,447 & 35 & 45,790 \\
Radio communications systems & 10,574 & 1,995 & 21,510 & 22 & 34,102 \\
Electronics-applied equipment & 78,775 & 70,798 & 290,099 & 23,695 & 463,367 \\
Computers & 77,940 & 48,618 & 261,937 & 20,262 & $\mathbf{4 0 8 , 7 5 7}$ \\
Test \& measuring instruments & 3,990 & $15, \mathbf{4 6 9}$ & 52,677 & 376 & 72,511 \\
Office equipment & 15,616 & 119 & 1,818 & 8 & 17,561 \\
Total & $\mathbf{1 2 4 , 0 4 5}$ & $\mathbf{8 9 , 5 9 9}$ & $\mathbf{3 9 5 , 5 5 1}$ & $\mathbf{2 4 , 1 3 6}$ & $\mathbf{6 3 3 , 3 3 2}$ \\
\hline Electronic Components and Devices & & & & & \\
Passive and other components & 154,804 & 14,505 & 59,228 & 1,332 & 229,870 \\
Active devices & 169,444 & 32,356 & 280,626 & 497 & 482,923 \\
Electronic tubes & 26,573 & 2,045 & $\mathbf{1 2 , 0 0 5}$ & 7 & $\mathbf{4 0 , 6 3 0}$ \\
Discrete semiconductors & 39,821 & 3,317 & 11,367 & $\mathbf{6 8}$ & $\mathbf{5 4 , 5 7 3}$ \\
Integrated circuits & 103,049 & 26,995 & 257,254 & 421 & $\mathbf{3 8 7 , 7 1 9}$ \\
Others & 235,211 & 36,876 & 257,902 & 13,446 & 543,435 \\
Total & $\mathbf{5 5 9 , 4 5 9}$ & $\mathbf{8 3 , 7 3 8}$ & $\mathbf{5 9 7 , 7 5 6}$ & $\mathbf{1 5 , 2 7 5}$ & $\mathbf{1 , 2 5 6 , 2 2 8}$ \\
\hline \hline Grand Total & $\mathbf{8 1 4 , 3 4 2}$ & $\mathbf{1 8 0 , 9 3 9}$ & $\mathbf{1 , 0 1 0 , 8 5 3}$ & $\mathbf{3 9 , 4 6 5}$ & $\mathbf{2 , 0 4 5 , 6 0 1}$ \\
\hline
\end{tabular}

Items in shaded areas do not count separately in totals; they are subtotaled directly above shaded areas. Totals are rounded.

Source: Japan Electronics Almanac 1994/1995, 53.

\section{Technological Relationships}

Japan's manufacturing technology exports were $¥ 321$ billion in 1990 , and its imports were $¥ 364$ billion. The electronics industry’s technology exports accounted for $¥ 97$ billion, or $29 \%$ of Japan's total technology exports. Other major exports included chemicals, $17 \%$ ( $¥ 58.2$ billion) of total technology exports; industrial machinery, $4 \%$ ( $¥ 14.4$ billion); and ceramics, $3 \%$ ( $¥ 11.9$ billion). Thirty percent of technology exports went to the United States; Asia accounted for $45 \%$, the major recipients being South Korea (14\%), Thailand $(7 \%)$, Taiwan $(5 \%)$, Singapore $(6 \%)$, and Indonesia $(6 \%)$; Europe accounted for $18 \%$, with the U.K. $(6 \%)$ being the primary partner. 
Electronics also accounted for the majority of Japan’s technology imports $-43 \%$ ( $¥ 160$ billion), compared to $14 \%$ for transportation ( $¥ 52$ billion), $8 \%$ for industrial machinery ( $¥ 31$ billion), and $3 \%$ for precision machinery ( $¥ 11.4$ billion). The United States was the source for $70 \%$ of Japan's total technology imports. Outside of North America, these imports came primarily from European countries (29\%), including Germany (7\%), France $(6 \%)$, and the Netherlands (5\%).

Manufacturing industries accounted for over $90 \%$ of Japan’s $¥ 9.3$ trillion in R\&D expenditures in 1990. While R\&D expenditures had tripled since 1980, they were expected to double again by the mid-1990s. The Japanese government set a goal in 1992 of doubling Japan's R\&D expenditures as a percent of GNP. Japan's electronics industry R\&D expenditures ( $¥ 3.1$ trillion) accounted for over $37 \%$ of total R\&D expenditures ( $¥ 8.7$ trillion), as shown in Table 1.6 :

Table 1.6

Japanese R\&D Expenditures

\begin{tabular}{|l|r|c||}
\hline \multicolumn{1}{|c|}{ Sector } & R\&D Spent (Y) & \% of Total \\
\hline \hline Electric Machinery Equipment & 996 billion & $12 \%$ \\
\hline Communication/Electronics/Measuring & 2,150 billion & $25 \%$ \\
\hline Subtotal, Electronics Industry R\&D & $\mathbf{3 , 1 4 6}$ billion & $\mathbf{3 7 \%}$ \\
\hline \hline Chemical Industry & 1,416 billion & $16 \%$ \\
\hline Transportation Machinery & 1,496 billion & $17 \%$ \\
\hline Other Manufacturing Industries & 2,601 billion & $30 \%$ \\
\hline Total Manufacturing Industries R\&D & $\mathbf{8 , 6 6 0}$ billion & $\mathbf{1 0 0 \%}$ \\
\hline
\end{tabular}

Source: Dodwell 1993, 51

The growth rate of $\mathrm{R} \& \mathrm{D}$ in communication, electronics, and measuring equipment was the highest, having grown by a factor of four over the past decade. While the pharmaceutical industry showed the highest ratio of R\&D to sales at $8 \%$, communications, electronics, and measuring equipment R\&D followed at $6.1 \%$ of sales. Electrical machinery R\&D was $5.4 \%$ of sales, followed by chemicals ( $4 \%)$ and autos $(3.7 \%)$.

\section{Planning for Future Products}

Japan's electronics industry is driven by expected growth in consumer products. The Electronics Industry Association of Japan forecasts growth by product category as shown in Figure 1.4, which projects audiovisual production for the years 1995 and 2000. The most significant projected growth comes from the shift to high definition televisions and VCRs. Projected output growth of minidisc and digital compact cassette players was expected to triple during the latter half of this decade. Combination telephone/color TV sets were expected to become a new growth product by the end of the decade. This forecast shows 
very little that is totally new; most categories show development of next-generation models of products currently on the market. This type of industry projection provides the roadmaps for most Japanese companies as they develop plans for future products. Such roadmaps help to identify the technologies that will be needed to produce the coming generations of products.

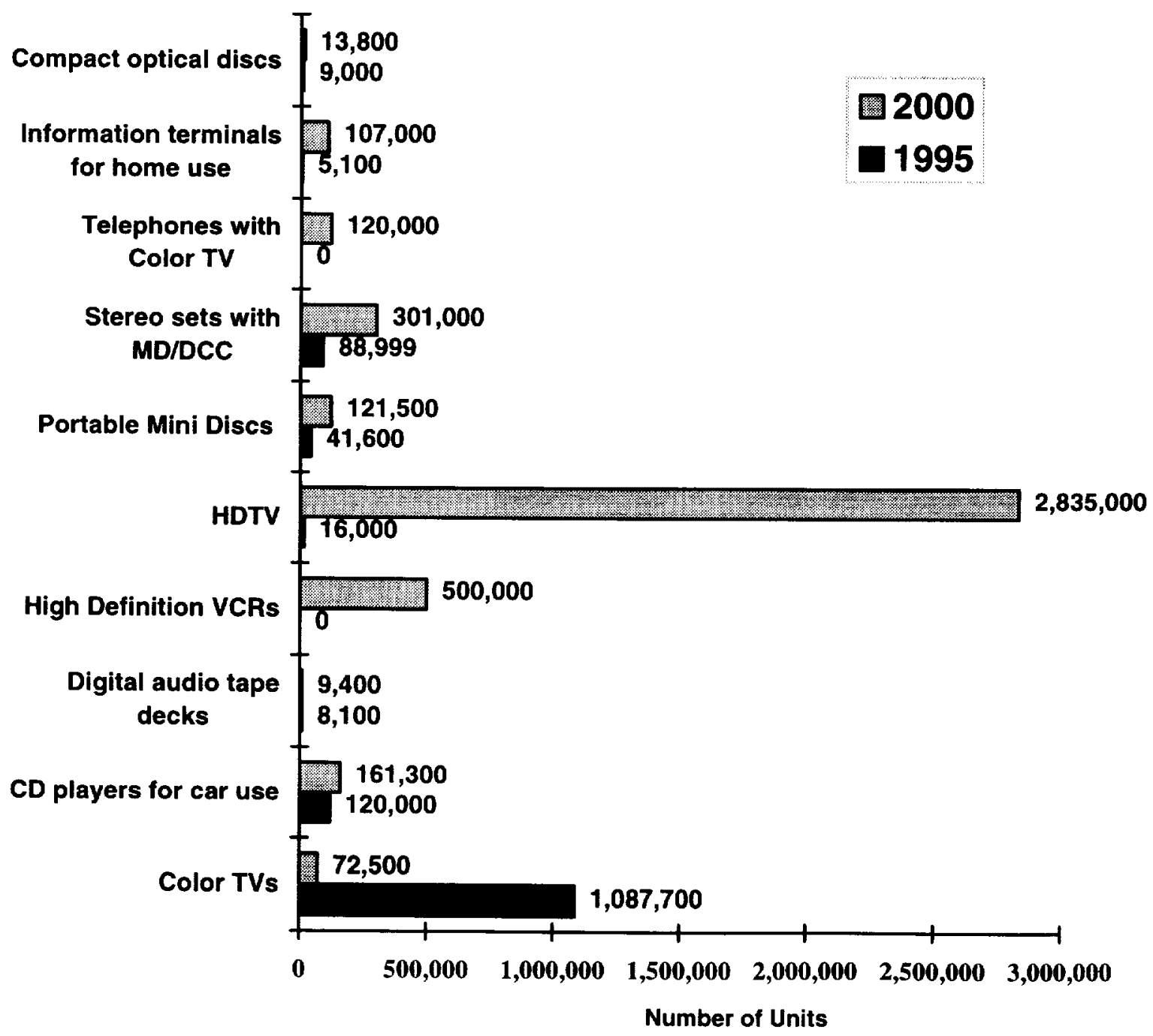

Figure 1.4. Japanese forecast of audiovisual production in 1995 and 2000 (Electronics Industry Association of Japan).

Forecasts for growth in computer-related products to 1995 are shown in Figure 1.5. The highest volume of production is expected at the low-priced end of the product spectrum. High-volume desktop computers put few constraints on product size but are differentiated 
by advanced functions. In contrast, notebook computers and personal digital assistants will push the limits of product miniaturization. (Notebook computers have allowed new competition to enter the industry from outside Japan and the United States.)

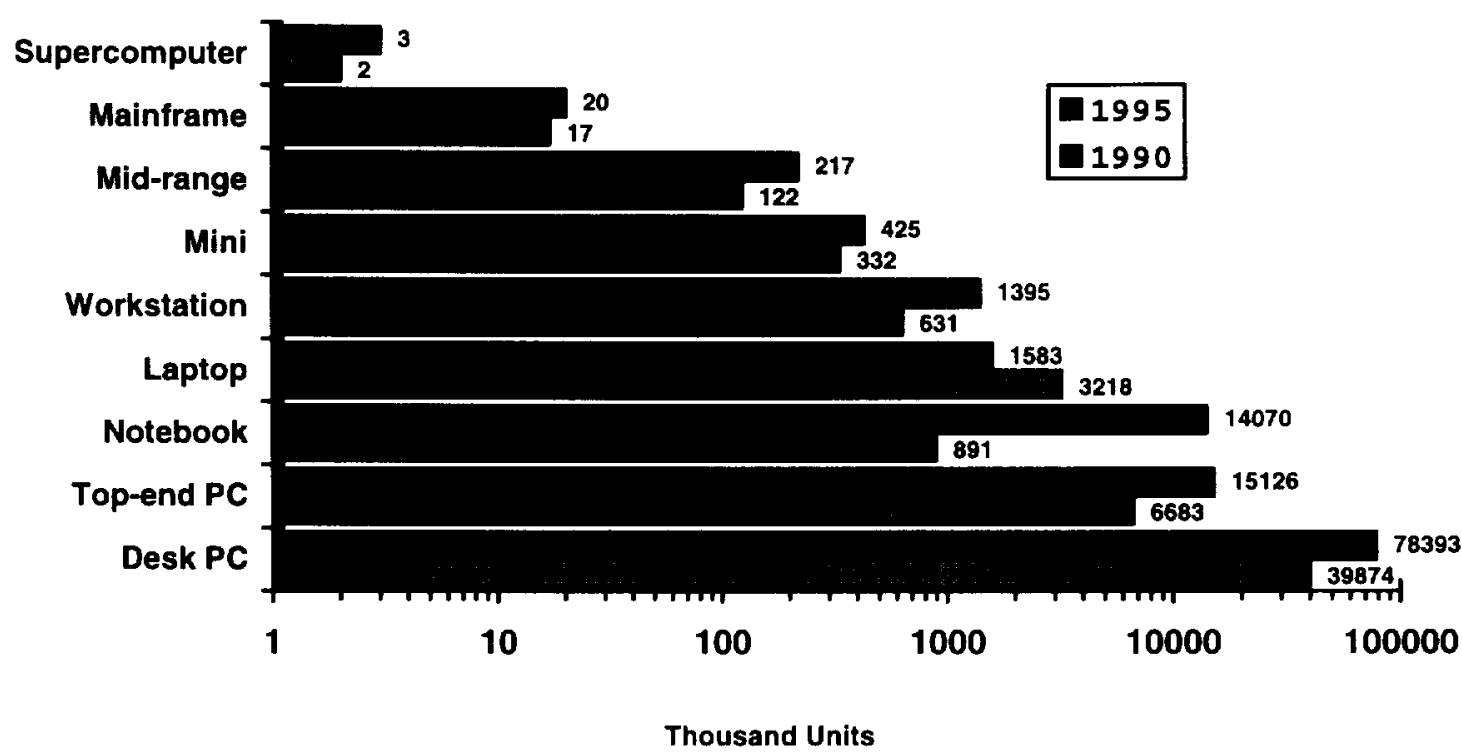

Figure 1.5. Number of computer-related systems worldwide (BPA, Dataquest).

\section{Supporting Technologies}

Japan's heavy emphasis on the electronics industry has lead it to become a major player in the production and export of electronic components. In 1992, 52\% of electronics components were active components (electron tubes $8 \%$, discrete semiconductors $9 \%$, and integrated circuits $35 \%$ ); $15 \%$ were passive components such as capacitors, resistors, and inductors; and $31 \%$ were other electronic parts (mechanical parts $14 \%$, and audio parts $7 \%$ ). Total production of electronic components was valued at $¥ 8.8$ trillion in 1991, an increase of $6 \%$ over the previous year. The growth rate 1986 to 1991 was $10 \%$ per annum. Active components production totaled $¥ 4.6$ trillion in 1991, up $6 \%$ over 1990 .

Passive component production totaled $¥ 4.3$ trillion, up over $5 \%$ from 1990 . The highest growth areas were discrete semiconductors, passive devices and parts such as connectors, switches, relays, and PCBs, growing at over 7\% in 1991. Japan was the largest semiconductor market in the world, accounting for $39 \%$ of 1991 sales, compared to $28 \%$ for the United States, $18 \%$ for Western Europe, and $15 \%$ for the rest of the world. As shown in Table 1.7, while electronic device sales were down in 1992, they were forecast to come back again in 1993. 
Table 1.7

\section{Electronic Devices and Parts Output}

\begin{tabular}{|l|r|r|r|r|r|r||}
\cline { 2 - 7 } \multicolumn{1}{c|}{} & \multicolumn{2}{c|}{1991} & \multicolumn{2}{c|}{1992 estimate } & \multicolumn{2}{c|}{ 1993 forecast } \\
\hline \hline $\begin{array}{c}\text { Electronic Devices/ } \\
\text { Electronic Parts }\end{array}$ & $\begin{array}{c}\text { Units } \\
(\mathbf{0 0 0})\end{array}$ & $\begin{array}{c}\text { Yen } \\
\text { (millions) }\end{array}$ & $\begin{array}{c}\text { Units } \\
(\mathbf{0 0 0})\end{array}$ & $\begin{array}{c}\text { Yen } \\
\text { (millions) }\end{array}$ & $\begin{array}{c}\text { Units } \\
\text { (000) }\end{array}$ & $\begin{array}{c}\text { Yen } \\
\text { (millions) }\end{array}$ \\
\hline \hline Electron tubes & - & 718,650 & - & 694,790 & - & 713,920 \\
\hline Discrete Semiconductors & - & 761,623 & - & 690,060 & - & 708,180 \\
\hline Integrated Circuits & - & $3,125,191$ & - & $2,810,500$ & - & $2,994,770$ \\
\hline Liquid Crystal Displays & 217 & 255,039 & 417 & 323,130 & 480 & 399,070 \\
\hline Total Electronic Devices & & $\mathbf{4 , 8 6 0 , 5 0 4}$ & - & $\mathbf{4 , 5 1 8 , 4 8 0}$ & - & $\mathbf{4 , 8 1 5 , 9 4 0}$ \\
\hline \hline Passive Parts & - & $1,337,718$ & - & $1,161,780$ & - & $1,196,620$ \\
\hline Transistor Parts & - & 490,987 & - & 421,690 & - & 399,590 \\
\hline Connecting Parts & - & $1,442,977$ & - & $1,258,750$ & - & $1,286,810$ \\
\hline Other & - & $\mathbf{7 7 5 , 1 6 7}$ & - & 690,940 & - & $\mathbf{7 0 7 , 6 3 0}$ \\
\hline Total Electronic Parts & - & $\mathbf{4 , 0 4 6 , 8 4 9}$ & - & $\mathbf{3 , 5 3 3 , 1 6 0}$ & - & $\mathbf{3 , 5 9 0 , 6 5 0}$ \\
\hline \hline
\end{tabular}

Source: The Electronics Industry Association of Japan

Japan exported $57 \%$ of its electronic components production in 1991 , totaling $¥ 5.1$ trillion. Active components represented $33 \%$ of all exports, passive components $7 \%$, electronics parts $6 \%$, and audio parts $3 \%$. With the increasing production of components in Asia, Japan's components imports grew $8 \%$ to $¥ 1.3$ trillion in 1991 , equivalent to one-quarter the value of Japan's exports.

\section{THE MICROELECTRONICS INDUSTRY STRUCTURE}

High-volume, low-cost electronic packaging technologies are critical for many of today's consumer electronics markets. Control of electronic packaging technologies provides companies with the competitive capabilities to design and manufacture smaller and more sophisticated consumer products like camcorders, cameras, and digital databooks. With innovative merging of semiconductor, packaging, and display technologies, also evolving are second- and third-generation technologies that will increasingly affect the design parameters of future products. Firms with capabilities in materials, equipment, design, and advanced manufacturing will be the future producers of low-cost electronic packages.

In Japan, unlike in the United States, most companies that are heavily invested in downstream electronics markets are also vertically integrated and heavily invested in upstream technologies. Six vertically integrated firms produced $85 \%$ of Japan's semiconductors, $80 \%$ of its computers, $80 \%$ of its telecommunications equipment, and $60 \%$ of its consumer electronics products. In the United States, approximately $80 \%$ of all semiconductors are manufactured by merchant firms that manufacture few or no other upstream materials and equipment or downstream products. The absence of upstream involvement can be readily seen from Figure 1.6. This U.S. electronic industry's depiction of the electronics technology chain shows a total neglect in identifying those products that 
need to be targeted (Gover and Gwyn 1992, 18). Instead, it describes the broad range of markets for which the technologies can be applied, without providing the roadmaps for technology and component development. While upstream electronics technology has a significant impact on downstream market development, the technology can be most effectively developed with a knowledge of specific product development requirements.

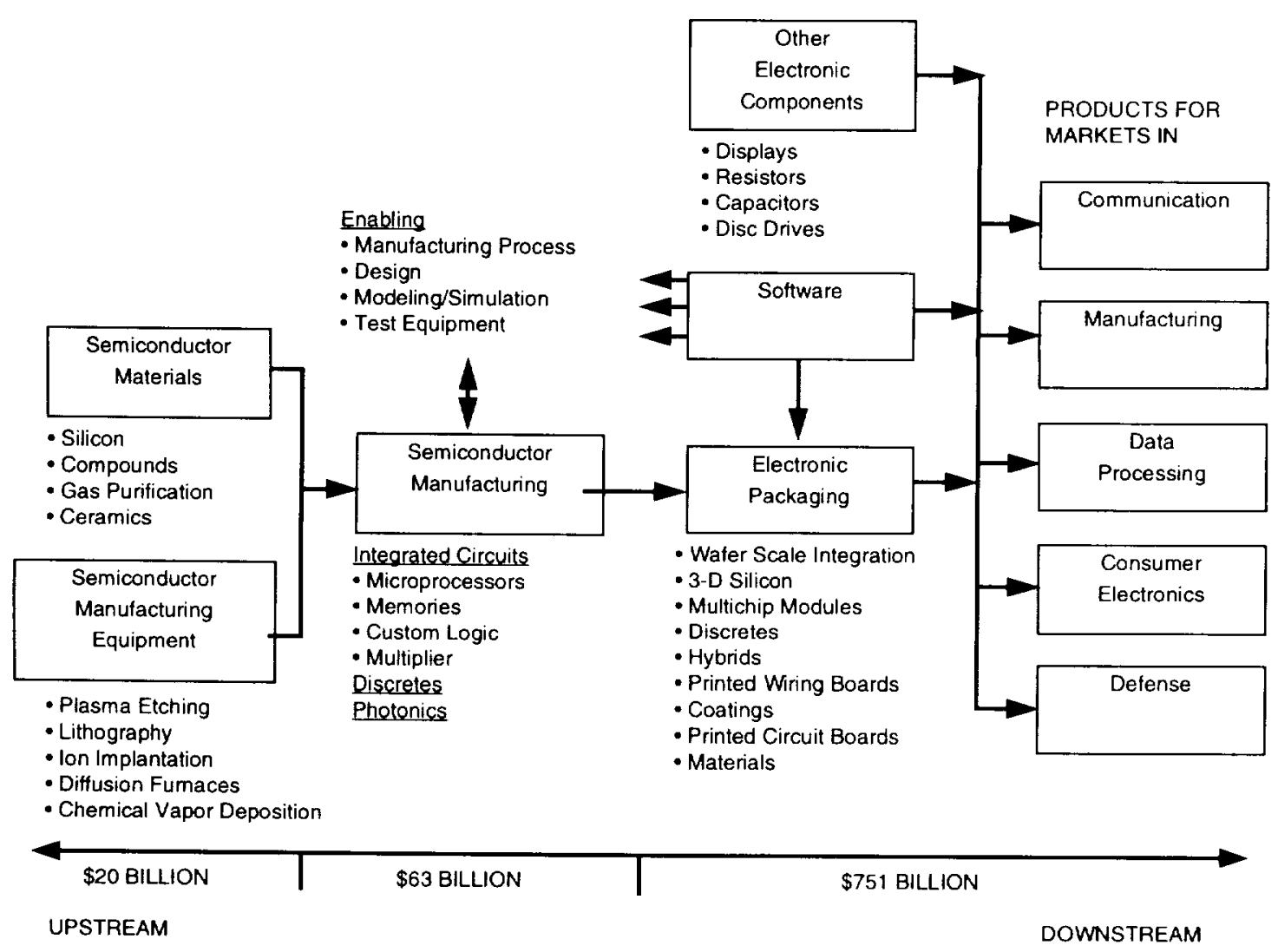

Figure 1.6. Microelectronics world market structure 1990 (Gover \& Gwyn 1992).

A firm's involvement in downstream products and markets provides the vision for setting priorities in developing future upstream technologies. Electronic packaging and other component technologies are becoming the critical technologies for advanced product designs and functions. Japanese firms have developed dominant positions in display technologies, in the miniaturization of low-cost, high-volume electronic packages, and in the development of advanced manufacturing equipment for ultrasmall component assembly. In order to introduce its "next-generation" products, Japanese firms have had to push the development of a number of technologies:

- fine-pitch devices

- advanced flex circuit designs

- cost-effective flip chip technology 
- cost-effective high-density printed circuit boards

- cost-effective connector technology

- advanced flat panel display technology

- small passive components

- small, low-cost package assembly equipment

- high-speed pick and place equipment for ultrasmall components

These developments now provide Japanese firms with the ability to either design-in greater functionality and performance for any given size product, or to reduce the size or cost of products at any given level of functionality or performance. These "intermediate" packaging capabilities are expected to provide much of the value added for future electronic products from supercomputers to cameras. In fact, Sony argues that $65 \%$ of a product's value added comes from key component and device contributions, as compared to only $12 \%$ coming from final assembly operations. Therefore, some Japanese firms are reducing dependence on suppliers for key components as a strategy to improve financial performance. To focus development efforts in these high-value-added "intermediate" device markets, firms need a vision of new product concepts or next-generation product developments.

Sony's historical success is based on a strategy of developing key components to support new product developments such as the transistor radio in 1955, the Trinitron in 1968, the Betamax in 1975, the Walkman in 1979, the CD player in 1982, and the $8 \mathrm{~mm}$ camcorder in 1985. Sony's introduction of the Trinitron color television was dependent upon the development of its single electron gun with three electron beams and an aperture grill. After eight years of development, Sony's technological breakthrough was considered the next generation beyond the shadow mask developed by RCA. Its Trinitron technology continues to provide Sony with a basic technology for use in advanced high definition television applications. Sony also developed the charge-coupled device (CCD) as an image-sensing device. After two years of basic research, Sony took five years to produce the first small CCD camera for use in the industrial market; it took five more years to develop the mass production technology required to enter the consumer market. Miniaturization of the video camera gave Sony a dominant position in the $8 \mathrm{~mm}$ video camera market.

Sharp has used a similar key device development strategy. It introduced the first commercial application of a LCD in an electronic calculator in 1973. Since then, it has pioneered the application of LCDs in Japanese word processors and PCs in 1986, the development of the world's first 14-inch color thin-film-transfer (TFT) LCD panel in 1988, and the development of LCD video projectors in 1989. Sharp's Hi-8 LCD ViewCam, introduced in 1992, was the world's first camcorder with a 4-inch color TFT LCD monitor. In 1993, Sharp's ViewCam surpassed both Matsushita and JVC products to take second place in the video camera market. Sony now plans a similar LCD camcorder to respond to Sharp's innovation. Ability to take the lead in critical component technologies is vital to developing market leadership. 
In support of next-generation product development and miniaturization goals, the Japanese electronics industry is investing in upstream technologies. In 1992 Lloyd Thorndyke, CEO of DataMax, found that electronic packaging technologies of Japan's supercomputer makers were highly advanced. He commented on this in his report:

I was told that the Japanese super computer companies overtook U.S. companies in super computer packaging five years ago, and that now the lead is insurmountable. I tend to agree, but for a different reason. The newer technologies require increasingly greater capital and tooling funding to enter production. However, most U.S. super computer companies are relatively small, have low volumes, and limited capital money $(1993,31)$.

With their heavy commitment to consumer electronics products, Japanese firms have created a tremendous demand for upstream electronic technologies, including DRAM memory chips and many intermediate electronic component and parts technologies. Growing domination of these intermediate component and packaging technologies, including video display technology, provides competitive advantages for future product developments. For example, advanced display technology, integrating both display and packaging technologies, is expected to pull the development of other microelectronics technology into new consumer product applications ranging from hand-held computers to high definition television sets.

These conclusions are neither new nor surprising. The Council on Competitiveness reported $(1991,35)$ that the United States was losing badly or had already lost important electronic technologies in display materials, ceramics for electronics, electronic packaging materials, gallium arsenide materials, silicon materials, integrated circuit fabrication and test equipment, microelectronics memory chips, multichip packaging systems, printed circuit board technology, electroluminescent displays, plasma displays, vacuum fluorescent displays, and optical information storage. The Computer Systems Policy Project, composed of the major U.S. computer manufacturers, had come to a similar conclusion in 1990, determining that the United States was behind in displays, manufacturing technology, ultralarge-scale integrated (ULSI) circuit fabrication equipment and facilities, microelectronics, and electronics packaging. These studies identified six areas as needing special attention: optoelectronics, electronic packaging, electronics and semiconductor materials, display technology, ULSI fabrication equipment, and memory chips. It was estimated that these six technologies would represent a world market worth of over $\$ 100$ billion by the year 2000 . What is more important, it is expected that whoever dominates these areas of technology will also dominate the world market for electronics products that is expected to exceed $\$ 2$ trillion in revenues.

It was clearly evident to the JTEC panel that Japanese companies do not intend to give their competitive advantages away. Recently, Sony has limited the number of outsiders who visit its operations, for fear of losing proprietary information. In cases where outsiders are allowed to visit Sony, they are shown production technology that the company is already selling to outside customers. The same is true with Matsushita, the 
world leader in semiconductor insertion equipment, where advanced equipment developed in-house is used for several years before being made available on the open market. As product life cycles continue to shorten, six-month or one-year delays in product availability can mean the difference between substantial profits and significant losses over the short life of a product. The component requisition problems are not political issues but rather competitiveness issues. Pragmatic business executives are not likely to sell their advanced microelectronics technologies or equipment if doing so creates competitors in critical downstream markets. Even U.S. semiconductor firms stopped selling components to downstream calculator assemblers once they realized the potential for profit in producing calculators themselves. As Texas Instrument's chairman Patrick Haggerty reflected (1976), "TI's biggest mistake may have been in not integrating forward into portable radios in the early 1950s." It was the development of portable radios that gave Sony its first major consumer market success.

\section{REFERENCES}

Computer Systems Policy Project. 1990. Perspectives: Success Factors in Critical Technologies.

Council on Competitiveness. 1991 (July). Gaining New Ground: Technology Priorities for America's Future.

Dataquest Incorporated and Quick, Finan and Associates. 1988. The Drive for Dominance: Strategic Options for Japan's Semiconductor Industry.

Dempa Publications. 1993. Japan Electronics Almanac 1993/1994. Tokyo.

Dempa Publications. 1994. Japan Electronics Almanac 1994/1995. Tokyo.

Dodwell Marketing Consultants. 1993. The Structure of the Japanese Electronics Industry. Tokyo.

Gover, James E., and Charles W. Gwyn. 1992. Strengthening the US Microelectronics Industry by Consortia. Albuquerque, NM: Sandia National Laboratories.

Haggerty, Patrick. 1976. Personal interview with the author.

IEEE-USA Technologies Activities Council. 1989. Workshop on Creation of Government/Industry Partnerships (February 13-14).

Microelectronics and Computer Technology Corporation and Sandia National Laboratory (MCC/Sandia). 1993. Industrial Competitiveness in the Balance: A Net Technical Assessment of North American vs. Offshore Electronics Packaging Technology. (U.S. Department of Energy Contract \#AD-3474.)

National Advisory Committee on Semiconductors. 1991 (February). Toward a National Semiconductor Strategy: Regaining Markets in High-Volume Electronics.

National Advisory Committee on Semiconductors. 1992 (February). Attaining Preeminence in Semiconductors: Third Annual Report to the President and the Congress. Arlington, Virginia.

Newsweek (Asian edition). 1993 (November 15). "The Coming Eclipse of Greater Japan.": 15.

Thorndyke, Lloyd M. 1993. "Supercomputer Packaging Technologies Compared." SIB, 18 Feb. 

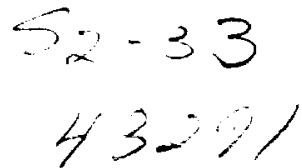

\title{
CHAPTER 2
}

\section{BUILDING THE ELECTRONIC INDUSTRY'S ROADMAPS}

\author{
William R. Boulton
}

JTEC panelists found a strong consistency among the electronics firms they visited: all the firms had clear visions or roadmaps for their research and development activities and had committed resources to ensure that they achieve targeted results. The overarching vision driving Japan's electronics industry is that of achieving market success through developing appealing, high-quality, low-cost consumer goods - ahead of the competition. Specifics of the vision include improving performance, quality, and portability of consumer electronics products. Such visions help Japanese companies define in detail the roadmaps they will follow to develop new and improved electronic packaging technologies.

\section{DIMENSIONS OF PRODUCT DEVELOPMENT IN JAPAN}

Companies with clear product development visions know what types of investments are required to maintain their market positions. As life cycles of new product generations become shorter, companies can ill afford to delay their product development activities. Product development has therefore become the centerpiece of today's competitive strategies. Being first to market for next-generation products is what makes companies like Intel and Microsoft successful. Japanese companies have long shared a competitive vision. Sony's Akio Morita explained this in a speech to the Keidanren (1992):

In pursuit of the goal to "overtake and outrun the Western industries," Japanese manufacturers have invested all possible resources into technology development, product development, productivity improvement and quality control, and, all of a sudden, we have found that a broad range of Japanese products including cars, electronics and machine tools boasts astonishingly competitive strength in the world market. High-quality, high-performance Japanese products are relatively inexpensive against those of the same level offered by European and American competitors. Consequently, Japanese products have outsold the competition and brought success to us in the market. 


\section{Quality, Cost, and Delivery}

Japan's competitive objectives in consumer electronics have been clear: lower prices with higher quality and performance. But as product life cycles continue to shorten, speed of product development has also become a critical factor for success. Since the mid-1980s, Japanese companies have coined the acronym QCD (quality, cost, delivery) for their competitive strategy. As shown in Figure 2.1, quality, cost, and delivery time to market have measurable market share implications. According to Boston-based Strategic Planning Institute's PIMS (profit improvement through market share) analysis (1982), firms with a low-price, high-quality position relative to competitors have typically gained $1.1 \%$ market share per year. In contrast, firms with a high-price, low-quality position relative to competition have on average lost $0.7 \%$ market share per year. Thus firms that can continuously reduce product costs and improve product quality can annually gain nearly $2.0 \%$ in market share from less aggressive competitors. However, with shorter product life cycles, firms have less time to make incremental improvements before next-generation products are introduced.

\section{New Product Introductions}

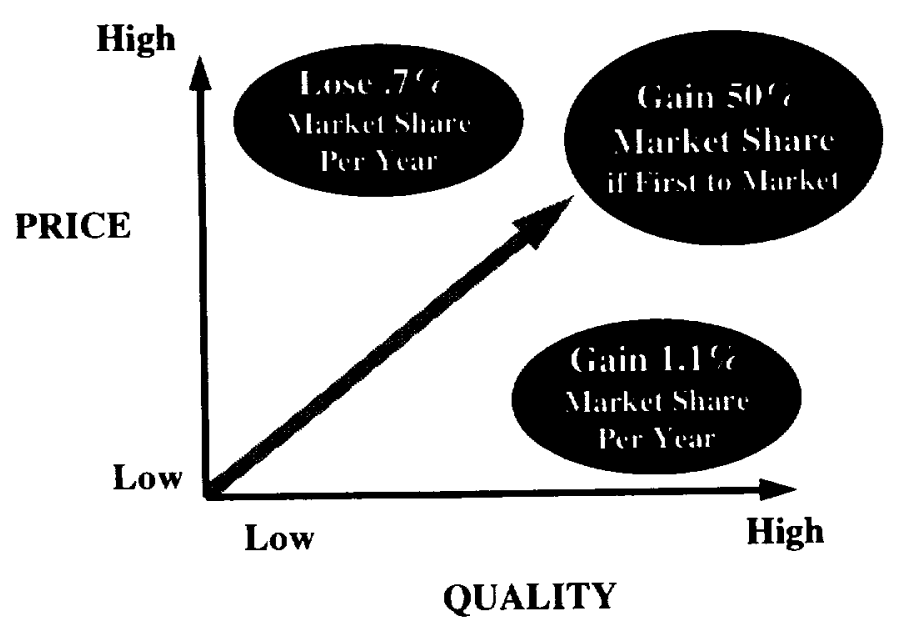

Figure 2.1. Strategic objectives for product development (@William R. Boulton, 1993).

\section{First to Market}

Also, as Figure 2.1 shows, the "first-to-market" company is typically able to attain a $50 \%$ market share. As long as product leaders continue to stay ahead in developments, they can maintain a dominant share of the market; fast followers might hold a $25 \%$ market share, but late entrants seldom achieve over $10 \%$ of the market. For example, Sony continued to hold $49.1 \%$ of the Japanese CD player market in 1992, Matsushita held a $27.6 \%$ share, and 
Kenwood held a $12.3 \%$ share. In $8 \mathrm{~mm}$ video cameras, Sony held a $75.2 \%$ market share, followed by Hitachi with only a $7.6 \%$ share. In the VHS video camera market, Matsushita held a $72.2 \%$ market share, followed by Victor Company of Japan with a $23.2 \%$ share.

The dominance of Sony and Matsushita in these markets is based on their ability to introduce model updates faster than the competition. Japan's leading electronics companies continue to introduce new products that allow them to maintain their global leadership. Some of the more recent introductions by Japanese companies include the following:

- Matsushita introduced the industry's first hi-fi "DCC" (digital compact cassette) decks and tapes in September 1992. Conventional analog tapes are compatible with the decks.

- Matsushita introduced a new VCR for home use in 1992 that employs circuitry for complete digital processing of pictures. The new VCR has improved picture quality and a significant reduction in number of parts.

- Toshiba and Sharp jointly introduced a washing device for electronic components that uses their "Techno-Care" CFC-free washing agent.

- Sony introduced a hi-fi MD (minidisc; $6.4 \mathrm{~cm}$ diameter) that records and replays digital audio signals. The company began licensing the new technology to 49 makers of hardware in December 1992.

- Sony introduced a new palm-sized camcorder in April 1992 and was almost immediately producing 60,000 per month for sales in Japan, the United States, and Europe.

- Canon introduced a bubble jet printer downsized to notebook size with improved resolution, quiet operation, and light weight $(1.8 \mathrm{~kg})$.

As shown in Figure 2.2, one of the characteristics of first-to-market companies is that their products incorporate the latest technologies. The technology of new personal computers (PCs) is more advanced than that of most current mainframe computers. This results from the life cycles of today's personal computers being under one year, compared to the multiyear cycles of most mainframes. Rapid product updates allow more "learning" in product design and faster response to changing customer demands for new features or technologies. The incorporation of new materials or processes, or the reduction in numbers of components in design updates, often leads to lower costs. For Compaq, these facts support its strategy of selling distributed PC server-driven networks in competition with traditional mainframe networks.

"First-to-market" strategies provide significant financial rewards. Wheelright and Clark, in their book Revolutionizing Product Development (1992), found that the early entrant makes very high profits, as shown in Figure 2.3: firms that introduce products six months ahead of the competition can make profits up to three times greater than the industry average. In contrast, firms that are six months late to market are unlikely to ever make a profit. Intel microprocessors are a good example of successful early market entry. 


\section{Characteristics of “First-to Market” Product Leaders}

\section{Product \\ Generations}

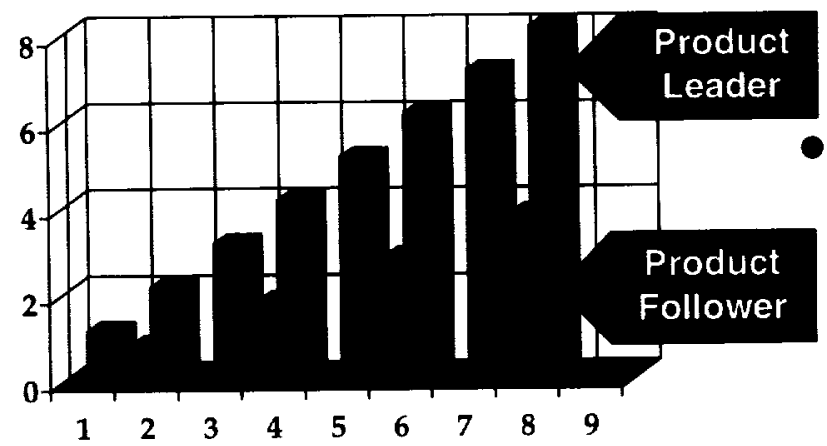

- Faster development

- Newer technology

Figure 2.2. First-to-market advantages (@Clark and Fujimoto, 1991, Effective Product Development).

\section{Cumulative Profitability of First-to-Market Leaders}

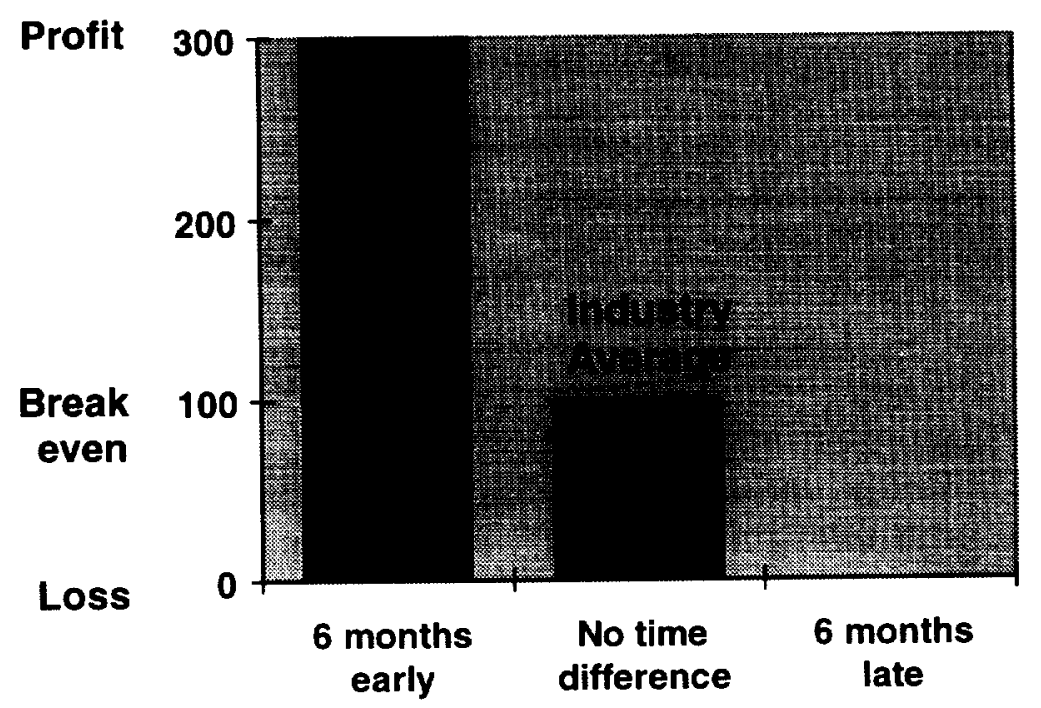

Figure 2.3. Financial advantages for product leadership (CClark and Fujimoto, 1991, Effective Product Development). 
Table 2.1 shows recent financial performances of Japan's key electronics firms. Sharp, regarded as the most innovative company in Japan today, shows income levels that surpass companies with sales three times as great. In 1993, Sharp introduced the $8 \mathrm{~mm}$ ViewCam, a low-priced minidisc CD player, a high-performance washing machine, and an efficient refrigerator.

Table 2.1

1993 First-Half Performance of Major Japanese Electronics Companies (\% change over previous year first half)

\begin{tabular}{||l|c|c|c|c|c|c||}
\hline \multirow{2}{*}{ Company } & \multicolumn{2}{|c|}{ Parent Company Sales } & \multicolumn{2}{c|}{ Operating Income } & \multicolumn{2}{c||}{ Ordinary Income } \\
\cline { 2 - 7 } & $\begin{array}{c}\text { Yen } \\
\text { (millions) }\end{array}$ & $\begin{array}{c}\text { \% } \\
\text { Change }\end{array}$ & $\begin{array}{c}\text { Yen } \\
\text { (millions) }\end{array}$ & $\begin{array}{c}\% \\
\text { Change }\end{array}$ & $\begin{array}{c}\text { Yen } \\
\text { (millions) }\end{array}$ & $\begin{array}{c}\text { \% } \\
\text { Change }\end{array}$ \\
\hline \hline Sony & 852,607 & -0.6 & 2,008 & -94.5 & 16,849 & +25.2 \\
Sharp & 575,246 & -1.4 & 11,980 & -23.7 & 20,177 & 3.5 \\
Matsushita & $2,147,827$ & -6.4 & 11,711 & -57.1 & 29,694 & 1.4 \\
Hitachi & $1,932,236$ & 1.9 & 14,374 & -40.2 & 29,863 & 1.6 \\
Toshiba & $1,535,712$ & 1.2 & 5,618 & -70.6 & 22,419 & 1.5 \\
NEC & $1,332,363$ & -2.2 & 11,127 & -40.8 & 7,135 & 0.5 \\
Fujitsu & 995,298 & -14.1 & $-6,356$ & n.m. & $-13,793$ & -1.4 \\
\hline
\end{tabular}

n.m. = no meaning; Source: Nikkei Electronics

\section{Sony's Leadership With Vision}

The JTEC panel's visit to Sony provided an important insight into the use of product development roadmaps in Japan. The whole team spent one full day at Sony, and some members spent a second day visiting Sony's advanced production facilities. Sony has been a product leader in Japan since it introduced the first "pocket-sized" transistor radio in 1955. Sony is well known for being one of the most creative and innovative companies in Japan. Akio Morita, the company's chairman, has not relied on market research to decide on product development and to this day does little such research. According to Morita, "You Americans worry too much about market research. The market research is all in my head! You see, we create markets."

Sony's type of entrepreneurial activity is seldom characteristic of large bureaucratic firms like NEC, Mitsubishi, or Hitachi; product vision is at the highest levels of the Sony organization. The project manager for each of Sony's new product development teams has been either Dr. Ibuka, Mr. Morita, or Mr. Ohga, the corporation's successive chairmen and presidents. Sony's current president Ohga was responsible for the minidisc development. Teruaki Aoki, Sony's senior general manager, explained (1989, 5):

I believe one of the most important elements that led us to success was the fact that our top management, Dr. Ibuka, Mr. Morita, and Mr. Iwama, who were enthusiastic engineers as well as businessmen themselves, were able to present a clear target for research and development in the form of a product idea. 
Sony's chief executives have provided their organization with the vision, direction, and resources needed to accomplish technological breakthroughs. The concept of the Sony Walkman, for example, originated when Sony's past chairman, Masaru Ibuka, brought a heavy tape recorder and ear phones into Akio Morita's office one day to listen to music. It was hard to walk around the office wearing headphones tied to the large tape deck. Morita then suggested the need for a more portable unit and asked his staff to make a small experimental cassette player with light, comfortable headphones. But the Walkman, introduced in 1979, was not quickly accepted by his own organization. According to Morita (Range 1982, 18),

When we developed the first Walkman, a lot of our salespeople said a small machine like that would not sell - especially since it had no recording capability. But I had a hunch it would sell. I said, "Well, a car tape deck doesn't record, either." They were still unenthusiastic. So I said that if we did not sell 100,000 sets by the end of the year, I would give up my chairmanship of Sony.

The Walkman sold over 4.5 million units by 1982 , and Morita remained as chairman.

Sony's original pocket-sized radio took four years to develop and required R\&D expenses that amounted to $12 \%$ of sales. The Trinitron color TV took eight years to develop at an accumulated R\&D cost that amounted to $19 \%$ of sales. The CCD (charge-coupled device) development required for the $8 \mathrm{~mm}$ video camera took thirteen years and cost $\$ 200$ million. With the continued growth of the company, these project management responsibilities once held by senior management have now been passed to the "grouplevel" general managers.

The vision of portable consumer products has been very successful for Sony, leading to the introduction of such products as the portable TV, CD player, and $8 \mathrm{~mm}$ video camera. Successful development is credited to clear management policies such as the following (Aoki 1989, 14): (1) clear product targets given by top management; (2) focused R\&D under the strong leadership of top management; (3) intensive R\&D for production technology; and (4) transferring many engineers from the research center to the pilot plant and transferring the same engineers from the pilot to production - the transfer of engineers smoothes the transition from development to production.

\section{The Vision of Miniaturization}

Sony's continued success has required more than product innovations. In addition to creating markets, Sony has maintained its market share vis-à-vis competitors like Matsushita, JVC, and Sanyo through timely development of next-generation products. Sony's vision of next-generation products has been that they should be half the price and one-third the weight or size of current products. Sony has maintained its market leadership with successful product line expansions and new product developments based on this vision. The long-term trend in product development can be depicted as shown in Figure 2.4. 


\section{Next Generation Models}

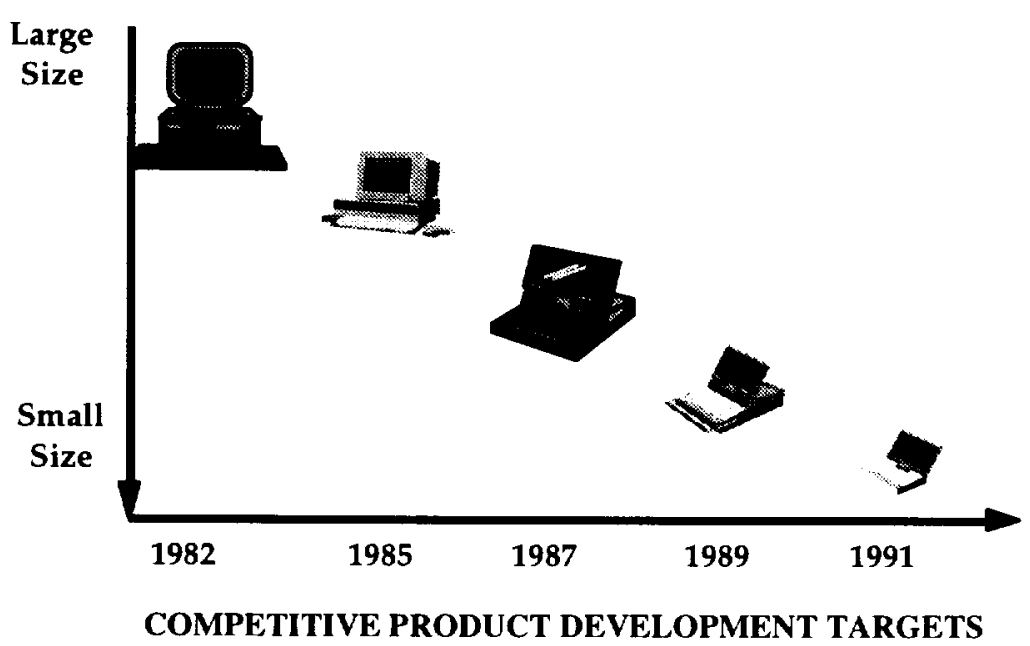

Figure 2.4. Next-generation product roadmaps (CWilliam R. Boulton, 1993).

Sony has recently introduced the first portable compact disc player, called the Discman. It has reduced the volume of the Sony Walkman from $250 \mathrm{cc}$ to $100 \mathrm{cc}$, approaching the size of a cigarette pack. Sony's vision of portability and miniaturization has spread to most consumer electronics markets. NEC's cellular telephone was $600 \mathrm{cc}$ in 1982 , but had been reduced to $150 \mathrm{cc}$ by 1991 . Televisions with built-in LCD monitors have shrunk from $650 \mathrm{cc}$ to $400 \mathrm{cc}$. The early desktop computers introduced by Apple and IBM have been eclipsed by today's notebook computers and, more recently, by hand-held "personal digital assistants." Electronic notebooks have reached $50 \mathrm{cc}$ in size.

Since Sony's introduction of the pocket-sized radio in 1955, the concept of miniaturization has spread in Japan, where lifestyles and small homes support rapid market acceptance of the concept. Small-sized TVs and stereos are suitable for typically small living spaces. Unlike Americans, most Japanese use mass transit; the "Walkman" has made it possible to listen to radio or tapes privately during the commute. Likewise, small-sized paperbacks are easy for commuters to carry and read - their introduction revitalized a stagnant book industry in Japan. In the food business, package portions have gotten smaller as the average number of family members has declined. In clothing, down ski jackets have been reduced in thickness from $20 \mathrm{~mm}$ to $5 \mathrm{~mm}$. In automobiles, Honda introduced its miniature "City" car. Even Japan's miniature bonsai trees have gotten smaller with the introduction of "mini" bonsai trees. The Nippon Keizai newspaper described Japan's miniaturization trend in 1982 with the term kei-haku-tan-sho (kei, lightweight; haku, thin; tan, short; and sho, small). Sony and other Japanese electronics firms continue to lead the miniaturization trend. 
Since the introduction in 1985 of the portable $8 \mathrm{~mm}$ video camera/recorder, 3 successive generations of Sony $8 \mathrm{~mm}$ camcorders have weighed in at $1,200,800$, and 400 grams, respectively. The size or weight reductions of next-generation products require a broad range of technological developments. Camcorder development provided the technological roadmap for Japan's electronic components and packaging industry for over five years. Every company that JTEC panelists visited in Japan had a "roadmap" for future products tied to its technology development activities. As one host at TDK noted, "The handycam used to be the primary driver for miniaturization activities. ...Today the cellular phone is pushing development activities at $0.2 \mathrm{~kg}$. The PDA (personal digital assistant) may be the next multimedia product. We think the cellular phone will be a major growth product."

\section{Downsizing Technologies for Electronics Products}

The continuing miniaturization of portable electronics equipment requires supporting technological improvements. The introduction of NTT's Mova (type TZ-804) cellular telephone at only 150 cubic centimeters rivals the Walkman or Electronic Calendar for miniaturization technologies. The reduction in size from $400 \mathrm{cc}$ to $150 \mathrm{cc}$ included reduction in antenna size, reductions in size and thickness of the receiver through IC developments, controller size reduction by development of an ASIC, reduction in battery size through power management methods, and significant reduction of the body vacancy by using $0.4 \mathrm{~mm}$ thin parts, $0.5 \mathrm{~mm}$ pitch LSIs, and ultrasmall 1005 parts. Of the $250 \mathrm{cc}$ in size reduction, approximately $150 \mathrm{cc}$ came from electronic packaging technologies and about $75 \mathrm{cc}$ came from the integration of functions within semiconductor designs.

The JTEC panel was impressed by the degree of consensus among Japan's electronic industry participants on the future direction of the industry and on its electronic packaging technology roadmap. Miniaturization of supporting parts and components is clearly an integral part of that roadmap. Figure 2.5 describes Hitachi's "application-driven" electronic packaging requirements, including higher performance, speed, and power; smaller, thinner,

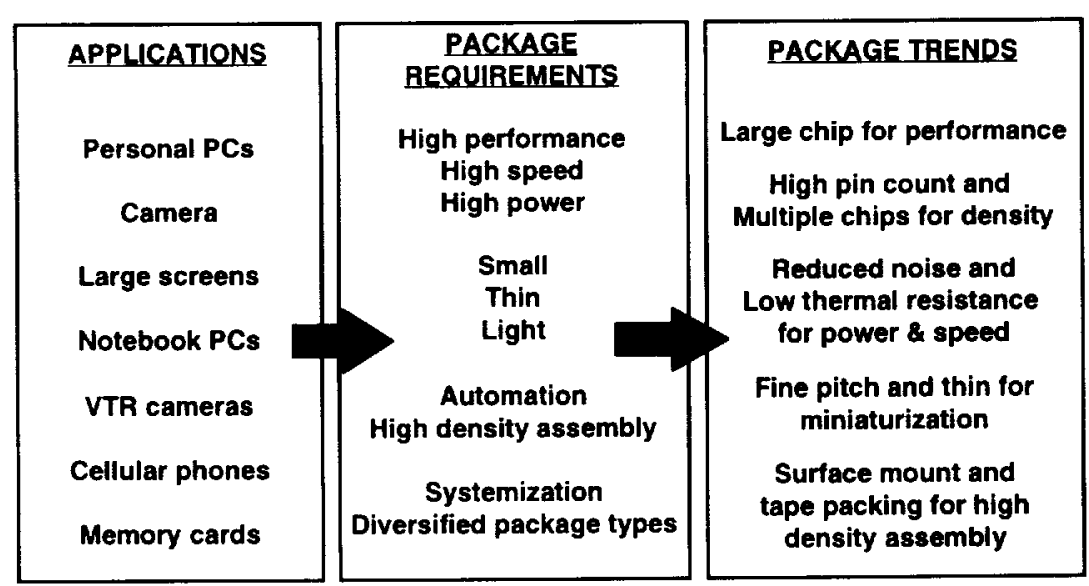

Figure 2.5. Market-driven demands for electronic packaging (Hitachi Corp.). 
and lighter packages; higher density assembly and advanced automation; and multiple package types and integrated multichip module systems.

As another example of a roadmap used by the electronics industry in Japan, Nitto Denko, a leading "packaging technology" firm, provided Table 2.2 to the panel. Although this table was produced by the U.S. Semiconductor Industry Association, Nitto Denko follows a very similar roadmap. The key characteristics of this roadmap include finer pattern width and pin pitch, and multichip modules.

The primary technologies used for downsizing of electronic packaging include continued miniaturization of surface mount devices (SMD), increased integration of circuit packaging, and reduced printed circuit board (PCB) dimensions.

Table 2.2.

Packaging Technology for the 21st Century

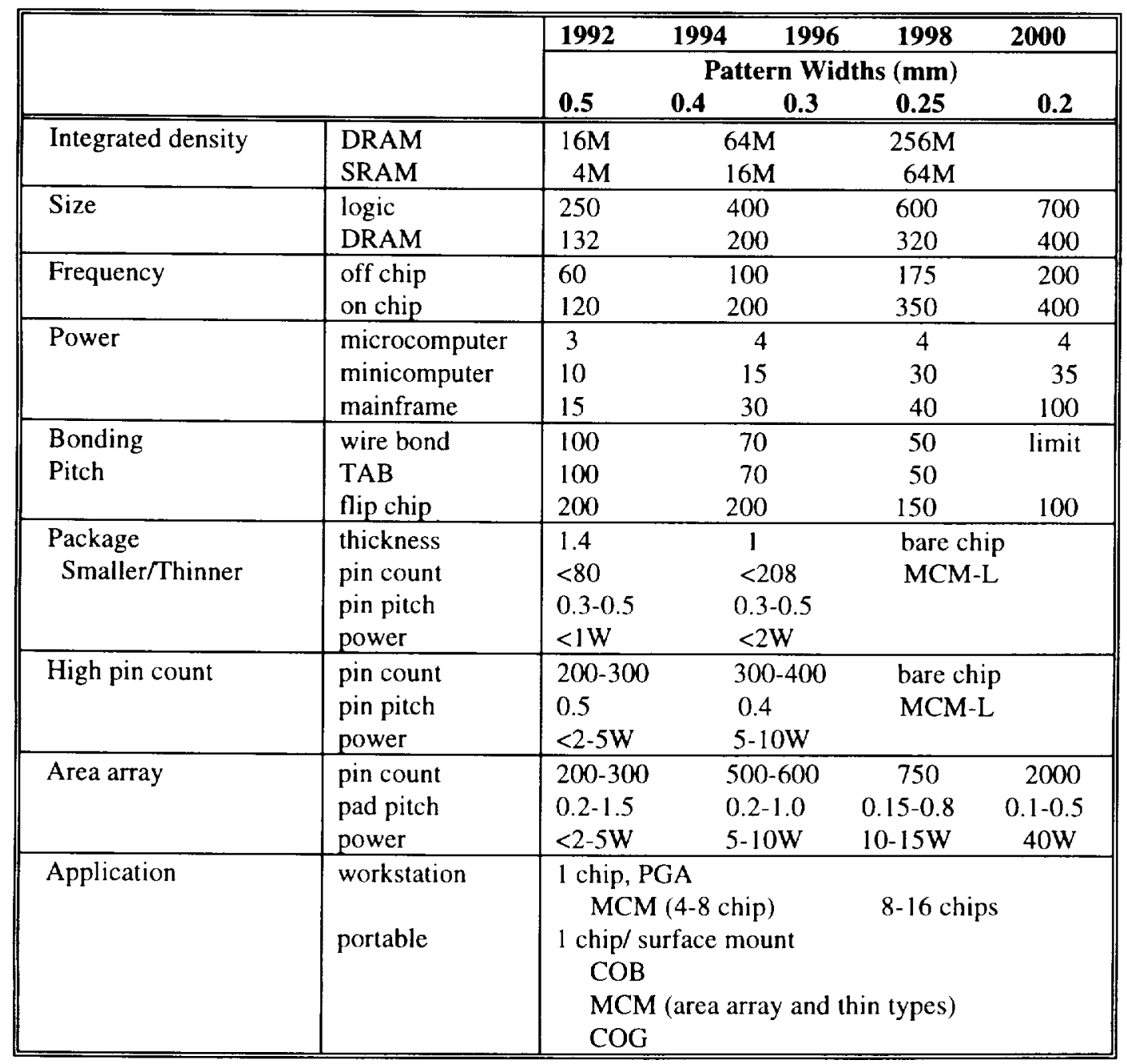

Source: U.S. Semiconductor Industry Association. 
Surface Mount Devices. With the development of surface mount technology (SMT), electronic parts such as transistors and capacitors no longer need leadwires. This reduces size requirements as well as potential quality problems related to bending, inserting wires into holes on PCBs, soldering, and cutting inserted wires. In the mid-1980s, new 3216type $(3.2 \mathrm{~mm}$ by $1.6 \mathrm{~mm}$ parts) resistors and condensers began to replace the traditional leadwire type parts for use in surface mount applications. These new parts only require placement and soldering functions.

Since the introduction of surface mount parts and application equipment, surface mount technologies have been used widely in the design and manufacture of portable consumer electronics such as calculators, radio-cassette decks, cameras, and video cameras. According to a survey of the Japan Printed Circuits Association, calculators used 100\% SMD for assembly. Products using over $90 \%$ SMD in assembly included radio-cassette decks, still cameras, and video cameras. There has been rapid growth in the application of SMD to industrial products, with larger computers using nearly $90 \%$ SMD, and computer peripherals, telephones, and electric parts using around $80 \%$.

The continued application of SMT has allowed parts sizes to be continuously downsized, reaching 1608-type $(1.6 \mathrm{~mm}$ by $0.8 \mathrm{~mm})$ parts in 1990 and 1005 -type $(1.0 \mathrm{~mm}$ by $0.5 \mathrm{~mm})$ in 1993. This is a reduction to one-third the initial length and one-tenth of the area of earlier parts. As explained to the JTEC panel by our TDK hosts,

When we talk about things that are small in Japan, we call them like a grain of rice. Rice grains are $5.09 \mathrm{~mm}$. Sesame seeds average $3.72 \mathrm{~mm}$ in diameter. In the early $1980 \mathrm{~s}$, the average size of capacitors and resistors were $3.2 \mathrm{~mm}$ by $1.6 \mathrm{~mm}$. That was the same time that the next generation was introduced, but the $2.0 \mathrm{~mm}$ by $1.25 \mathrm{~mm}$ capacitors and resistors didn't become the standard until about 1990 . Our 1608 multilayer ceramic capacitor of $1.6 \mathrm{~mm}$ by $0.8 \mathrm{~mm}$ was introduced in the late 1980s. We introduced the $1.25 \mathrm{~mm}$ by $0.6 \mathrm{~mm}$ versions around 1990, but don't expect it to become the standard until around the mid-1990s. Our smallest chip is 1005 , or $1.0 \mathrm{~mm}$ by $0.5 \mathrm{~mm}$. It is smaller than a poppy seed, which is $1.18 \mathrm{~mm}$. People cannot handle this size chip. We need machines to mount these small chips.

The weight of 1005 is so light that the tension of solder exerts a force greater than the weight of the component. So 1005 creates new structural problems. Today, there are four machine makers that produce machines for 1005, but users are not yet buying them. These machines were introduced at the same time as the 1005 components through close coordination. The next generation may be 0.65 by 0.3 . Many people are thinking about the solder problem and are trying to develop reliable solder materials.

Critical to vendor introduction of new SMT devices was the simultaneous development and introduction of assembly equipment that could handle the new components. With vendors supplying both the components and the equipment, the time required for customers to utilize the new technology has been reduced. Sharp, for example, designed new 1005 
components into the PCB of its new $8 \mathrm{~mm}$ ViewCam. When asked if there were any problems introducing the new component technology, the plant manager said, "No, we just asked our suppliers to help us."

Integrated Circuit (IC) Packaging. New IC packaging technologies have increasingly been developed for SMT applications. For example, 100-pin QFP (quad flat packages) with $0.65 \mathrm{~mm}$ lead pitch were introduced in the mid-1980s. In the 1990s, these are being replaced with 120-pin TQFP (thin quad flat packages) with $0.5 \mathrm{~mm}$ lead pitch and $1.4 \mathrm{~mm}$ thickness. Two-hundred-pin VSQFP (very small quad flat packages) with $0.3 \mathrm{~mm}$ lead pitch are expected to be introduced in 1994. Toshiba recently developed TAB (tape automated bonding) equipment for 520-pin, $0.2 \mathrm{~mm}$ lead-pitch packages. The new equipment utilizes CCD image sensors to scan outer leads using 400,000 pixel image density. There are also many approaches using multichip module designs to improve density for product miniaturization.

Oki Electric Industry Company, a major supplier of electronic components, was especially helpful in providing roadmaps for logic LSI packaging, memory LSI packaging, and tape carrier packages. The Oki roadmap for logic LSI packaging is shown in Table 2.3.

Table 2.3

Logic LSI Package Roadmap

\begin{tabular}{|c|c|c|c|c|c|c|}
\hline Year (CY) & & 1990 & 1993 & 1996 & 1999 & 2002 \\
\hline \multirow{5}{*}{$\begin{array}{l}\text { LSI } \\
\text { Chip } \\
\text { Trend }\end{array}$} & Gate density & $200 \mathrm{~K}$ & $300 \mathrm{~K}$ & $500 \mathrm{~K}$ & $1 \mathrm{M}$ & $2 \mathrm{M}$ \\
\hline & Max . chip size & $15 \mathrm{~mm}$ & $15 \mathrm{~mm}$ & $17.5 \mathrm{~mm}$ & $20 \mathrm{~mm}$ & $25 \mathrm{~mm}$ \\
\hline & Max. power & $1.5 \mathrm{~W}$ & $2 \mathrm{~W}$ & $3 \mathrm{~W}$ & $5 \mathrm{~W}$ & $10 \mathrm{~W}$ \\
\hline & Max. speed & $50 \mathrm{MHz}$ & $150 \mathrm{MHz}$ & $300 \mathrm{MHz}$ & $500 \mathrm{MHz}$ & $500 \mathrm{MHz}$ \\
\hline & Max. pin count & 250 & 350 & 500 & 750 & 1000 \\
\hline \multirow{5}{*}{$\begin{array}{l}\text { Package } \\
\text { Technology }\end{array}$} & $\begin{array}{l}\text { High } \\
\text { Pin Count } \\
\text { QFP }\end{array}$ & $\begin{array}{c}208 \\
(40 \times 0.65) \\
(28 \times 0.5)\end{array}$ & $\begin{array}{c}304 \\
(40 \times 0.5) \\
176 \\
(20 \times 0.4)\end{array}$ & $\begin{array}{c}256 \\
(28 \times 0.4) \\
344 \\
(28 \times 0.3)\end{array}$ & $\begin{array}{c}504 \\
(40 \times 0.3)\end{array}$ & \\
\hline & $\begin{array}{l}\text { C-PGA } \\
\text { (BPGA) }\end{array}$ & & $\begin{array}{c}401 \\
(40 \times 1.778)\end{array}$ & $\begin{array}{c}526 \\
(32 \times 1.27)\end{array}$ & $\begin{array}{c}750 \\
(36 \times 1.27)\end{array}$ & $\begin{array}{c}1000 \\
(40 \times 1.27) \\
\end{array}$ \\
\hline & $\begin{array}{l}\text { Thin Pkg. } \\
\text { (Pkg. Height) }\end{array}$ & $\begin{array}{c}\text { TQFP } \\
(1.2 \mathrm{~mm})\end{array}$ & $\begin{array}{c}100 \quad 144 \\
(14 \times 0.5)(20 \times 0.5) \\
\text { TTQFP* } \\
(0.8-0.5 \mathrm{~mm})\end{array}$ & $\begin{array}{c}216 \\
(24 \times 0.4) \\
176 \\
(14 \times 0.4)\end{array}$ & $\begin{array}{c}344 \\
(28 \times 0.3) \\
240 \\
(20 \times 0.3) \\
\end{array}$ & $\begin{array}{c}296 \\
(24 \times 0.3) \\
\end{array}$ \\
\hline & High Power & $\begin{array}{l}\text { Cu lead } \\
\text { frame }\end{array}$ & $\begin{array}{c}\text { QFP with } \\
\text { heat spreader }\end{array}$ & $\begin{array}{c}\text { QFP with } \\
\text { cool module }\end{array}$ & & \\
\hline & High Speed & $\begin{array}{c}\text { Single } \\
\text { layer lead } \\
\text { frame }\end{array}$ & $\begin{array}{l}\text { QFP with } \\
\text { multilayer } \\
\text { PCB }\end{array}$ & & & \\
\hline
\end{tabular}

* Thin, thin quad flat packages. Source: Oki Electric Industry Co. 
Printed Circuit Boards. By 1991, single-sided rigid PCBs represented about $14.4 \%$ of the applications. One-third of the applications were double-sided rigid PCB applications. But to improve density, multilayer PCBs are growing rapidly, having doubled their application in four years. Rigid boards with three to four layers accounted for $20.3 \%$ of the applications in 1991, with five-to-nine-layer boards accounting for $14.4 \%$, and ten-layer boards accounting for $3.1 \%$.

With the increasing fluidity of product designs, there has also been growth in flexible printed circuits (PCs). One-sided flex circuits represented about 3\% of applications in 1991, with multilayer circuits accounting for $5.6 \%$ of applications. New technologies for flexible PCs include flex-rigid and copper clad laminate (CCL) for adhesiveless two-layer structures that enable high-temperature soldering at $350^{\circ} \mathrm{C}$ for small electronic products. Chip on flex-board (COF) has become a key downsizing technology with IC chips wire-bonded directly to the flexible PC. This is used in NTT's most recent "wristwatch-style" pager. Camera makers incorporate the most extensive use of flex-board technology in their miniaturization efforts.

Matsushita provides an interesting example of video camera miniaturization efforts. One of the measures used to assess the efficiency of design in PCB layout is the number of components per square centimeter. Matsushita recently described the improvements in the design and layout of its video camera between 1990 and 1993; Table 2.4 shows the increasing density of components used on the "camera" and "video" boards.

Table 2.4

Matsushita Video Camera Board Designs

\begin{tabular}{|c|c|c|c|c|c|c|}
\hline & & $\begin{array}{c}\mathrm{Si} \\
(6 / 90)\end{array}$ & $\begin{array}{c}\text { S5 } \\
(5 / 91)\end{array}$ & $\begin{array}{l}\text { S9 } \\
(91)\end{array}$ & $\begin{array}{c}\text { TI } \\
(4 / 92)\end{array}$ & $\begin{array}{c}\text { CS1 } \\
(4 / 93)\end{array}$ \\
\hline $\begin{array}{l}\text { PCB size } \\
(\mathrm{sq} \cdot \mathrm{cm})\end{array}$ & $\begin{array}{l}\text { Video bd. } \\
\text { Camera bd. } \\
\text { Total size }\end{array}$ & $\begin{array}{r}113 \\
98 \\
211\end{array}$ & $\begin{array}{r}103 \\
87 \\
190\end{array}$ & $\begin{array}{r}108 \\
62 \\
170\end{array}$ & $\begin{array}{c}\text { (one } \\
\text { board) } \\
122\end{array}$ & $\begin{array}{c}\text { (one } \\
\text { board) } \\
\mathbf{7 5}\end{array}$ \\
\hline $\begin{array}{l}\text { Number of } \\
\text { components }\end{array}$ & $\begin{array}{c}\text { Video bd. } \\
\text { Camera bd. } \\
\text { Total \# }\end{array}$ & $\begin{array}{r}1100 \\
700 \\
1800\end{array}$ & $\begin{array}{r}1050 \\
650 \\
1700\end{array}$ & $\begin{array}{r}1050 \\
400 \\
1450\end{array}$ & 1433 & 930 \\
\hline $\begin{array}{l}\text { Average \# of } \\
\text { components } \\
\text { per sq. cm. }\end{array}$ & $\begin{array}{c}\text { Video bd. } \\
\text { Camera bd. } \\
\text { Overall }\end{array}$ & $\begin{array}{l}9.7 \\
7.1 \\
8.5\end{array}$ & $\begin{array}{r}10.2 \\
7.5 \\
8.9\end{array}$ & $\begin{array}{l}9.7 \\
6.5 \\
8.5\end{array}$ & 11.7 & 13.0 \\
\hline \multicolumn{2}{|c|}{ Highest density } & 11 & 12 & 12 & 14 & 16 \\
\hline
\end{tabular}

Source: Nikkei Electronics 1993,6.

The following conclusions can be drawn from Matsushita's data:

- integration of functions has reduced the number of components by half 
- increase in number of components per square centimeter (8.5 to 13) has allowed a $50 \%$ improvement in density

- combined increases in functional integration and component density have allowed a $65 \%$ reduction in $\mathrm{PCB}$ size

- between 1990 and 1993, the most compact video camera was also reduced in weight by 200 grams and in size by 100 cubic centimeters

\section{Developing Next-Generation Technologies}

Japanese consumer electronics producers continue to work on evolutionary technological developments that allow them to introduce new or next-generation products. Pioneering technical developments announced in 1992 included the following:

- a 256M bit DRAM memory cell - the world's smallest size (NEC)

- a 16M-bit NAND flash memory - only 2.3 times the size of 4M-bit models (Toshiba)

- a new STN-type LCD that delivers $40 \%$ higher light transmission for use in notebooktype PCs (Toshiba)

- an artificial retina chip that recognizes images in 200 microseconds and characters in 3 microseconds. The new chip, 100 to 10,000 times faster than old processors, will be applied to robots and remote sensors (Mitsubishi)

- a 9:16-aspect CRT display that includes a converter for HDTV applications (Mitsubishi)

- an orange-color semiconductor laser for use in high-density optical disks, displays, and laser pointers (Sanyo)

- a high-temperature semiconductor laser for 780-nanometer applications such as nextgeneration laser beam printers that are small, lightweight, quiet, and high speed (Sharp)

Japanese roadmaps for future product development all stress the continued design of lighter, thinner, and smaller products, with development of enabling packaging and manufacturing technologies to support such products. At the time of the JTEC team's visit the trend had already seen the shift from "desk top" to "laptop" to "notebook" to "palm top" electronics products. The chip packages were shifting from dual inline packages (DIP), to small outline packages (SOP) and quad flat packages (QFP), to chip on board (COB) and tape automated bonding (TAB) components. An increase in bare chip applications is expected as a transition to multichip modules. At the same time, chip components have been reduced in size from $3216(3.2 \mathrm{~mm}$ by $1.6 \mathrm{~mm})$ to $2125(2.1 \mathrm{~mm}$ by $2.5 \mathrm{~mm})$ to 1608 $(1.6 \mathrm{~mm}$ by $0.8 \mathrm{~mm})$ to $1005(1.0 \mathrm{~mm}$ by $0.5 \mathrm{~mm})$ in a period of under six years. According to TDK managers, the next generation is likely to be $0.65 \mathrm{~mm}$ by $0.3 \mathrm{~mm}$. New technologies for manufacturing are critical to support these miniaturization efforts as production equipment shifts from insertion machines to surface mount machines capable of handling a greater variety of devices. 


\section{CONCLUSIONS}

Reflecting on the successes of the Japanese consumer electronics business, the JTEC panel finds that having a clear vision of new or next-generation products and their supporting technological developments is a critical factor. Gearing for specific end-products by proceeding along a well-defined road for developing components within specific size and performance parameters has allowed for efficient use of resources and rapid development timeframes. There is little doubt in the minds of panel members that the Japanese companies they visited will be successful in their development efforts, particularly since members of Japan's electronics industry cooperate to overcome technical barriers.

The ability to develop and introduce next-generation products is based on a broad range of technological and manufacturing capabilities that has shifted in importance over the past decades. Reductions in product life cycles and component sizes have placed manufacturing technologies at the center of the competitive equation today. With the increased miniaturization of products and their components and parts, equipment nonavailability can become a barrier to rapid introduction of new products and components. Updated process technology is one of the underlying forces highlighted in this report that is critical to future success in electronic packaging and consumer electronics.

While companies like Sony have been product innovators, introducing a series of new products that have created new markets, the majority of Japanese suppliers have been successful by concentrating their efforts on developing succeeding generations of innovative feeder products. U.S. innovations have been lost over time to foreign competitors who quickly have exploited the technology to advance their product strategies. There must be a vision of next-generation developments for product leadership to be maintained over time.

\section{REFERENCES}

Aoki, Teruaki. 1989. Sony's Way: R\&D Strategy. Sony's Innovation and Management Series, Vol. 3. Sony Corp.

Morita, Akio. 1992. “' 'Japanese-style Management' in Peril: Why the West Denounces the Practice of 'High Quality at Low Price'." Speech to the Keidanren (February).

Nikkei Electronics 1993 (August):6.

Strategic Planning Institute. 1982. Publication \# 28.

Range, Peter Ross. 1982. "Playboy Interview: Akio Morita." Playboy, August, page 18.

Wheelright, Steven, and Kim Clark. 1992. Revolutionizing Product Development. New York: The Free Press. 


\title{
33.33
}

\author{
CHAPTER 3

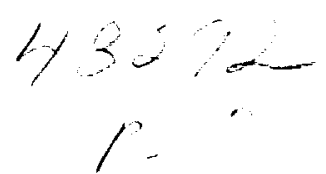

\section{JAPAN'S TeChNOLOGY AND MANUfaCtURING INFRASTRUCTURE}

\author{
William R. Boulton \\ Eugene S. Meieran \\ Rao R. Tummala
}

The JTEC panel found that, after four decades of development in electronics and manufacturing technologies, Japanese electronics companies are leaders in the development, support, and management of complex, low-cost packaging and assembly technologies used in the production of a broad range of consumer electronics products. The electronics industry's suppliers provide basic materials and equipment required for electronic packaging applications. Panelists concluded that some Japanese firms could be leading U.S. competitors by as much as a decade in these areas. Japan's technology and manufacturing infrastructure is an integral part of its microelectronics industry's success.

\section{OVERVIEW OF JAPAN'S TECHNOLOGY INFRASTRUCTURE}

A 1993 study by the U.S. Department of Commerce's Technology Administration (DOC/TA 1993) identified both the national and local levels of Japan's technology infrastructure. At all levels, the technology infrastructures in the United States and Japan have a number of similarities:

- industry associations provide forums for industry people to meet

- professional societies publish journals and sponsor technical meetings and standards committees

- $R \& D$ consortia allow companies to jointly develop and manage technology 
- public and private groups diffuse technology to small- and medium-sized companies

- consulting firms provide technical information to companies

- networks (such as regional networks of engineers) facilitate communication among professionals

- education and training programs transfer knowledge and help organizations be better receivers of technology

- government organizations, such as the National Technical Information Service in the United States and the Japan Information Center for Science and Technology, disseminate technical information

- technical databases make up-to-date information widely accessible

Despite these similarities, there are many differences between the U.S. and Japanese technology infrastructures. According to the DOC report, industry associations in Japan are more deeply involved in technology development and management than those in the United States. In Japan it is large companies, rather than consulting firms as in the United States, that play a major role in transferring technology within the industry. Japan also has extensive experience with utilizing consortia as a mechanism for developing technologysharing activities across companies and industries. At the regional level, Japan has 172 kohsetsushi centers that provide technological services to small- and medium-sized companies that lack strong keiretsu (company groupings) ties. Prefectural laboratories are involved in research, development, and transfer of advanced technologies. Close proximity of engineering societies in Japan allow for extensive personal networks, and likewise, personalized supplier-customer relations provide for close technical relationships. In contrast, the United States relies more heavily on computer networks like Bitnet and Internet. Finally, Japan relies more heavily than does the United States on education and training within companies, on institutional training programs, and on individual training programs outside companies.

\section{Japanese Government Support For High-Technology Industries}

Support of high-technology industries by the Government of Japan (GOJ) is at least four decades old. In 1952, Japan's Agency of Industrial Science and Technology (AIST) was reorganized under the newly established Ministry of International Trade and Industry (MITI) to coordinate Japan's technological developments. Manufacturing and electronic technology developments were the responsibility of the Mechanical Engineering Laboratory (MEL) and the Electro-Technical Laboratory (ETL). Two major laws were passed - the Machinery Industry Law in 1956 and the Electronics Industry Law in 1957 - to promote experimental research and initial production, and also to promote industrial rationalization of machine tools and electronic technologies. Under these laws, subsidies for technology R\&D were provided, along with special loans and tax incentives for firms that developed or used advanced production technologies. By 1980, Japan had become the world leader in machine tools for component production and in robots for assembly. 
In Japan, about one-fifth of technology R\&D funding comes from government sources. (By comparison, about half of all U.S. technology R\&D spending comes from government sources.) Government R\&D policy in Japan supports the rationale that basic research should be carried out by universities and national laboratories, and much of Japan's government R\&D funds support basic research. In addition, however, the government has attempted to stimulate industrial R\&D in areas that are important for the future of the nation's industrial technology base. The government's role has been primarily that of providing strategic leadership and of acting as the catalyst for private R\&D investment. Japanese capital markets support longer-term investments in technology, training, and other activities that improve a firm's long-term growth potential than do U.S. capital markets (DOC/TA 1993). The GOJ does fund strategic investments that address perceived needs for advanced, precompetitive technology in private industry where projects are considered too risky in financial or technical terms for private investment.

The GOJ policy to provide leadership and promote private investment for advanced technology development has required extensive communication between industry and government in determining R\&D priorities in Japan. The lack of antitrust enforcement in Japan has facilitated cooperation and coordination of industry research activities. In a number of ways, government policies in Japan function to support consensus and interdependence within the high-technology industries.

\section{JAPAN'S TECHNOLOGY DEVELOPMENT STRATEGY}

Japanese culture views technology as a tool for making marketable products. Production technology is central to such a view and has become a clear force in developing competitive advantage for Japan's industrial giants, as shown in Figure 3.1. An effective vision of next-generation products combined with continuous product improvements provide the vision for "upstream" developments. Japan's focus on production equipment and process improvements is directed towards designing for cost and manufacturability: that is, Japan's focus is on designing processes to improve productivity, increase quality, and decrease cost; designing concurrent engineering methods to speed product introductions; developing software to implement and improve factory automation; and devising effective management methods related to all of the above. The following are some of the JTEC panel's findings regarding technology R\&D in Japan:

- Japan uses its patent system to facilitate the transfer of intellectual property rather than to protect it. The Japanese patent system is meant to educate, as opposed to protect an invention as in the U.S. system. Japanese patent applications are made public and open to rebuttal by competitors. As a result, it is difficult for a firm to exploit its own technology. There are many examples of Japanese firms flooding a market with trivial patents around a basic patent for the purpose of forcing the basic patent owner to cross-license its core technology, in order to gain access to that market. A second strategy is to develop a portfolio of related or similar patents that likewise make it difficult for a firm to exploit its core technology alone. 


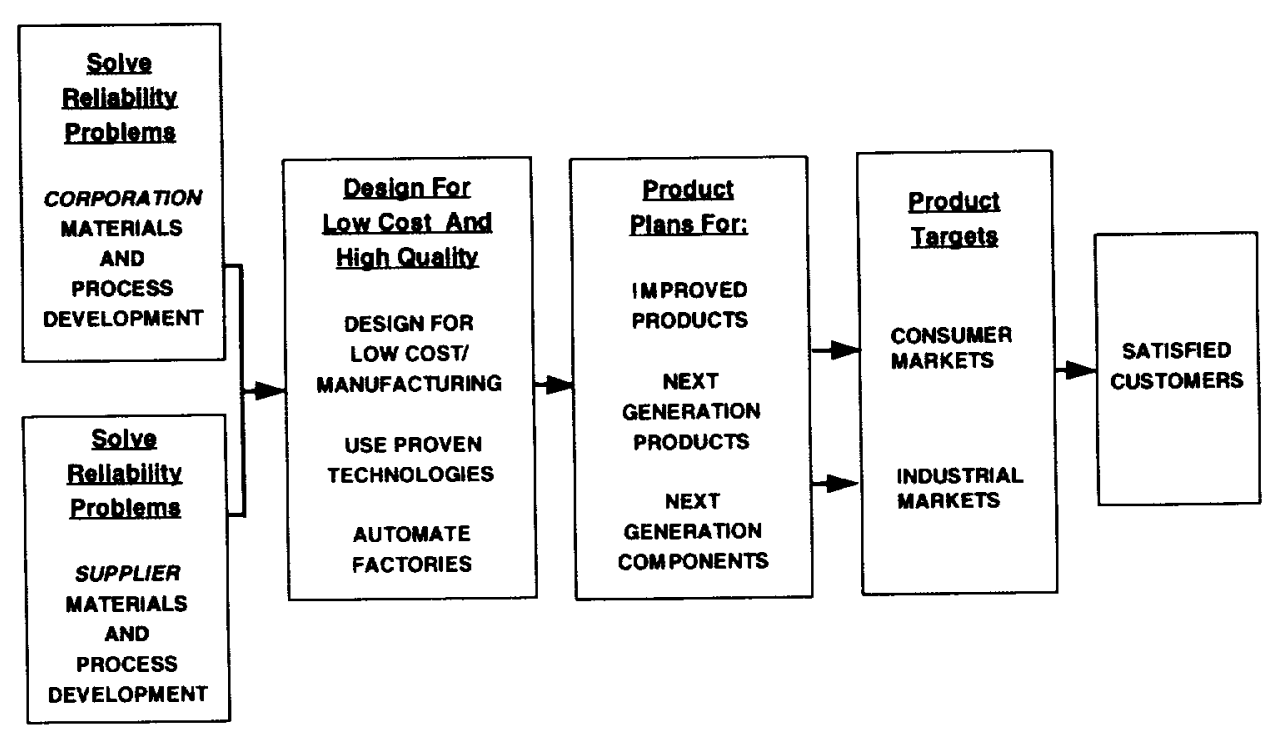

Figure 3.1. Japan's successful production development strategy.

- Japanese firms appoint a greater number of technically trained managers to head up their companies. Past studies show that as many as $75 \%$ of the CEOs of manufacturing firms have engineering degrees.

- Japanese firms invest heavily in the development of production automation technology. Japanese firms concentrate on developing in-house process and equipment technologies that provide competitive capabilities.

- Japanese firms have separate $R \& D$ organizations for production technologies. R\&D for such activities can account for as much as two-thirds of R\&D investments; most of the remaining one-third is for product development. U.S. ratios are reversed.

- Japanese firms seek to identify customer needs as the basis for developing new products and setting roadmaps for technological development. In Japan it is product requirements that drive advanced technology development activities (product pull rather than technology push as in the United States). To keep costs down, Japanese firms utilize proven technologies that have been tested and can be incrementally improved. New technologies are used only when other alternatives will not work.

- Japanese firms make long-term commitments to the development of new products, components, equipment, and technologies. There are numerous examples of Japanese commitments to long-term developments, such as Sony's 13-year program to introduce charge-coupled device (CCD) image pickup components for the camcorder. One JTEC panelist saw the same presentation he had seen three years earlier, updated to show the progress that had been made. Development of batteries and ceramics for automobiles has continued since the 1960s and has yet to see a payback. Sharp licensed RCA's liquid crystal display (LCD) technology and spent nearly a billion dollars over a decade before its development efforts were brought to market. 
- Japanese firms use teams with a common vision as the basis for concurrent engineering activities. A dedicated and skilled team approach is standard operating procedure in Japan, in contrast to one centered on highly educated individualists as in the United States. Japanese team members understand the entire systems view of the product vision, which results in products that look and function as though they were designed by a single person. This team approach is found throughout the industry "food chain." It involves hundreds of vendors, many of which are small family operations, and many large parent companies or customers. It is often said that the strength of Japan's industrial system comes from this "small family" approach.

- Japanese firms have limited research relationships with universities. There are only a few examples of strong research relationships between Japanese universities and industry. Large companies conduct their own basic research or license it from outside Japan. The dean at Sophia University recently complained that Japanese firms were spending more in U.S. universities than in Japanese universities. In contrast, U.S. universities have contributed heavily to the basic research required by U.S. industry.

- Local government supports industrial research activities. To support development activities within local communities, nearly 160 municipal industrial research institutes (MIRIs) have been established through local industry and municipal government cooperation. Their facilities are impressive, with well-equipped research laboratories and libraries. One Nagoya MIRI has a staff of 100, including 25 engineering Ph.D.s. They provide consulting, testing, analysis, research, technical information, seminars, and courses for local industry. No comparable facilities exist in the United States.

- Japanese firms conduct parallel development programs for both long-and shortterm product improvements. Departments often pursue two to five technologies simultaneously in order to ensure that they can be ready to introduce next-generation products in a timely manner. Corporate research centers typically conduct development work on efforts requiring over five years. Often, research centers are heavily involved in the development of next-generation products, while divisions make incremental product improvements on an annual basis. In contrast, U.S. research organizations seek freedom to do independent research without direct application objectives; as a result, U.S. product developments are delayed, and technology transfer is typically difficult. Figure 3.2 illustrates the Japanese parallel development strategies.

As Figure 3.2 shows, Japanese firms have developed a systematic approach to longterm product development. Business units are responsible for ongoing operations and the competitive improvement required to maintain current market positions. For most products, minor changes are made annually; for products like the Sony Walkman, such changes are made every six months or less. Corporate-level product teams are responsible for development of substantive product improvements before the competition. (For Sony, that has meant smaller and smaller camcorders.) Ability to provide new product innovations depends on a company's development of new component technologies like LCDs or CCDs, which is dependent upon long-term research. Corporate level technology research teams are responsible for long-term technological developments. The JTEC panel found that most large firms work at all 
three levels to maintain their market positions and to develop products, such as multimedia products, to meet future market demands.

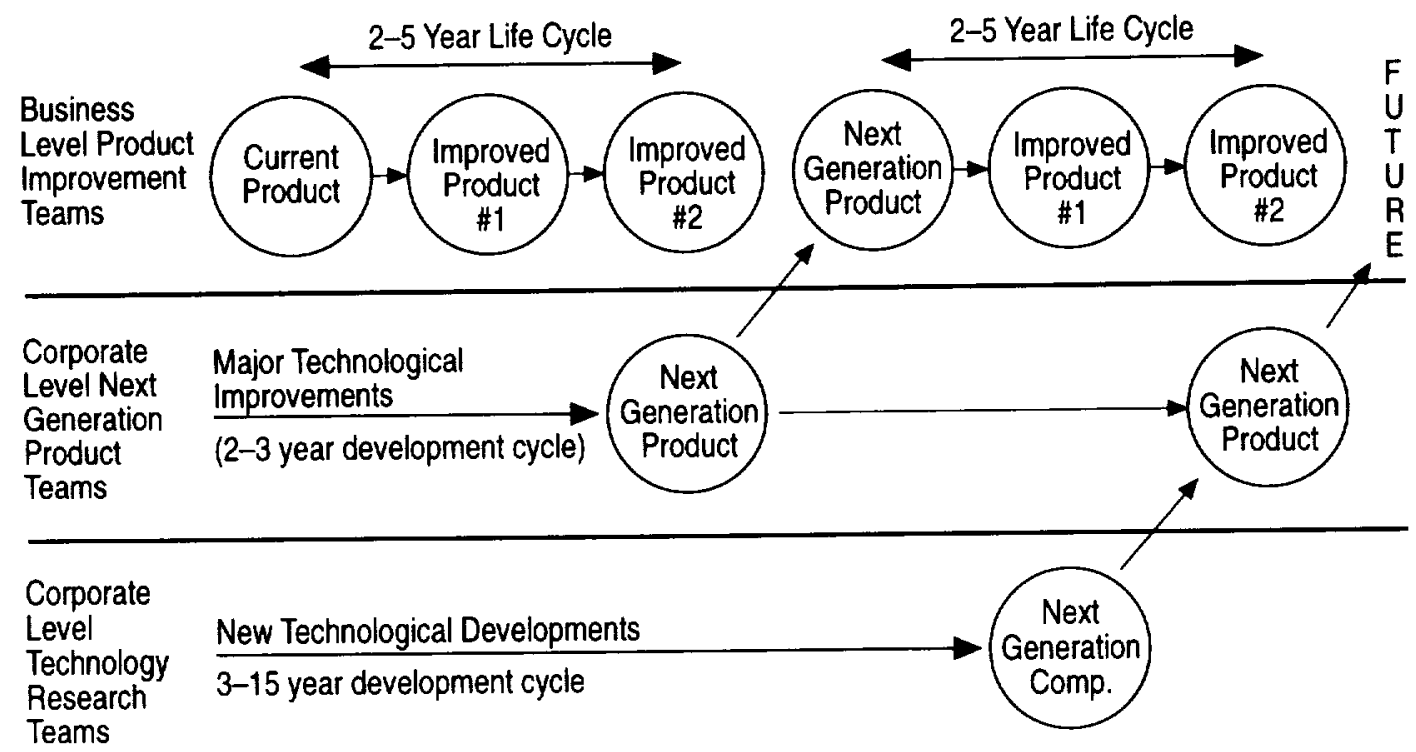

Figure 3.2. Parallel product development strategies in Japan.

- Japanese companies have a clear vision and philosophy for their product development activities. Japanese managers set lofty goals for their companies. Murata's management is committed to improving "worldwide development of industry and culture" by pursuing "total quality and customer satisfaction, while continuously introducing innovative products in integrated and interrelated technologies which will allow our company, our employees, customers and other partners, and our communities to grow and prosper with an appreciative feeling of mutual pride and trust." As shown in Figure 3.3, TDK's product development strategy begins with recognizing market needs, and moves through developing a product vision, initiating the $R \& D$ concept, and specifying quality and cost targets, to designing the product, process, and factory automation system and equipment. The results are quality products. Product size, shape, cost, and function are clearly specified to meet target markets. Such vision is typically derived from detailed customer and competitive product analysis that reveals the critical elements for product — and thus technology — development.

Japan has created a major competitive advantage from its development of low-cost, highvolume consumer products. This advantage is based on the effective integration of materials, production, and design technologies, as shown by Murata's model in Figure 3.4. 


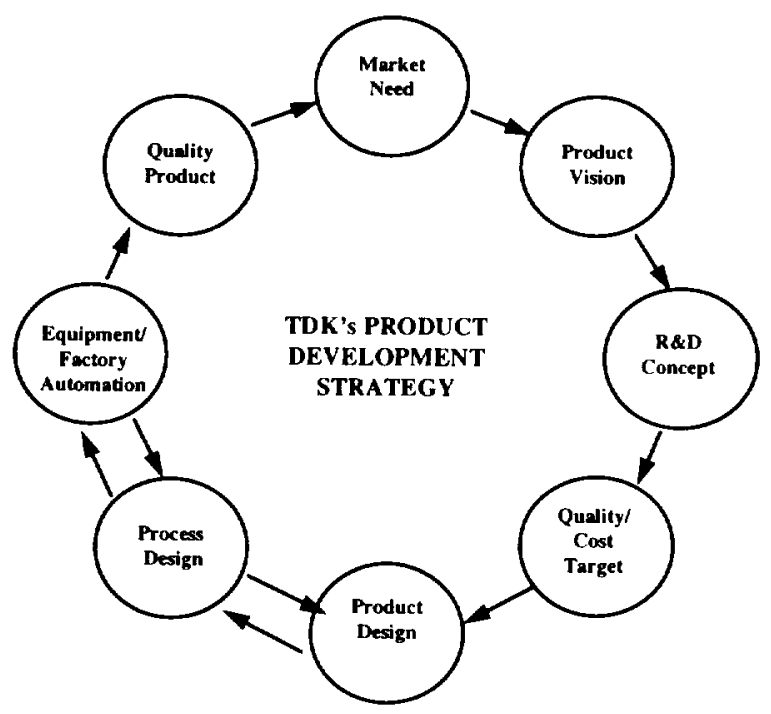

Figure 3.3. TDK's product development strategy.

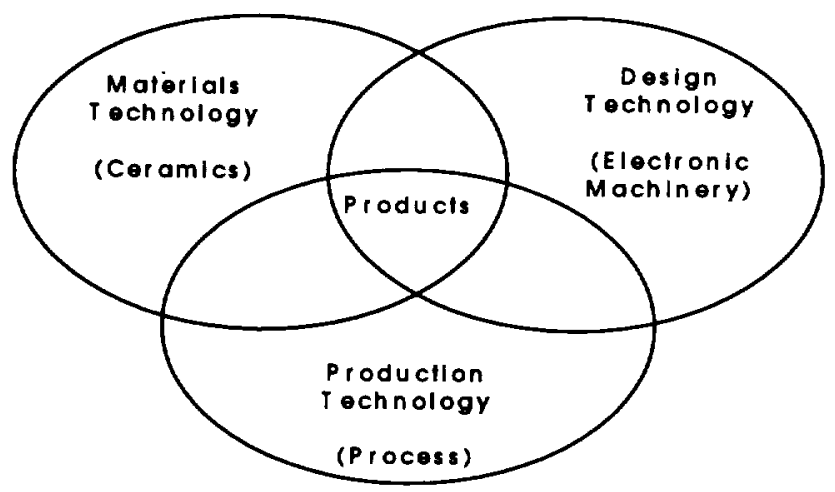

Figure 3.4. Japanese passive component strategy (Murata).

The technological imperative of Japan's integration strategy is "cost comes first." While Japan is developing competitive technologies for high-performance products like supercomputers, it also has the leadership in low-cost, high-volume consumer products like camcorders, televisions, and stereos. That provides Japanese firms with the unique advantage of having technological capabilities in both high-performance and low-cost technologies. Low-cost, high-volume products provide the impetus to develop mass production technologies that reduce production costs while also raising production quality and volume. Increased demand for product variety has provided further incentives for Japanese firms to develop flexible assembly systems that allow development of lower- 
volume products at mass-production costs and quality. These systems can now be applied to a variety of lower-volume, intermediate-cost industrial products. U.S. firms have lacked adequate product volumes to invest in equivalent manufacturing technologies and are now finding it difficult to compete in higher-priced and intermediate-priced industrial markets.

\section{JAPAN'S PRODUCT DEVELOPMENT STRATEGY}

As can be seen from the above observations of Japan's technology development strategy, at the heart of Japan's electronics industry infrastructure is a highly focused market orientation that influences all activities from research to refinement of assembly processes. Although not all Japanese firms approach the market with identical strategies, there are a number of commonalities in their approaches. After examining Japan's microelectronics industry, the JTEC panel recognized the product development strategy's dependency on materials, component technologies, and production equipment, as shown in Figure 3.5.

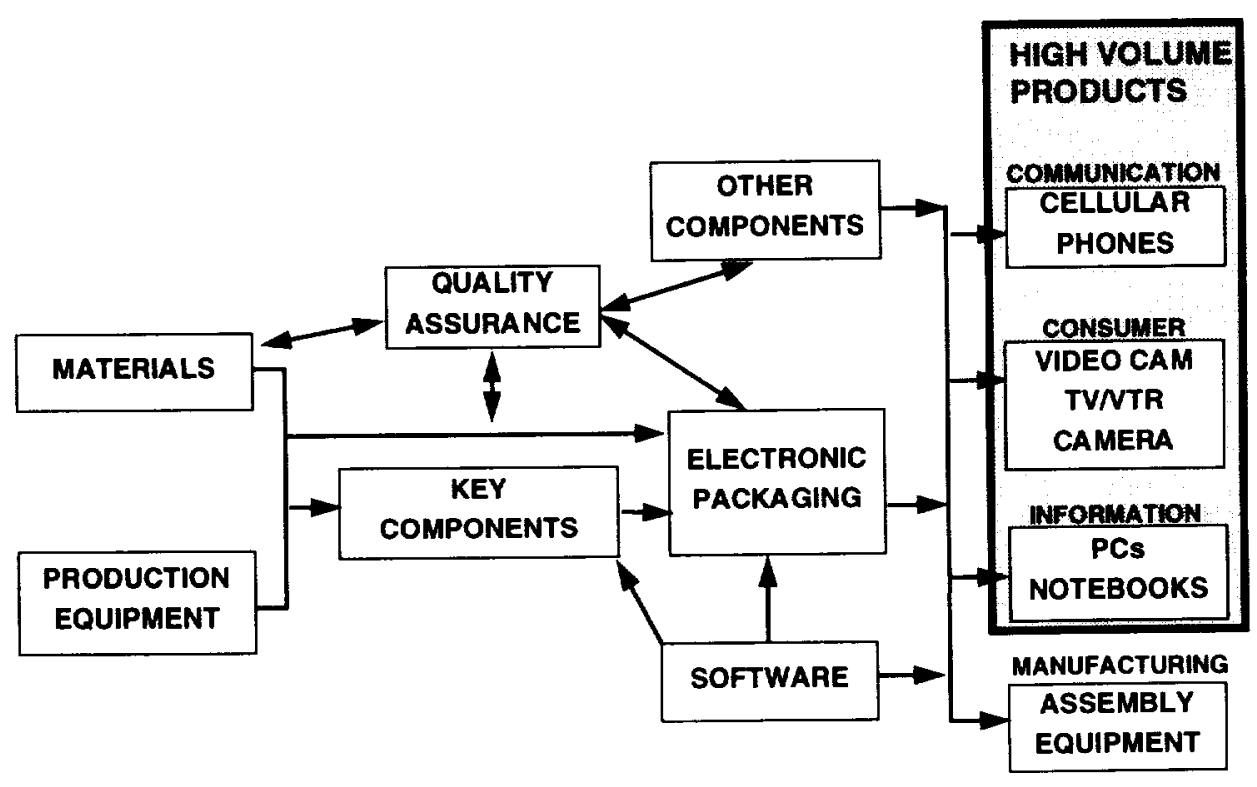

Figure 3.5. Japan's product development strategy (@William R. Boulton \& Assoc., 1994).

In Japan, electronic component and packaging leadership is based on continuous advances in both materials and manufacturing technologies. Japanese suppliers of advanced components frequently provide the manufacturing equipment necessary for further applications of their components into final products. Key products such as cellular telephones, portable video cameras, and portable computers have provided the demand for development of advanced materials, equipment, component, and packaging technologies. 


\section{Competitive Advantages in Component Technologies}

Component technologies provide the greatest opportunities for Japanese companies to apply their manufacturing expertise to competitive advantage, because the mechanical and electrical components for most consumer products have long life cycles. Sony developed its CCD and Sharp its LCD in the mid-1980s. While external design changes in product color, shape, or features may occur every six months for products like Sony's Walkman or annually for products like Sharp's ViewCam, major improvements in component technologies occur only every three to five years. For example, during a time period that Sony introduced over 160 models of the Walkman, there were only five changes in its mechanical component "platform."

After developing key component technologies, Japanese companies have been able to design and introduce a wide range of products based on those technologies. Huge industries have evolved from development of components for such products as personal computers, VCRs, video disks, and cellular telephones. Sharp, for example, is applying LCD technology for home entertainment, audio equipment, home appliances, and medical equipment. Key components with broad applications provide long-term growth potential. Semiconductor and communications technologies have been the basis for many of today's product developments. In essence, these new products have created new market demands through a strategy of "technology push." When Sharp's president encouraged managers to apply LCD technology to their product lines, he implemented a technology-push strategy.

\section{Competing in Next-Generation Components}

Every industry has its own "rules of conduct" and strategies for targeting market segments to stimulate market share growth. With regard to high-volume electronic assembly, Japan's strategy has been to lower costs, reduce size and weight, and improve functionality. Camcorders, cellular telephones, VCRs, stereos, and CD players have all been subjected to this strategy. These product demands have then generated the roadmaps for component and packaging development.

Microprocessors are one of the few components that are still controlled by U.S. firms. According to Gordon Moore, CEO of Intel, the complexity of integrated circuit devices will roughly double every device generation, one generation lasting about 18 months, resulting in a straight-line on a $\log$ scale as shown in Figure 3.6. The semiconductor industry sees no short-term departure from this trend. As a consequence, feature size and resolution of geometries used in production follow the same trend, with feature size reductions of about $20 \%$ per component generation. At the same time, increased functional integration has lead to larger chip sizes, which has required materials development for increased wafer size and equipment development for handling larger wafers. The projected characteristics of next-generation IC components allow designers to plan for nextgeneration products. 


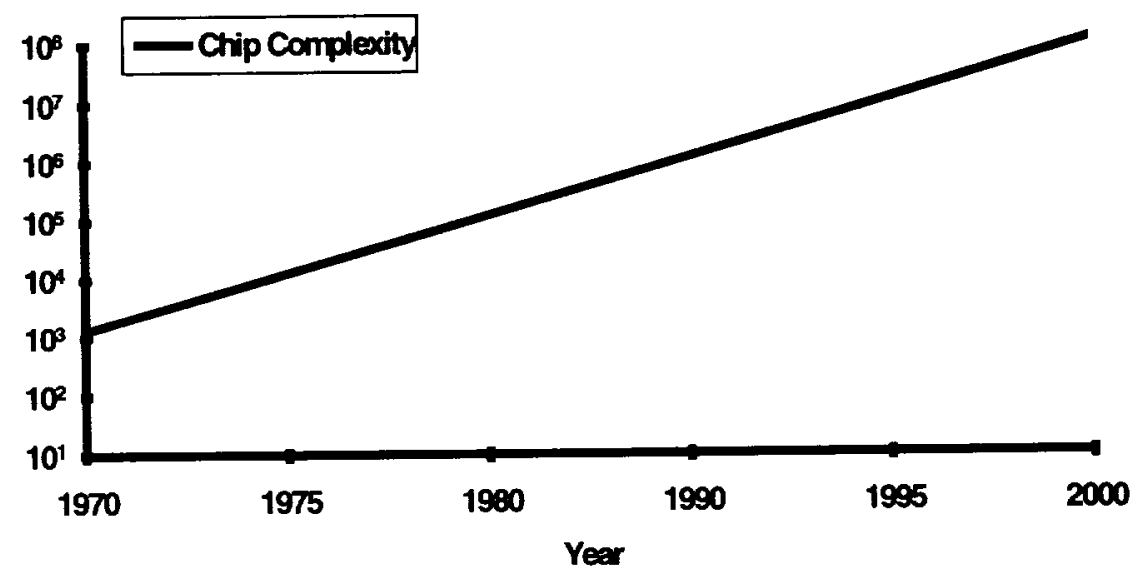

Figure 3.6. Moore's Law of Active Element Density.

Recent Intel advertisements have clearly presented the company's progress in improving processor performance. For example, using Intel's performance computations, the following ratings have been achieved with its most recent microprocessors:

$\begin{array}{ll}\text { i486 SX-25 } & 100 \\ \text { i486 SX-33 } & 133 \\ \text { i486 DX-33 } & 160 \\ \text { IntelDX2-50 } & 233 \\ \text { IntelDX2-66 } & 290 \\ \text { Pentium Processor-60 } & 525 \\ \text { Pentium Processor-66 } & 560\end{array}$

By adding increased capability with each component generation, microprocessor designers give potential customers a broader range of design capabilities. Moore once stated that while he did not know what people will do with all of the transistors being manufactured, he was confident that demand will exist for increased functions, power, and speed that give added design options to the innovative users of these advanced components. Indeed, demand continues to grow as new applications are developed for each new component introduction or update. In addition to providing next-generation complex instruction set chip (CISC) microprocessors, Intel provides a full range of processors to fit a wide range of product applications from servers to notebook computers. The United States has dominated the high-end semiconductor device market by continuing such rapid developments. 


\section{Higher Component Density and Better Assembly Equipment}

The goal of Japanese companies involved in electronics products competition is to meet customer requirements. Of all customer requirements, five seem to dominate: lower cost, higher reliability, better performance, longer life before battery recharge, and lighter weight/smaller size. All five factors depend on a few key, "lower-tech" capabilities related to making more-integrated components; these in turn depend on good assembly equipment that can put a large number of small components into smaller and smaller areas.

With increased component density also comes an increase in the density of component assembly. For Matsushita's video camera, the component density increased between 1990 and 1993 from 8.5 components per square centimeter to 13.0 components, a $50 \%$ increase. Matsushita's and Sharp's most recent consumer products have average component densities of 16 units per square centimeter. As customers seek smaller, lighter-weight, more sophisticated products, pressures mount for increased component integration and higher-density assembly technologies. Sony's model TR1 video camera was introduced at the end of 1992 with a component density of 20 components per square centimeter, and its component density is expected to reach 30 components per square centimeter.

The manufacturing law in electronic assembly that might be equated to Moore's law of chip element density is, "the density of assembled components will double every generation." Sony has suggested that PC board component densities could reach 50 pieces per square centimeters by 1998 , as Figure 3.7. shows.

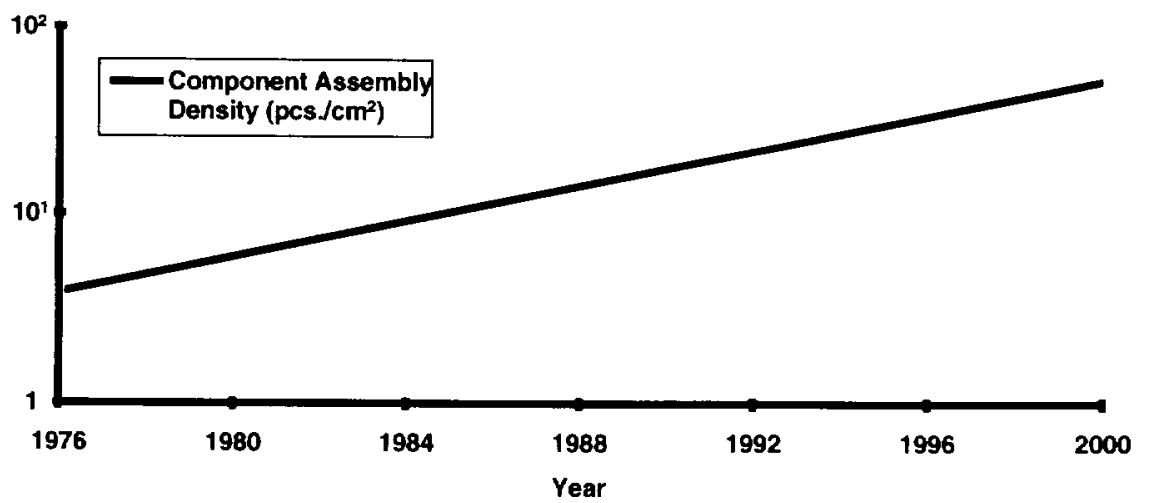

Figure 3.7. PC board component density.

Doubling component density every generation is a clear objective in Japan's electronics industry. As in the semiconductor industry where there is a cascade of new technology resulting from following Moore's Law, there is a cascade of technology resulting from following the "higher density law of electronic assemblies." In the latter case, this is a consequence of better, more reliable, highly flexible electronic assembly equipment. 


\section{New-Technology-Based Innovations Versus Process-Based Improvements}

It has repeatedly been stated that U.S. research and development is driven by a technology push, in contrast to Japanese research and development, which is primarily driven by a product or market pull. There are, of course, occasions when the technology is virtually indistinguishable from the product driven by the technology; microprocessor technology, for example, is ubiquitous to digital electronics, but when referring to an Intel " 486 or Pentium, it is often the personal computer product that comes to mind. Thus a technology innovation can spawn a new product and, at times, spawn a whole new industry.

Indeed, in the past several decades "new technology" has supported the development of many new electronics industries. Examples include the personal computer, VCR, CDROM, and cellular telephone, satellite communications, neural networks, expert systems, semiconductor memories for electronics, and information-sciences-based products. In the case of the personal computer, an entire industry that now affects the global economy developed from an innovation for making video games available to the home market.

When a new market is created around a new product based on a new technology, market demand is created largely by the customers' interest in the newness of the product. As the market develops, the technology creator can maintain market advantage by continuously enhancing the technology and introducing newer and more improved products in response to customer demands, as discussed in Chapters 2 and 4 . The product enhancements initiated by repeated introduction of new technology keep competitors in a continuous state of playing "catch-up." If successful, the technology leader captures a major share of the market long before the competition can respond, and the leader can sustain that position as long as the product family continues to be improved and meets customer demands. As pointed out in Chapter 2, Sony and Sharp are two Japanese firms that have market strength based on introduction of innovative products.

In general, the United States has long operated under the belief that technology innovations will, by themselves, sustain industrial growth and market strength. New technology and resulting new products often originate in university or industrial research laboratories. The better and more attractive the technology, the broader the range of product applications is expected, and the stronger the customer demand for newer and more enhanced products based on the technology. The more rapidly the market develops, the greater the advantage for the technology developer.

In contrast to this U.S. R\&D operating scenario, Japan has operated under the belief that new technology developments have to be focused on continually upgrading products to meet customer demands for highest possible quality at lowest possible cost. The leader stays ahead of the competition by being faster or less expensive in bringing out upgraded products. Over time, however, process technology improvements can often be a deciding factor in whether or how fast product quality can be improved and cost reduced. Depending on the nature of the product and its state of market maturity, an aggressive 
manufacturer can take the lead away from the product or technology innovator and become a market giant. Matsushita did this in the VCR market, and Compaq appears to be doing this in the PC market.

\section{The Importance of Process Technology}

There is a clear market transition from the stage when an innovative product is first introduced, to the stage of continuing development of the product in response to consumer demands. In the first phase, the consumer is attracted to the product largely because of its novelty, and the innovator is temporarily unchallenged in the market. In the second phase, the consumer becomes increasingly cost and quality conscious, and many competitors may enter the market; then the emphasis on manufacturing technology takes over from the emphasis on new technology.

The camcorder, the cellular telephone, the Walkman, the CD-ROM, and the personal computer all appear to be maturing into more manufacturing-process-influenced industries. With the resulting increased competition in the marketplace, there is increased pressure to lower cost, improve performance, make the product easier to use, etc. At this stage, process technologies and component upgrade technologies can easily become more important than the original technology innovations. The market for Dynamic Random Access Memory (DRAM) invented by Intel is now dominated by innovative and highly competitive manufacturers, predominantly Japanese (Fujitsu, NEC, etc.) or Korean (Samsung, Gold Star, etc.). The market for VCRs, for which the fundamental technology was invented by Ampex, is now dominated by Matsushita and Sony.

Technology development activities of the Japanese manufacturing leaders are customerand product-driven. Dominant market position is occupied by suppliers that best understand how to meet and increase market needs. The criteria for success are attention to detail, clear understanding of customer needs, and flawless execution. Clearly, with regard to high-volume electronic assembly, customers demand lower cost, improved functionality, smaller size, and lighter weight, especially for more mobile products. Japanese packaging, component, and process technology development is driven by these parameters.

While it might be reasonably argued that the U.S. "technology push" approach to R\&D produces more Nobel Prize winners, the Japanese "customer (or product) pull" approach to R\&D has produced market leadership for Japan, especially thanks to its emphasis on process technology R\&D. U.S. automakers were pushed by Japanese competition into learning how to make cars quality-competitive with those made by the Japanese. Automated electronic assembly factories in the United States, such as SCI and AVEX, are now as good as any Japanese factory, although many use Japanese-built equipment. However, manufacturing in the electronic assembly and packaging arena has not been targeted as an area for U.S. attention, as in the case of the automobile industry. The implications of this omission may be truly ominous. 


\section{INDUSTRIAL COMPUTERIZATION}

\section{Automated Systems}

Japan has a long history of using mainframe computers for central processing and control activities that facilitate productivity. Japan's computerization blueprint, developed in the mid-1960s, was specifically directed at improving productivity. According to Masaru Murai, president of Compaq (Japan), this blueprint has since been implemented.

Prior to the Olympic Games and the introduction of the shinkansen bullet train in 1964, there was no computer-based automation in Japan. Hitachi introduced computerized ticketing systems and scheduling controls for the shinkansen. The steel company Yahata purchased the 1964 Olympics' mainframe computer to build an automated mill with computer-controlled processing. It also bought IBM's sensor-based 1710 process computers. At about the time steel firms started using computers for automated production control systems, Toyota started using computers to control just-in-time production systems, and banks started using computers for ATM and savings account automation. Today, Japanese electronics companies have fully automated factories. Every aspect of manufacturing, from product design to shipping, except maintenance and some limited assembly activities, is computer-controlled.

\section{Software}

In 1985, the International Robotics and Factory Automation Association was formed in Japan for the purpose of developing factory automation software. The objective was to develop a standard language for use in computer-integrated factories. General Motors' "MAP" protocol was used as the basis for this effort. By 1992, a full-scale integrated factory was demonstrated at the Japan Exhibition Center in Makuhari Messe, near Tokyo. All equipment makers in Japan had standardized new advanced equipment around "mini MAP," Japan's approach to widespread application of computer-integrated manufacturing concepts. Mini MAP utilized only four of the seven levels of MAP capability. However, this demonstrated the feasibility of the approach and provided a lower-cost language for equipment makers to apply to advanced manufacturing equipment.

Japanese companies continue to apply productivity-based tools like CAD/CAM/CAE software, to speed the time for product development and production start-up. Sharp's new ViewCam utilized full application of CAD/CAM software in the development of the product and its manufacturing system.

\section{Information Systems}

While Japan may be a leader in automated production and control technologies, it is behind in information network developments. The deregulation of the telecommunications industry has been slow and has limited the availability of advanced communication systems. At Hitachi, e-mail systems were available at the time of the JTEC visit, but 
access and use was limited by the absence of a computer-based infrastructure; there was only one computer for every eight engineers. At NEC, a corporate-wide e-mail system was planned for 1995. Insufficient office space has kept Japanese firms from installing computers on every desk. JTEC panelists noticed that most computers were in a location separate from offices.

Instead of relying on information systems, Japanese firms continue to rely on human-based communications through teamwork, fax communications, and face-to-face interactions. Because most individuals live within three hours of Tokyo, meetings continue to be the dominant form of communications. The world's major corporations have offices within a 45-minute commute from central Tokyo.

Collaborative team-building activities have helped to build Japanese economic strength. Companies like Sony hold monthly meetings between researchers, laboratories, and corporations to discuss and share research results. As a consequence, results are widely disseminated. Conferences are used for industrywide problem-solving efforts that spur continuous technological improvements. There is little duplication of effort, as progress is regularly shared between industry players. As JTEC panelists visited companies like Hitachi, Oki, Matsushita, TDK, and Nitto Denko, they heard similar descriptions of technical problems and found a high level of agreement between competitors as to potential solutions. Widespread industry consensus in Japan was a major panel finding.

Building a national information infrastructure, recently announced as a U.S. objective, was also adopted as a national objective by the Japanese government in 1993. As companies adopt the new vision of an information superhighway, they are expected to invest heavily in multimedia products. Japan recently established the Hi-Vision Promotion Center, the Hi-Vision Promotion Association, and a museum of the Association for Promotion of Hi-Vision, all for the purpose of coordinating and communicating HDTV developments in anticipation of future multimedia and interactive environments. Japan's forecasts for the year 2000 show HDTV being the number one consumer electronics product of the future. Sony is considered the leader in multimedia technologies and is attempting to position itself to take advantage of the information superhighway.

\section{ELECTRONICS RESEARCH ACTIVITIES}

Japanese electronics firms are investing billions of dollars in R\&D activities. As shown in Table 3.1, the top ten electronics firms in Japan invested an average of $7.8 \%$ of sales in $\mathrm{R} \& \mathrm{D}$ in 1991. They continue to search for those advanced technologies and components that will assure future competitive advantage in the marketplace.

The recession in Japan affected investment levels only slightly. For example, Matsushita's revenues fell from $¥ 7.4$ trillion in 1992 to $¥ 7.0$ trillion in 1993 , with a drop in profits from $¥ 363$ to $¥ 170$ billion; Sony’s revenues grew slightly from $¥ 3.9$ to $¥ 3.95$ trillion, but profits fell from $¥ 197$ billion to $¥ 80$ billion; still, Matsushita's R\&D expenditures increased from 
$¥ 418$ to $¥ 420$ billion, and Sony's R\&D expenditures increased from $¥ 240$ to $¥ 245$ billion. In contrast, both Matsushita and Sony cut facilities investments $40 \%$ for 1993 . Despite stagnant or declining revenues and income, most Japanese consumer electronics companies continued to increase R\&D expenditures slightly in 1993.

Table 3.1

Japanese Major Electronics Firms' Capital \& R\&D Investments ( $¥$ billion)

\begin{tabular}{|c|c|c|c|c|c|c|c|}
\hline \multirow{3}{*}{$\begin{array}{c}\text { Hitachi } \\
\text { Hot }\end{array}$} & \multicolumn{2}{|c|}{$\begin{array}{l}\text { Electronic Sales } \\
\text { (\% of total sales) }\end{array}$} & \multirow{2}{*}{\multicolumn{3}{|c|}{$\begin{array}{c}\text { Consumer Industrial Components } \\
\text { Electronics Electronics Electronics } \\
(\% \text { of total sales for } 1991) \\
\end{array}$}} & \multirow{3}{*}{$\begin{array}{c}\text { Capital } \\
\text { Investment, } \\
\text { \% of sales } \\
5.6 \%\end{array}$} & \multirow{3}{*}{$\begin{array}{c}\text { R\&D } \\
\text { Expense, } \\
\text { \% of sales } \\
6.7 \%\end{array}$} \\
\hline & 1987 & 1991 & & & & & \\
\hline & $\begin{array}{r}2,230 \\
(45 \%) \\
\end{array}$ & $\begin{array}{r}3,883 \\
(50 \%) \\
\end{array}$ & $\begin{array}{r}932 \\
(12 \%) \\
\end{array}$ & $\begin{array}{r}1,553 \\
(20 \%) \\
\end{array}$ & $\begin{array}{l}1,398 \\
(18 \%) \\
\end{array}$ & & \\
\hline Matsushita & $\begin{array}{l}3,415 \\
(71 \%) \\
\end{array}$ & $\begin{array}{c}5,825^{*} \\
(78 \%) \\
\end{array}$ & $\begin{array}{c}2,733^{*} \\
(47 \%) \\
\end{array}$ & $\begin{array}{c}1,419 * \\
(19 \%)\end{array}$ & $\begin{array}{r}896^{*} \\
(12 \%) \\
\end{array}$ & $7.3 \%$ & $5.6 \%$ \\
\hline Toshiba & $\begin{array}{r}2,320 \\
(65 \%) \\
\end{array}$ & $\begin{array}{r}3,258 \\
(69 \%) \\
\end{array}$ & $\begin{array}{r}944 \\
(20 \%) \\
\end{array}$ & $\begin{array}{r}1,558 \\
(33 \%) \\
\end{array}$ & $\begin{array}{r}755 \\
(16 \%) \\
\end{array}$ & $10.3 \%$ & $7.0 \%$ \\
\hline Sony & $\begin{array}{c}1,431 \\
(100 \%)\end{array}$ & $\begin{array}{r}3,915 \\
(100 \%) \\
\end{array}$ & $\begin{array}{r}3,132 \\
(80 \%) \\
\end{array}$ & $\begin{array}{r}587 \\
(15 \%) \\
\end{array}$ & $\begin{array}{r}196 \\
(5 \%) \\
\end{array}$ & $11.9 \%$ & $6.3 \%$ \\
\hline NEC & $\begin{array}{r}2,634 \\
(97 \%) \\
\end{array}$ & $\begin{array}{r}3,661 \\
(97 \%) \\
\end{array}$ & $\begin{array}{r}264 \\
(7 \%) \\
\end{array}$ & $\begin{array}{r}2,831 \\
(75 \%) \\
\end{array}$ & $\begin{array}{r}566 \\
(17 \%) \\
\end{array}$ & $8.5 \%$ & $18.9 \%$ \\
\hline Fujitsu & $\begin{array}{r}2,947 \\
(100 \%) \\
\end{array}$ & $\begin{array}{r}3,442 \\
(100 \%) \\
\end{array}$ & $\begin{array}{r}69 \\
(2 \%) \\
\end{array}$ & $\begin{array}{r}2,994 \\
(87 \%) \\
\end{array}$ & $\begin{array}{r}379 \\
(11 \%) \\
\end{array}$ & $10.2 \%$ & $11.4 \%$ \\
\hline Mitsubishi & $\begin{array}{r}1,540 \\
(65 \%) \\
\end{array}$ & $\begin{array}{r}2,273 \\
(68 \%) \\
\end{array}$ & $\begin{array}{r}602 \\
(18 \%) \\
\end{array}$ & $\begin{array}{r}1,103 \\
(33 \%) \\
\end{array}$ & $\begin{array}{r}568 \\
(17 \%) \\
\end{array}$ & $9.6 \%$ & $5.0 \%$ \\
\hline Canon & $\begin{array}{r}700 \\
(83 \%) \\
\end{array}$ & $\begin{array}{r}1,589 \\
(85 \%) \\
\end{array}$ & $\begin{array}{r}1,215 \\
(65 \%) \\
\end{array}$ & $\begin{array}{r}280 \\
(15 \%) \\
\end{array}$ & $\begin{array}{r}93 \\
(5 \%) \\
\end{array}$ & $9.0 \%$ & $5.1 \%$ \\
\hline Sanyo & $\begin{array}{r}700 \\
(59 \%) \\
\end{array}$ & $\begin{array}{r}1,050 \\
(65 \%) \\
\end{array}$ & $\begin{array}{r}727 \\
(45 \%) \\
\end{array}$ & $\begin{array}{r}242 \\
(15 \%) \\
\end{array}$ & $\begin{array}{r}81 \\
(5 \%) \\
\end{array}$ & $5.9 \%$ & $5.2 \%$ \\
\hline Sharp & $\begin{array}{r}980 \\
(80 \%) \\
\end{array}$ & $\begin{array}{r}1,275 \\
(82 \%) \\
\end{array}$ & $\begin{array}{r}700 \\
(45 \%) \\
\end{array}$ & $\begin{array}{r}342 \\
(22 \%) \\
\end{array}$ & $\begin{array}{r}233 \\
(15 \%) \\
\end{array}$ & $8.7 \%$ & $6.7 \%$ \\
\hline TOTAL & $18,108^{*}$ & 30,171 & 11,318 & 12,909 & 5,165 & $8.7 \%$ & $7.8 \%$ \\
\hline
\end{tabular}

Totals are rounded. ${ }^{*}$ As reported. Source: Dodwell 1993, 86.

\section{Overseas Research Facilities}

Japanese direct investment in research and development abroad increased significantly during the late 1980s. According to Japan's Science and Technology Agency (STA 1992), over one hundred Japanese private companies with capitalization of over $¥ 10$ billion had established R\&D facilities in over 180 overseas locations by 1989 . Japan's Ministry of International Trade and Industry estimated that the number of overseas research facilities 
owned by Japanese companies increased 86.6\% between 1986 and 1989, and during the same period the number of researchers employed by these facilities more than doubled, from 3,300 to 6,975 (MITI 1991). In 1992, the STA survey reported 117 Japanese manufacturing companies operating 276 overseas R\&D facilities (STA 1992).

The number of Japanese electronics R\&D facilities in the United States increased from about 22 facilities in 1987 to nearly 110 facilities in 1992. This shift corresponded to the growing presence of Japanese goods in the U.S. marketplace. Of 150 Japanese facilities in the United States in 1993, over 70\% were established between 1986 and 1992 (DOC 1993, 17). A majority of these facilities focus on computers, computer software, semiconductors, telecommunications, television-audio-radio, and optoelectronics.

In 1992, Sony had fifteen R\&D facilities in the United States, Fujitsu had eleven, and Matsushita had nine. In addition to moving development activities closer to their markets, Japanese firms set up these R\&D facilities in the United States because they recognized the weakness of basic scientific research activities in Japan. To take advantage of U.S. scientific leadership, Japan established R\&D facilities near major U.S. university and industry technology centers. This was expected to shorten development cycles and allow early access to new business opportunities (DOC 1993, 23).

\section{Basic Research}

In the United States, innovation often comes out of university or industry basic research activities. For example, a large number of new concepts and products have come from such institutions as MIT, Stanford, Bell Labs, IBM, Fairchild, Intel, and Texas Instruments. In contrast, Japanese labs visited by the JTEC panel focused primarily on improving products that already had established markets. University and government laboratory equipment was considered outdated and not as sophisticated as that of corporate laboratories. Since 1981, Japan's austerity budget had cut finding for government laboratories. Most government-funded laboratories had deteriorated with the budget cuts by the time of the JTEC visits.

Instead of relying on domestic university or government basic research, Japanese firms have continued to rely heavily on research from U.S. facilities such as MIT's Media Laboratory. Japanese companies have also continued to establish basic research facilities in the United States. In Japan, the best-equipped industrial labs appear narrowly focused and tightly structured. On the other hand, firms are attempting to improve creativity through the development of more "Western"-type incentive programs. Sony and TDK recently developed reward systems to encourage more innovative research.

Japanese firms are adept at understanding the product opportunities resulting from U.S. research efforts. For example, Apple Computer developed a strategic alliance with Sharp Corporation for the manufacture of the new personal digital assistant called Newton. Sharp introduced its lower-priced version of the Newton nearly four months before Apple was able to complete the "complex" technical developments of the Newton. As one TDK 
executive explained, "We are very good at making things for our customers, but we do not really understand what product we should make." However, once they learn what to make, Japanese companies are very fast at product development and market introduction.

In the observation of JTEC panelists, the best Japanese industrial labs are comparable with U.S. labs in the nature and amount of equipment. Japanese technical publications are of outstanding quality, but most research is directed at short-term, incremental technical improvements. The work has very pragmatic goals - to solve very specific technical problems rather than invent new technologies. Panelists did not detect an atmosphere of great excitement in the labs. Still, there are several notable Japanese companies committed to the long-term development of future technologies as well as to shorter-term product development. Hitachi's research structure, described below, is representative of the broad R\&D capabilities of Japan's most influential electronics firms.

\section{HITACHI'S R\&D STRUCTURE}

The R\&D philosophy of Hitachi is that of the company's founder, Namihei Odaira, "Though we cannot live one hundred years, we should be concerned about one thousand years hence." Hitachi's stated research goal is to perform "long-term, continuous research to meet social needs and corporate policy in the next decades through development of original science and/or significant patents." Therefore, Hitachi's advanced and central research laboratories are devoted to the long-term development of new fields of science and technology. The following are some examples of Hitachi's ongoing research programs, with their development time frames:

\section{Three to five years}

- neural networks on silicon chips that mimic learning

- multimedia offices, where computers have high-resolution screens and hi-fi audio and double as video conference terminals

- magnetic levitation trains three times faster than today's fastest traditional trains

\section{Five to ten years}

- hand-held computers that obey handwritten or voice commands and exchange information over radio waves

- virtual-reality technology that allows users on a network to meet and interact in computer-simulated environments

\section{Ten to twenty years}

- superconducting chips packing 100 times more data, 10 times the speed of today's chips

- neural computers made of tens of thousands of powerful microprocessors, combining optical and electronic circuits and able to learn and reason 
- electronic switches made from a single atom

- translation software for any of the world's languages

- high definition television with thin liquid-crystal or plasma screens $>30$ " wide

- underground magnetic levitation conveyors linked by software for distribution of goods in congested cities

- fusion reactors based on the process that fuels the sun

\section{More than 20 years}

- biocomputers, whose organic materials can repair themselves like living creatures

- intelligent cities, with homes and offices wired with fiber optics that send voice, image, and computer data, and are run by electronic control centers

Hitachi's allocation of R\&D funds is broken down according to general categories in Figure 3.8

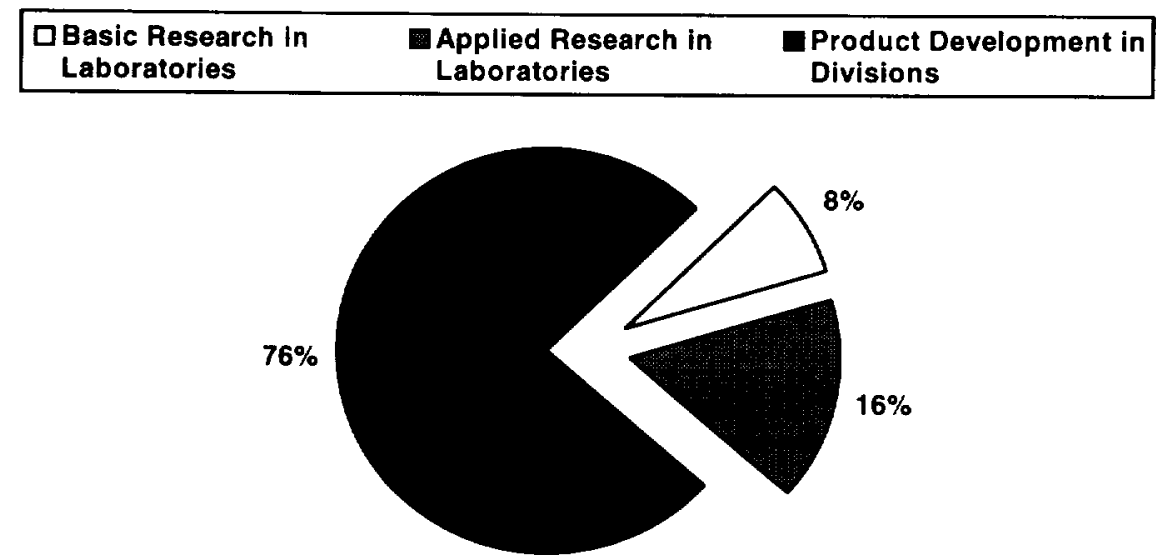

Figure 3.8. Hitachi's distribution of R\&D funds.

Over the years Hitachi has built a strong portfolio of intellectual property assets that it has used to gain strategic positioning in high-technology markets. Hitachi ranks fourth in total number of U.S. patents granted since 1963, right after IBM, GE, and AT\&T. Since 1985, the company has earned more income from licenses than it has paid out; in 1991 it reported a net profit on technology licensing activities of $¥ 24.5$ billion ( $\$ 200$ million), about $20 \%$ of its operating profits before taxes. Hitachi has twenty patent lawyers on payroll. The company's recent patenting strategy has been to develop a smaller number of patents strong enough to provide negotiating power for cross-licensing arrangements. It does not want to be left out of new product areas because of patent restriction, and it therefore attempts to 
obtain basic patents in areas of potential competition. As a result of its change in strategy, the number of patents filed per year by Hitachi declined from 22,000 in 1981 to 15,000 in 1991. When the company perceives no external threat to a technology it has newly developed, it keeps the technology as a trade secret and makes no attempt to patent.

\section{Hitachi's Corporate Research Laboratories}

In August 1993, Hitachi had over 18,000 employees in 38 research laboratories and factories, including 1,180 researchers with Ph.D. degrees. Hitachi Limited employed about 13,500 people, including 4,500 in its nine corporate research laboratories and 9,000 in its factory development laboratories. There were 935 employees with Ph.D. degrees. According to Y. Sonoyama, now Senior Advisor of Hitachi's corporate laboratories, "We see them [Ph.D.s], increasingly, as strategic assets."

At the time of the JTEC panel's visit, the corporate research laboratories reported to Y. Takeda, now Senior Executive Managing Director, who reported to Mr. Sonoyama. The nine corporate research laboratories are described in Table 3.2

Table 3.2

Hitachi Limited's Corporate Research Laboratories (August 1993)

\begin{tabular}{|l|c|c|c|l||}
\hline Laboratory & Established & Location & Employees & Main Research Fields \\
\hline \hline $\begin{array}{l}\text { Central Research } \\
\text { Laboratory }\end{array}$ & 1942 & Tokyo & 1300 & $\begin{array}{l}\text { Information technology, micro- } \\
\text { electronics and their fundamental } \\
\text { technologies }\end{array}$ \\
\hline $\begin{array}{l}\text { Hitachi Research } \\
\text { Laboratory }\end{array}$ & 1934 & Hitachi & 1300 & $\begin{array}{l}\text { Macro systems, media electronics, and } \\
\text { materials }\end{array}$ \\
\hline $\begin{array}{l}\text { Mechanical } \\
\text { Engineering } \\
\text { Research Laboratory }\end{array}$ & 1966 & Tsuchiura & 700 & $\begin{array}{l}\text { Mechatronics, energy equipment and } \\
\text { related systems }\end{array}$ \\
\hline $\begin{array}{l}\text { Energy Research } \\
\text { Laboratory }\end{array}$ & 1971 & Hitachi & 350 & $\begin{array}{l}\text { Nuclear power generation, and } \\
\text { computational science }\end{array}$ \\
\hline $\begin{array}{l}\text { Production } \\
\text { Engineering } \\
\text { Research Laboratory }\end{array}$ & 1971 & Yokohama & 600 & $\begin{array}{l}\text { Computer integrated manufacturing } \\
\text { factory automation, mass production } \\
\text { process for electronic products }\end{array}$ \\
\hline $\begin{array}{l}\text { Systems Development } \\
\text { Laboratory }\end{array}$ & 1893 & Yokohama & 380 & $\begin{array}{l}\text { System technologies and software for } \\
\text { AI and communications }\end{array}$ \\
\hline $\begin{array}{l}\text { Image \& Media } \\
\text { Systems Laboratory }\end{array}$ & 1957 & Tokyo & 180 & $\begin{array}{l}\text { AV and multimedia systems } \\
\text { visual identity }\end{array}$ \\
\hline $\begin{array}{l}\text { Design Center } \\
\text { Advanced Research } \\
\text { Laboratory }\end{array}$ & 1985 & Hatoyama & 170 & $\begin{array}{l}\text { Electron/radiation beam physics, } \\
\text { biotechnology, software science and } \\
\text { materials science (basic research) }\end{array}$ \\
\hline
\end{tabular}

Source: Hitachi Corporation 
The three biggest and most important Hitachi labs are the Central Research Laboratory (CRL) with 1,300 researchers, which focuses on electronics research; the Hitachi Research Laboratory, the oldest lab, with 1,300 researchers, which does research on macro systems such as traffic and power systems and also on media electronics and new materials; and the Mechanical Engineering Laboratory, with 700 researchers, which was established in 1966 to do research into mechatronics, energy equipment, and related systems. Hitachi's Energy Research Lab does research for nuclear power generation and computational science that requires large-scale simulations. The Production Engineering Research Lab, located near the consumer products factory, decides what kind of system or robots to use for production of new products such as video tape recorders (VTRs). The Systems Development Lab does research on computers and software. The Image and Media Systems Laboratory works on audiovisual and multimedia systems development. The Design Center concentrates on product design. The last laboratory, the Advanced Research Laboratory (ARL), does fundamental or basic research.

Hitachi's nine corporate research laboratories account for $24 \%$ of its R\&D expenditures. Research is funded in three different ways, two of which are shown in Table 3.3. First, corporate headquarters funds research expected to take over five years to get to the market; second, the business divisions or subsidiaries pay for commissioned research of under five years, usually two to three years out; third, research that is likely to make it to market within two years is mostly conducted in the business divisions' product development laboratories. Of total research and development funds, about $30 \%$ is either paid for by corporate headquarters or commissioned by one of the business divisions; $70 \%$ is funded by the business divisions and subsidiaries for their own short-term product developments.

Table 3.3

Hitachi Corporate Research Funding

\begin{tabular}{||l|l|l||}
\hline & Independent Research & Commissioned Research \\
\hline \hline R\&D Funding & Head Office & Business divisions/subsidiaries \\
\hline Project Authority & Laboratory Manager & Sponsor/Laboratory \\
\hline Time Horizon & Beyond five years & Within five years \\
\hline
\end{tabular}

Source: Hitachi Corporation

The two laboratories that receive the greatest proportion of funding from corporate headquarters are CRL and ARL. CRL receives about $45 \%$ of its funding from corporate headquarters; ARL gets $100 \%$ of its funding from corporate headquarters. Hitachi's president reviews all projects funded by headquarters and authorized by the general manager of the laboratory. Commissioned projects are authorized by the sponsoring business division or subsidiary. For technology or product developments expected to reach the market within one to two years, each business group has its own product development laboratory. For example, the computer group develops its own products and pays $100 \%$ of the cost for current product development. 
The Central Research Laboratory, considered the lead laboratory for Hitachi applied research, is located on a 51 -acre campus west of Tokyo. Since 1988, the company's R\&D objectives have been to invest $20 \%$ of total R\&D funds in long-term research (beyond the next ten years), $40 \%$ in intermediate-range microelectronics and digital systems research (from five to ten years in the future), and $40 \%$ in near-term microelectronics and digital systems research (with results expected within the next five years).

The Advanced Research Laboratory was established in 1985 to focus on basic research in pursuit of scientific breakthroughs. Its scientists are not driven by costs or results in the marketplace - its $\$ 33$ million budget comes directly from headquarters. The general manager, Shojiro Asai, is hoping the lab will generate breakthroughs like the transistor. He encourages young scientists to present papers at international symposiums. According to Asai, "It's critical for people to go out and get feedback from the world's top scientists."

\section{Growing Concern for Technology Commercialization - Hitachi's SPROT Projects}

Hitachi continues to view research and development as essential to future growth of the company and is attempting to increase the effectiveness of its $R \& D$ activities through careful selection of themes, smooth execution of projects, and efficient use of limited resources. In 1992, Hitachi introduced the Strategic Business Projects (SPROT) system that aims to more closely link the results of R\&D efforts with the company's operations and to put attention on major projects. More specifically, the SPROT system, shown in Figure 3.9, was introduced to shift Hitachi's R\&D focus to one that is market-driven.

Prior to this change, corporate "Tokken" projects had been the center of Hitachi's research efforts. The Tokken system, short for tokubetsu kenkyu (special research projects), started about thirty years ago. In the past, this was a "heavyweight" team system with corporatelevel support for urgent or important R\&D projects. At Hitachi, proposals always originated from lower levels and were reviewed by upper levels. In the past, Tokken was used for mainframe, VTR, and similar developments. Tokken projects led to development of Hitachi products such as supercomputers, semiconductors, magnetic disks, displays, power plants, and AI robots. Tokken results helped create the image of Hitachi's excellence in technology. The Tokken system was quite popular in Japan, and even some foreign firms adopted the system. But Tokken had nothing to do with market development.

Hitachi's new SPROT system was intended to improve the market focus of R\&D projects. It was recognized that it would take time to move away from the current bottom-up approach that drove the Tokken system, with its own corporate culture and egalitarian and individualistic style. Y. Takeda, executive managing director of Hitachi's corporate laboratories, told the panel that the SPROT goal was to improve overall synergy:

In the past, all research activities were based on a bottom-up system. But unless someone takes the leadership, there will be no synergistic affect. The problem is that researchers have no outside contacts and, therefore, are unable to generate any synergy within the company. So we are changing our thrust to put these projects 
under the corporate business planning division, not under the laboratories. The aim of strategic projects is to bring together people from accounting, sales, marketing and R\&D. The general manager of the division is going to have strong responsibility for decision-making of the project.

R\&D PROMOTION METHODS

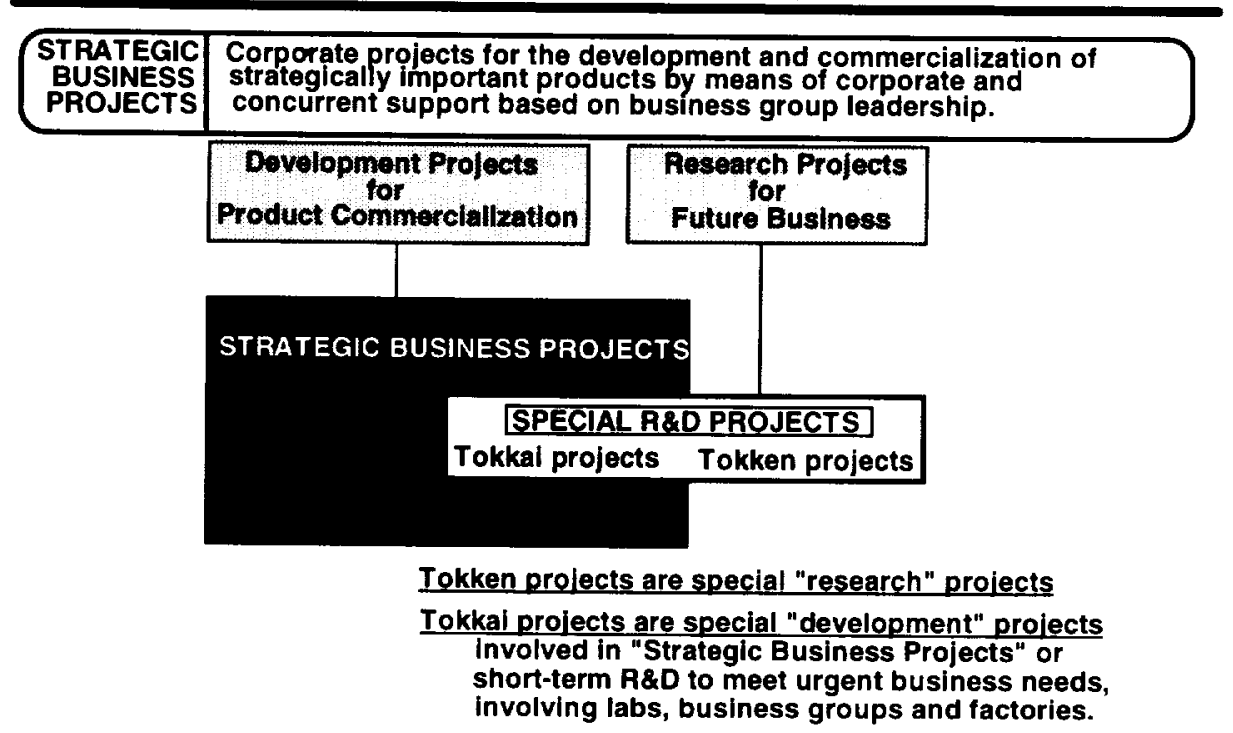

Figure 3.9. Hitachi's Strategic Business Projects system.

Tokken was converted into a subsystem of the SPROT system, no longer an independent project system. Instead, SPROT is to be the center of R\&D projects. It was also subdivided into Tokken and Tokkai (tokubetsu kaihatsu, special development) projects. Projects are classified Tokken if commercialization will be over five years or Tokkai if commercialization will be within three years. According to Takeda, projects are classified by the time it takes for commercialization so that researchers will think about the market. "Innovation criteria requires that strategic projects be successful in the market. This means that we must do R\&D for the market, not only for the product."

As it is now understood, since SPROT projects are to be directed at product commercialization, they are to involve personnel from accounting, finance, advertising and marketing, as well as from R\&D. The decision-making person is to be a division manager - a business person rather than a researcher. The planner for Hitachi's computer business was appointed to head the new R\&D Promotion Headquarters. Each new project is to be initiated at a thrust meeting, chaired by the senior R\&D executive, Mr. Sonoyama, including high-level managers from sales, control, planning, etc. While Hitachi typically had thirty to forty Tokken projects underway at any one time, at the time of the JTEC visit only three strategic business projects had been designated. It was expected that every division should be able to develop a project for its business areas. 
It is clear that Hitachi is constantly working to refine its market orientation and thereby the efficiency and long-term viability of its operations: It expects to be around "one thousand years hence." However, despite the company's successful development of new technology, this has not been adequate to compete with technologically applied companies like Sony, Sharp, or Matsushita. To stay competitive, Hitachi, like many U.S. firms, is also having to learn how to commercialize its technologies more rapidly.

\section{CONCLUSION}

While the United States may be a nation of explorers, entrepreneurs, innovators, and inventors who have developed products like the airplane, TV, personal computer, video tape machine, and cellular phone, the United States has had difficulty maintaining leadership in many of these industries. Being "first to market" has not guaranteed success in developing next-generation products. It has been Japanese companies with expertise in miniaturization technologies and manufacturing equipment that have garnered the competitive advantages in developing next-generation products.

The Japanese companies look for new growth markets where they can apply their miniaturization and manufacturing skills to next-generation products. By identifying and solving difficult technical problems, the Japanese have been able to outperform U.S. firms in many industries. Motorola is one of the few U.S. firms that has been able to maintain its market position by continuously miniaturizing its products and applying advanced manufacturing technologies to cellular telephones.

In electronic packaging, Japan's vast supplier base is constantly working to solve the technical problems related to next-generation products. Thanks to leadership at the national level and ongoing, industry-wide communication and cooperation, everyone understands the technical requirements, and the microelectronics industry is focused on solving the most difficult technical problems. Clear market orientation, nurturing of intraindustry and industry-public sector interdependence, good communication, and on-going research and development of component and process technology as well as new technology all seem to be critical components of Japan's microelectronics industry infrastructure.

\section{REFERENCES}

Dodwell Marketing Consultants. 1993. Structure of the Japanese Electronics Industry. Tokyo.

U.S. Department of Commerce Technology Administration (DOC/TA). 1993 (May 3). Report of the U.S. -Japan Technology Transfer Joint Study Panel. PB93-182921.

U.S. Department of Commerce (DOC). 1993. U.S. Research Facilities of Foreign Companies.

Japan Science and Technology Agency (STA). 1992 (February). Survey Report on Research Activities in Private Enterprises.

Ministry of International Trade and Industry of Japan (MITI). 1991. "The 4th Basic Survey on Japanese Business Activities Abroad." MITI News No. 3. 


\title{
CHAPTER 4
}
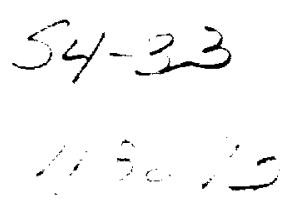

\section{Japan's Electronic Packaging Technologies}

\author{
Rao R. Tummala \\ Michael Pecht
}

The JTEC panel found Japan to have significant leadership over the United States in the strategic area of electronic packaging. Many technologies and products once considered the "heart and soul" of U.S. industry have been lost over the past several decades to Japan and other Asian countries. The loss of consumer electronics technologies and products is the most notable of these losses, because electronics is the United States' largest employment sector and is critical for growth businesses in consumer products, computers, automobiles, aerospace, and telecommunications. In the past there was a distinction between consumer and industrial product technologies. While Japan concentrated on the consumer market, the United States dominated the industrial sector. No such distinction is anticipated in the future; the consumer-oriented technologies Japan has dominated are expected to characterize both domains. The future of U.S. competitiveness will therefore depend on the ability of the United States to rebuild its technological capabilities in the area of portable electronic packaging.

\section{INTRODUCTION}

A 1993 study by MCC and Sandia National Laboratory on U.S. industrial competitiveness in electronic packaging technology concluded the following:

- U.S. companies lead the world in several integrated circuit (IC) markets, but this lead is weakened by an ill-equipped low-cost packaging infrastructure.

- Japanese IC packaging and assembly are significantly superior in terms of miniaturization and cost-effectiveness. 
- Japanese market share in consumer electronics has created the "product pull" required to justify large investments in manufacturing processes that in turn help all other electronic segments, such as supercomputers and telecommunications (MCC/Sandia 1993).

As shown in Figure 4.1, the United States leads in microprocessors, computer systems, software, and industrial electronics markets, while Japan is a clear leader in DRAMs, batteries, displays, and electronic packaging technologies that support its domination of consumer electronics markets.

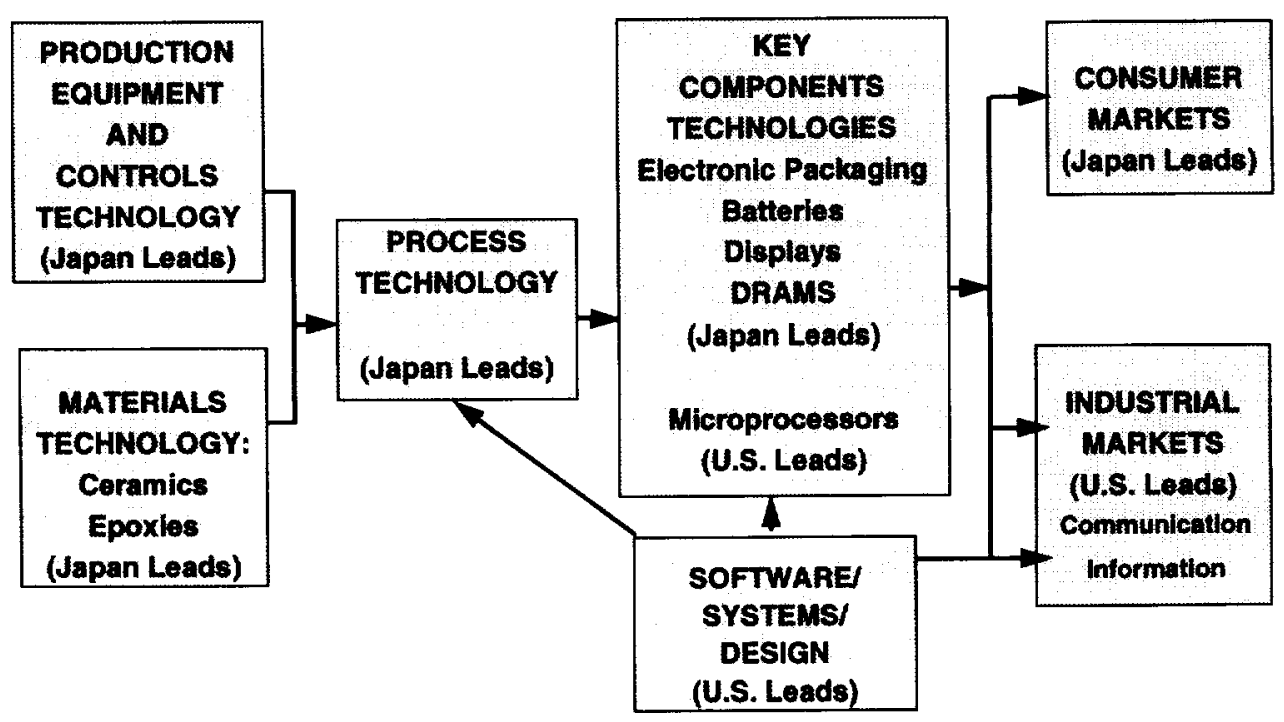

Figure 4.1. Japan's technological and market leadership.

As packaging technologies and related components become essential to next-generation products, an increasing proportion of components and equipment required for the production of commercial products must be imported by the United States from Japan or other Asian countries. The market for such imports is expected to exceed $\$ 100$ billion by the year 2000, a tenfold increase over today's market.

\section{JAPAN'S ELECTRONIC PACKAGING STRATEGIES}

As Figure 4.2 shows, Japan's competitive edge over the United States in electronic packaging derives from the breadth of its packaging expertise. There are few areas in which Japan lags the United States. In fact, Japan is covering all its bases by investing in packaging technologies that are required to protect existing markets and in new technologies to grow next-generation electronics markets. The Japanese electronics 
industry has invested heavily in the full range of packaging technologies, including plastic and ceramic packages, passive components, printed wiring board (PWB), and surface mount technologies (SMT). To keep costs down, Japan continues to stress the incremental development of packaging technologies for mass production, as shown in Figure 4.3.

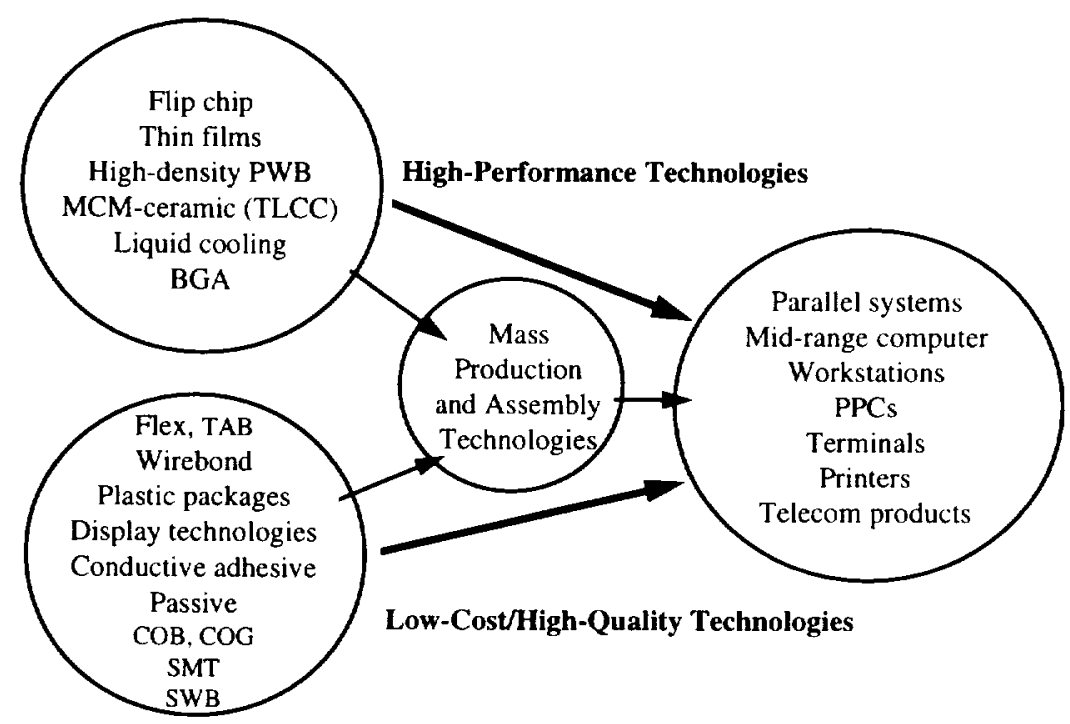

Figure 4.2. Japanese competitive advantage from breadth of technology.

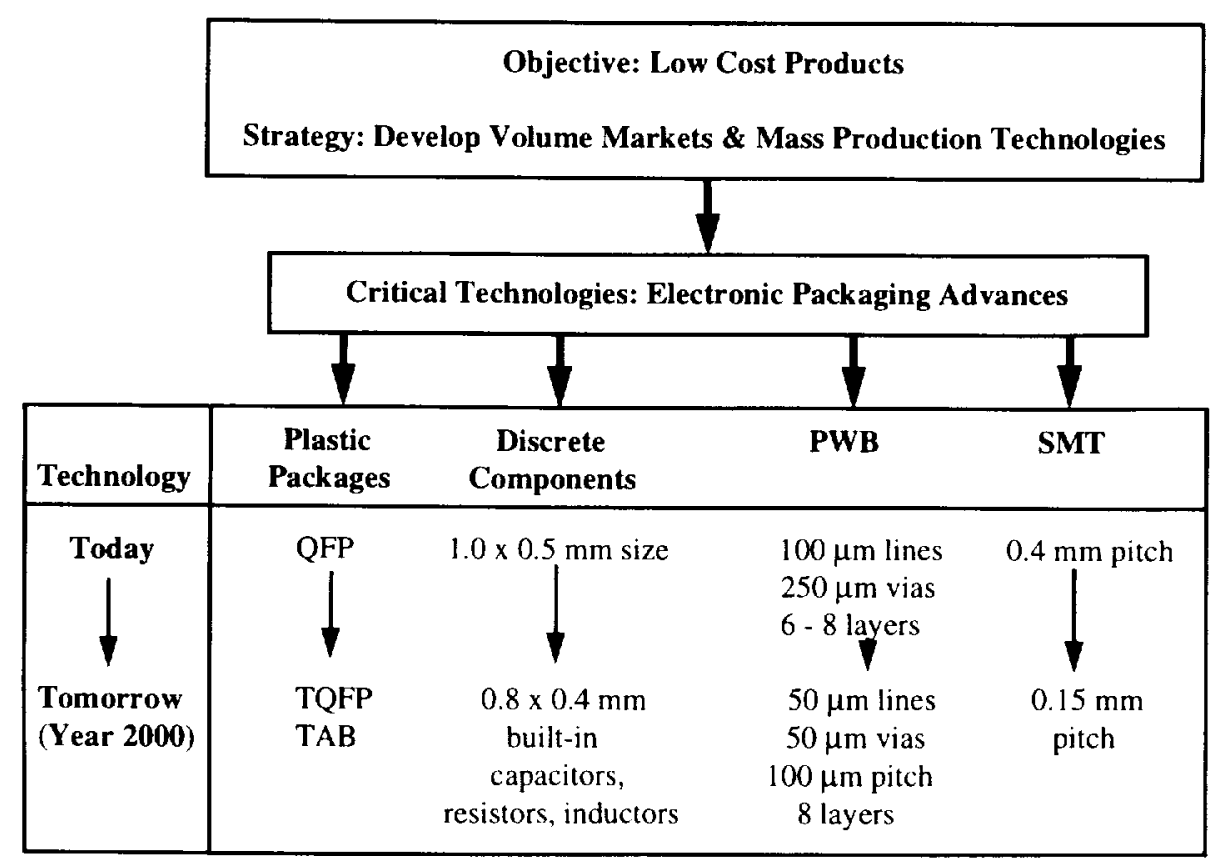

Figure 4.3. Mass production strategy for low-cost electronic products. 
The JTEC panel's research suggests that Japanese firms will continue to push the miniaturization of electronic packaging technologies. Plastic packaging technologies will continue to evolve low-cost quad flat packs (QFP) into thinner and smaller-profile packages such as thin quad flat packs (TQFP) and tape-automated bonding (TAB) packages. The high-volume applications of discrete components are expected to continue to shrink in size from the current $1.0 \times 0.5 \mathrm{~mm}$ to $0.8 \times 0.4 \mathrm{~mm}$ built-in multichip packages of capacitors, resistors, and inductors. Printed wiring boards will also reduce line and via widths from the current $100 \mu \mathrm{m}$ and $250 \mu \mathrm{m}$, respectively, to $50 \mu \mathrm{m}$. The current six-toeight-layer boards are expected to average eight layers. All these technologies are expected to continue to be applied to surface mount applications. The current limit of $0.4 \mathrm{~mm}$ pitch in SMT applications is expected to reach $0.15 \mathrm{~mm}$ pitch by the turn of the century.

For nearly a decade, the camcorder has driven packaging technology developments for miniaturization, reduced weight, and digitization. As shown in Figure 4.4, this has driven IC packaging to fine-pitch and thin packages while pushing the exploitation of multichip modules. Since the early 1990s, cellular telephones have added pressure for miniaturization through increased functional integration. Today, personal computers are adding pressure for higher speed and multiple functions. The result is a push for development of new heat-dissipation solutions and for development of vertical packages. Japan's continued economic success is expected to rely on its ability to maintain leadership in a broad range of packaging technologies to achieve competitive cost reductions for future "personal electronic" units.

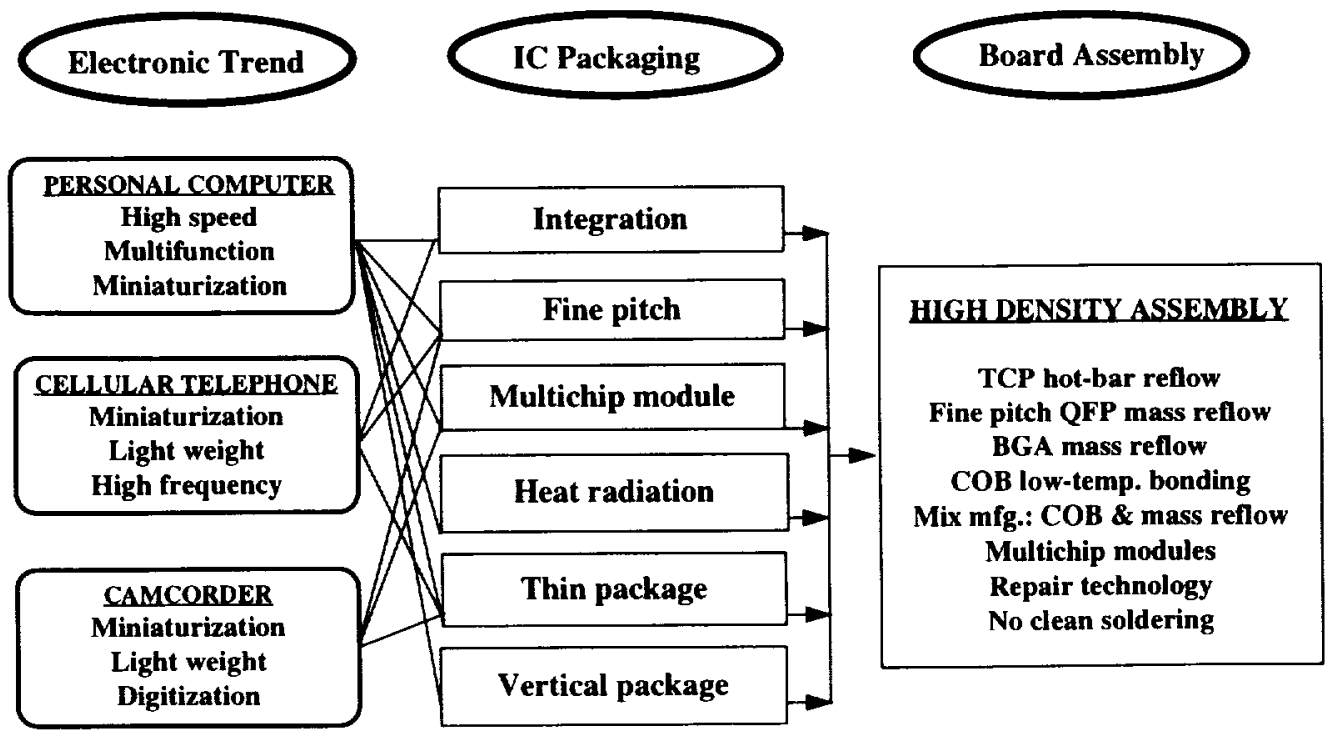

Figure 4.4. Electronic packaging trends (Matsushita Electric Co., Inc.).

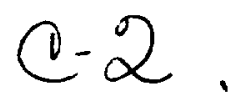


The trend towards finer pin pitch creates a number of issues that must be addressed. For example, open leads and solder bridging must be prevented. The corresponding size of solder balls must also be reduced. Thin, small-outline packages (TSOP) require improved resins and filler materials to reduce cracking during IR reflow. New designs for heat dissipation include the addition of heat-sinks under the die. Package miniaturization requires further developments in high-density board assembly.

\section{PLASTIC PACKAGING TECHNOLOGIES}

With the development of enhanced materials and production methods, plastic packaging has become the low-cost, acceptable-reliability package of choice. Japan's electronics industry is committed to incremental continuous improvements in all areas of chip making and package assembly technologies. Professor Kenji Otsuka of Meisei University told the JTEC panel, "If we would lose packaging (plastic) technologies, we would get winter season for a long time."

Thin, small-outline packages, with their compact profiles, have become a key product of the 1990s. By most estimates, they will also be used increasingly in surface mount packages in the future, especially for memories, as demand for space-saving packages grows. Other thin package types include the thin quad flat pack (TQFP), thin sealed small outline (TSSOP), and thin-body plastic dual in-line (PDIP) packages. Integrated circuit packages with width and/or length shrink include the fine-pitch quad flat pack (FPQFP), quartersize small outline package (QSSOP), shrink dual in-line processing (SDIP), shrink quad flat pack (SQFP), shrink small outline package (SSOP) and very small outline package (VSOP). With these or new shrunken packages, suppliers will continue to provide more functions in less board space, and boards will become smaller. This trend to skinnier housings will challenge die thinning, wafer transportation, chip pad mounting, leadframe design, lead bonding, board interconnection, molding, and soldering technologies.

Continued development of plastic packaging technologies, as discussed above, is essential to support Japan's focus on low-cost consumer electronics products. As shown in Figure 4.5, plastic QFP remains the low-cost single chip electronic packaging technology. $\mathrm{TAB}$ is higher-cost but is utilized in cases where finer pitch is required to achieve miniaturization objectives. Ceramic pin grid array (PGA) is the highest-cost technology and is generally limited to uses where reliability and performance are critical.

Present packaging issues depend on different uses for plastic quad flat packs (P-QFP) in Japanese and U.S. manufacturing. The U.S. Joint Electron Devices Engineering Council (JEDEC) is addressing the problems of bond pad pitch requirements finer than $0.65 \mathrm{~mm}$ (26 mils). A few Japanese manufacturers have tooled for $0.5 \mathrm{~mm}$ (20 mils) pitch parts and have plans for smaller pitch in various stages of development. The Electronic Industry Association of Japan P-QFP version has received wider acceptance by ASIC (application-specific integrated circuit) users and manufacturers, since greater volumes have been generated at lower costs than for the U.S. JEDEC version. 


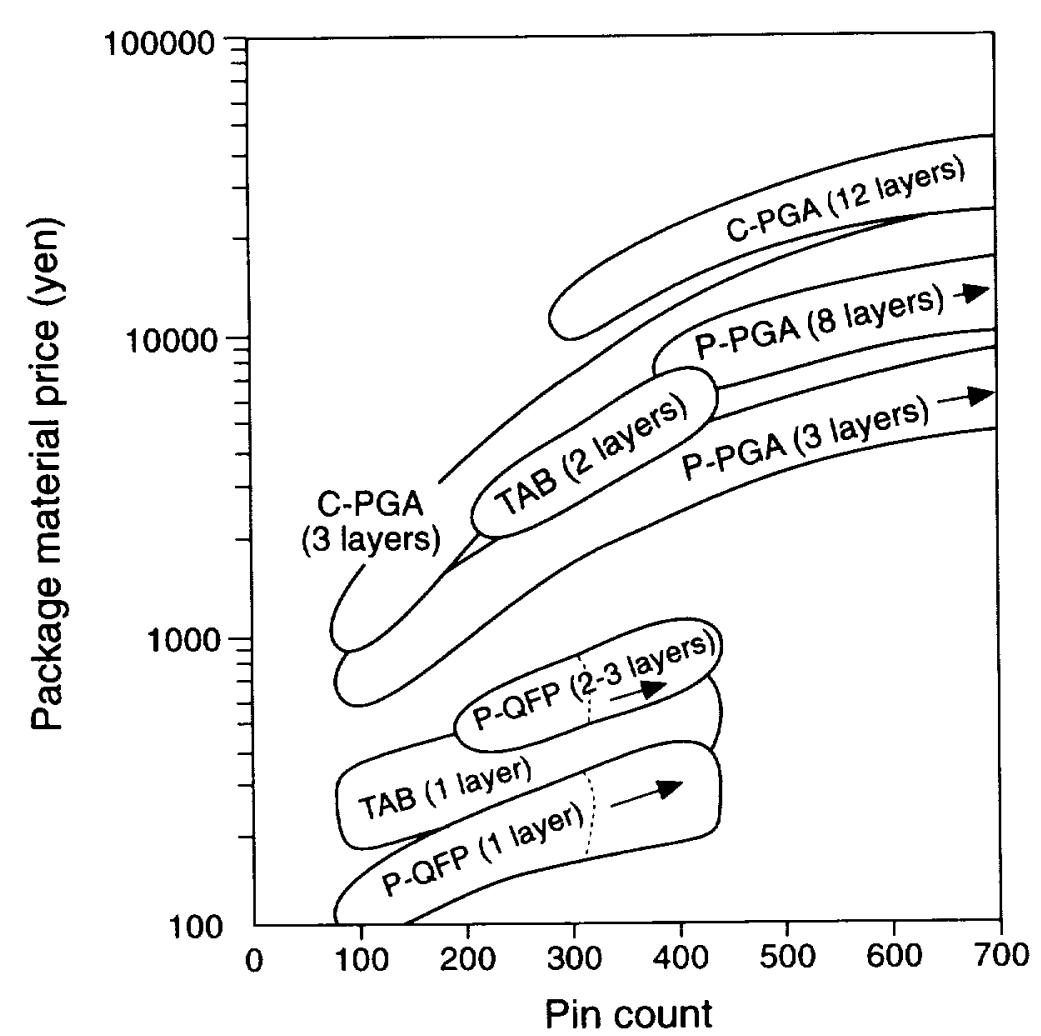

Figure 4.5. Single chip packaging costs (Otsuka).

\section{Plastic Molding Materials and Processes}

As shown in Table 4.1, Nitto Denko is working to improve and develop molding materials to meet the needs of future packages. Manufacturing technology and the cost of advanced materials required for high-quality and reliable plastic packaging determine both acquisition and lifetime cost, and drive technology for the widespread use of plastic epoxy molded (PEM) packages in all markets. Performance criteria naturally adapt to the cost constraints of the market. The high-performance molding processes of the most common packages produces about 800 packaged devices per hour.

Future packages using thinner leadframes, fine-pitch wire bonding, and flip chip or TAB structures will need low-viscosity molding compounds at low molding temperatures to reduce shear-rate-induced yield losses. Higher production rates are required to compete with PGAs and premolded packages. Smaller molds with fewer cavities and a total cycle time (including in-mold cure) of one to two minutes will be needed. A high level of automation will result in lower-cost, uniform-quality packages with less damage to fragile high-1/O-count assemblies. Clean manufacturing environments will also reduce contamination-related failures. 
Table 4.1

Molding Compound Development in Japan

\begin{tabular}{||l|l|l|l||}
\hline \multicolumn{1}{|c|}{ Discrete } & \multicolumn{1}{|c|}{ MP-2000 } & \multicolumn{1}{c|}{ Moldability } \\
\hline \hline 1970s & Small DIP & MP-3000 & Moisture resistance, moldability \\
& Middle DIP & " & HC-10-2 \\
& Large DIP, SOP & MP 150SG & Low stress \\
\hline 1980s & PLCC & MP-180 & Low stress \\
& QFP & MP-190 & Low stress, processability \\
& SSOP, TSOP & MP-7000 & Soldering resistance \\
& SQFP, TQFP & MP-7000 & “ \\
\hline 1990s & SOP, DIP & MP-80 & Anti-delamination, processability \\
& PLCC, QFP & MP-8000 & Floor life for soldering, low stress, high adhesion \\
& Large package & Target 1 & Soldering resistance, low stress, moldability \\
& Ultrathin package & Target 2 & Moldability, soldering resistance \\
& Specific package & Target 3 & Adaptability to components \\
\hline
\end{tabular}

Source: Nitto Denko

Automation will play an increasingly important role in PEM manufacturing in Japan. One approach is partial automation of various labor-intensive aspects of the process, such as preform heating and handling. A robotic arm may place the heated preform into the transfer pot and start the process sequence of transferring, curing, and ejecting the molded leadframes. In this automation approach, a single operator can handle four or five transfer presses. In the total automation approach, the process runs without any operator assistance, although typically 10 to $20 \%$ of an operator's time is spent moving different cassettes and checking equipment malfunctions. The use of a smaller molding tool with fewer cavities in conjunction with faster-curing molding compounds will further increase productivity. Such a packaging system is usually totally enclosed to maximize process cleanliness and personnel safety. The cassettes of molded leadframes feed an automated trim-and-form press and then move on to a code-marking station.

The partial or total automation of single-pot systems has been superseded by multiplunger technology in multiproduct production environments. In automated multiplunger systems, 6 to 12 pots feed 6 to 24 cavities, with 1 to 4 cavities per transfer pot. Because of the very short flow length, they are very effective in minimizing voids and promoting high molding compound density. State-of-the-art encapsulants, i.e., very fast-curing molding compounds with a total cycle time of less than two minutes in the molds, will be used in these manufacturing systems. Figure 4.6 shows the trend in encapsulant molding compounds.

\section{Process Controls and Quality Assurance}

Stringent contamination control of package assembly components during fabrication of PEMs is necessary for quality assurance and long-term reliability. Over and above the practice of using semiconductor fabrication type class 100,000 or better clean-room 


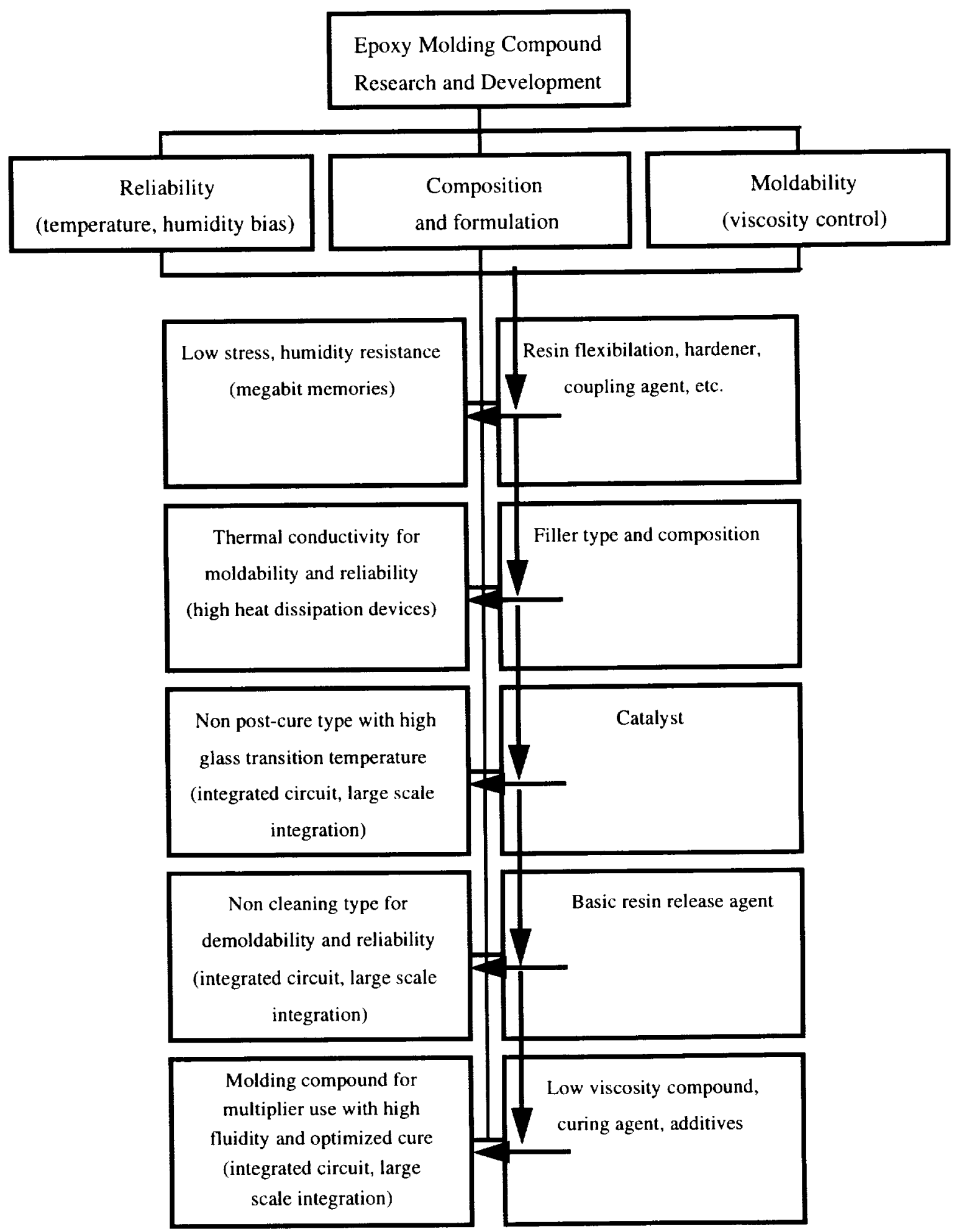

Figure 4.6. Current development trends of epoxy molded compounds. 
operation, high-technology integrated-circuit wafer cleaning processes will increasingly spread into packaging process technology. Plasma cleaning of the pad and leadframe assembly for improved bonding with plastics may become widespread. As a function of oxygen/carbon tetrafluoride/argon plasma treatment, lap-shear strength of epoxy adhesives should increase. Ultrahigh purity chemicals are sure to find their way into PEM fabrication lines as initial cleaning agents for particulate contamination control.

The increasing use of analytical techniques and microsensors to fine-tune materials and control process-induced defects falls into the category of enhanced process control and quality assurance. $\mathrm{X}$-ray radiography and $\mathrm{C}$-mode scanning acoustic microscopytomography are finding increased use as nondestructive techniques for evaluating a number of processes: plastic delamination; die metal, die attach and bonding wire deformation; die metal and wirebond voiding; leadframe, die passivation, die attach, wire, wirebond and case brittle fracture; and dendritic growth under bias. Mercury porosimetry has also been used successfully to find the number and size of epoxy and epoxy-metal pores in epoxyencapsulated packages. Epoxy pores are less than $0.2 \mu \mathrm{m}$ in diameter, epoxy-leadframes voids are about $1 \mu \mathrm{m}$ in diameter, and surface pores range from $5-500 \mu \mathrm{m}$ in diameter. Piezoresistive strain gauges integrated into test chips will continue to be used to directly measure the mechanical stress induced inside a PEM by encapsulation, die bonding, and other factors, either during fabrication or under environmental stress testing. Solid-state moisture microsensors will also be used to measure the moisture content at any specific location inside a PEM.

\section{Fine-Pitch Interconnections}

Challenged by higher integration levels (particularly in ASICs) with tighter bond pad pitches at the die level, leading edge pitches will be at 0.060 to $0.075 \mathrm{~mm}$ ( 2.5 to $3 \mathrm{mils}$ ) by the late 1990s. Beyond $0.1 \mathrm{~mm}$ (4 mils) pitch, bonding with gold wire may be done by wedge bonding. The combination of tight pad pitches and shrink packages demands not only low wire looping $(0.09$ to $0.18 \mathrm{~mm})$, but also different loop shapes. This requires modifying the dopants in the wire to offer the right set of mechanical properties. With tight pitches, the physical limits of leadframe technology will also force the placement of lead contacts at ever-increasing distances from the package center to control wire sweep. Low looping also promotes wire-to-die edge shortening when the die has inbound bonding pads to avoid encapsulation stress concentration zones. Edge shortening can be prevented by use of wirebonder software that allows an extra bend in the wire at the predetermined site.

The demands of tightly spaced inner-lead bonding $(0.05$ to $0.075 \mathrm{~mm})$ and outer-lead bonding $(0.15$ to $0.35 \mathrm{~mm})$, high pin counts, high-end performance-driven applications, and high-volume production, could also move bumped tape automated bonding (TAB) to the forefront of the packaging industry - a potential for which Japan already has the capability and infrastructure. Limiting factors for $T A B$ application have been the expense of tape, the lead time needed to obtain it, and the capital needed for the bonding equipment. Bump fabrication has also been an obstacle. Better tape metallurgy, currently available, 
now permits burn-in and longer shelf life before encapsulation. Laser bonding of finepitch devices are particularly suited to TAB.

\section{Leadframe Fabrication}

Trends in leadframe technology have important implications for the future of molded plastic packaging. Japanese companies are replacing copper alloys with $42 \mathrm{Fe} / 58 \mathrm{Ni}$ (Alloy 42) as the leadframe material, especially for moderate to high heat dissipating devices such as processors and logics. For thin $(\leq 0.15 \mathrm{~mm})$ leadframes with close lead tips for very high lead-count packages, chemical etching has replaced mechanical punching.

\section{Plastic Packaging Advancements}

New materials and component designs are required for continuous miniaturization. Tables 4.2 and 4.3 (following pages) show Nitto Denko's development roadmap for semiconductor encapsulating materials. As shown in Table 4.4, Ibiden's plan for future plastic PGA technology is expected to increase pin count from the current $500-600$ pins to 2000 pins by the year 2000 . This increase in pin count is possible with multilayer plastic packaging technology that includes new materials with lower dielectric constant and higher glass transition temperature, finer-line wiring, down to $25 \mu \mathrm{m}$ lines on $100 \mu \mathrm{m}$ pitch, and layer counts up to fifteen. Ibiden expects land grid arrays (LGAs) and ball grid arrays (BGAs) to approach 600 pins before the end of the decade.

Table 4.4

Future Plastic PGA Technology

\begin{tabular}{|l|c|c|c|c||}
\hline & 1992 & $1993-1994$ & $1995-1996$ & $1997-1998$ \\
\hline \hline Pin Count & $300 \sim 400 \mathrm{pin}$ & $500 \sim 600 \mathrm{pin}$ & $1000 \mathrm{pin}$ & $2000 \mathrm{pin}$ \\
\hline Pin Pitch & $2.54 \mathrm{~mm}$ & $1.8 \mathrm{~mm}$ & $\begin{array}{c}1.5 \mathrm{~mm} \text { (LGA) } \\
1.27 \mathrm{~mm} \text { (PGA) }\end{array}$ & $1.27 \mathrm{~mm}$ \\
\hline B'g Pitch & $180 \mu \mathrm{m}$ & $\sim 140 \mu \mathrm{m}$ & $\sim 120 \mu \mathrm{m}$ & $\sim 100 \mu \mathrm{m}$ \\
\hline Line Width & $100 \mu \mathrm{m}$ & $\sim 80 \mu \mathrm{m}$ & $\sim 50 \mu \mathrm{m}$ & $\sim 25 \mu \mathrm{m}$ \\
\hline Trace Thickness & $18 \mu \mathrm{m}$ & $\sim 18 \mu \mathrm{m}$ & $-10 \mu \mathrm{m}$ & $\sim 10 \mu \mathrm{m}$ \\
\hline Multi Layer & $61 \mathrm{layers}$ & $10 \mathrm{layers}$ & $10 \mathrm{layers}$ & $15 \mathrm{layers}$ \\
\hline Via Hole Size (dia.) & $0.3 \mathrm{~mm}$ & $0.2 \mathrm{~mm}$ & $0.1 \mathrm{~mm}$ & $0.1 \mathrm{~mm}$ \\
\hline Insulation Layer Thickness & $0.1 \mathrm{~mm}$ & $0.06 \mathrm{~mm}$ & $0.06 \mathrm{~mm}$ & $0.06 \mathrm{~mm}$ \\
\hline Dielectric Constant & 4.4 & 4.4 & 3.5 & 3.5 \\
\hline Impedance Control & $\pm 15 \%$ & $\pm 10 \%$ & $\pm 10 \%$ & $\pm 5 \%$ \\
\hline T.C.E. PPM & 14 & 14 & 10 & 10 \\
\hline T'g Point & $180^{\circ} \mathrm{C}$ & $180^{\circ} \mathrm{C}$ & $200^{\circ} \mathrm{C}$ up & $200^{\circ} \mathrm{C}$ up \\
\hline Material & $\mathrm{BT}$ & $\mathrm{BT}$ & New BT & New BT \\
\hline
\end{tabular}




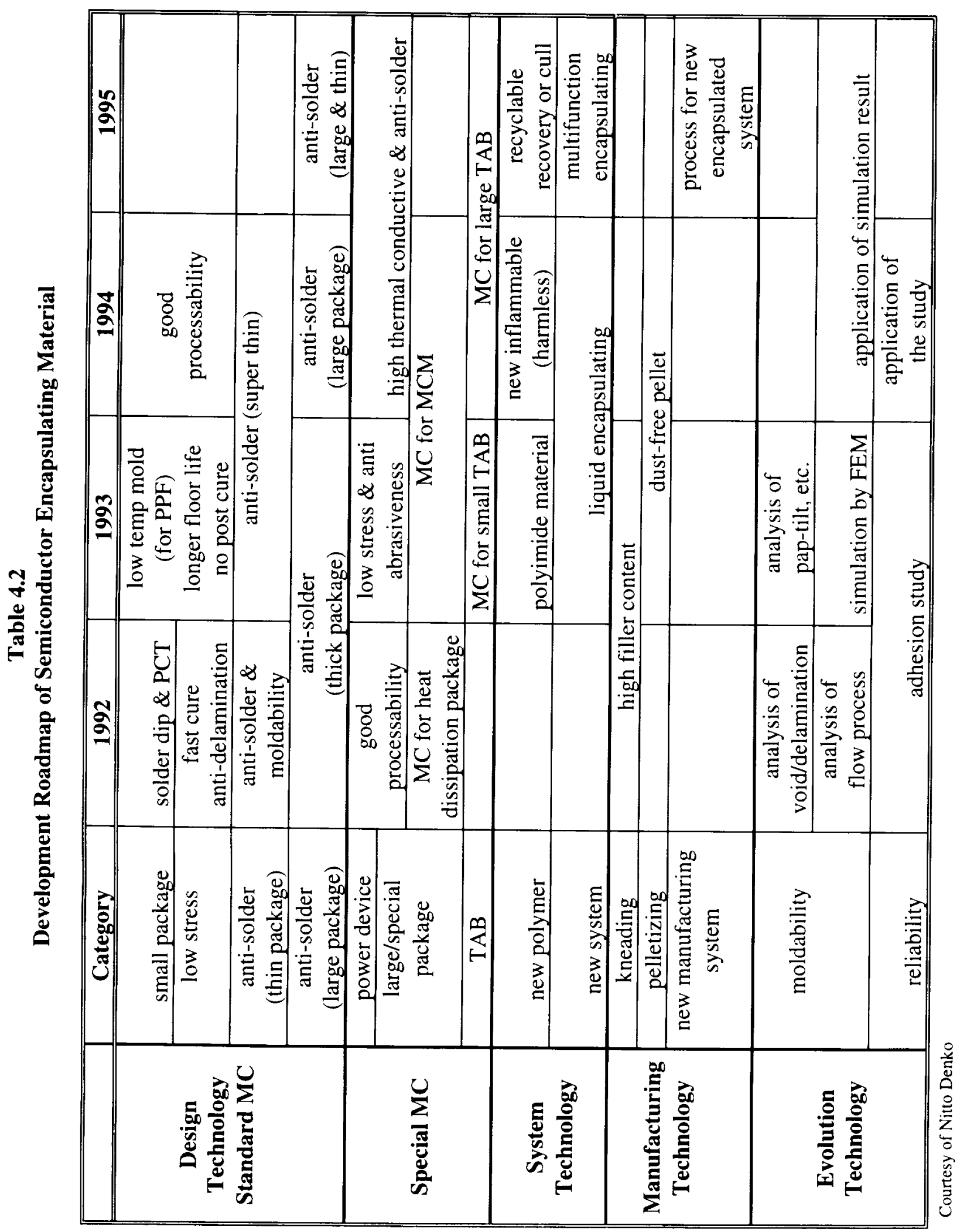




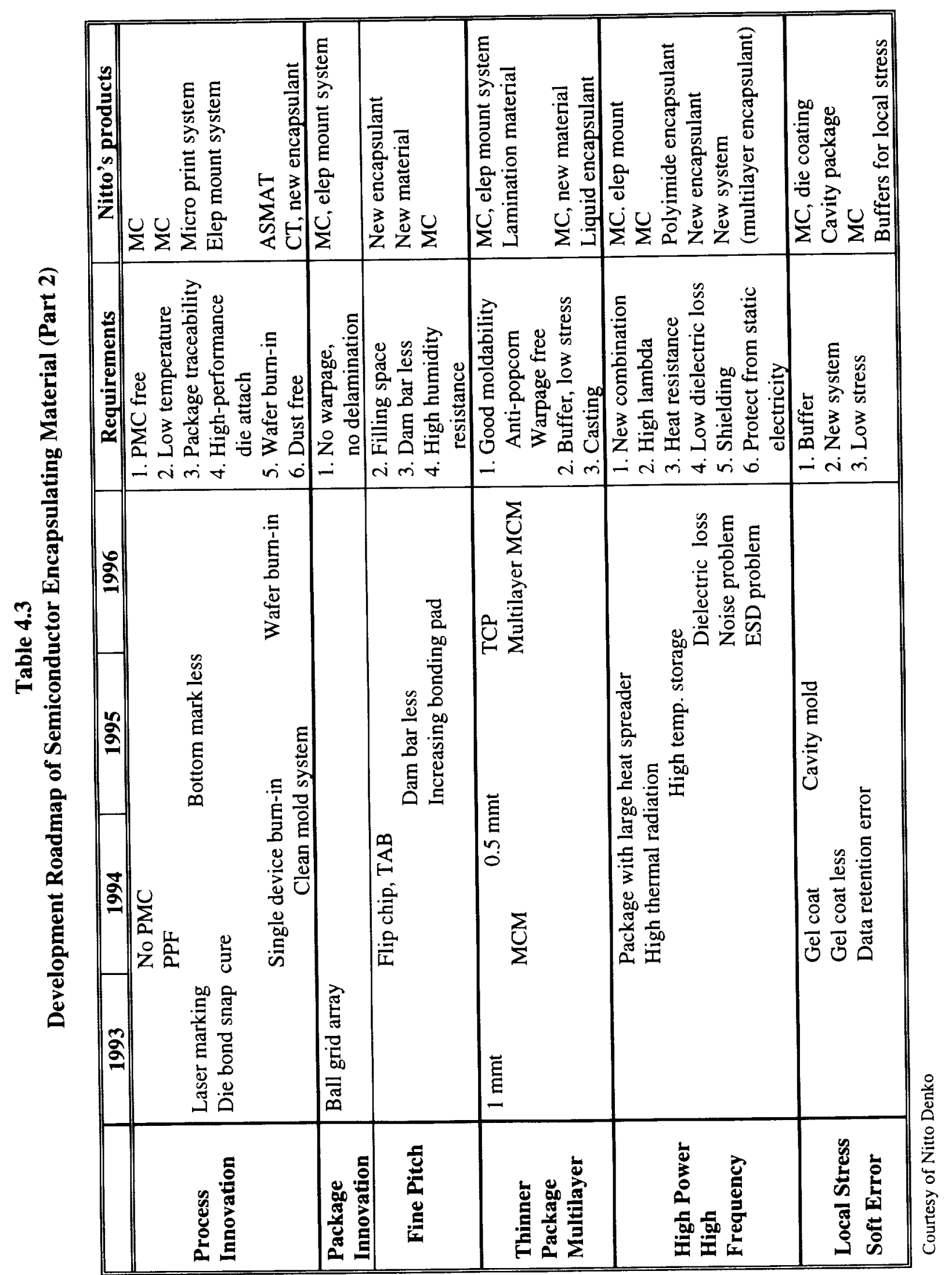


New materials, new component designs, and continuous process improvements define the direction of plastic packaging improvements in Japan. Oki's roadmap for planned TSOP improvements in memory packaging for DRAMS, as shown in Table 4.5 , is typical of plastic packaging roadmaps followed by Japan's consumer electronics industries: it shows reductions in package mounting and wire loop profile heights, reductions in leadframe thicknesses, and new materials to achieve improved reliability.

Table 4.5

Memory Package (TSOP) Technology Roadmap

\begin{tabular}{|c|c|c|c|c|c|c|}
\hline & & 1990 & 1993 & 1995 & 1998 & 2001 \\
\hline \multirow{2}{*}{$\begin{array}{l}\text { Device } \\
\text { Configuration }\end{array}$} & Density & $4 \mathrm{M}$ & $16 \mathrm{M}$ & $64 \mathrm{M}$ & $256 \mathrm{M}$ & $1 \mathrm{G}$ \\
\hline & Die Size $(\mathrm{mm})$ & 90 & 130 & 190 & 280 & 400 \\
\hline \multicolumn{2}{|c|}{$\begin{array}{l}\text { Package Mounting Height } \\
\text { (mm) }\end{array}$} & 1.2 & 1.2 & 1.2 & 1.0 & 0.8 \\
\hline \multirow{2}{*}{$\begin{array}{l}\text { Customer } \\
\text { Usage } \\
\text { Condition }\end{array}$} & Storage & 1 Day Usage & 1 Week Usage & $\longleftarrow$ & Dry Pack Free & $\longleftarrow$ \\
\hline & $\begin{array}{l}\text { Reflow } \\
\text { Condition }\end{array}$ & $\operatorname{IR}\left(220^{\circ} \mathrm{C}\right)$ & $\operatorname{IR}\left(240^{\circ} \mathrm{C}\right)$ & $\operatorname{IR}\left(240^{\circ} \mathrm{C}\right)$ & $\longleftarrow$ & $\longleftarrow$ \\
\hline \multicolumn{2}{|c|}{$\begin{array}{l}\text { Ratio of Die Size and Package } \\
\text { Size }(\%)\end{array}$} & 64 & $72 \sim 75$ & 79 & 80 & 80 \\
\hline \multicolumn{2}{|c|}{$\begin{array}{l}\text { Spacing between Package } \\
\text { Edge and Die Edge }(\mathrm{mm})\end{array}$} & 1.0 & 0.5 & 0.4 & $\longleftarrow$ & $\longleftarrow$ \\
\hline \multirow{3}{*}{$\begin{array}{l}\text { Packaging } \\
\text { Technology }\end{array}$} & Minimization & Conventional & LOC & LOC & $\longleftarrow$ & $\longleftarrow$ \\
\hline & $\begin{array}{l}\text { Low Profile } \\
\text { Wire Loop } \\
\text { Height } \\
\end{array}$ & $\begin{array}{l}200 \mu \mathrm{m} \\
\mathrm{MAX}\end{array}$ & $\begin{array}{l}150 \mu \mathrm{m} \\
\mathrm{MAX}\end{array}$ & $120 \mu \mathrm{m}$ MAX. & $100 \mu \mathrm{m}$ MAX. & $\longleftarrow$ \\
\hline & $\begin{array}{l}\text { Lead Frame } \\
\text { Thickness }\end{array}$ & 0.15 & 0.15 & 0.15 & $0.1-0.125$ & $\longleftarrow$ \\
\hline \multicolumn{2}{|c|}{$\begin{array}{l}\text { Reliability (Reflow Resistance) } \\
\text { Molding Epoxy Resin }\end{array}$} & $\begin{array}{l}\text { Conventional } \\
\text { (EOCN) }\end{array}$ & $\begin{array}{l}\text { Biphenyl } \\
\text { (High } \\
\text { Adhesion) }\end{array}$ & Biphenyl & \multicolumn{2}{|c|}{$\begin{array}{c}\text { Imid Modified Epoxy } \\
\text { (High Tg) }\end{array}$} \\
\hline
\end{tabular}

EOCN: Epoxy Ortho Cresol Novolak. Source: OKI

Table 4.6 shows a roadmap for logic ICs. It illustrates planned QFP, C-PGA, and TTQFP (thin-thin quad flat pack) developments. Future packages are expected to use $0.3 \mathrm{~mm}$ pin pitch for QFPs, $1.27 \mathrm{~mm}$ pitch for C-PGAs with $1000 \mathrm{I} / \mathrm{Os}$, and $0.3 \mathrm{~mm}$ heights on TTQFPs.

In a potentially very significant development, Fujitsu in 1994 introduced bump integration technology (BIT) for flip chip applications. BIT allows $0.12 \mathrm{~mm}$ bump pitch with pin counts between 300 and 600 on $200 \mathrm{~mm}^{2}$ to $500 \mathrm{~mm}^{2}$ areas. Equal sized BGA packages would have fewer than 200 pins. 
Table 4.6

Logic LSI Package Roadmap

\begin{tabular}{|c|c|c|c|c|c|c|}
\hline \multicolumn{2}{|c|}{ Year (CY) } & 1990 & 1993 & 1996 & 1999 & 2002 \\
\hline $\begin{array}{l}\text { LSI } \\
\text { Chip } \\
\text { Trend }\end{array}$ & $\begin{array}{l}\text { Gate density } \\
\text { Max. chip size } \\
\text { Max. power } \\
\text { Max. speed } \\
\text { Max. pin count } \\
\end{array}$ & $\begin{array}{c}200 \mathrm{~K} \\
15 \mathrm{~mm} \\
1.5 \mathrm{~W} \\
50 \mathrm{MHz} \\
250 \\
\end{array}$ & $\begin{array}{c}300 \mathrm{~K} \\
15 \mathrm{~mm} \\
2 \mathrm{~W} \\
150 \mathrm{MHz} \\
350 \\
\end{array}$ & $\begin{array}{c}500 \mathrm{~K} \\
17.5 \mathrm{~mm} \\
3 \mathrm{~W} \\
300 \mathrm{MHz} \\
500 \\
\end{array}$ & $\begin{array}{c}1 \mathrm{M} \\
20 \mathrm{~mm} \\
5 \mathrm{~W} \\
500 \mathrm{MHz} \\
750 \\
\end{array}$ & $\begin{array}{c}2 \mathrm{M} \\
25 \mathrm{~mm} \\
10 \mathrm{~W} \\
500 \mathrm{MHz} \\
1000 \\
\end{array}$ \\
\hline \multirow{4}{*}{$\begin{array}{c}\text { Package } \\
\text { Technology }\end{array}$} & $\begin{array}{l}\text { QFP Size }(\mathrm{mm}) \\
\text { QFP Pitch }(\mathrm{mm})\end{array}$ & $\begin{array}{c}40 \\
0.65 \\
\end{array}$ & $\begin{array}{l}40 \\
0.5 \\
\end{array}$ & $\begin{array}{l}28 \\
0.4 \\
\end{array}$ & $\begin{array}{l}40 \\
0.3 \\
\end{array}$ & $\begin{array}{l}-- \\
--- \\
\end{array}$ \\
\hline & $\begin{array}{l}\text { C-PGA I/O } \\
\text { Size }(\mathrm{mm}) \\
\text { Pitch }(\mathrm{mm}) \\
\end{array}$ & $\begin{array}{l}-- \\
--- \\
--- \\
\end{array}$ & $\begin{array}{c}401 \\
40 \\
1.778 \\
\end{array}$ & $\begin{array}{c}526 \\
32 \\
1.27 \\
\end{array}$ & $\begin{array}{c}750 \\
36 \\
1.27 \\
\end{array}$ & $\begin{array}{c}1000 \\
40 \\
1.27 \\
\end{array}$ \\
\hline & $\begin{array}{l}\text { Thin Package } \\
\text { UO } \\
\text { Size }(\mathrm{mm}) \\
\text { Height }(\mathrm{mm})\end{array}$ & 1.2 & $\begin{array}{l}144 \\
20 \\
0.5 \\
\end{array}$ & $\begin{array}{c}216 \\
24 \\
0.4 \\
\end{array}$ & $\begin{array}{c}344 \\
28 \\
0.3 \\
\end{array}$ & $\begin{array}{c}2966 \\
24 \\
0.3 \\
\end{array}$ \\
\hline & Coding & $\begin{array}{l}\text { Cu Lead } \\
\text { Frame }\end{array}$ & vith & $\begin{array}{l}\text { with } \\
\text { Spreader }\end{array}$ & $\begin{array}{l}\text { with } \\
\text { Module }\end{array}$ & \\
\hline
\end{tabular}

Source: Oki

\section{CERAMIC PACKAGING TECHNOLOGIES}

As with plastic packaging technologies, Japan leads the world in the production of ceramic packages. Over $80 \%$ of all ceramic packages used in noncaptive markets are supplied by three large Japanese companies: Kyocera, NTK, and Sumitomo Metals and Alloys. In addition, companies supplying their own in-house needs for ceramic packages include Shinko, Ibiden, NEC, Hitachi, Matsushita, Oki, Toshiba, and others. The primary ceramic package applications today fall into two categories: single-chip and multichip packages. Single-chip PGAs are the dominant ceramic package application, with a market estimated at $\$ 1.2$ billion in 1993 and projected to grow to $\$ 2.0$ billion by 1997 . The highest-volume applications for PGA packages include computer and telecommunications products. The market for multichip packages was about $\$ 670$ million in 1993 , half the size of the PGA market. But multichip packages are expected to surpass the PGA market by 1997 with sales of over $\$ 3.0$ billion. The growth in multichip packaging is driven by the increased demands of advanced personal computers, workstations, mainframes, supercomputers, and evolving HDTV applications.

Like plastic packaging development, ceramics have also had improvements in materials, design, and process technologies. The state-of-the-art in ceramic packaging, plotted in Figure 4.7 , shows the current wiring dimension to be about $50 \mu \mathrm{m}$ vias and lines, spaced about $100 \mu \mathrm{m}$ apart. The number of layers used in ceramic packages is typically 20 ; however, 61 layers have been demonstrated. IBM uses a 63-layer multichip module (MCM) in its R6000 workstation. 


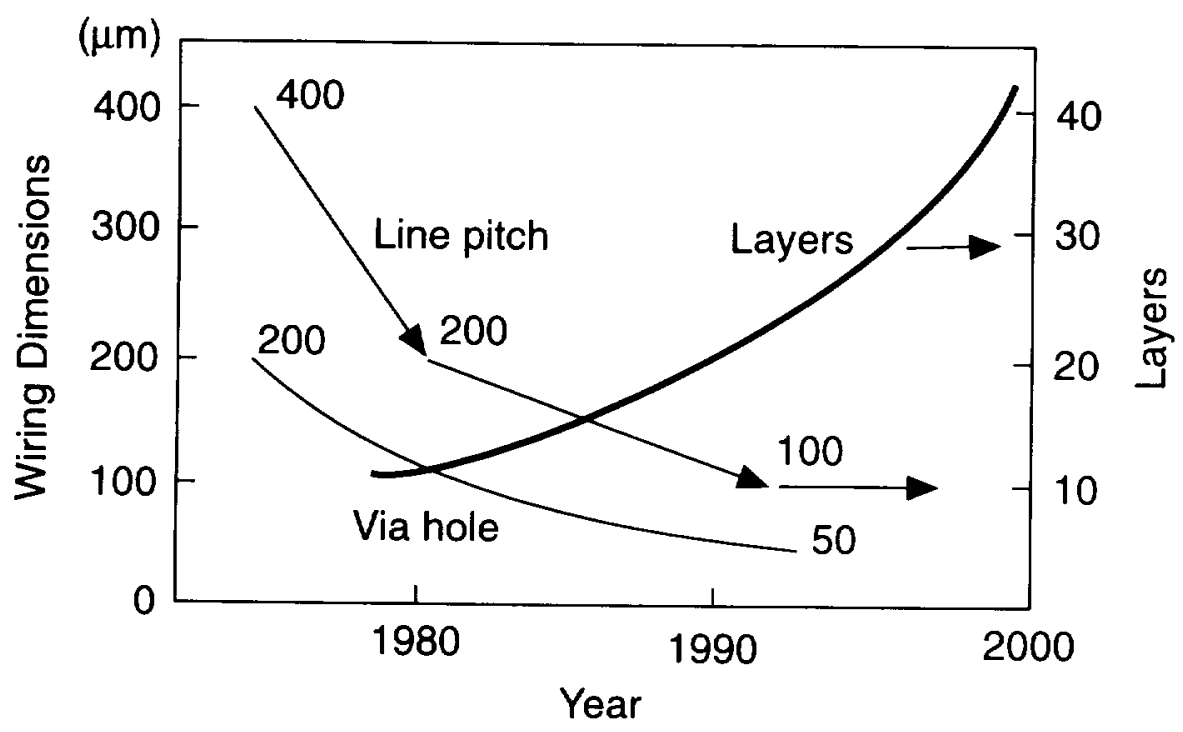

Figure 4.7. Ceramic packaging trends.

Table 4.7 shows the variety of materials being used with ceramic substrates. These materials include $\mathrm{Al}_{2} \mathrm{O}_{3}, \mathrm{AIN}$, mullite, and a variety of glass-ceramics that include both glass added to alumina and crystalizable glasses. Whereas most of these low-temperature ceramics are metalized with $\mathrm{Ag}, \mathrm{Ag} / \mathrm{Pd}$, or $\mathrm{Au}$ as fired in air, a few firms are beginning to co-fire with copper using special binders, or special atmosphere cycles, to remove organics from greensheets. Table 4.7 illustrates the properties of some of the glass-ceramics being pursued by Kyocera, Panasonic, Oki, Fujitsu, NEC, and NTK.

Table 4.7

Japanese Ceramic Substrate Materials

\begin{tabular}{|c|c|c|c|c|c|c|c|c|c|}
\hline & \multirow[t]{2}{*}{ Alumina } & \multirow[t]{2}{*}{ Mullite } & \multirow{2}{*}{$\begin{array}{c}\text { AIN } \\
\text { (Ibiden) }\end{array}$} & \multicolumn{6}{|c|}{ Glass-Ceramic } \\
\hline & & & & Kyocera & Panasonic & Oki & Fujitsu & NEC & NTK \\
\hline $\begin{array}{l}\text { Thermal } \\
\text { Conductivity } \\
\text { (W/mk, RT) }\end{array}$ & 18 & 5 & 180 & 2 & 2 & 2 & 2 & 2 & 2 \\
\hline $\begin{array}{l}\text { T.C.E. } \\
\left(10^{-6} /{ }^{\circ} \mathrm{C}\right) \\
40-400^{\circ} \mathrm{C} \\
\end{array}$ & 7.0 & 4.4 & 4.5 & 4.0 & -- & $4-6$ & 4.5 & 3.5 & 3.2 \\
\hline $\begin{array}{l}\text { Dielectric } \\
\text { Constant } \\
(1 \mathrm{MHz}, \mathrm{RT}) \\
\end{array}$ & 10.0 & 6.8 & 8.9 & 5.0 & 7.4 & $4-5$ & 5.6 & 4.4 & 5.0 \\
\hline $\begin{array}{l}\text { TAN } \delta \\
\left(1 \times 10^{-4}\right)\end{array}$ & 24 & 10 & 1 & 20 & $-\cdot$ & -- & -- & - & -- \\
\hline $\begin{array}{l}\text { Conductor } \\
\text { Metal }\end{array}$ & W, Mo & W, Mo & W & $\mathrm{Cu}$ & $\mathrm{Ag}, \mathrm{Cu}$ & $\mathrm{Au} / \mathrm{Ag}$ & $\mathrm{Cu}$ & $\mathrm{Au}$ & $\mathrm{Cu}$ \\
\hline $\begin{array}{l}\text { Sheet } \\
\text { Resistance } \\
(\mathbf{m} \Omega / \mathbf{s q})\end{array}$ & 10 & 10 & 15 & 3 & $2 \sim 5$ & 5 & 3 & 3 & 5 \\
\hline
\end{tabular}


Of particular interest to the consumer electronics industry is the aspect of ceramic technology often referred to as LTCC (low-temperature ceramic carrier), currently metalized with Ag/Pd and co-fired with capacitors and resistors. The LTCC illustrated in Figure 4.8 was designed and developed for use in VCRs and other consumer video products by Panasonic at its plant in Saijo.
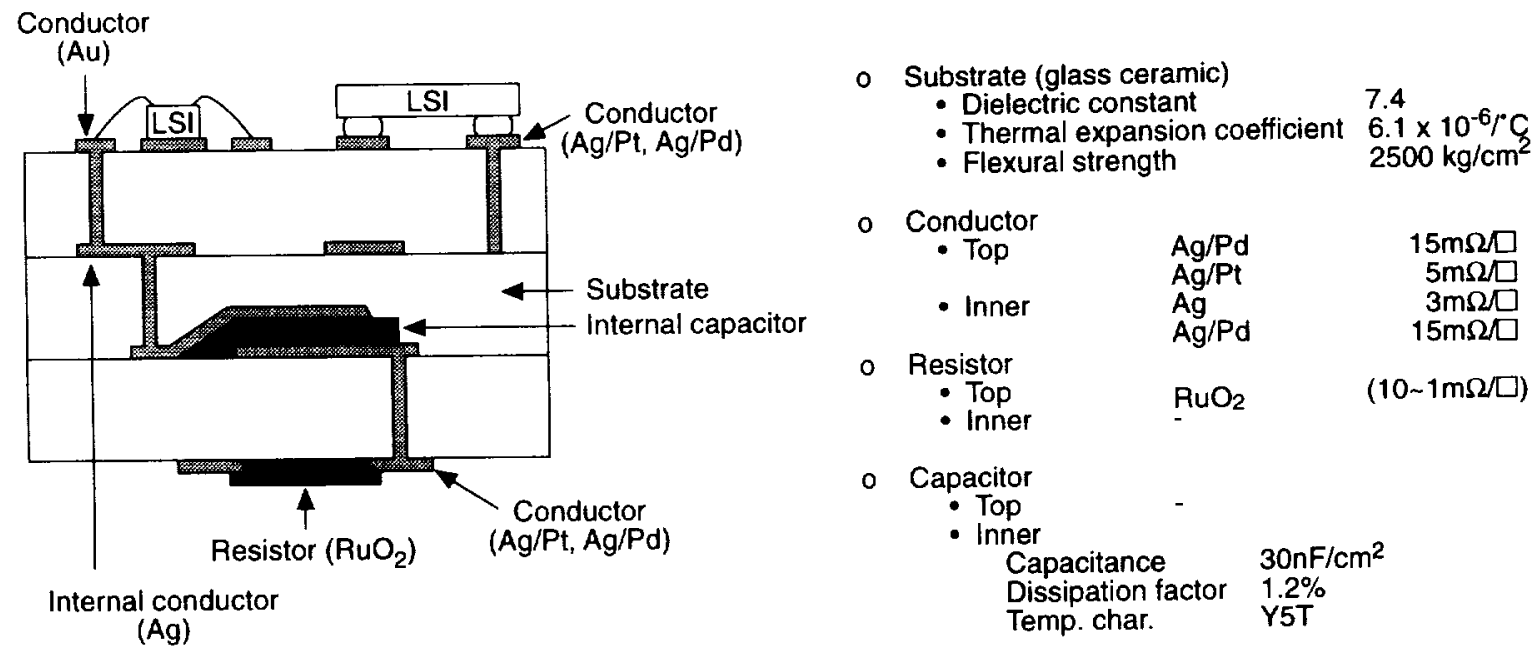

Figure 4.8. Consumer ceramic substrate (Panasonic).

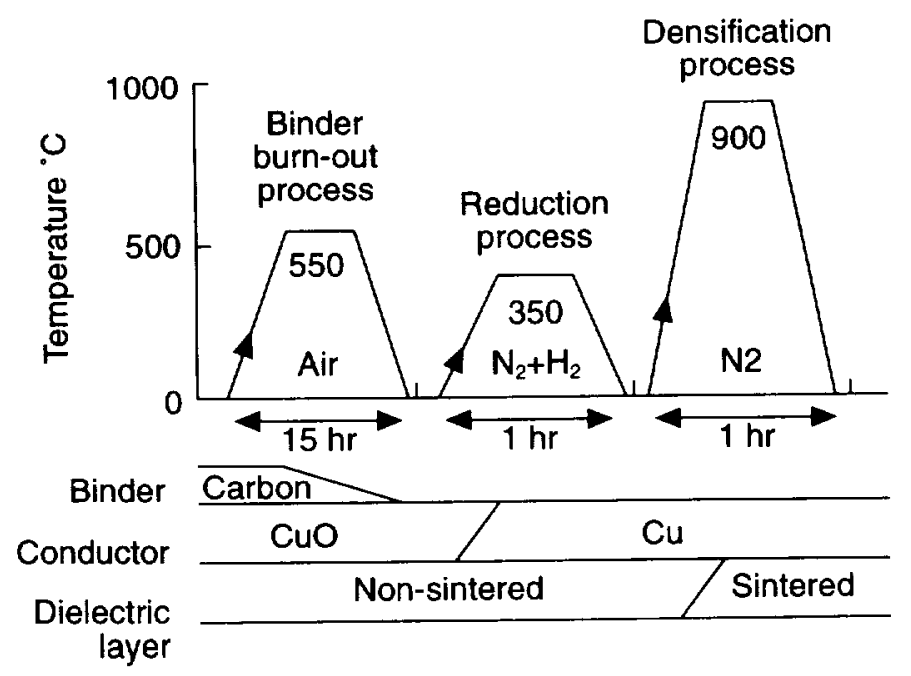

Figure 4.9. Low-cost ceramic co-firing process with copper (Panasonic).
Panasonic also designed and developed a low-cost process technology for co-firing with copper that is illustrated in Figure 4.9. This process involves forming thick films with $\mathrm{CuO}$ and co-firing in air to initially remove organics from greensheets and paste, and then reducing the oxide in forming gas, and finally forming a bond between glass that flows from ceramic walls and slightly oxidized copper in the via in $\mathrm{N}_{2}$ atmosphere. 
Panasonic package designers expect to integrate capacitors and resistors into the substrate in the near future. Figure 4.10 illustrates glass ceramic/copper with surface resistors currently practiced by Panasonic.

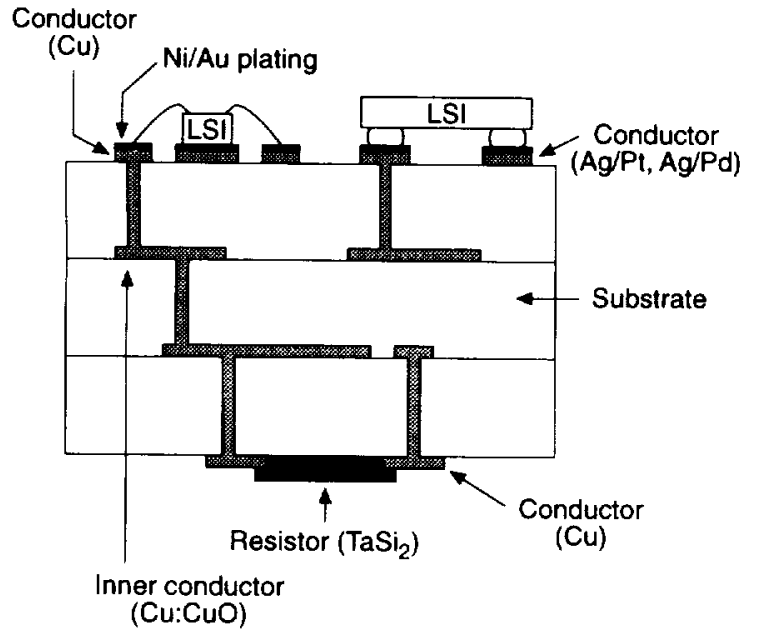
- Substrate (glass ceramic)
- Dielectric constant 7.4
- Thermal expansion coefficient $6.1 \times 10^{-6} /{ }^{\circ} \mathrm{C}$
- Flexural strength $2500 \mathrm{~kg} / \mathrm{cm}^{2}$

a Conductor

- Top $\quad$ Cu $2 m \Omega \square$

- Inner $\quad$ Cu(CuO)

- Resistor

- Top $\quad \mathrm{TaSi}_{2} \quad(100 \sim 10 \mathrm{~K} \Omega \square)$

- Inner

$-$

Figure 4.10. Consumer ceramic substrate with $\mathrm{Cu}$ (Panasonic).

The large companies in Japan like NEC, Hitachi, Toshiba, and Fujitsu understand the importance of ceramic packaging in relation to other technologies, since they utilize the full compass of packaging technologies for products that range from camcorders to supercomputers. Figure 4.11 compares Kyocera's design rules for PWB and ceramic technologies. The leading companies perceive laminated MCMs based on PWB technology to be low cost, but it makes the high wiring density needed for high performance difficult to achieve. Japanese firms believe they can realize high density, but only at a higher cost, as with ceramics.

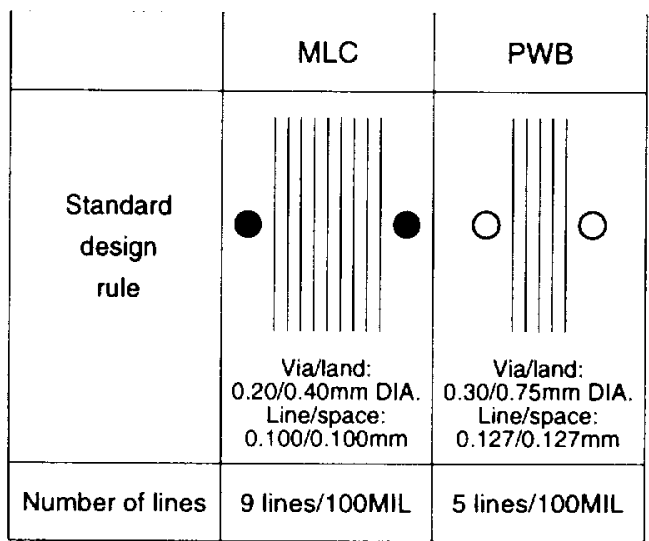

Figure 4.11. Multilayer ceramic (MLC) and printed wiring board (PWB) compared (Kyocera). 
Thin-film technology has been demonstrated and used by NEC in its mainframe and supercomputers, but only at very high cost. NEC believes ceramic MCM technology has the best potential; where it lags, NEC plans to supplement with surface thin-film layer or layers to achieve the required redistribution and wiring. NEC understands the cost implications of the technologies but has only recently been able to develop and deliver the ceramic greensheets. A material that NEC recently developed, G100, has a dielectric constant of 4.4 and is co-firable with gold, having a thermal expansion coefficient of $4.5 \times 10^{-6} \%^{\circ} \mathrm{C}$. The material used in accomplishing this 4.4 dielectric constant consists of $15 \%$ quartz glass plus $20 \%$ cordierite plus $65 \%$ borosilicate glass. Fired in air at $900^{\circ} \mathrm{C}$, the material has a mechanical strength of $1600 \mathrm{~kg} / \mathrm{cm}^{2}$. The ceramic packaging technology roadmap followed by NEC during the last fifteen years is illustrated in Table 4.8.

\section{Table 4.8}

\section{NEC's Ceramic Roadmap}

\begin{tabular}{||c|c|c|c||}
\hline \hline 1980 & $1985-1990($ G10) & 1990 & $1995(\mathbf{G 1 0 0})$ \\
\hline \hline $\begin{array}{c}\text { Alumina } \\
\text { with } \mathrm{W}\end{array}$ & $\begin{array}{c}\text { Glass + Ceramic } \\
\text { with } \mathrm{Ag} / \mathrm{Pd}\end{array}$ & $\begin{array}{c}\text { Alumina }+ \text { Glass } \\
\text { Glass + Ceramic } \\
\text { Ag Rich } / \mathrm{Pd}\end{array}$ & $\begin{array}{c}\text { Cordierite + Glass } \\
\text { Glass + Ceramic } \\
\text { Gold }\end{array}$ \\
\hline $\begin{array}{c}\mathrm{E}_{\mathrm{r}}=9 \\
\rho=15 \mu \cdot \Omega \cdot \mathrm{cm}\end{array}$ & $\begin{array}{c}\mathrm{E}_{\mathrm{r}}=7.8 \\
\rho=10 \mu \cdot \Omega \cdot \mathrm{cm}\end{array}$ & $\begin{array}{c}\mathrm{E}_{\mathrm{r}}=4.4 \\
\rho=3.5 \mu \cdot \Omega \cdot \mathrm{cm}\end{array}$ & $\rho=3.0 \mu \cdot \Omega \cdot \mathrm{cm}$ \\
\hline
\end{tabular}

NEC is exploring ways to achieve an even lower effective dielectric constant. One approach is to develop hollow space between ground and signal planes (Fig. 4.12). Plotting dielectric constant and signal propagation delay for various NEC materials, including the new material with and without the above hollow structure (Fig. 4.13), shows that 4.4 material behaves normally with signal propagation delay of $7.6 \mathrm{nsec} / \mathrm{m}$, but the hollow structure behaves as if it has dielectric planes. The transmission properties are greatly influenced by the configuration of ground plane and wiring plane open area and signal line channel.
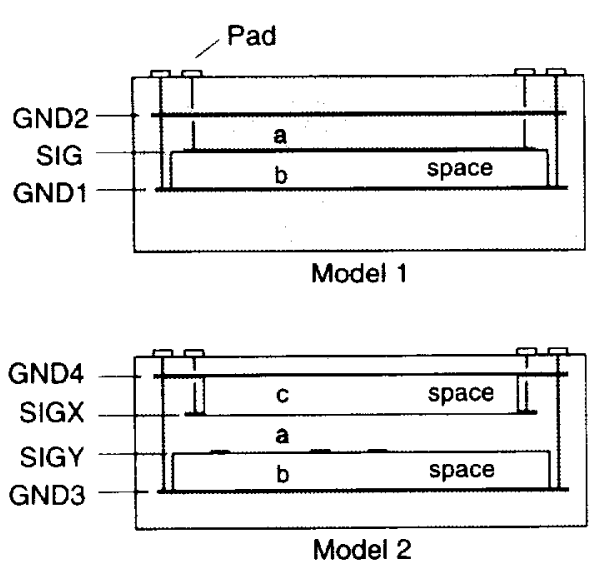

Figure 4.12. Hollow structure in ceramic for improved dielectric constant.

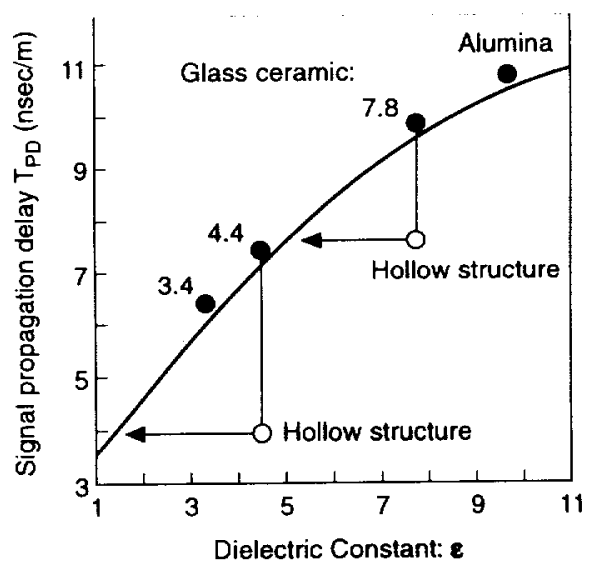

Figure 4.13. Propagation delay versus dielectric constant (NEC). 
As illustrated in Figure 4.14, the rectangular open area seems to give constant overlap area between ground pattern and signal line, thus minimizing the capacitance variation that is typical of conventional square mesh patterns. NEC has applied this new material for a medium-cost, $156 \mathrm{Mb} / \mathrm{s}$ optical inter-connection module. In this application this technology has reduced (1) the number of modules to one from two from previous SMT/PWB technology, (2) the volume size by one-seventh, and (3) the power consumption by one-third. The total size of the final unit is $10 \mathrm{cc}$. NEC expects to use this new ceramic package in its personal computers

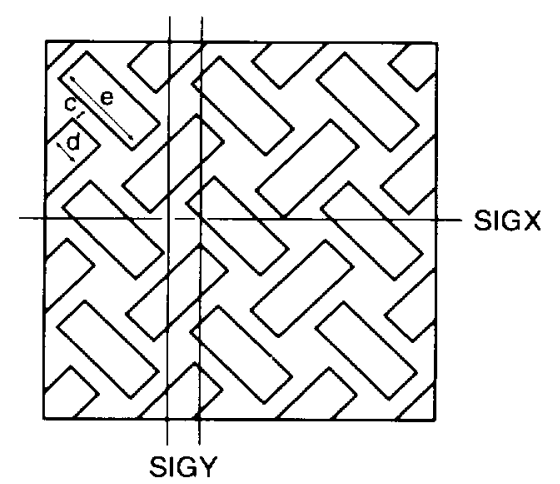

Figure 4.14. Package design improvement. as an interface to the CRT.

Use of aluminum nitride is much more emphasized in Japan than in the United States. Ibiden, Kyocera, NTK, NEC, Toshiba, and Sumitomo Electric are some of the firms that have invested very heavily in developing and producing AIN pin grid arrays, as well as high-thermal-conductivity heat sinks. Ibiden, for example, makes a large substrate by hot pressing to achieve a thermal conductivity of $180 \mathrm{~W} / \mathrm{mk}$. NEC claims to have achieved as high as $200 \mathrm{~W} / \mathrm{mk}$ and has transferred the technology to its subsidiary. The Japanese market for AlN is currently estimated at $\$ 100$ million per year, much less than previously projected. The primary reason for this slow growth has been attributed to the twenty to thirty times higher raw material cost over standard alumina and the one-half to two times higher substrate cost. NEC expects to use AIN for high-performance applications requiring higher thermal conductivity, where the additional cost can be justified.

A new ceramic substrate approach being pursued by Ibiden involves bonding epoxy-glass FR-4 layers to porous ceramic. Such a structure, illustrated in Figure 4.15, improves TCE, dielectric constant, and mechanical strength, and permits direct flip chip bonding.

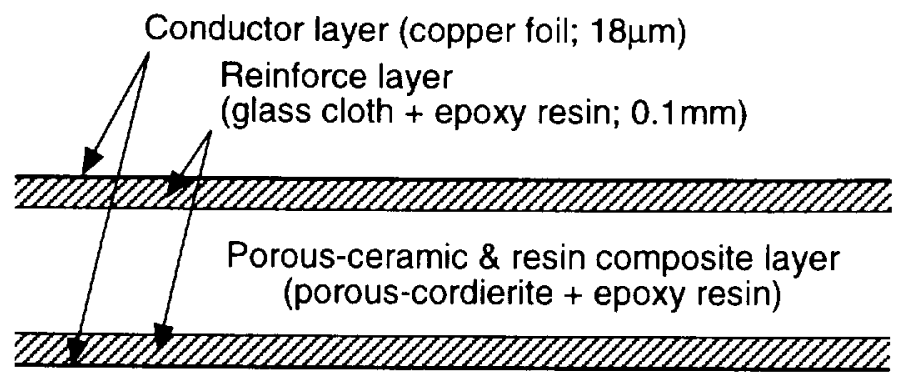

Figure 4.15. Ceracom substrate with low TCE and low dielectric constant (Ibiden). 


\section{PASSIVE COMPONENT TECHNOLOGIES}

Passive components are important contributors to the miniaturization of most electronic products. Passives include capacitors, resistors, piezoelectrics, and coils. Heavy reliance on analog circuitry requires a large number of passive components to be used in consumer products like VCRs, camcorders, and cellular phones. In Hitachi's video camera, for example, there are currently 475 passive components required. Current development plans will reduce that number to 290 , as illustrated in Figure 4.16. Continued miniaturization is expected to reduce power consumption as the number of ICs and passive components are decreased for smaller and lighter products. The miniaturization trend for coils and capacitors is illustrated in Table 4.9.

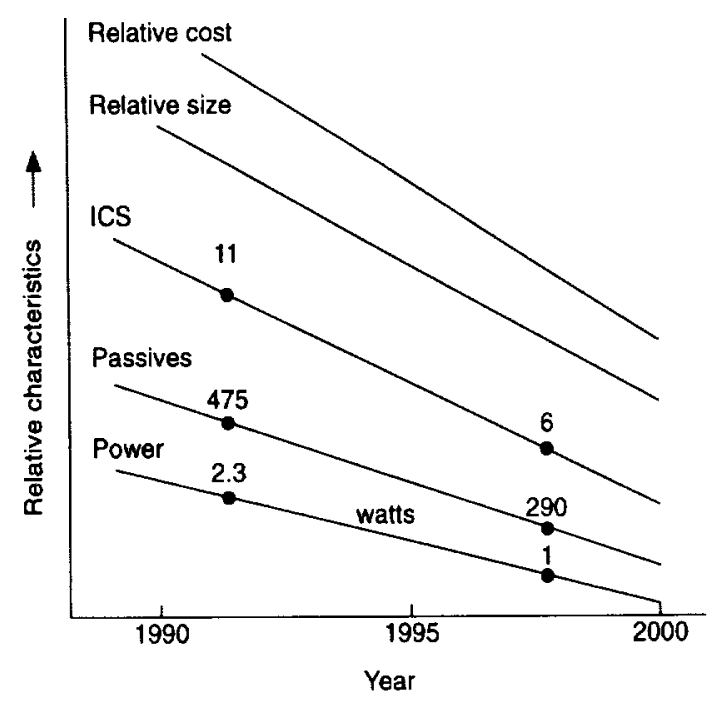

Figure 4.16. Components trend in camcorders (Hitachi).
Table 4.9

Component Miniaturization

\begin{tabular}{|c|c|c|}
\hline Year & Coil Size & $\begin{array}{c}\text { Capacitor } \\
\text { Size }\end{array}$ \\
\hline 1986 & $\begin{array}{l}26 \times 17 \times 10 \mathrm{~mm} \\
\text { alumina thick film } \\
\text { co-axial resonator }\end{array}$ & $\begin{array}{c}3.2 \times 1.6 \\
\mathrm{~mm}\end{array}$ \\
\hline 1990 & $\begin{array}{l}16 \times 12 \times 4.0 \mathrm{~mm} \\
\text { glass-epoxy subst. } \\
\text { co-axial resonator }\end{array}$ & $\begin{array}{c}2.1 \times 1.25 \\
\mathrm{~mm}\end{array}$ \\
\hline 1992 & $\begin{array}{l}10 \times 10 \times 4.0 \mathrm{~mm} \\
\text { multilayer ceramic } \\
\text { triplate resonator }\end{array}$ & $\cdots$ \\
\hline 1993 & $\begin{array}{l}10 \times 7 \times 2.5 \mathrm{~mm} \\
\text { multilayer ceramic } \\
\text { triplate resonator }\end{array}$ & $\begin{array}{c}1.0 \times 0.5 \\
\mathrm{~mm}\end{array}$ \\
\hline 1997 & $\begin{array}{c}7 \times 7 \times 2.5 \mathrm{~mm} \\
\text { multilayer ceramic } \\
\text { triplate resonator }\end{array}$ & $\begin{array}{c}\text { Module } \\
\text { Integration }\end{array}$ \\
\hline
\end{tabular}

As with plastic and ceramic packaging technologies, Japanese firms also lead in passive component technologies. Three Japanese companies, Murata, TDK, and Kyocera (AVX in the United States), account for most of the world market in this industry.

Japanese investments in passive component developments are aimed at continued reduction of cost and size rather than increased integration. Integration was used to achieve miniaturization requirements, but was often considered to be a higher-cost or nextgeneration alternative. The primary $R \& D$ activities pursued by Murata, as an example, include the following: 
- microwave modules for digital cordless phones:

oscillator, mixer, synthesizer developments

- power supplies ( $\mathrm{SW}$ frequency $2 \mathrm{MHz}$ ):

$\mathrm{CAD}$, substrate, transformer, capacitor, package developments

- functional sensor module:

gyro sensor, IR sensor, signal processing developments through technology integration

- capacitor (miniaturization and higher capacitance):

thin-film multilayer, ceramic, reliability, electrode material developments

- filter (for communications):

piezoelectric ceramic products, high ceramics, thin-film process

The JTEC panel was most impressed with the passive component technology and manufacturing capabilities of the Japanese firms visited. Companies like Murata and TDK, for example, have highly automated factories and produce their own in-house equipment to manufacture millions of parts, some the size of poppy seeds, using multilayer metalization and dielectrics.

\section{ADVANCED MULTICHIP PACKAGING DEVELOPMENTS}

Multichip packaging is being developed to meet the demands for higher performance and further miniaturization. These design developments apply array technologies, SMT, and a variety of plastic, ceramic and thin-film materials. Advanced technologies like BGAs and MCMs have historically been limited to applications in high-performance products like supercomputers. Today, the Japanese are moving these technologies into lower-cost products through the use of MCM and chip-on-board (COB) applications using BGA connections for assembly and SMT mass production equipment. As shown in Figure 4.17, Japanese industry is pursuing multichip packaging technologies, but with applications using printed wiring and ceramic technology. Such integration of low-cost production is consistent with Japan's approach for low-cost product design and production, which encompasses three major issues.

The first issue of integrated low-cost production design is that the silicon efficiency of MCM designs must be improved in terms of circuits or chips packaged per unit area. This goal can be accomplished by packaging ICs onto very-thin, compact, and lightweight microcarriers using area array connections, as shown in Figure 4.18.

BGA provides advanced connector technology for use with SMT technologies. Large vertically integrated companies in Japan such as Hitachi and NEC have experience in multichip packaging using this microcarrier approach. Hitachi has used BGA for the central processing unit of its latest supercomputer and is confident in its quality. It has 
achieved silicon packaging efficiency in excess of $40 \%$, which is about five times more efficient than the normal SMT approach. This technology is now being developed for applications in cost-sensitive consumer electronics products.

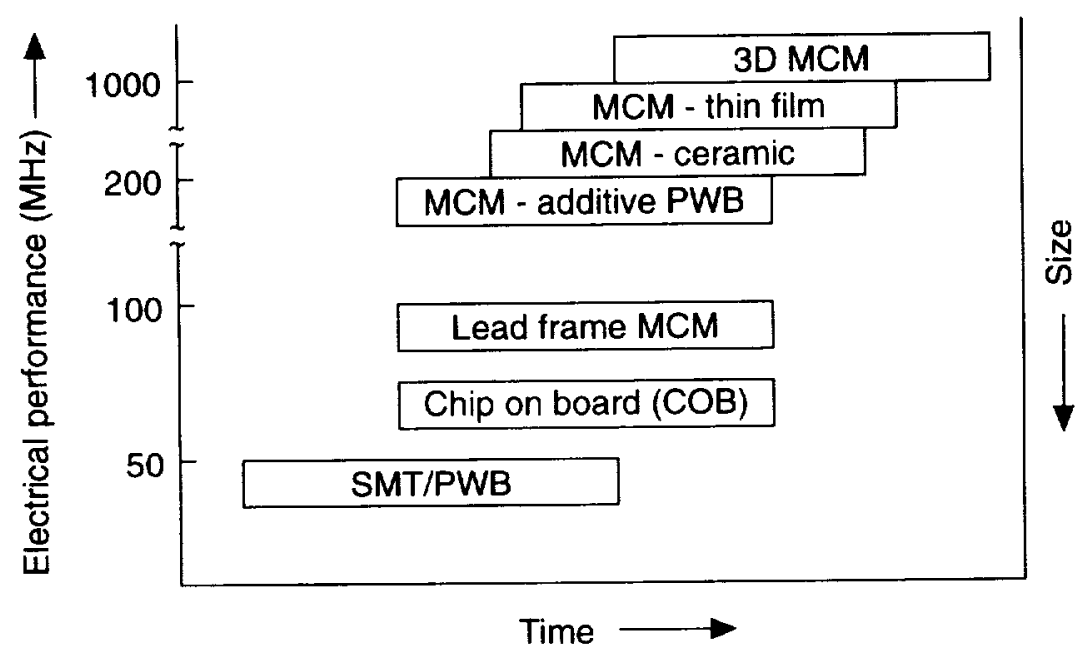

Figure 4.17. Overall Japanese packaging strategy.

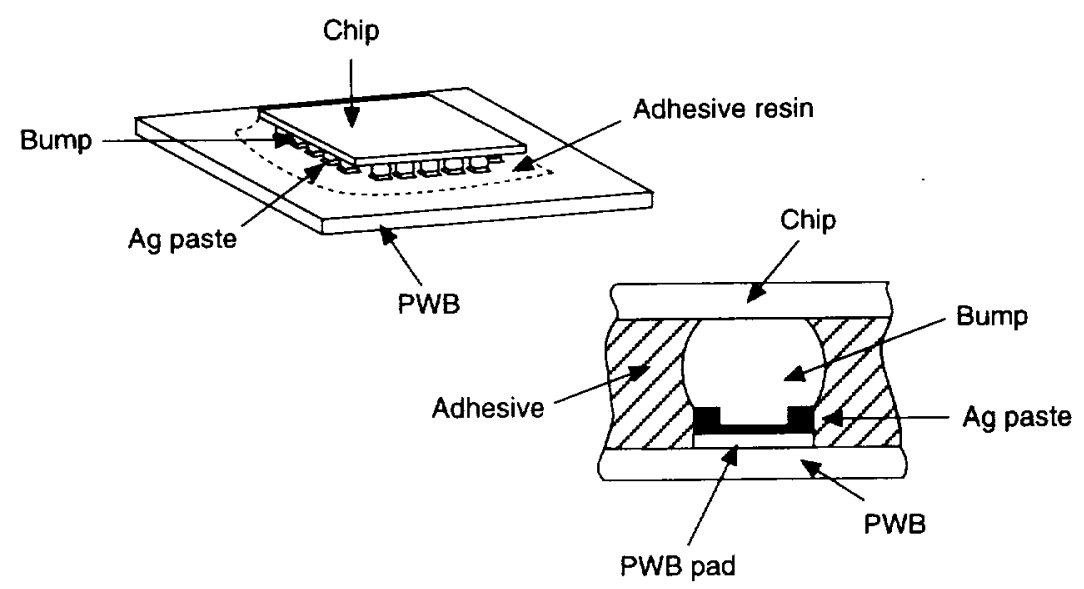

Figure 4.18. Flip chip processing conductive adhesive (Fujitsu).

The second issue of integrated low-cost production design is that to exploit current wirebond, PWB, and SMT investments, many Japanese firms wire-bond chips onto a small MCM-type leadframe, as shown in Figure 4.19. This design is similar to ceramic and plastic 
packages using substrate materials, PWBs, and leadframes attached to QFP forms; the only difference is that each QFP contains two or more chips, typically 2-8 chips. This approach is referred to as QFP-MCM. In the United States, Motorola is offering $28 \mathrm{~mm}$ QFP-MCMs with 128, 160, or 208 leads and $40 \mathrm{~mm}$ packages with 232 or 304 leads. The lead pitch is typically $0.5 \mathrm{~mm}$. Japanese companies exploiting this technology include Kyocera, NTK, and Sumitomo in ceramics, and Ibiden, Hitachi, and Oki in plastics.

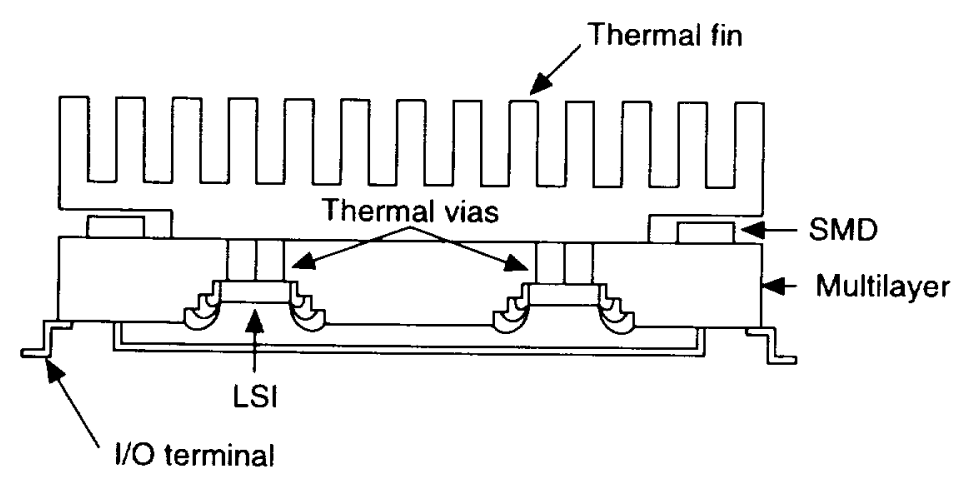

Figure 4.19. QFP-MCM in ceramic (Oki, Kyocera).

The major advantage of QFP-MCM is its lower cost and ease of assembly with existing SMT manufacturing equipment. The MCM system, however, is expected to cost between $50 \%$ and $100 \%$ more than the single-chip QFP solution. However, QFP-MCMs are expected to meet demands for smaller size, better performance, and reduction in the number of system-level parts. Another advantage of QFP-MCM is that it needs no bumping technology. QFP-MCMs are typically made in 4 to 10 layers, each containing copper lines that are $75 \mu \mathrm{m}$ wide, spaced $75 \mu \mathrm{m}$ apart. The smallest drilled hole is 12 mils $(300 \mu \mathrm{m})$. Power dissipation depends on the leadframe material and package design, but it is generally limited to 5 watts using PWB technology or ten times higher using ceramic technology. Part of the increased production of MCM components comes from Japanese firms' application of tape automated bonding (TAB) technologies for more accurate chip placement in the production of MCMs, rather than application of typical lower-cost wire bonding technologies.

The third issue of integrated low-cost production design is that three MCM developments in Japan are similar to ones in the United States: MCM-L (laminated PWB), MCM-C (ceramic), and MCM-D (thin-film dielectrics). These three generic technologies have already been applied in Japanese products from consumer electronics to supercomputers. The thin-film MCM-D has been applied by NEC with up to seven layers on a large $225 \mathrm{~mm}$ ceramic substrate, and by Hitachi on a microcarrier/interposer. Since these technologies are very expensive to use, efforts are currently underway by NEC, Hitachi, Fujitsu, Oki, NTK, Kyocera, Toshiba, and others to reduce the application cost. 
Approaches to cost reduction include (1) development of lower-cost materials such as lowcost photosensitive materials, (2) development of large-area processing, as practiced in the fabrication of displays, (3) application of large-area lithography, and (4) application of lowcost metalization processes as practiced in PWB fabrication. Toray, Asahi Chemical, Sumitomo Bakelite, Hitachi Chemical, and Nitto Denko are aggressively pursuing polymeric developments, aimed at polyimides with low thermal expansion, very good mechanical properties, low water absorption, and good adhesion to ceramics and metals. The Asahi polymer, based on a modified BPDA-PDA chemistry, seems to meet all the required properties, including photosensitivity to $\mathrm{g}$ - and $\mathrm{i}$-lines with $10 \mu \mathrm{m}$ vias in $10 \mu \mathrm{m}$ cured film. The resulting thermal expansion mismatch stress on a silicon wafer is about $30 \mathrm{MPa}$, about half that of conventional polymers. The cost per kilogram is around $\$ 600$. Nitto Denko seems to have made further cost improvements through its novel-blended approach involving polyimide plus acrylic monomers and photo-initiators. The properties and relative costs of such dielectrics are listed in Table 4.10.

Table 4.10

\section{Nitto Denko's Blend Polymer Dielectric}

\begin{tabular}{||l|l||}
\hline Parameter & Specification \\
\hline \hline Sensitivity $\left(\mathrm{mJ} / \mathrm{cm}^{2}\right)$ & 250 \\
\hline Thermal stability $\left({ }^{\circ} \mathrm{C}\right)$ & 370 \\
\hline Dielectric constant & 3 to 4 \\
\hline Adhesion to conductor & $>$ double* \\
\hline Stress & 60 to $70 \% *$ \\
\hline Materials cost & $1.5^{*}$ \\
\hline \hline
\end{tabular}

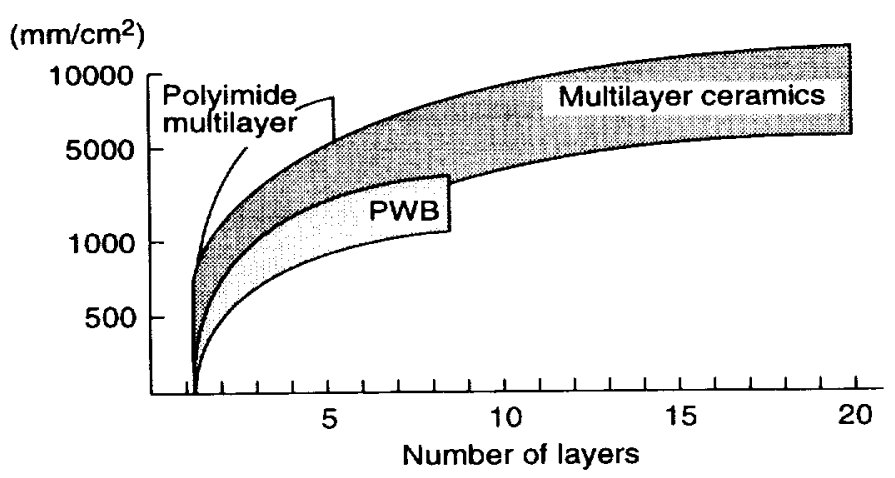

Figure 4.20. Wiring density comparison between PWB/ceramic (Kyocera).
MCM-C is generally considered in Japan to be more cost-effective than thin film and provides a system-level solution for workstations based on superior wiring density, as illustrated in Figure 4.20. Toshiba, Hitachi, Fujitsu, NEC, and Oki are planning to apply this technology because of advantages like lower cost, lower electrical resistance, higher thermal dissipation, and higher reliability over $\mathrm{MCM}-\mathrm{L}$ and MCM-D designs. 
The primary advantage of ceramic over PWB (previously shown in Figure 4.11) is in the number of lines/vias per $100 \mathrm{mil}$ channel, ceramic providing as many as 9 lines, each $100 \mu \mathrm{m}$ wide, compared with 5 lines in PWB. But the Japanese are driving both technologies to much higher densities and to much lower costs. The technology improvements in PWB, however, come as process improvements as opposed to the development of parallel co-fire ceramic processes. Low-cost applications in VCRs and camcorders are beginning to appear using ceramic technology. Panasonic, for example, is already using its low-temperature ceramic carrier (LTCC) components in peripheral tape memory systems and is expected to further apply it in cellular, automotive, camcorder, and computer applications. By using the LTCC as a lead-array hybrid $(1.0 \mathrm{~mm}$ pitch) with through-hole mounting onto a PWB, Panasonic found it to be less expensive than the typical PWB approach. The embedded capacitors made of $\mathrm{Pb}\left(\mathrm{Mg}_{1 / 3} \mathrm{Nb}_{2 / 3}\right) \mathrm{O}_{3}-\mathrm{PbTiO} \mathrm{O}_{3}-\mathrm{PbO}$ provide a capacitance of $30 \mathrm{nf} / \mathrm{cm}^{2}$. Canon camcorders have also used LTCC, presumably manufactured by Kyocera.

MCMs based on PWB technology are expected to be the most dominant because of prior investments and the existing infrastructure in Japan. The PWB base is being enhanced by (1) new materials, such as aramid fiber, BT resin, maleimide styryl, and photosensitive epoxy, (2) new processes such as additive plate and laser/photo vias, and (3) large-area, low-cost processing in not-so-clean facilities. These enhancements are in addition to those being pursued in conventional subtractive processes. The chip assembly to form multichip modules has already been practiced by direct wire bonding, TAB, and flip chip bonding of bare die. The wire bonding experience comes from consumer product $\mathrm{COB}$, and TAB is employed in performance computers and consumer products. Flip chip is a recent introduction by Hitachi in its mainframes, and by IBM (Japan) in its PC products, wherein bumped chip is solder-bonded to PWB using eutectic solder. In addition, Fujitsu is exploring the same with conductive epoxy, eliminating both $\mathrm{Pb}$ solder and flux. In 1994, Mitsubishi's new cellular telephone used advanced flip chip assembly techniques.

\section{PRINTED WIRING BOARD TECHNOLOGIES}

Japan is enhancing printed wiring board (PWB) technology to meet market demands for low-cost, thin, and lightweight consumer products. PWB enhancements fall into several categories:

- Thin and fine-line conventional subtractive etching process.

- Low-cost, fine line, thin film, additive process. Shown in Figure 4.21, this is a new sequential process involving deposition of photosensitive polymer or epoxy, formation of via holes by large-area photo exposure, and subsequent chemical etching and metalization by catalytic chemical seeding and electroless plating. The advantages of this process are many, including pattern shape, pattern thickness control, pattern width control, mounting reliability, and most importantly, small via size. Ibiden compares the subtractive and additive processes in Figure 4.21. 


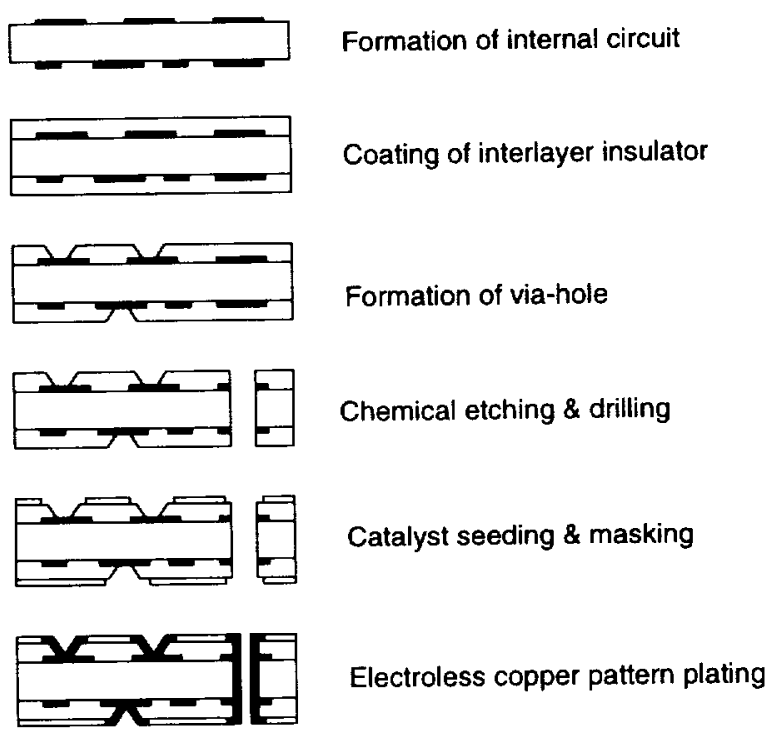

Figure 4.21. Low-cost fine line thin film process.

- Minimization of solder bridge by using dry film. This is shown in Figure 4.22.

- New materials. Examples include aramid-based laminates with low thermal expansion, good electromigration resistance, high glass transition temperature, and excellent processability. Another material is ceracom, a combination of porous ceramic laminated with glass and epoxy resin to form very low TCE boards suitable for direct chip bonding (see Fig. 4.15).

- Direct bonding of chip. This may be by COB (wire bonding), tape on board (TAB), and flip chip on board to the printed wiring board with appropriate low-stress encapsulants (see Fig. 4.19).

Japan has invested in a variety of PWB materials that include FR-4, polyimide-glass, maleimide styryl, BT resin, and a new aramid-based laminate consisting of aramid-based paper as a reinforcement in a matrix of a new epoxy resin by Teijin Limited. The superior properties of this aramid-based board for potential MCM applications include low TCE $\left(6-16 \mathrm{PPM} /{ }^{\circ} \mathrm{C}\right)$, very high electrical resistance, very low impurities in the aramid fiber, and processability with fine via holes.

The shape and accuracy of conductor patterns, as well as the mounting reliability of solder bridging, as illustrated in Figure 4.22, compares with the standard subtractive process. Table 4.11 indicates the dielectric and metal ground rules, as well as the drilled and photolith dimensions resulting in fine-line, thin-film structures on both sides of a PWB. The structure of the additive process as practiced by IBM (Japan) and Ibiden is illustrated in Figure 4.23, using two layers on each side of the PWB. 


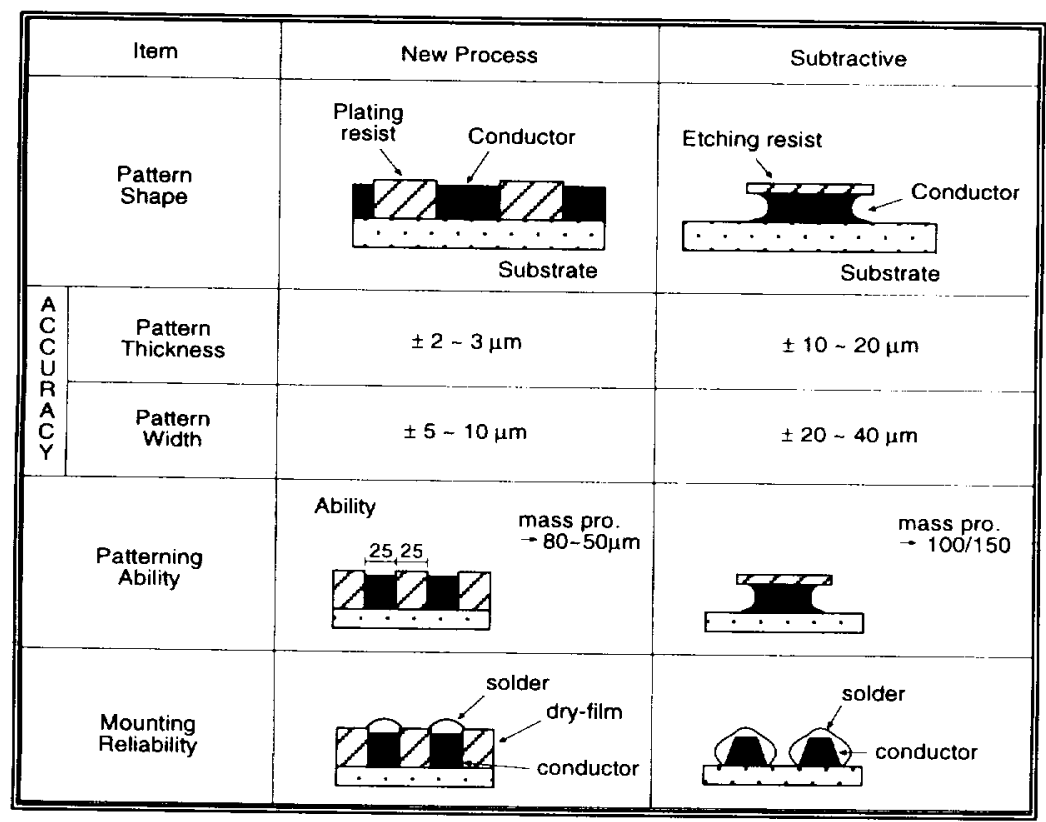

Figure 4.22. Shape and accuracy of conductor pattern by additive process (Ibiden).

Table 4.11

Characteristics Of Additive-Plated PWB

\begin{tabular}{|c|c|c|c|}
\hline \multicolumn{2}{|c|}{$\begin{array}{l}\text { Number of Layers } \\
\text { Thickness } \\
\text { Insular Thickness } \\
\text { Conductor Thickness } \\
\text { Minimum Wiring Width/Space/Pitch } \\
\text { Minimum Via } \phi\end{array}$} & \multicolumn{2}{|c|}{$\begin{array}{l}6 \\
0.8 \mathrm{~mm} \\
50 \mu \mathrm{m} \\
15 \mu \mathrm{m} \\
50 \mu \mathrm{m} / 50 \mu \mathrm{m} / 100 \mu \mathrm{m} \\
100 \mu \mathrm{m}\end{array}$} \\
\hline & Drill $\phi$ & Land $\phi$ & Note \\
\hline $\begin{array}{l}\text { 1. Inner Via (Drill) }(\mathrm{mm}) \\
\text { 2. Blind TH (Photo) }(\mathrm{mm}) \\
\text { 3. Through Hole (Drill) }(\mathrm{mm})\end{array}$ & $\begin{array}{l}\phi 0.2 \\
\phi 0.3 \\
\phi 0.5 \\
\end{array}$ & $\begin{array}{l}\phi 0.4 \\
\phi 0.5 \\
\phi 0.7 \\
\end{array}$ & $\begin{array}{l}\mathrm{t} 0.4 \\
\mathrm{t} 0.6 \\
\mathrm{t} 1.0 \\
\end{array}$ \\
\hline
\end{tabular}

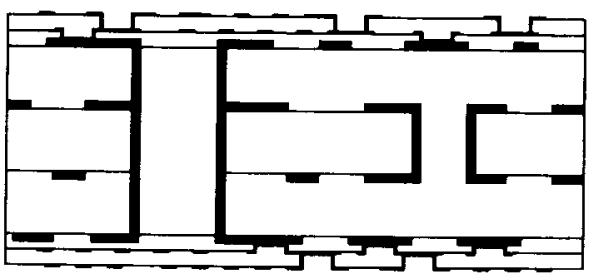

Build-up

Lamination

multilayer

Build-up

Figure 4.23. Additive process enhancement (IBM Japan, Ibiden). 


\section{Conductive Adhesives}

Conductive adhesives are alternatives to solder and braze connections in chip and packaging assemblies. The concept shown in Figure 4.24 allows electrical connection to be made as a result of the $\mathrm{z}$-axis alignment of particles. Because of low cost and process simplicity, the technology is currently used for LCD connections. Conductive adhesives are being explored and applied by almost all major Japanese consumer product companies. The materials typically consist of thermoplastic and thermoset materials that provide adhesion to surrounding metallic particles, typically $\mathrm{Ag}$ solder; these are then applied as paste.

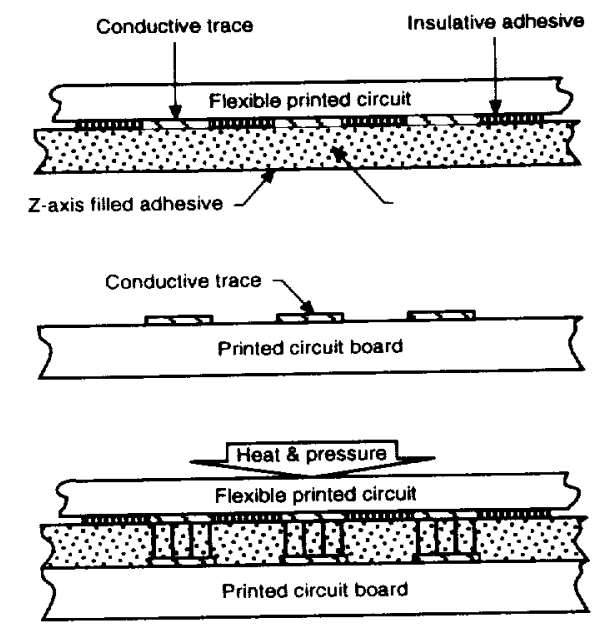

Figure 4.24. Anisotropic conductive conductor system.

The conductive adhesive technology that includes a specialty technology referred to as anisotropic adhesive connection (ACA) is ideally suited for low-cost, lightweight, and lowprofile applications. Examples of the use of this technology include (1) the connection between an LCD driver IC and the display panel, as in Fujitsu's notebook computer, and (2) the connection between a bumped chip and a PWB used by Fujitsu (see Fig. 4.19). A variation of the conductive adhesive used by Sharp in display modules uses spherical polymeric materials coated with nickel and gold, presumably by electroless plating. Such a system provides stress relief in the conductive adhesive joint due to the low modulus of core organic particles, yet it provides the required electrical conduction.

\section{Flex Circuits}

Japan places very high priority on flex film technology, which it has used in cameras, connectors, and video games. It has also used this technology to connect ICs to LCD displays. Its advantages include 3-dimensional conformal nature, light weight, and thin film. There are several examples of direct chip on flex, as used in the wrist pager, making packages even more compact. Sharp is currently developing multilayer flex film for future consumer product applications.

\section{CHIP ASSEMBLY TECHNOLOGIES}

Japan is practicing chip assembly in more ways than does the United States. It is pushing wire bonding to its limits and is highly successful in the use of TAB, having applied it from consumer to supercomputer packaging. The Japanese have applied and continue to apply flip chip both with solder and with conductive adhesive technologies. In addition, they are continuing to push chip on board, not only by wire bonding the chip to the board, but also by TAB bonding to board and flip chip solder bonding to organic board. In a new development Fujitsu is offering its BIT system for notebook computer applications. 
Table 4.12 demonstrates Oki Electric's development plan, typical of most large Japanese companies, for all three technologies - wire bond, tape automated bonding, and flip chip. It sets the development goals for wire bond by ball bond and wedge bond technologies at a pitch of $50 \mu \mathrm{m}$ and for $\mathrm{TAB}$ at a pitch of $75 \mu \mathrm{m}$. Japan expects to push wire bond up to $1200 \mathrm{I} / \mathrm{Os}$ on a $20 \times 20 \mathrm{~mm}$ chip using a staggered pin configuration.

Table 4.12

Japanese Chip Assembly Plan (Oki)

\begin{tabular}{|c|c|c|c|c|}
\hline & & 1993 & 1995 & 1997 \\
\hline \multirow{3}{*}{ W/B } & $\begin{array}{l}\text { LSI Chip } \\
\text { Size }(\mathrm{mm}) / \mathrm{L} / \mathrm{O} \text { count }\end{array}$ & $15 \times 15 / 700$ & $20 \times 20 / 1000$ & $20 \times 20 / 1200$ \\
\hline & $\begin{array}{l}\text { Wire Pitch } \\
\text { Ball bond }(\mu \mathrm{m})\end{array}$ & $\begin{array}{c}105 \\
\text { (Line) } \\
\end{array}$ & $\begin{array}{c}70 \\
\text { (Staggered) }\end{array}$ & $\begin{array}{c}60 \\
\text { (Staggered) }\end{array}$ \\
\hline & Wedge bond $(\mu \mathrm{m})$ & 100 & 65 & 55 \\
\hline \multirow{3}{*}{ TAB } & $\begin{array}{l}\text { LSI Chip } \\
\text { Size }(\mathrm{mm}) / \mathrm{VO} \text { count } \\
\end{array}$ & $15 \times 15 / 500$ & $20 \times 20 / 1000$ & -- \\
\hline & $\begin{array}{l}\text { Lead Pitch } \\
\text { Inner bond }(\mu \mathrm{m}) \\
\end{array}$ & $\begin{array}{c}100 \\
\text { (Wire bump) } \\
\end{array}$ & $\begin{array}{c}75 \\
\text { (Plating bump) }\end{array}$ & --- \\
\hline & Outer Bond $(\mu \mathrm{m})$ & 100 & 75 & -- \\
\hline \multirow{3}{*}{ FC } & $\begin{array}{l}\text { LSI Chip } \\
\text { Size (mm)/ I/O count }\end{array}$ & $15 \times 15 / 900$ & $15 \times 15 / 1000$ & --- \\
\hline & Bump Pitch $(\mu \mathrm{m})$ & $\begin{array}{c}250 \\
\text { (Grid) } \\
\end{array}$ & $\begin{array}{c}125 \\
\text { (Grid) } \\
\end{array}$ & --- \\
\hline & Bump Diameter $(\mu \mathrm{m})$ & 130 & 75 & \\
\hline
\end{tabular}

The progress and trend in TAB listed in Table 4.13 show two or more layers with an inner lead bonding pitch of $60 \mu \mathrm{m}$ and an outer lead bonding pitch of $90 \mu \mathrm{m}$. On a $28 \mathrm{~mm}$ size chip, these leads provide in excess of $1100 \mathrm{~L} / \mathrm{Os}$. Various advancements in TAB technology are being pursued by such Japanese companies as Shinko-Denshi, NEC, Fujimitso, Mitsui-Kinzoku, Oki, and Nitto Denko.

One particular enhancement of TAB being pursued by Nitto Denko is illustrated in Figure 4.25 , comparing the new two-layer direct copper bonding process with a conventional three-layer process. The new process coats polyimide onto copper, the opposite of the $3 \mathrm{M}$ process in the United States that coats copper on Kapton or other polyimides by electroplating. The advantages of this new process, shown in Table 4.14, include high heat resistance, low moisture absorption by proper selection of polyimide, and better adhesion. There are other advantages to using this new process: (1) a very high aspect ratio $25 \mu \mathrm{m}$ diameter holes in a $50 \mu \mathrm{m}$ thick film; (2) large area processing $(300 \times 300 \mathrm{~mm})$; and (3) complete wiring patterns (both vias and lines). Nitto is also applying this technology for burn-in electrical testing, as illustrated in Figure 4.26. 
Table 4.13

Japanese TAB Package (TCP) Characteristics (Oki)

\begin{tabular}{|c|c|c|c|c|c|}
\hline & & 1990 & 1993 & 1996 & 1999 \\
\hline \multirow{4}{*}{ TAB Tape } & Signal Layer & 1 Layer & 1 Layer & 2 Layer & 2 Layer \\
\hline & Max. Tape Width & $35 \mathrm{~mm}$ & $70 \mathrm{~mm}$ & $70 \mathrm{~mm}$ & $70 \mathrm{~mm}$ \\
\hline & Cu Thickness Min. & $35 \mu \mathrm{m}$ & $25 \mu \mathrm{m}$ & $18 \mu \mathrm{m}$ & $18 \mu \mathrm{m}$ \\
\hline & Plating & \multicolumn{4}{|c|}{ Tin, $\mathrm{Pb} / \mathrm{Sn}$ Solder, Gold } \\
\hline \multirow{3}{*}{ Min. Pattern } & Inner Lead Pitch & $100 \mu \mathrm{m}$ & $80 \mu \mathrm{m}$ & $60 \mu \mathrm{m}$ & $60 \mu \mathrm{m}$ \\
\hline & Outer Lead Pitch & $200 \mu \mathrm{m}$ & $120 \mu \mathrm{m}$ & $90 \mu \mathrm{m}$ & $90 \mu \mathrm{m}$ \\
\hline & Pattern Pitch & $100 \mu \mathrm{m}$ & $80 \mu \mathrm{m}$ & $60 \mu \mathrm{m}$ & $60 \mu \mathrm{m}$ \\
\hline \multicolumn{2}{|c|}{ Max. Height } & $1.0 \mathrm{~mm}$ & $0.8 \mathrm{~mm}$ & $0.7 \mathrm{~mm}$ & $0.6 \mathrm{~mm}$ \\
\hline \multicolumn{2}{|c|}{28 Max. Pin Count } & $520 \mathrm{p}$ & $864 p$ & $1152 \mathrm{p}$ & $1152 \mathrm{p}$ \\
\hline
\end{tabular}

Table 4.14

Nitto Process

\begin{tabular}{|c|}
\hline 2 layer substrate \\
\hline Polyimide \\
\hline Copper \\
\hline
\end{tabular}

Others

\begin{tabular}{|c|}
\hline 3 layer substrate \\
\hline Polyimide \\
\hline Adhesive \\
\hline Copper \\
\hline
\end{tabular}

Unique features:

- 2 layer substrate $\rightarrow$ no adhesive layer

- Polyimide $\rightarrow$ synthesized by Nitto

- Polyimide onto Cu by coating (Nitto)

- Cu onto polymide by electroplating (US)

Figure 4.25. Nitto process for TAB.

Advantages of the Nitto Process

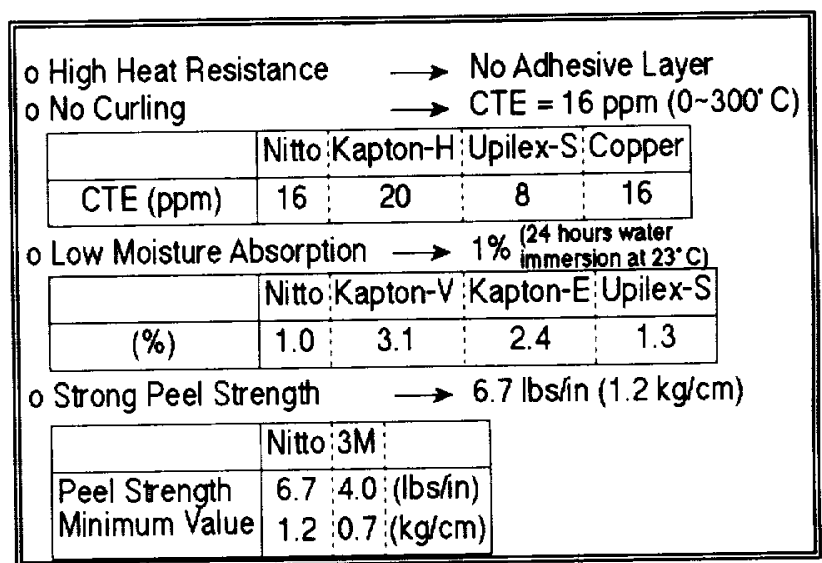

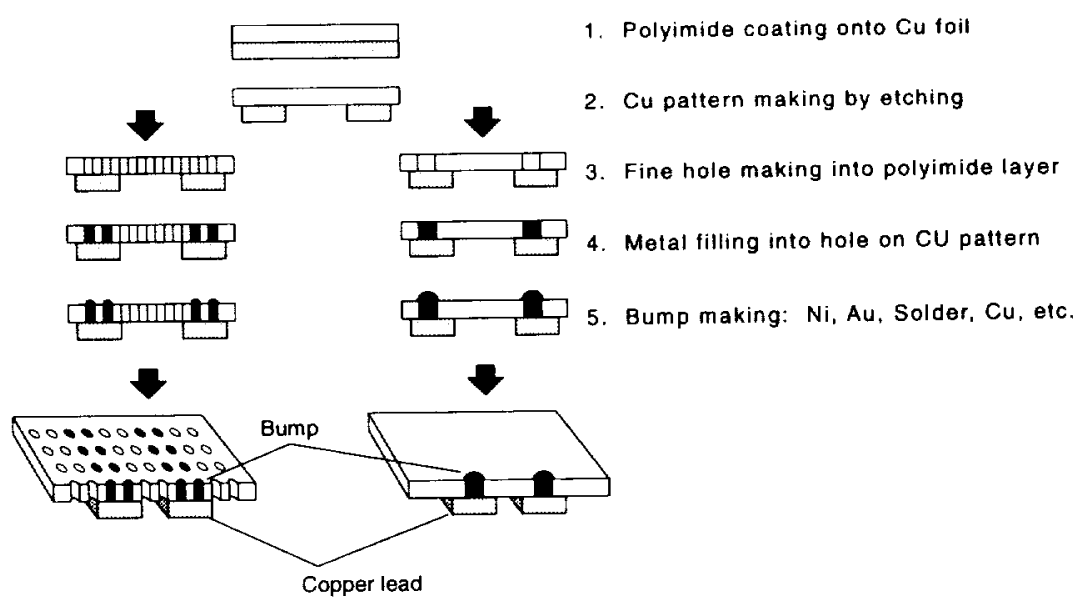

Figure 4.26. Nitto bump making process. 
Flip chip technology is being extensively studied by almost all major Japanese firms and is already used in products by Hitachi and IBM (Japan). The Hitachi flip chip, together with microcarrier BGA assembly to next-level package (mullite glass-ceramic), is illustrated in Figure 4.27. The microcarrier, which is only bigger than the chip itself by about $2 \mathrm{~mm}$, is a single-chip carrier fabricated with seven-layer mullite ceramic and five levels of polyimidealuminum thin-film technology. Flip chip enhancements being pursued by Japanese electronic companies generally consist of one of two approaches - solder bonding (including $\mathrm{Pb}-\mathrm{Sn}, \mathrm{Pb}-\mathrm{In}$ ), and conductor adhesive bonding. Bump technology itself, like Fujitsu's bump integration technology (BIT), is generating considerable interest. One example is illustrated in Figure 4.28 using thin-film and electroplating processes. In contrast, the Germans are pursuing electroless-plate bumping, while the British are trying gold ball bumping by wire-bonding tools.

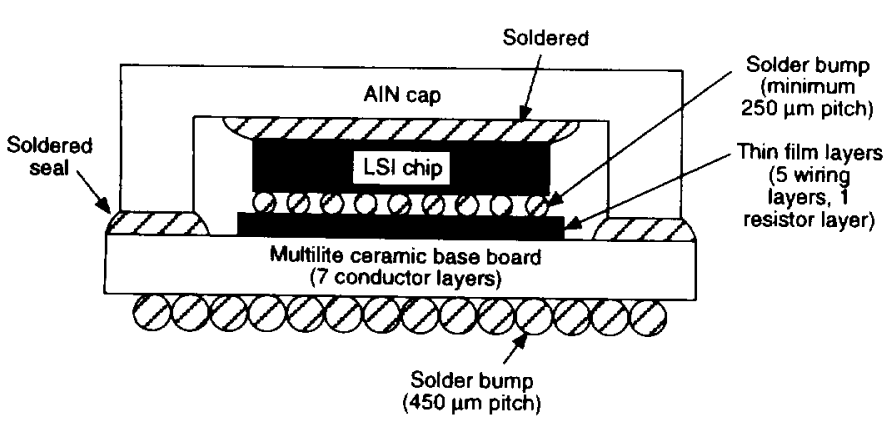

Figure 4.27. Microprocessor carrier (BGA) for LSI (Hitachi).
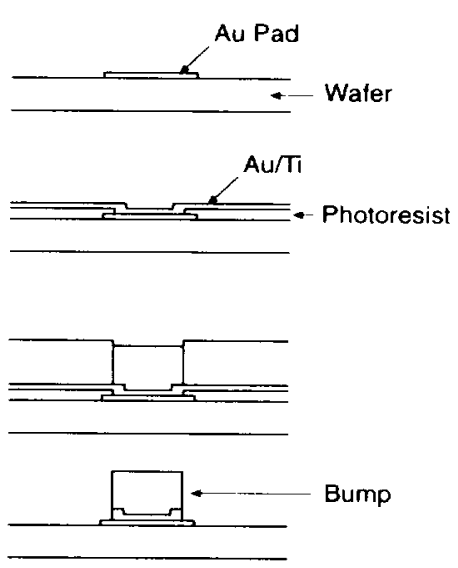

Figure 4.28. Bump fabrication process (Sharp).

The flip chip bonding receiving the greatest interest in Japan is the technology IBM (Japan) pioneered as an extension of IBM (U.S.) flip chip technology developed three decades ago. It involves direct bonding of a bumped chip to a PWB by the use of low- temperature solder that is hot-injection-deposited onto PWB through a mask. The challenge here is to develop a thermally compatible encapsulant to reduce the strain on the solder joint arising from the great mismatch in thermal expansions between PWB (17 PPM) and chip (3 PPM).

Figure 4.29 illustrates a tenfold strain reduction when the encapsulant is used between the PWB and the chip. This discovery has major implications for the Japanese packaging industry, particularly for consumer electronics, as it allows Japanese investments in PWB to be incrementally improved over the next decade. Figure 4.30 shows the eutectic solder to be more effective than high- $\mathrm{Pb}$ solder $(95 / 5)$ in achieving the desired fatigue life.

Japanese manufacturers have used and continue to use chip-on-board technology using wire bond to PWB. 


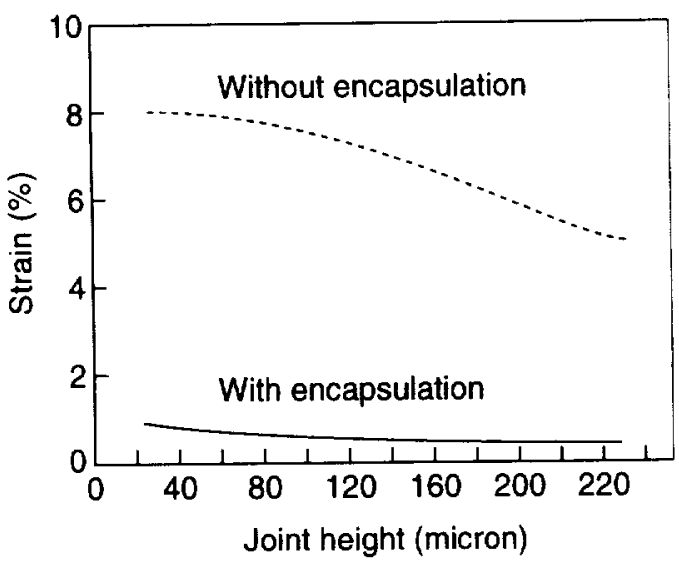

Figure 4.29. Effects of encapsulation on strain in solder (IBM Japan).

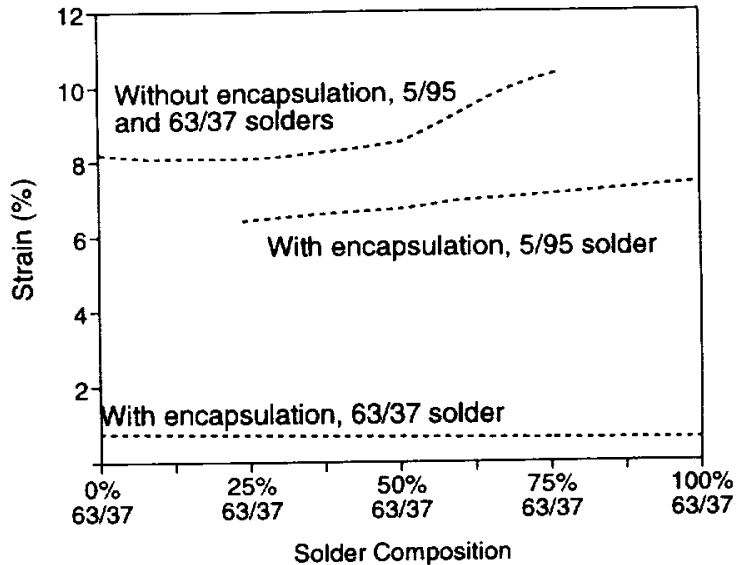

Figure 4.30. Effects of encapsulation and solder composition on strain in solder (IBM Japan).

\section{PACKAGE ASSEMBLY TECHNOLOGIES}

Package assembly involves attaching components to the next-level assembly, usually printed wiring boards. Assembly includes active plastic and ceramic components containing logic and memory chips as well as nonactive components like capacitors, resistors, and inductors. The assembly itself involves either surface mount or pin-throughhole (PTH) attachment. PTH is expensive, space-consuming, and heavy compared to SMT. Given the need for both low cost and portability in consumer products, Japan has invested very heavily in and has continually improved the technology to achieve assembly densities of 20 components $/ \mathrm{cm}^{2}$ as in Sony's Video TR-5, based on $0.5 \mathrm{~mm}$ QFP pitch and passive component sizes of $1.0 \times 0.5 \mathrm{~mm}$. This trend in increasing density is illustrated in Figure 4.31 for notebooks, palmtops, cellular phones, organizers, and camcorders. Assembly density in Japan is expected to reach 50 components $/ \mathrm{cm}^{2}$ by the year 2000 .

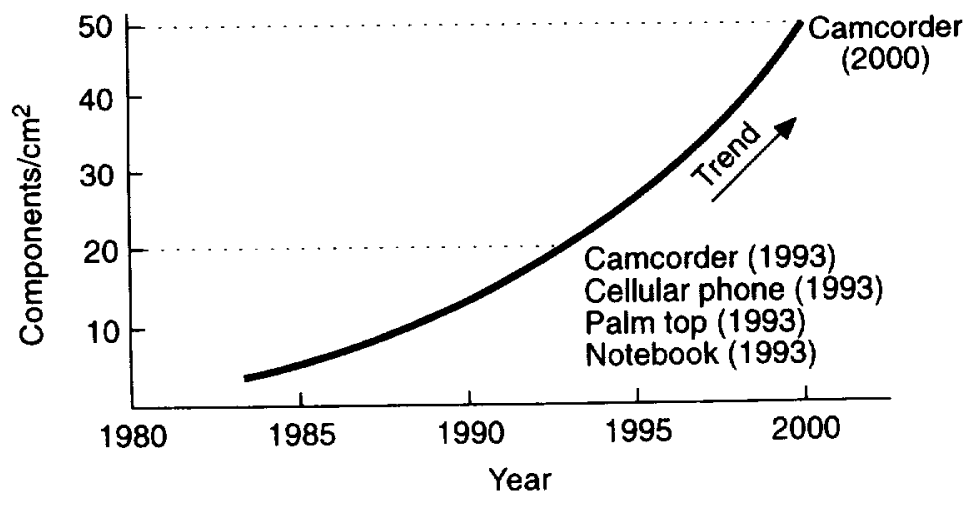

Figure 4.31. Japanese consumer product component density trend (Sony). 
Consumer products require thin and lightweight packaging. Plastic packages such as QFP that are surface-mounted onto PWB have effectively met consumer product requirements. The Japanese vision of next-generation products requires packages that are smaller and cheaper than in the past, roughly $50 \%$ smaller for each new generation. Given Japan's past investments in PWB and SMT technologies, and given increased global cost-competitive pressures, Japan is expected to pursue the use of plastic packages to the ultimate limit. The ultimate limit accepted by Japan currently is $0.15 \mathrm{~mm}$ leadframe pitch, giving rise to 800 pins in $30 \mathrm{~mm}^{2}$ and 1000 pins in $38 \mathrm{~mm}^{2}$ sizes.

The continued use of P-QFP beyond the current $0.4 \mathrm{~mm}$ pitch toward $0.15 \mathrm{~mm}$ pitch, however, requires major enhancements in SMT pick and placement tools, solder deposition technologies, reflow tools and technologies, inspection, solder repair for opens and shorts, and electromigration resistance of both the plastic package and the printed wiring board. Contrary to what U.S. companies might expect, Japanese industry will incrementally enhance each of these to a level that will guarantee high yield and high reliability. This conclusion is supported by (1) Sony's advancements in factory automation and (2) Oki's single-PPM-defect-soldering systems. These systems and processes have lowered assembly defects to less than 20 PPM, as shown in Figure 4.32. Sony's precision robots have improved placement repeatability to $0.01 \mathrm{~mm}$ from $0.05 \mathrm{~mm}$ during the last six years. Matsushita's new SMT machine has 11 placement heads with $0.01 \mathrm{~mm}$ repeatability. Toshiba's advanced TAB equipment can place $0.2 \mathrm{~mm}$ pitch parts using $C C D$ vision, since pitch size has reached the limits of human vision.

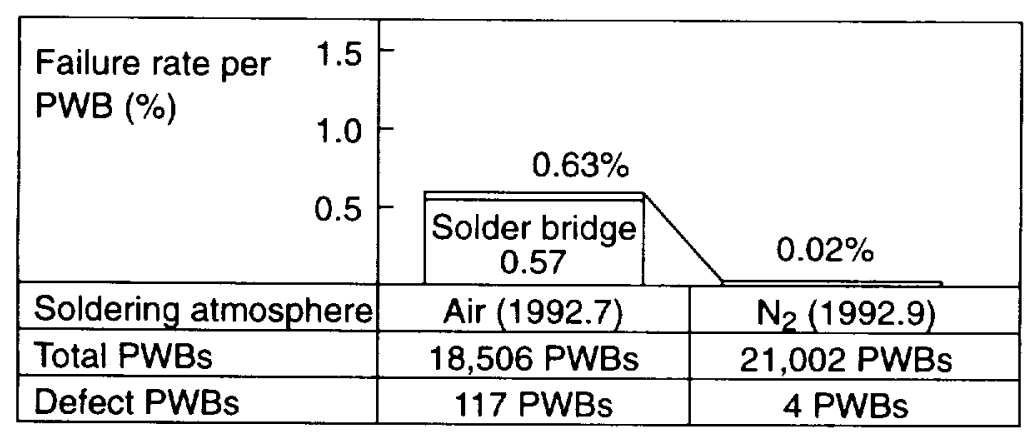

Figure 4.32. Soldering defect improvement achieved at Oki.

With increased miniaturization, soldering technologies continue to evolve. For example, Oki's single PPM defect technology includes developments in the following:

- new wave soldering machine for zero defects

- nitrogen flow soldering process technology

- rheology and printability of solder paste

- inspection technique for solder paste printability and printing parameter optimization

- development of an automatic solder-joint inspection system 
Figure 4.33 illustrates the general trend in soldering techniques that the Japanese microelectronics industry is expected to follow, shifting from reflow to local soldering techniques in order to meet ultrafine pitch assembly requirements.

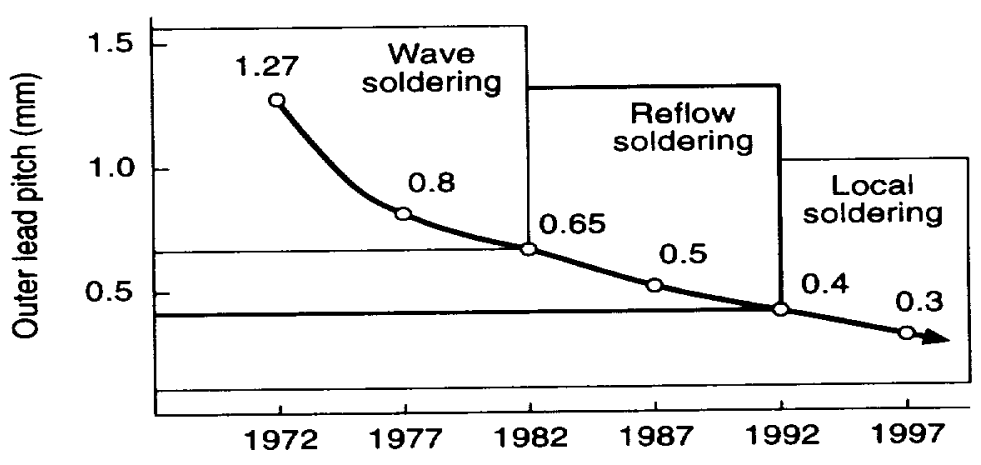

Figure 4.33. Soldering technology trend in Japan (Hitachi).

\section{FUTURE PACKAGE DECISIONS}

Discussions with large vertically integrated companies such as Hitachi and NEC reveal a belief that the practical economic limit to QFP packages is $0.3 \mathrm{~mm}$, beyond which other technologies will be cheaper and higher in quality and performance. The driving force behind the QFP lies in the facts that this package can be thinned by almost 4 times and that the mounting height can be one of the lowest of any packages in the industry except TAB. In addition, this is the lowest cost single-chip package in the industry.

Figures 4.34 and 4.35 compare the package weight and mounting height on PWB for a number of packages as a function of pin count. Only TAB and TSOP, besides QFP, can meet future competitive requirements for thinness and light weight in packages.

As shown in Figure 4.36, Hitachi has selected QFP, TAB, and PGA as strategic packages. There is general agreement that the best alternative to QFP in low-pin-count consumer products and high-pin-count computer products will be BGA (ball grid array) or surface mount PGA (pin grid array). Japan sees BGA as a high-speed, high-pin-count package that also provides a compact solution. Figure 4.37 shows how BGA provides a smaller footprint at $1 \mathrm{~mm}$ pitch than the ultimate $0.15 \mathrm{~mm}$-pitch QFP beyond $600 \mathrm{~V} / \mathrm{Os}$.

In contrast to the inspection needs of fine-pitch QFP, manufacturers like Hitachi do not believe there is a need to inspect the BGA joint, even though X-ray inspection may be possible. This is so because of the large pitch the area BGA provides. Hitachi also claims great flexibility in circuit design using BGAs, allowing $V_{c c}$ and $V_{d d}$ connection everywhere in addition to providing power and ground for each group of output buffers, reducing the simultaneous switching noise. The QFP approach does not provide this flexibility. 


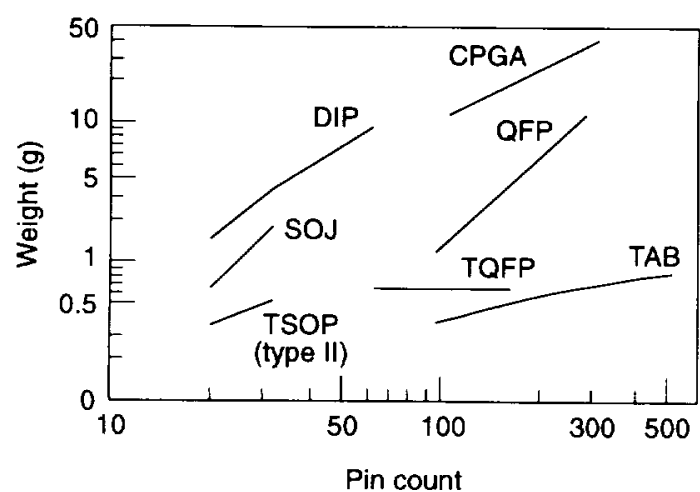

Figure 4.34. Package weight versus pin count.

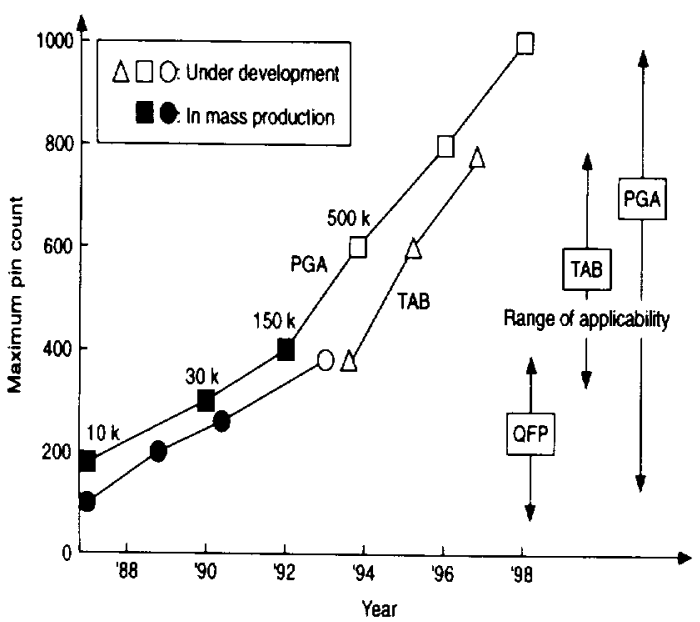

Figure 4.36. High pin count packages (Hitachi).

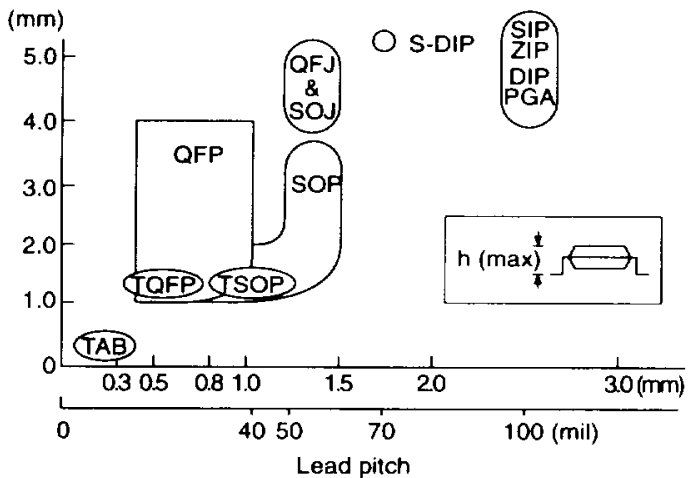

Figure 4.35. Lead pitch and mounting height.

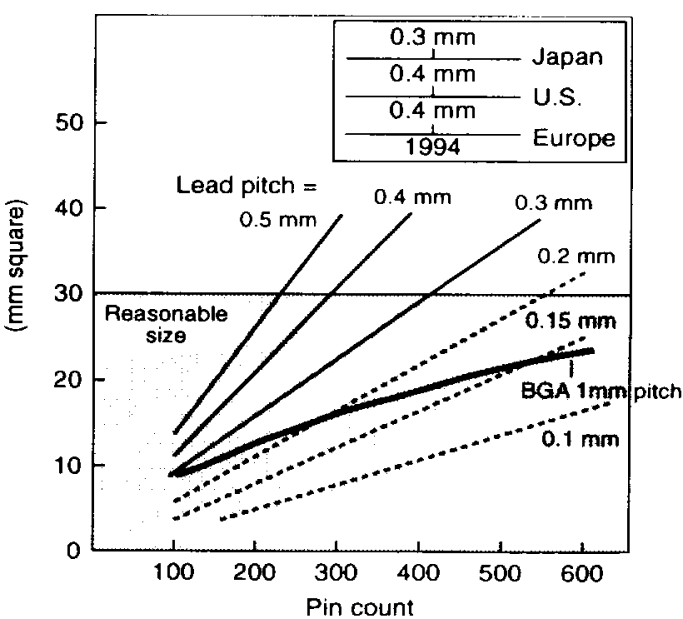

Figure 4.37. Relative package areas: BGA versus QFP.

In parallel to surface mount options, Japanese industry is pursuing PGA options both in ceramics and plastics. Toshiba, for example, is already pursuing an 820-pin ceramic PGA on a $60 \mathrm{~mm}$ square ceramic substrate. The pin-grid pitch in this package is $1.27 \mathrm{~mm}$ (50 mils). Toshiba chose $\mathrm{TAB}$ connection to the $20 \mathrm{~mm}$ size chip using gang inner lead bonding and single-point outer lead bonding. The plastic PGA trend providing in excess of $2000 \mathrm{H} / \mathrm{Os}$ is discussed above in the plastic package section. 
Figure 4.38 summarizes the overall Japanese packaging assembly trend, illustrating thin quad flat pack (TQFP) as its main thrust, with TAB and PGA as parallel thrusts. The BGA is expected in applications requiring over 400-600 V/Os. Beyond the miniaturization of QFP technologies, Japanese firms continue to develop chip on board, tape automated bonding, and flip chip technologies to meet increasing packaging density future requirements, as shown in Figure 4.39.

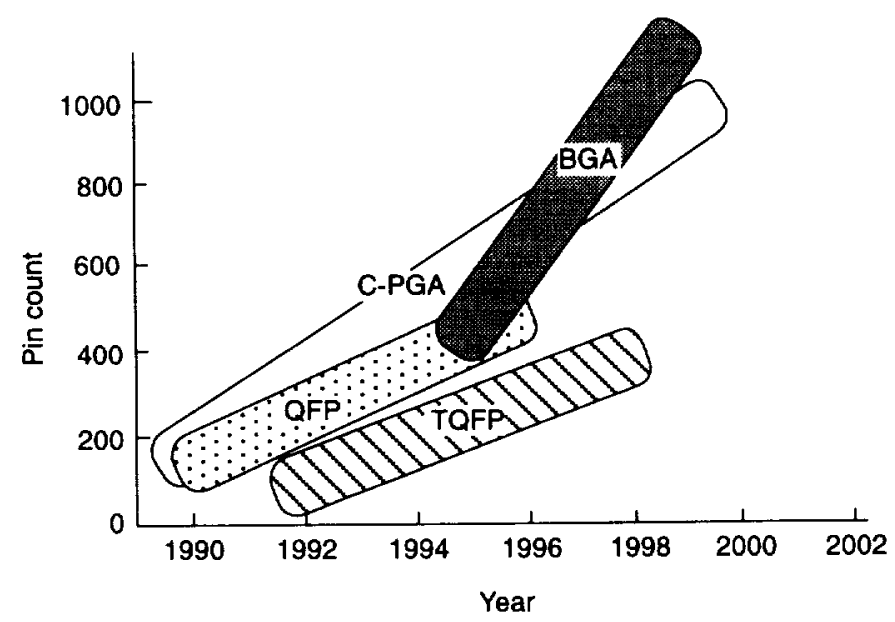

Figure 4.38. Japanese high pin count strategy (Oki).

\begin{tabular}{|c|c|c|c|c|}
\hline Technology & SMT/PWB & COB & TOB (TAB) & Flip chip \\
\hline $\begin{array}{c}\text { Cross } \\
\text { Section }\end{array}$ & Low & Low Medium & Medium High & High \\
\hline $\begin{array}{c}\text { Packaging } \\
\text { density }\end{array}$ & Today & & Future & \\
\hline Time & & & & \\
\hline
\end{tabular}

Figure 4.39. Japanese packaging assembly strategy (Sharp). 


\section{SUMMARY OF JAPANESE PACKAGING TRENDS}

A summary of the Japanese electronic packaging roadmaps is listed in Table 4.15, indicating the expected advancements in component-mounting density, semiconductor packaging, passive component size, and second-level organic/inorganic board technologies.

Table 4.15

Japanese Packaging Technology Trends

\begin{tabular}{|c|c|c|c|c|}
\hline & 1985 & 1990 & 1995 & 2000 \\
\hline Mounting form & Single side & Both sides & $\begin{array}{l}\text { Bare chip } \\
\text { Mixed mounting }\end{array}$ & $\begin{array}{l}\text { Thin and thick } \\
\text { 3D mounting }\end{array}$ \\
\hline Mounting density/ $/ \mathrm{cm}^{2}$ & $5-10$ & 15 & 20 & 50 \\
\hline $\begin{array}{l}\text { Parts: } \\
\text { - Semiconductor } \\
\text { - Passives }\end{array}$ & $\begin{array}{l}\text { DIP SOP } \\
- \\
3.2 \times 1.6 \mathrm{~mm} \\
\end{array}$ & $\begin{array}{l}\text { QFP } \\
100-200 \text { pin } \\
0.8 \times 0.65 \mathrm{~mm} \\
2.1 \times 1.25 \mathrm{~mm} \\
\end{array}$ & $\begin{array}{l}\text { TAB } \\
300-500 \text { pin } \\
0.5 \times 0.3 \mathrm{~mm} \\
1.0 \times 0.5 \mathrm{~mm} \\
\end{array}$ & $\begin{array}{l}\text { Multichip } \\
\text { module } \\
\text { Module with } \\
\text { built-in C, R, L }\end{array}$ \\
\hline $\begin{array}{r}\text { Basic board: } \\
\text { - Organic } \\
\text { - Ceramic }\end{array}$ & $\begin{array}{l}\text { One side print } \\
150 \mu \text { lines } \\
\text { Alumina } \\
W\end{array}$ & $\begin{array}{l}4 \text { layer } \\
100 \mu \text { lines } \\
\text { Glass } \pm \text { ceramic } \\
\text { Ag-Pd conductor }\end{array}$ & $\begin{array}{l}6 \text { layer } \\
80 \mu \text { lines } \\
\text { Low dielectric constant } \\
\text { Glass + ceramic } \\
\text { Cu conductor } \\
\text { AlN/W }\end{array}$ & $\begin{array}{l}10 \text { layer } \\
50 \mu \text { lines } \\
\text { Built-in C, R } \\
\text { Built-in C, R }\end{array}$ \\
\hline
\end{tabular}

\section{CONCLUSION}

A graphic comparison of Japanese and U.S. electronic packaging technologies may be found in Table E.1 of the Executive Summary, page xviii. This table clearly shows that Japan leads the United States in almost every category.

The JTEC panel maintains that much of Japan's advantage comes from its focus on highvolume production technologies that force the extension of existing technologies to keep costs down. In the future, we can expect to see these advantages applied to more of our traditional industrial markets where smaller volumes have been typical. Lack of basic packaging technologies will lead to loss of U.S. industries unless corrective action is taken.

\section{REFERENCES}

Microelectronics and Computer Technology Corporation and Sandia National Laboratory (MCC/Sandia). 1993. Industrial Competitiveness in the Balance: A Net Technical Assessment of North American vs. Offshore Electronics Packaging Technology. (U.S. Department of Energy Contract \#AD-3474.) 
4. Japan's Electronic Packaging Technologies 


\title{
Electronics Manufacturing and Assembly IN JAPAN
}

\author{
John A. Kukowski \\ William R. Boulton
}

In the consumer electronics industry, precision processing technology is the basis for enhancing product functions and for miniaturizing components and end products. Throughout Japan, manufacturing technology is seen as critical to the production and assembly of advanced products. While its population has increased less than 30 percent over twenty-five years, Japan's gross national product has increased thirtyfold; this growth has resulted in large part from rapid replacement of manual operations with innovative, high-speed, large-scale, continuously running, complex machines that process a growing number of miniaturized components.

The JTEC panel found that introduction of next-generation electronics products in Japan goes hand-in-hand with introduction of new and improved production equipment. In the panel's judgment, Japan's advanced process technologies and equipment development and its highly automated factories are crucial elements of its domination of the consumer electronics marketplace - and Japan's expertise in manufacturing consumer electronics products gives it potentially unapproachable process expertise in all electronics markets.

\section{JAPAN'S DISTINCTIVE COMPETENCE IN MANUFACTURING}

\section{Building the Manufacturing Infrastructure}

The Japanese government began in 1951 to provide special tax incentives for the import of new or highly efficient production equipment that was not produced in Japan. Beginning 
in the mid-1950s, the government began subsidizing research and development for advanced production equipment. By 1984, Japan was the undisputed world leader in machine tool sales; its sales totaled $\$ 4.4$ billion, compared to $\$ 2.9$ billion for the USSR, $\$ 2.8$ billion for West Germany, and $\$ 2.4$ billion for the United States.

Development in Japan of production technology for electronics began with passage of the Law on Temporary Measures for the Promotion of the Electronics Industry in 1957. This law was enacted to overcome problems of low productivity and small-scale production. Low-interest-rate loans were provided for modernization of equipment and upgrading of process technology. The law continued to be renewed and updated to encourage development and application of advanced production systems. Any equipment that utilized computer control technology for automation received special tax incentives and accelerated depreciation. By the late $1970 \mathrm{~s}$, Japan was the world leader in industrial assembly robots, and in 1992 it operated over $69 \%$ of all installed industrial robots in the world, compared to $15 \%$ operated by Europe and $12 \%$ operated by the United States.

Manufacturing processes in Japan are becoming unmanned, automated, and continuous flow operations. Nonstop operations are even more difficult in discrete assembly industries than in process industries, since hardware must deal with different shapes and sizes of components. To cope with the demands of nonstop operations, engineers must address problems of parts feeding and orientation, line balancing, cleaning, and parts ejection and dislodging. Although machines are not absent from work, their reliability or mean time before failure suffers from parts variations and defects. General wear affects equipment precision and product quality, and low precision affects product quality. The growing application of sensors is an attempt to ensure that equipment is meeting specifications at all times in order to meet product quality requirements.

Continuous innovation in manufacturing equipment and processes requires companies to promote on-site engineering know-how to increase the reliability of equipment with regard to its quality of output products, avoidance of breakdowns, maintainability, safety, and operability. Japan's leadership in manufacturing technology, therefore, depends on competency in factory automation, equipment development, production engineering, and equipment-oriented management. All these capabilities have been developed in Japan over the past four decades.

Japanese-made products have often been able to outperform the same products made by the inventors or innovators. Japanese firms have achieved these results through continuous improvements of the basic technologies and processes used for manufacturing. Within two years of the time that Kawasaki Steel licensed the Unimation robot technology, the Japanese version of the robot was outperforming the American robot in reliability. Worldclass Japanese manufacturers are continuously learning how to take advantage of their process improvements in order to upgrade their products and components. In this way, Japanese firms have taken the lead away from U.S. firms to become the market leaders. Nowhere is this more evident than in manufacturing technology for consumer electronics. 


\section{Achieving Production Efficiency and Quality}

Engineering innovations in equipment have resulted in simplified manufacturing processes, improved product designs and quality, and a lower skill level requirement for those operations still done manually. Furthermore, advanced machines and equipment have been developed to process an increasing number of part shapes and sizes, requiring more advanced management methods to improve machine reliability and to prevent breakdowns. For example, there are hundreds of parts in radios, thousands of parts in televisions, tens of thousands of parts in automobiles, hundreds of thousands of parts in jet aircraft, and millions of parts in an Apollo spacecraft: If there are five hundred parts and $99.99 \%$ reliability per unit of time, combined reliability is reduced to as little as $96.24 \%$. It is therefore imperative to ensure not only that parts are designed to be reliable, but also that preventive maintenance of automated machinery is undertaken with precision and that maintenance personnel receive the increased level of training necessary.

Beginning in the 1950s, the Japan Management Association developed practices to improve the efficiency of Japanese manufacturing companies. One of the pioneers in this activity, Yoshikazu Takahashi, established the Institute of Productive Maintenance Technology to provide principles for improved productivity, quality, cost, safety, and motivation. Such principles include the following (Takahashi and Osada, 1990):

- maximize the use of existing equipment with the goal of "zero breakdowns"

- design, operate, and analyze a maintenance system

- develop a proactive maintenance prevention engineering program

- upgrade the skills of workers through technical training

- create an environment whereby workers feel heightened self-esteem and work satisfaction due to their involvement in the improvement process

Innovative technologies have been aggressively implemented in Japanese manufacturing operations. However, to stay cost-competitive, companies have also been careful to restrict unnecessary equipment investment, to ensure maximum utilization of existing equipment, to reduce personnel through equipment enhancements, and to reduce the costs of energy and source materials through innovations in equipment design and use. All these tasks require total employee participation and are fundamental to reforming a company's manufacturing structure.

\section{Research and Development in Manufacturing}

Throughout Japan, research and development in production engineering focuses on computer-integrated manufacturing (CIM), factory automation (FA), electronic packaging, precision machining, and inspection/recognition technologies. In 1985, Japan's Ministry of International Trade and Industry (MITI) produced a roadmap for the development of computer-integrated manufacturing in Japan. The overall roadmap is shown in Figure 5.1. 


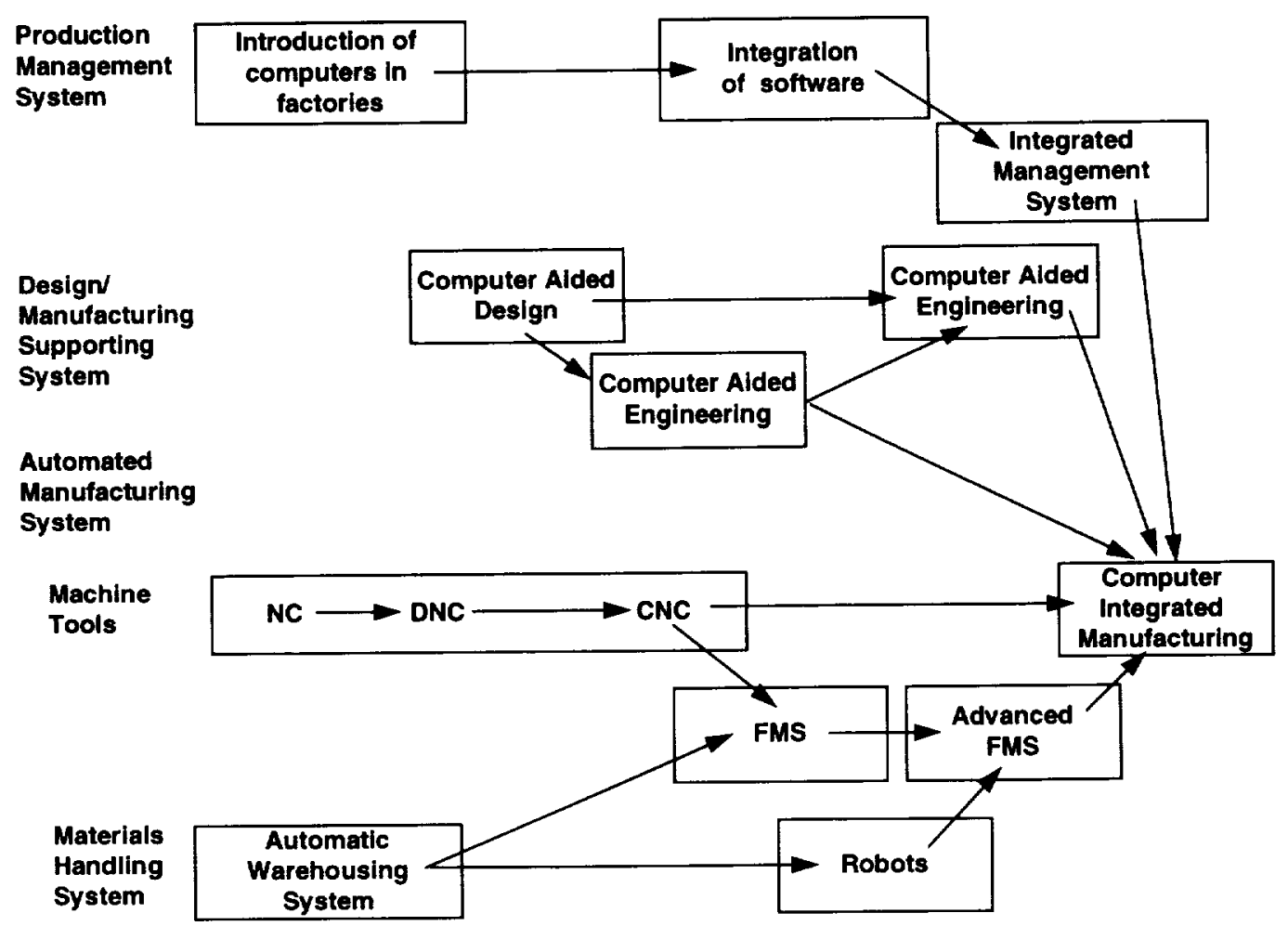

Figure 5.1. Japan's development of computer-integrated manufacturing ( MITI).

Computer-Integrated Manufacturing. In 1985, the Japanese initiated a project to develop a standard protocol for factory automation. The International Robotics and Factory Automation Association was established that year for the purpose of setting the standard for communication between equipment used on the factory floor. The approach, called miniMAP, was based on the lower four levels of the MAP manufacturing automation protocol introduced by General Motors in the 1980s. The first prototype demonstrations were made in 1992 and 1993 at the Japan Exhibition Center at Makuhari Messe, where over twenty equipment makers demonstrated factory integration of their equipment using the miniMAP standard protocol. To quote Hitachi's literature, "CIM is the only technology capable of handling the explosive diversification of consumer goods in today's fast-paced market environment driven by increasingly shorter concept to finished product."

The development of Japan's factory automation capabilities began with Toyota's prototype integrated factory in 1972. In 1978, MITI initiated a national R\&D project to develop a flexible manufacturing factory, which was demonstrated in 1985 at MITI's mechanical engineering laboratory in Tsukuba. The problem of standardizing the communication 
interface between equipment vendors was then addressed by the International Robotics and Factory Automation Association. By 1990, Japan was the world leader in installed flexible manufacturing system (FMS) lines and industrial robots and was working to develop full CAD/CAM (computer-assisted design/manufacturing) capabilities for computer-integrated manufacturing. FANUC, a major supplier of industrial robots and control systems for General Motors, began implementing full CAD/CAM capabilities for its own factory automation in the late-1980s.

Leading Japanese electronic manufacturing and assembly companies have developed their own advanced production and computer-integrated manufacturing capabilities. In-house capability protects intellectual property, assures timely delivery, reduces costs, and reduces response times required for new product introductions. Such capabilities provide the Japanese with self-reliance and the ability to implement real "concurrent engineering" methodologies. Most companies, however, are selling their proprietary manufacturing technology in the open market in order to increase the return on their equipment investment. The availability of the equipment in the open market is usually preceded by long periods of utilization in Japanese facilities. Sony demonstrated to the JTEC panel a full range of production and assembly equipment developed for component manufacturing and final assembly applications. Sony's equipment sales now represent $2 \%$ of the company's sales. In the United States Polaroid Corporation has installed a complete assembly line that uses over 100 Sony robots.

\section{Production Engineering Capabilities}

Production technology is a key strength of Japanese firms. Most leaders in the electronics industry have established separate organizations to manage developments in production technology. Their goals are to maximize manufacturing efficiency and high-quality output. On a corporate level, production engineering research laboratories provide the critical link between product development and the development and application of advanced production equipment and processes. Every major business unit within a firm has its own production engineering staff and production engineering laboratory to develop process design and process technology. Production technology development drives concurrent equipment, component, and product developments - final product design and development are synchronized with production technology development. The importance of production engineering in Japanese firms is demonstrated by the fact that in companies like Hitachi and NEC the production engineering departments report directly to the company presidents, alongside the other company research laboratories.

Most leading Japanese electronics companies also have materials characterization laboratories. Expertise in both materials and manufacturing processes guarantees highquality outputs and improved reliability. It was evident to JTEC panelists that in Japan both are the focus of attention when quality or reliability problems occur; likewise, improvements in materials, package architectures, and manufacturing processes remove the failure causes. 


\section{Equipment Development Capabilities}

Without exception, every company visited by the JTEC panel has its own equipment development teams for designing and building production equipment. Sony's factory automation and precision products group includes a thousand members. The FA systems division makes advanced equipment to manufacture new products developed within Sony. The robotics and FA components division developed Sony's Multi Assembly Robot Technology (SMART) systems. In addition, Sony has another three hundred people working within the machine tool, production technology, and production engineering divisions to develop production systems for customers. In 1993, Nippondenso, Japan's leading auto electronics firm, has over two hundred people at its Kota site to develop production equipment and processes. This commitment has led to advanced production systems. Nippondenso's main four-story building at Kota handles chip assembly, hybrid manufacturing, SMT board, and also final assembly, burn-in, and testing for more than 120 models of engine controllers on one 100-meter manufacturing line. The production line was replaced or upgraded every three to four years. Most of the Kota plant's equipment has been produced in-house. JTEC panel members have never seen such levels of commitment to process development in U.S. electronics firms.

Japanese industry as a whole has focused massive resources on the design and development of complex automated equipment, and the range of equipment development expertise within individual companies is tremendous. That expertise covers all the technological areas required to be self-sufficient and dominant in electronics manufacturing. The consensus in Japan is that equipment provides a major competitive advantage and that equipment development technology is mandatory in order to lead in the introduction of new products. Japanese drivers for equipment development include cost reduction, machine accuracy, reliability, speed, flexibility, peripheral integration, ease of operation, and links to CAD (CAD-CAM integration). Numerous Japanese companies are aggressively producing and marketing electronics manufacturing equipment worldwide.

Equipment Development Teams. The Japanese approach to equipment development is built on the team concept. Numerous individuals with varied technical backgrounds are teamed together during the development process. Members of the development team are ultimately transferred to the manufacturing facility for implementation and to continue equipment enhancements to maximize production efficiency. This ensures highly skilled technical personnel to operate, maintain, and continuously implement changes required to enhance the equipment.

Modular Systems. The concept of modular equipment, both in hardware and software, has become a prime objective for the Japanese equipment developers. Their goal is to design independent subsystems that can be quickly reconfigured to meet the demands of rapid product change with minimal cost. Sony's Multi Assembly Robot Technology (SMART) has a modular architecture and is presently being marketed worldwide. 
Development Priorities. The JTEC panel observed equipment development activity in the following key areas:

- integration of image acquisition and sensor technology for improvement of product quality and product yields

- integration of real-time control feedback loops to automatically adjust and calibrate automated manufacturing equipment for ensuring product reliability and improving process reliability

- implementation of automatic load/unload of raw materials for assembly equipment

- integration of peripheral equipment that is configured for rapid product changeover

- implementation of micromachining technology

\section{Advanced Electronic Assembly}

Japanese equipment makers have striven to produce the most advanced production systems for high-volume, low-cost manufacturing. For example, the manufacturing equipment division of Matsushita Electric provides "total production efficiency" through development and sale of electronic components insertion and placement machines, assembly processing and fastening robots, and FA systems and controllers. Most firms are seeking to provide the 24-hour, unmanned, integrated factory of the future. Matsushita's electronic components insertion and placement machines apply advanced circuit board assembly technologies for fine-pitch circuitry and ultrasmall components in a 24-hour non-stop CIM environment. This advanced assembly technology is based on surface mount (SM) devices and developments in application equipment. As Figure 5.2 shows, a wide range of SM devices, including passive, structural, and active devices, are available for low-cost, highvolume production of lighter weight electronic packages with improved reliability.

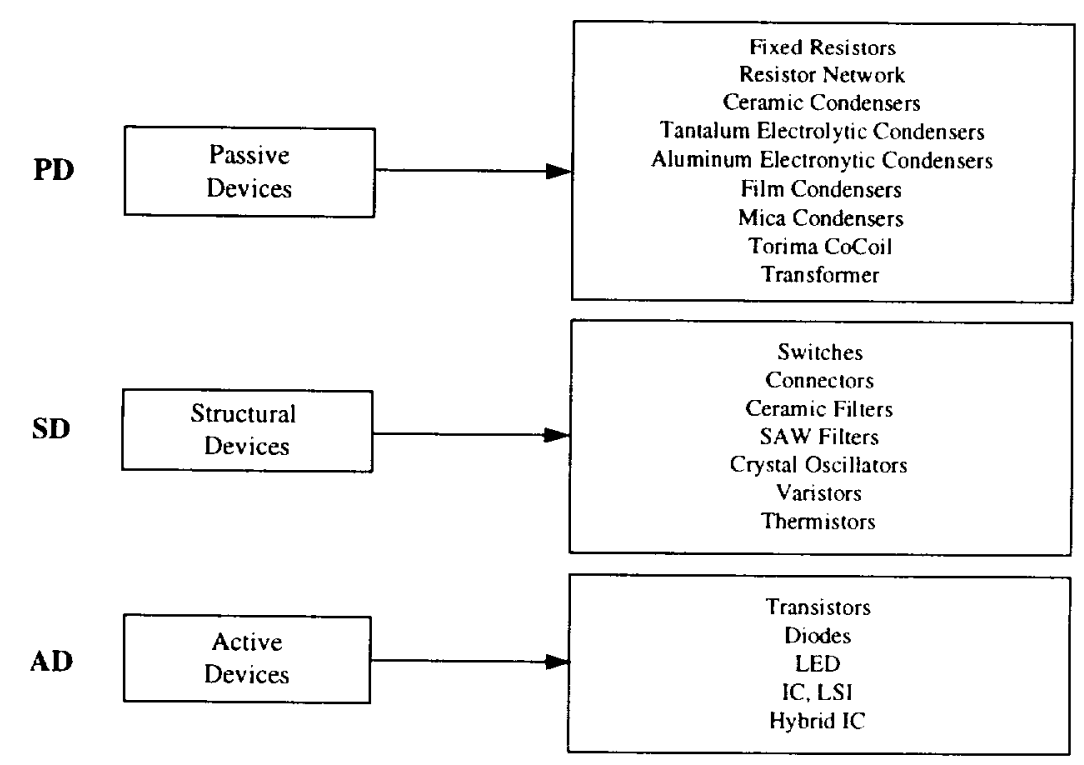

Figure 5.2. Japan's surface mount devices (Nikkei Electronics). 
High-volume consumer electronics markets have stimulated rapid development of passive devices for SM applications, as Figure 5.3 shows. Structural devices are being redesigned for SM applications.

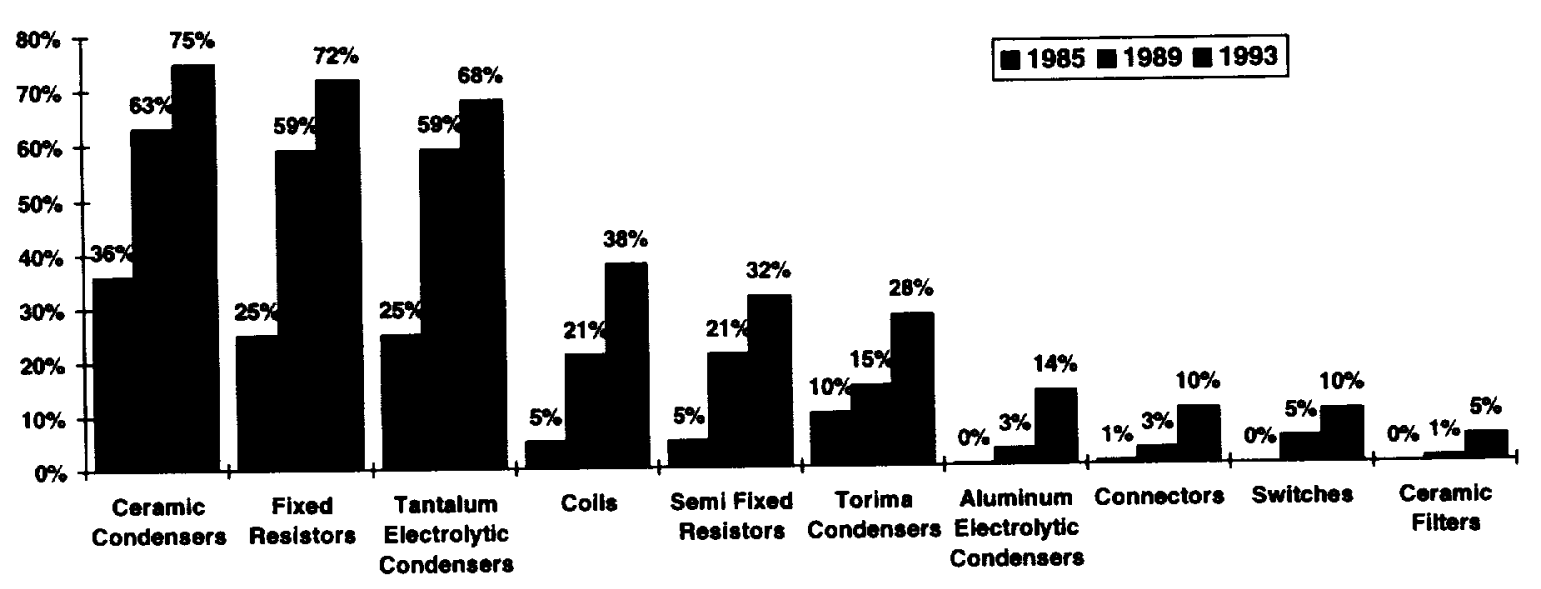

Figure 5.3. Japan's SM applications of major components ( EIAJ).

The number of companies supporting SM developments in Japan has given the country a competitive infrastructure. As shown in Figure 5.4, there are 29 companies providing surface mount equipment and 32 companies providing surface mount devices. Companies like Hokuriku, NEC, Panasonic (Matsushita), Sanyo, Taiyo Yuden, Tamura, TDK, and Toshiba have expertise in developing both SM devices and SM equipment.

Advances in electronic packaging technologies and related factory automation are shown in Figure 5.5. According to Matsushita, the evolution of component and production systems through the year 2000 will move to further miniaturization and direct connect technologies. For example, insertion assembly will continue to be applied to packages that do not require miniaturization or cost reductions; however, current "package on board" will be enhanced with tape-automated-bonding applications and a growing number of chip-on-board wirebonding applications. It is expected that direct chip-on-board flip chip bonding will be used for most miniaturization before multichip modules become the standard for nextgeneration miniaturization.

Surface mount technologies will continue to provide the low-cost solution for consumer electronic products. Figure 5.6 provides the roadmap for surface mount technologies through the year 2000 . Mounting methods will include greater levels of chip integration as designers move to bare-chip and three-dimensional mounting techniques. Mounting densities will increase to 50 components per square centimeter. Passive parts are expected 


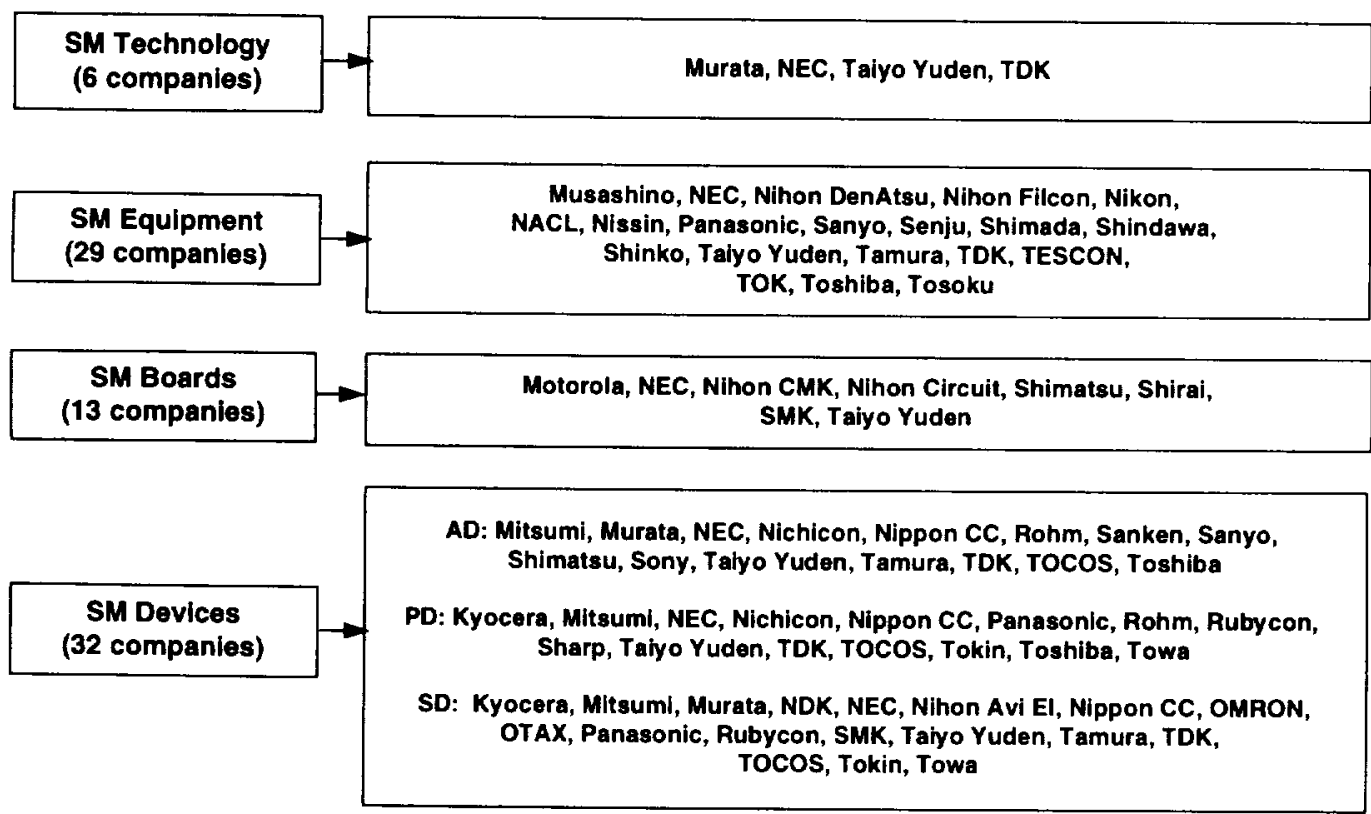

Figure 5.4. Major companies comprising Japan's surface mount infrastructure (Nikkei Electronics).

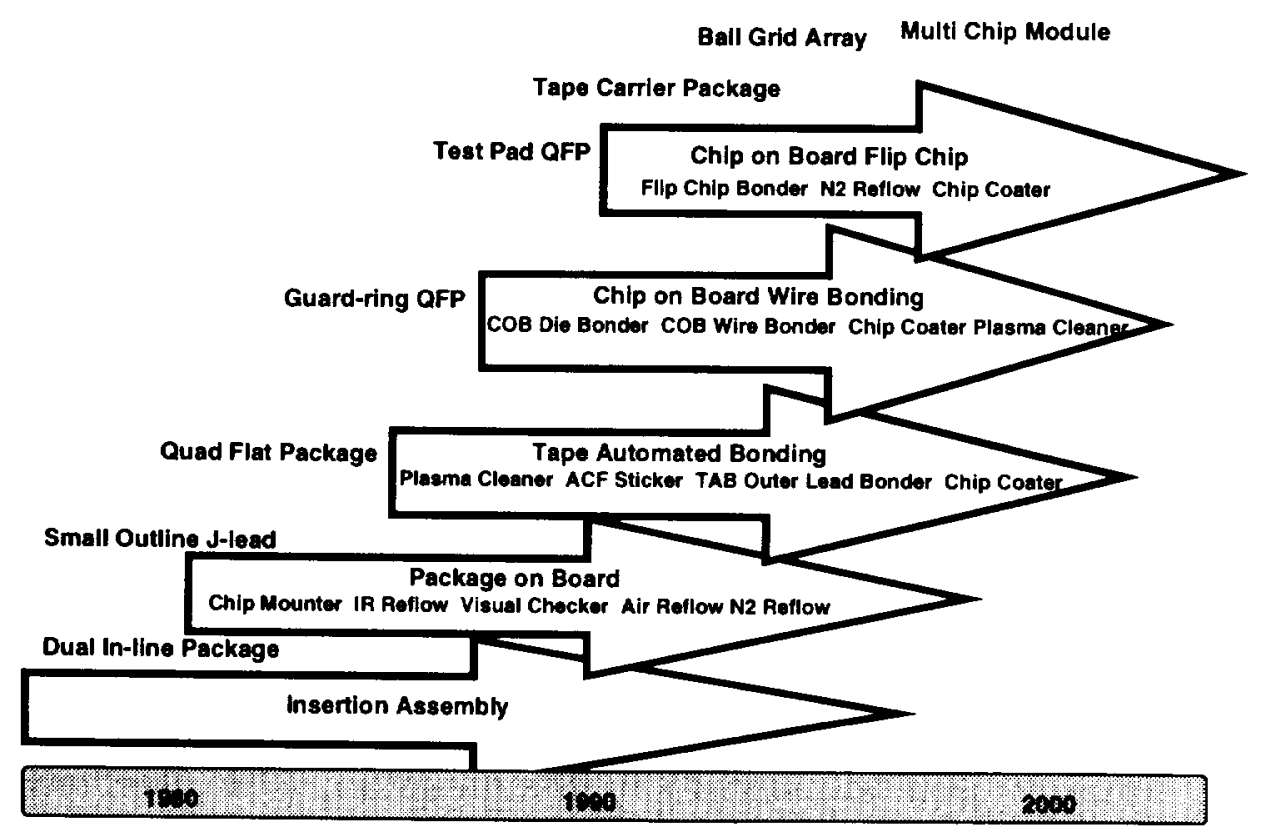

Figure 5.5. Japan's surface mount developments (Matsushita Electric Co.). 


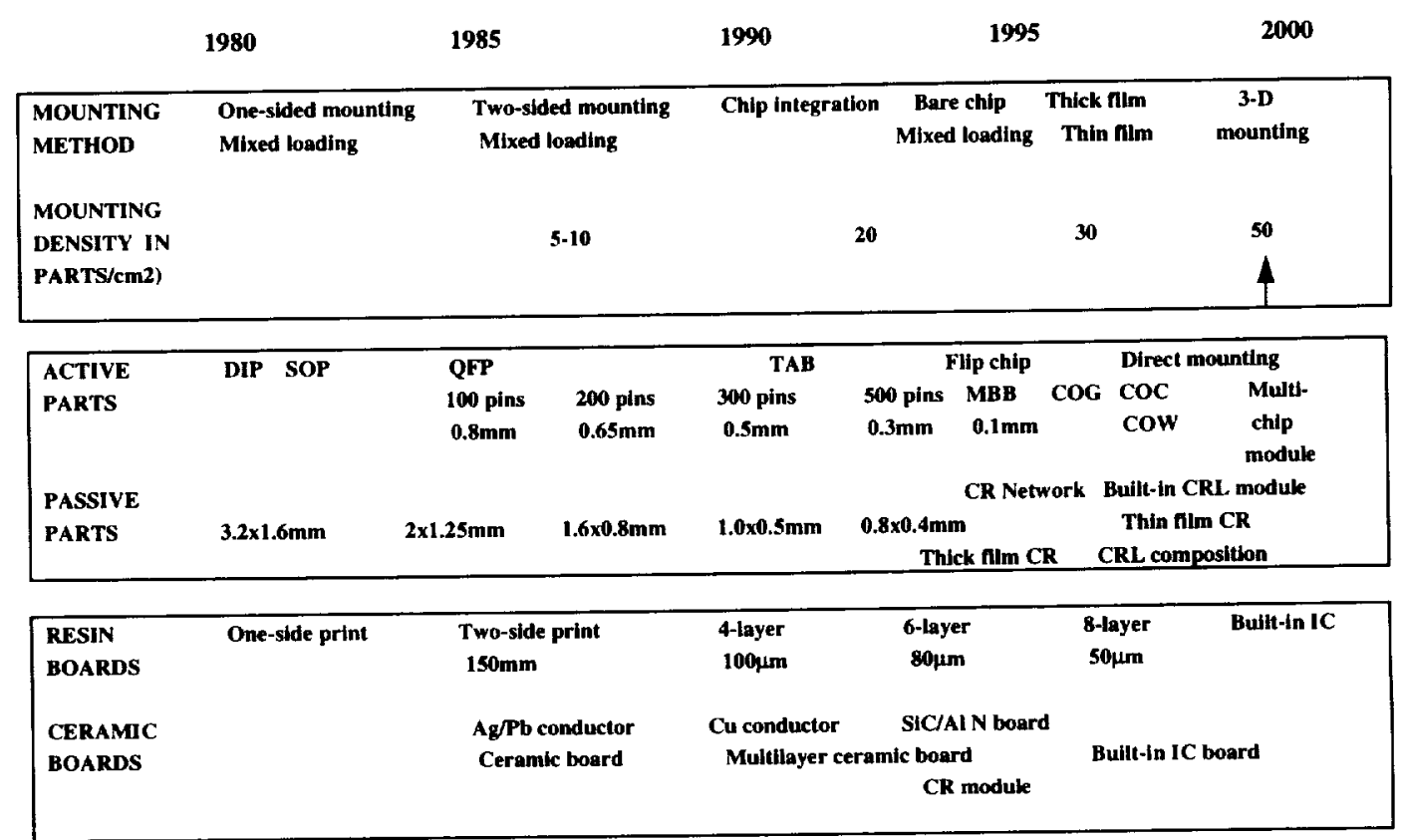

Figure 5.6. Next-generation surface mount technology (Nikkei Electronics).

to reach their limit at $0.8 \mathrm{~mm} \times 0.4 \mathrm{~mm}$ before they become integrated into modules. Active parts will move in to meet miniaturization requirements with pin pitch levels approaching $0.1 \mathrm{~mm}$ as advanced direct mounting technologies lead to low-cost multichip modules. Board technologies for low-cost resin boards will become standardized at eight layers before built-in chip solutions become common practice. Ceramic substrates will become more common as multilayer, high-performance techniques are implemented to make them cost-competitive.

\section{ENABLING TECHNOLOGIES}

Japan is relentless in its implementation of enabling technologies that will allow it to maintain and improve its present manufacturing power in the field of electronics. Key enabling technologies that are being actively pursued by the Japanese to achieve their goal of manufacturing excellence are outlined below.

Computer-Assisted Design and Computer-Assisted Engineering. The implementation of $\mathrm{CAD}$ for design is common throughout the industry. The move towards the implementation of CAE is viewed as an important step to achieve successful development of high-value-added products while simultaneously shortening the product development cycle and reducing development cost. Following are three examples of $\mathrm{CAD} / \mathrm{CAE}$ implementation: 
- Sony uses the technology to plan in detail how its product will look and perform at the board level. At the time of the JTEC visit, Sony was using design-for-assembly software; implementation of design-for-disassembly software was planned for 1994.

- Hitachi uses simulation software to develop new polymer materials for laptop computer cases. The system is used to simulate material flow properties during the molding process.

- Sharp's new ViewCam was designed for manufacturing and assembly using CAD/CAE/CAM software. The new production line at the time of the panel's visit incorporated the latest assembly equipment to assemble 1005 components onto the printed circuit board.

Sensor Technology. Research and development in the field of sensor technology is common throughout the Japanese electronics manufacturing industry. The philosophy is to maximize integration of sensor technology within automated production equipment to increase product yield, quality, and reliability. Process areas for implementation include solder paste circuit pattern inspection, shape inspection for via-hole fillings of green sheets, fine-pitch surface mount component geometry inspection, solder joint inspection, automated color inspection for color CRT displays, and verification and inspection of raw materials and discrete components.

Super Precision Processing Technology. To manufacture complex precise products, it became imperative for the Japanese to invest in research and development of precision processing technology. The following three examples demonstrate their ability to successfully implement precision processing technology:

- Sony has developed two ultraprecision machining devices, a head-winding machine and a high-speed slicer, to manufacture the camcorder recorder head. To manufacture the one-centimeter-wide head it is necessary to cut $2 \mu \mathrm{m}$ slices in ferrite material that is $110 \mu \mathrm{m}$ high. It is also necessary to wind $30 \mu \mathrm{m}$ wire 55 times around the head while simultaneously passing through a small slot in the head.

- Nippondenso has used its micromachine technology to manufacture accelerometers and other sensors for automotive applications. To demonstrate its expertise in micromachine technology, it produced, to scale, a miniature car about $5 \mathrm{~mm}$ long.

- Murata has initiated a new silicon micromachining program at its Yokohama R\&D Center to develop microminiature accelerometers, sensors, and oscillators.

\section{FACTORY AUTOMATION}

Production automation is fundamental to Japan's competitiveness in terms of the cost and quality of its consumer electronic products. In addition, a growing labor shortage, demands for improved working environments, and company-wide computer-integrated manufacturing have made automation a necessity for many companies. Since most 
fabrication activities have already been automated, the current focus of attention is on the automation of assembly lines, where labor content has been highest.

There are several stages of assembly line automation, with varying impacts on flexibility and product design. The move from hand assembly to robot assembly of existing products can be termed "first-generation" automation. "Second-generation" lines require some product design changes for assembly line automation. Automation that requires broad product design changes is termed "third-generation" automation.

The JTEC panel observed widespread automation during its plant tours. The leading Japanese electronic companies have implemented the following FA concepts (Kahaner 1993, 33-56):

- in-line systems with a series of progressive operations

- computer control of raw material storage and retrieval

- automated guided vehicles used in the delivery of material to the assembly line, and in some cases, automated loading of the assembly equipment

- bar code identification of raw material and product mix

- machine instructions downloaded from a host computer

- in-line automated assembly and process equipment

- in-line automated inspection and testing equipment following each preceding assembly or fabrication operation

- automated real-time process control to achieve automated calibration of assembly equipment and products

Key benefits cited for the use of automation include reducing factory set-up time, manufacturing defects, product lead time, and direct labor, and increasing the ability to rapidly deploy manufacturing operations around the world.

Sony management described the following as an example of the benefits gained from the company's factory automation activities: It took three to four months to start up Sony's original production lines in Japan, but it required only two to three weeks to bring replicated lines up to speed in Singapore and France. Changing models required only 9.1\% of additional capital investment in Sony's first changeover, $3.5 \%$ in the second changeover, and only $1.5 \%$ in the third changeover. In addition, the move to automation resulted in improved quality. The best defect rate using manual labor was 2000 parts per million (PPM), compared to 20 PPM after the first week of automation. Sony's personnel policy was to remove employees from manual labor jobs through automation so that "they could become more creative in solving problems and improving operations." Due to Sony's strong knowledge base in automation and its focus on design for manufacturability, between 1987 and 1990 it increased sales by $121 \%$ with an increase of only 35 employees. 


\section{Automation for Miniaturization}

Japanese electronics companies have made and continue to make large investments in production technologies and factory automation because of their commitment to miniaturization as well as to high product reliability and low product cost. As electronic components shrink to as small as $1.0 \mathrm{~mm}$ by $0.5 \mathrm{~mm}$ (called " 1005 " parts), and as component lead pitch approaches $0.2 \mathrm{~mm}$, human assembly is no longer feasible.

The Japanese strategy to develop key components for use in electronic products has also required investments in equipment development. "Off-the-shelf" equipment is generally inadequate to meet the manufacturing needs of new component technologies. Without exception, each Japanese company the JTEC panel visited was designing and building critical equipment in-house. According to these companies, equipment provides a major competitive advantage because it is designed to respond to the specific manufacturing requirements of the companies' components or products.

The JTEC panel was impressed by the fact that some Japanese component suppliers also supplied buyers with the equipment required to assemble their advanced components. TDK, Murata, and Matsushita, for example, developed internally the production technology to make 1005 parts, and they also supplied the assembly equipment required for customers to utilize these ultrasmall parts in SMD assembly. The equipment makers introduced the equipment at the same time as the new miniature parts were made available to the market. The production technology is being developed to ensure that new components are rapidly included in next-generation product designs.

Miniaturization is forcing assembly technologies to become faster and more precise. Precision robots have improved repeatability from .05 to $.01 \mathrm{~mm}$ over the past decade. Matsushita's latest SMT placement machine incorporates 11 placement heads with $.01 \mathrm{~mm}$ placement repeatability. Sony's high-speed robots now work at $.012 \mathrm{~mm}$ repeatability. These levels of precision are beyond human capabilities. As Figure 5.7 shows, Japanese electronics firms use miniaturization technologies to a much greater degree than U.S. firms.

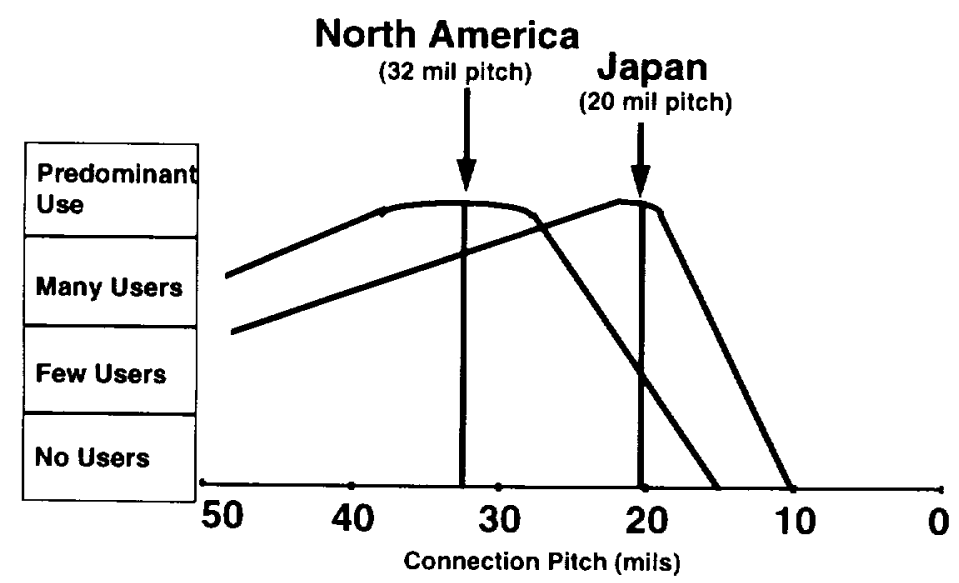

Figure 5.7. Predominant pitch capability for low-cost electronic packaging (MCC Portable Electronics Packaging Project). 


\section{Final Assembly Design Techniques}

In assembly operations, parts handling and feeding and line control are very complex; however, with the advances made in equipment, production control, and computers over the past decade, automated assembly lines are no longer unusual. Until now, such automation has been focused on high-volume, low-cost production operations like the manufacture of consumer electronics products or other products with relatively simple design structures.

Recent advances in production technology include robots and sensors, component feeding, line control, and production management techniques. There are three critical advances (Kahaner 1993, 34):

- positioning technology for robot control

- flexible line construction technology for mixed flow production of multiple product models

- modular product design technology for assembly line automation

Positioning is the most common problem for assembly automation. Different sizes and shapes of components make assembly difficult. Precision positioning of parts for printed circuit boards in consumer electronic products is especially challenging. If the board is out of position, the problem is compounded. This is a problem with board warpage where accurate sensor detection is especially difficult. NEC in Gunma Prefecture developed a triangular measuring optical sensor that is used in a procedure to detect the height of three points on a printboard. A two-dimensional curving warp can be represented by three points, so the company had to come up with innovations in measurement point selection and interpolation techniques.

Jigs are fundamental to positioning parts properly before assembly. Complex part shapes can make such positioning difficult. Visual sensors can detect the positions of parts and also allow for mixed-flow production operations. These sensors can also detect parts' shapes and therefore are useful in product quality control applications. Toshiba's most recent application of CCD technology to visual sensors has allowed for $0.02 \mathrm{~mm}$ positioning accuracy. More typical sensors, combined with the mechanical error of a robot, result in errors of several hundred microns.

Flexible lines are required to cope with the demands of multiple-model, mixed-flow production. Movable jigs and visual sensors are used to adjust to changing parts shapes. In mixed-flow assembly lines, product model information must be controlled to match parts with the models on the line. Some companies have used memory cards on parts pallets to achieve this control. Integration of such parts flows with mixed-line assembly is based on sophisticated parts-feeding equipment, which may account for $80 \%$ of the automation success. 
Modular product designs are used to reduce equipment costs and to improve product reliability. It is essential to implement design features that are compatible with automated assembly operations. It is then possible to simplify assembly and enhance operational reliability by orienting all the assembly steps in one direction or employing connection techniques amenable to automation. For complex assembly operations that could be handled by robots, Fujitsu developed special supplemental mechanisms that required changes in such details as screw shape.

Product structures are divided into a number of modules for design purposes. Each module is assembled on a subline, and the assembly operations not amenable to automation are concentrated in the final assembly line. It is easy to achieve higher automation rates in the total assembly process because each module is designed to be compatible with automated assembly. In the personal computer, for example, every component used in final assembly simply slides into a slot or connector without difficulty. At NEC's PC assembly factory, each module is designed to be compatible with automation of the total assembly process.

Now that robots have become highly functional, Seiko Epson has designed its printers for the lowest total manufacturing cost and then constructed its assembly line accordingly. It has set about improving the automation rate while developing ways to handle multiplemodule, mixed-flow production. The mixed-flow production approach helps hold down equipment costs and allows for flexibility in adjusting to demand fluctuations. Development of designs compatible with assembly automation is a new key concept that has great potential.

\section{JAPAN'S AUTOMATED ELECTRONICS ASSEMBLY DEMONSTRATED}

[Editor's note: The information on NEC and Seiko Epson that follows is based on research by David Kahaner of the Office of Naval Research, Tokyo - see reference section at the end of this chapter.]

\section{NEC: Personal Computer Assembly}

NEC's personal computer development and production center in Gunma Prefecture has had an automated assembly and inspection line for desktop computers since 1991. It produced over a million units in 1991. In 1988, the company automated packaging, and in 1989 it automated the printboard and inspection operations. In 1992, a robot line for final assembly and product inspection stages was completed that has reduced by two-thirds the skill requirements of the old manual line that required 15 skilled workers per shift. NEC's personal computer assembly factory, which produces $20 \%$ of Japan's personal computers, employs only forty people per shift to operate the factory.

NEC's aim has been to achieve production consistent with the market fluctuations of PCs. This required shorter "production lead time," the time required to double the number of PCs that the company plans to produce. 
NEC has installed a new robot line that uses nine assembly operations covering a length of 50 meters and 12 inspection operations that cover 30 meters, excluding the running test room. Four of the robots employed are 6-axis vertical articulated models, 8 are 3-axis transverse models, 1 is a 2 -axis transverse type, and 2 are horizontal articulated types, for a total of 15 robots. The total investment was approximately $¥ 500$ million. Only two assembly operations and three inspection operations are done manually; the two manual assembly operations involve hooking up and stringing cables, operations still difficult for robots. Investigations are being made to eliminate cables for easier automation of this task. The line reduced the number of skilled workers from 15 to 5 and reduced waiting time from 77 seconds to 57 seconds. The line can assemble 450 PCs per eight-hour shift.

Precision assembly requires both placement accuracy and warping adjustments. Increased precision leads to more expensive equipment and component costs. The most difficult problem has been motherboard assembly. Hole position had been marked sequentially from one edge of the board, thereby decreasing accuracy as the hole distance increased from the edge of the board. One of the most important improvements in the new line was to change the printboard design to indicate the positions of holes in terms of one standard hole located near the centerline. This eliminated the need to measure hole positions. Mounting and soldering of electronic components to the printboards have now been automated. The soldering is accomplished by wetting the printboards with molten solder. The heat from this process warps the board. The printboard warp is measured with optical sensors using triangulations at three points simultaneously.

Robots have a limited adaptability to model changes unless control programs can be changed and robot hands adjusted for different components. As the number of components is increased, a robot line loses its adaptability. To keep waiting time short, it is necessary to install more robots. This is an expensive approach for equipment costs and takes a lot of time. NEC has addressed this problem by giving robots a wider range of movement. For horizontal and vertical articulated robots, the movement range is $320^{\circ}$, leaving a $40^{\circ}$ arc through which the robot cannot move. When this unreachable arc is placed behind the robot, it is difficult to supply more than two components per robot; therefore NEC placed this unreachable arc on the side, which allowed for an increase in the number of components supplied, thus increasing efficiency. This has allowed a waiting time loss of only one second but has provided increased flexibility.

A new handling problem is how to reduce component pallet sizes in order to place three pallets next to the robot. With only ten components per pallet, the carrier vehicle has trouble feeding parts fast enough from the warehouse. NEC's monorail transporters have a maximum speed of $200 \mathrm{~m} / \mathrm{min}$ but operate at $180 \mathrm{~m} / \mathrm{min}$.

Inspection operations are still done manually but require devices to tell the difference between models. While external differences are easy to tell, many internal differences create difficulties. Bar codes and ID cards are used for each model. Four reflector plates on the jigs are used for identification; the robots, using sensors, tell which plates are open, and human inspectors visually view the display. 


\section{Seiko Epson: Printer Assembly}

Seiko Epson redesigned its printer in order to automate its assembly using a singledirection assembly process. The company uses ten design criteria for assembly automation; unidirectional assembly is one of the criteria used consistently since Seiko Epson's first robot assembly line in 1984. The fifth-generation robot assembly line was built in April 1992. Simultaneous design of both assembly and product has preceded factory construction. According to Sachiharu Suda of the equipment rationalization center, "We have not merely tried to make printers easier to assemble, but have sought to lower mold and die costs and component costs to reduce overall production costs." In the past, easy assembly was the number-one criterion that led to complex-shaped components, more difficult design, and higher costs of molds, dies, and components.

The assembly line for the export model LQ100 printer had 53 steps using 38 assembly stages, 7 inspection stages, and 8 packaging stages, of which 5 assembly operations were manual. The automated assembly operations used Seiko transverse robots that had been used on the fourth-generation line. The tact time was reduced $10 \%$, to 27.2 seconds, over the fourth-generation line. Vibrating parts feeders were used to supply small components to the robots, while pallets were used for large components. Three kinds of jigs were used to assemble the chassis, print head, and printboards. With the reduction in tact time, however, the most significant problem became the supply of parts to the line. Since multiple stages order parts simultaneously, the warehouse was unable to get the parts to the line fast enough. Parts locations in the automated warehouse were reevaluated to reduce the problem.

To further reduce costs, components that had been subcontracted out of the factory were reevaluated. The cost of palletizing and transporting parts to the factory could be eliminated if these parts were produced in-house. New jigs were developed to allow for the robots to assemble complex components on the line, and the assembly process was changed to accommodate this process. While cables are still installed manually, the power cable installation was robotized after developing new robot hand shapes and jigs that positioned the cables for correct cable positioning and robot grasping.

\section{Nippondenso: Electronic Control Assembly (Kota Plant)}

Engine control units are produced at Nippondenso's Kota facility. Five different engine controller product families, including over 120 different engine controllers, are made on a single assembly line. The line begins with traditional surface mount assembly, including solder paste application, component pick and place, solder reflow, and test. After test, a conformal coating is applied to the boards. The boards are then assembled into metal enclosures that are sealed and marked. The completed modules go through burn-in and temperature cycling before final test. After testing, the modules go into a stocker on the factory floor to await daily shipment to a nearby Toyota automobile assembly plant. 
The entire 100-meter manufacturing line has only one direct labor worker, who folds multiple rigid boards connected by flex cables into a metal enclosure. (Automating that task has not been cost-justified.) Nippondenso claims that there is zero changeover time between products on the line. Each product is identified by a bar code reader and driven by factory-level data from the CIM system. Automated guided vehicles are used to transport production materials to and from the assembly line. Simple and complex engine controllers are intentionally mixed on the line to balance the flow. The highly automated production line at Kota provides an exceptional degree of flexibility and a maximumquality product using minimum direct labor. Nippondenso's five-year plans are to add a second automated assembly line and to reduce the total work force from 3700 to 2000 .

The production equipment at Nippondenso's Kota plant is mostly produced internally. The company employs over 200 people at the Kota site for production equipment and process development. Factory equipment and production processes are designed by teams that include both hardware and software engineers. The Kota plant is responsible for all equipment customization, fixture development, and programming requirements for the site. Because of the unique production requirements, the company finds it cheaper to develop its own equipment than to purchase general-purpose tools. (One tool for inspecting solder joints took over two years to develop.) The average piece of equipment on the manufacturing line is replaced or upgraded every two to three years. Nippondenso has begun to market some production equipment, such as robots, to external customers.

\section{SUMMARY}

It was obvious to the JTEC panel that the Japanese have acquired the necessary skills and knowledge base to design and implement highly effective production systems. Although a high level of automation is evident in their production facilities, it is crucial to note that they strongly emphasize the importance of automation being closely linked to a highly skilled work force in order to obtain maximum production yields and to retain production flexibility.

With continuous commitment to process and equipment development, factory automation, and pursuit of enabling technologies, Japan has developed a strategic advantage over North America's electronics manufacturing industry. In the estimation of the JTEC panel, Japan's expertise in equipment, assembly, and component manufacturing is the most significant leading edge it has in electronic packaging.

\section{REFERENCES}

Kahaner, David K. 1993. "Assembly Line Automation Activities in Japan, 11 March 1993," Scientific Information Bulletin. Tokyo: Office of Naval Research Asian Office. JulySeptember: 33-55.

Takahashi, Yoshikazu, and Takashi Osada. 1990. TPM: Total Productive Maintenance. Tokyo: The Asian Productivity Organization. 


\title{
CHAPTER 6 \\ QuAlity ASSURANCE AND RELIABILITY IN THE JAPANESE ELECTRONICS INDUSTRY
}

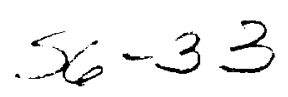

\author{
Michael Pecht \\ William R. Boulton
}

Quality and reliability are two attributes required for all Japanese products, although the JTEC panel found these attributes to be secondary to customer cost requirements. While our Japanese hosts gave presentations on the challenges of technology, cost, and miniaturization, quality and reliability were infrequently the focus of our discussions. Quality and reliability were assumed to be sufficient to meet customer needs. Fujitsu's slogan, "quality built-in, with cost and performance as prime consideration," illustrates this point. Sony's definition of a next-generation product is "one that is going to be half the size and half the price at the same performance of the existing one." Quality and reliability are so integral to Japan's electronics industry that they need no new emphasis.

\section{HISTORY OF JAPAN'S QUALITY MOVEMENT}

The quality movement in Japan began in 1946 with the U.S. Occupation Force's mission to revive and restructure Japan's communications equipment industry. General Douglas MacArthur was committed to public education through radio. Homer Sarasohn was recruited to spearhead the effort by repairing and installing equipment, making materials and parts available, restarting factories, establishing the equipment test laboratory (ETL), and setting rigid quality standards for products (Tsurumi 1990). Sarasohn recommended individuals for company presidencies, like Koji Kobayashi of NEC, and he established education for Japan's top executives in the management of quality. Furthermore, upon Sarasohn's return to the United States, he recommended W. Edwards Deming to provide a seminar in Japan on statistical quality control (SQC). 
Deming's 1950 lecture notes provided the basis for a 30-day seminar sponsored by the Union of Japanese Scientists and Engineers (JUSE) and provided the criteria for Japan's famed Deming Prize. The first Deming Prize was given to Koji Kobayashi in 1952. Within a decade, JUSE had trained nearly 20,000 engineers in SQC methods. Today Japan gives high rating to companies that win the Deming prize; they number about ten large companies per year. Deming's work has impacted industries such as those for radios and parts, transistors, cameras, binoculars, and sewing machines. In 1960, Deming was recognized for his contribution to Japan's reindustrialization when the Prime Minister awarded him the Second Order of the Sacred Treasure.

In 1954, Dr. Joseph M. Juran of the United States raised the level of quality management from the factory to the total organization. He stressed the importance of systems thinking that begins with product designs, prototype testing, proper equipment operations, and accurate process feedback. Juran's seminar also became a part of JUSE's educational programs. Juran provided the move from SQC to TQC (total quality control) in Japan. This included company-wide activities and education in quality control (QC), QC circles and audits, and promotion of quality management principles. By 1968, Kaoru Ishikawa, one of the fathers of TQC in Japan, had outlined the elements of TQC management:

- quality comes first, not short-term profits

- the customer comes first, not the producer

- customers are the next process with no organizational barriers

- decisions are based on facts and data

- management is participatory and respectful of all employees

- management is driven by cross-functional committees covering product planning, product design, production planning, purchasing, manufacturing, sales, and distribution (Ishikawa 1985)

By 1991, JUSE had registered over 331,000 quality circles with over 2.5 million participants in its activities. Today, JUSE continues to provide over 200 courses per year, including five executive management courses, ten management courses, and a full range of technical training programs.

One of the innovative TQC methodologies developed in Japan is referred to as the "Ishikawa" or "cause-and-effect" diagram. After collecting statistical data, Ishikawa found that dispersion came from four common causes, as shown in Figure 6.1.

Materials often differ when sources of supply or size requirements vary. Equipment or machines also function differently depending on variations in their own parts, and they operate optimally for only part of the time. Processes or work methods have even greater variations. Finally, measurement also varies. All of these variations affect a product's quality. Ishikawa's diagram has lead Japanese firms to focus quality control attention on the improvement of materials, equipment, and processes. 


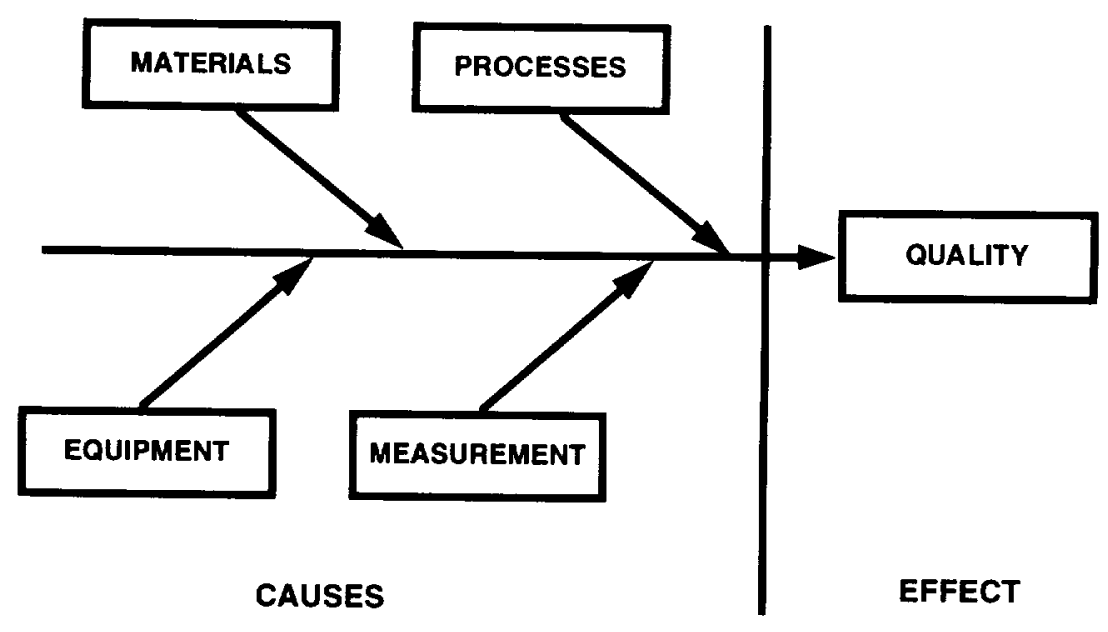

Figure 6.1. Cause-and-effect diagram (Ishikawa 1982, 13).

JTEC panelists observed statistical process control (SPC) charts, often with goal lines extending into 1995, in a few of the factories they visited in 1993. For example, at Ibiden, process control was apparent in its laminated process board manufacture, where there was extensive use of drawings and descriptions of the processes necessary to do the job. Companies that were competing for the Deming Prize made extensive use of such charts, and companies that had received ISO 9000 certification also posted the process information required for each machine. However, the panel was surprised at the relatively limited use of SPC charts within the factories visited. The Japanese believe that the greatest benefit occurs when defect detection is implemented within the manufacturing sequence, thus minimizing the time required for detection, maximizing return on investment, and indirectly improving product reliability.

\section{ISO 9000 Standards Certification}

The concept of certification and standards, however, breaks down when global competitiveness is at stake. Most recently, ISO 9000 certification has become a requirement for exports to Europe, and Japan has been forced to obtain ISO certification, not because it is a quality issue, but because it is a way of increasing market share. The Japanese companies provide some of the highest-quality products, typically using company product standards (best commercial practices) rather than external standards like QML or any U.S. military standards. 
The Japan Quality Association (JQA) is responsible for ISO certification. It was established in 1958 as the Japan Management Institute (JMI) under Japan's Ministry of International Trade and Industry for the purpose of export inspection. In 1960, JMI moved from inspection to process certification, and in October 1993, JMI was renamed JQA to more aptly identify its mission. It has provided ISO 9000 certification in Japan since 1990 after receiving training from the British Standards Institution's (BSI) quality assurance division, and it has memoranda of understanding with both BSI and Underwriters Laboratory (UL) in the United States for reciprocal certification acceptance.

By October of 1993, JQA had ISO-certified 300 firms in Japan, about $80 \%$ of which were electronics firms; the rest were chemical firms. JQA expected to have about 540 companies certified by the end of 1994. It was already booked through 1994, and there was a backlog of over a hundred companies waiting for certification. Most firms seeking certification were electronics firms that depended on exports to Europe. At the time of the JTEC visit, JQA was limited to about thirty assessments per month. It typically took companies one year to eighteen months to gain certification; most had little difficulty in obtaining ISO certification. In addition to JQA certification, there were an equal number of firms obtaining ISO certification from non-Japanese auditors.

When the JTEC panel visited Japan, Fujitsu, NEC, and Hitachi had the largest number of certified factories. Yamagata Fujitsu became ISO 9002-certified in February 1993 and was applying for ISO 9001 certification for early 1994. Fujitsu had over ten certified factories by the end of 1993. Most of the factories visited by the panel had either received ISO certification or were in the process of certification.

\section{QUALITY AND RELIABILITY REQUIREMENTS}

Quality is associated with the degree of conformance of the product to customer requirements, and thus, in a sense, with the degree of customer satisfaction. Implicit in Japanese quality products is an acceptable amount of reliability; that is, the product performs its intended function over its intended life under normal environmental and operating conditions. Reliability assessments are incorporated through simulation and qualification functions at the design and prototyping stages. With basic reliability designed in, quality control functions are then incorporated into the production line using in-line process controls and reduced human intervention through automation. Since the mid1980s, Japanese firms have found that automation leads to improved quality in manufacturing. They have high reliability because they control their manufacturing lines.

Reliability assurance tasks such as qualification are conducted (1) during the product design phase using analytical simulation methods and design-for-assembly software, and (2) during development using prototype or pilot hardware. Once again, it is the role of quality assurance to ensure reliability. Qualification includes activities to ensure that the nominal design and manufacturing specifications meet the reliability targets. In some 
cases, such as the Yamagata Fujitsu hard disk drive plant, qualification of the manufacturing processes and of the pilot lots are conducted together.

Quality conformance for qualified products is accomplished through monitoring and control of critical parameters within the acceptable variations already established, perhaps during qualification. Quality conformance, therefore, helps to increase product yield and consequently to lower product cost.

\section{Quality Assurance in Electronic Packaging}

Japan has a long history of taking lower-yield technology and improving it. In the United States, companies change technology if yields are considered too low. The continuous improvement of quad flat packs (QFPs) in contrast to the introduction of ball-grid arrays (BGAs) is an example of this difference. Both countries are concerned with the quality and reliability limits of fine-pitch surface mount products. The Japanese continue to excel at surface mount technologies (SMT) as they push fine-pitch development to its limits. Many Japanese companies are now producing QFP with $0.5 \mathrm{~mm}$ pitch and expect to introduce $0.3 \mathrm{~mm}$ pitch packages within the next several years. As long as current QFP technology can be utilized in the latest product introductions, the cost of manufacturing is kept low and current SMT production lines can be utilized with minimal investment and with predictable quality and reliability results.

Japan's leaders in SMT have introduced equipment for placing very small and fine-pitch devices, for accurate screen printing, and for soldering. They have developed highly automated manufacturing and assembly lines with a high degree of in-line quality assurance. Thus, in terms of high-volume, rapid-turn-around, low-cost products, it is in their best interests to push the limits of surface mount devices. Furthermore, QFPs do not require new assembly methods and are inspectable, a factor critical to ensuring quality products.

The United States is aggressively pursuing BGA technology; Hitachi, however appears to be applying an on-demand approach. It has introduced BGA in its recent supercomputer without any quality problems and feels comfortable in moving to new technology when it becomes necessary. Since Hitachi's U.S. customers are demanding BGA for computer applications, Hitachi plans to provide BGA products. However, Dr. Otsuka of Meisei University, formerly with Hitachi, believes that for Japanese customers that are still cost driven, QFP packages will reach $0.15 \mathrm{~mm}$ pin pitch to be competitive with BGA in highpin-count, low-cost applications. Dr. Otsuka believes that Japan's ability to continue using QFP will allow Japan to remain the low-cost electronic packaging leader for the remainder of this decade. Like the United States, Japan is pursuing BGA, but unlike the United States, Japan is continuing to improve SMT with confidence that it will meet most cost and functional requirements through the year 2000. Matsushita and Fujitsu are also developing bumped bare-chip technologies to provide for continued miniaturization demands. 
Similar differences in technical concerns exist for wire bonding and known good die (KGD) technologies. The U.S. Semiconductor Industry Association's roadmap suggests a technology capability limit to wire bonding that is not shared by the Japanese component industry. The Japanese industry continues to develop new wire materials and attachment techniques that push the limits of wire bonding technologies. The Japanese consider concerns with KGD to be a U.S. problem caused by the lack of known good assembly (KGA); that is, U.S. firms lack the handling and assembly capability to assemble multipledie packages in an automated, and thus high-quality, manner.

With productivity and cost reduction being the primary manufacturing goals, increased factory automation and reduced testing are essential strategies. As TDK officials explained to the JTEC panelists during their visit, inspection is a critical cost issue:

It is TDK's QA goal to produce only quality products which need no inspection. At TDK, it is our goal to have no inspection at all, either human or machine. Our lowest labor cost in TDK is 32 yen per minute, or one yen every two seconds. If one multilayer semi-capacitor takes roughly one second to produce, then it costs about 0.6 yen in direct cost. If someone inspects it for two seconds, then we add 1.2 yen in inspection cost. That means we have to eliminate inspection to stay competitive. If we can reduce human and machine inspection, we can improve profits. Inspection does not add any value to the product.

Quality control is implemented in the manufacturing lines to ensure that the processes stay within specified tolerances. Monitoring, verification, and assessment of assembly and process parameters are integral parts of the manufacturing line. Quality control ensures that all process variabilities beyond a specified tolerance are identified and controlled.

The key focus of parameter variability appears to be in manufacturing process parameters and human errors and inadequacies, rather than in materials or parts. Incoming inspection is negligible because of the view that the quality of suppliers' products can be trusted, and perhaps more importantly because the inspection process is not considered cost-effective. The global move to ISO 9000 certification helps guarantee supplier quality to further reduce inspection costs.

Selection of specific quality control methods is dictated by product cost. Hidden costs associated with scheduling, handling, testing, and production yields become critical with increasing global competition. As more components are sourced from outside of Japan, these cost factors become increasingly crucial in maintaining competitive costs.

Automation and its impact on quality. The Japanese have determined that manual labor leads to poor-quality output and that automation leads to higher-quality output. Sony's automation activities have reduced defect rates from 2000 to 20 parts per million. Quality has, therefore, become a key driver for factory automation in Japan. In addition, factory automation also adds the benefits of improving productivity and improving flexibility in scheduling the production or changeover of product types. Thus, whenever automation is 
cost-effective, it is used to replace manual assembly, handling, testing, and human inspection activities. This approach is applied to each new product and corresponding production line that is installed. For example, the old printed wiring board assembly line at Fujitsu's Yamagata plant used extensive manual inspection, while the new line is in a clean room and is totally automated, including final inspection and testing.

All of Nippondenso's plants have now implemented factory-wide CIM systems. The system at Kota, for example (see Chapter 5), uses factory-level data to meet quality standards and delivery times. Boards are inserted into metal enclosures, sealed and marked, then burned-in and tested before shipping. Out of several hundred thousand units produced each month, only a couple of modules failed testing each month, according to JTEC's hosts.

Inspection and screening. As noted above, incoming inspection was negligible at most of the companies that the JTEC panel visited, because of the view that the quality of suppliers' products could be trusted. Since the 1950s, the Japanese government has set quality requirements for any company that exports products from Japan. Suppliers have progressed in status from being fully inspected by their customers to being fully accepted. Qualified suppliers are now the standard for Japan, and most problems come from nonJapanese suppliers. Akio Morita of Sony lamented that finding quality U.S. suppliers was a major challenge for the company. Japanese suppliers were part of the "virtual" company, with strong customer ties and a commitment to help customers succeed.

Components were not being screened at any of the printed wiring board (PWB) assembly, hard disk drive, or product assembly plants visited by the JTEC panel. Defects are seldom found in well-controlled and highly automated assembly lines. Where specific problems are found, tailored screens are implemented to address specific failure mechanisms at the board or product assembly level. For example, Fujitsu noted that today's components do not require burn-in, although at the board level it conducts some burn-in to detect solder bridges that occur during board assembly. But with the increasing cost of Japanese labor, the greatest pressure is to avoid unnecessary testing activities. Suppliers simply have to meet quality conformance standards to keep customers satisfied. Lack of conformance to requirements would be considered noncompetitive.

With reliable components, assemblers must concentrate their efforts on the assembly process. Within a company's own production lines, automated inspection is central to factory automation activities. Older lines, like the $31 / 2$-inch disk drive line the panel saw at Fujitsu, have extensive $100 \%$ manual inspection of PWBs. Fujitsu's new line has fully automated inspection and testing. At Ibiden, automated inspection is part of the automated manufacturing process as a technique for alignment and assembly as well as for tolerance assessment and defect detection. Microscopic mechanical dimensioning is conducted on a sample basis. The newer the line, the greater the automation of inspection and testing. 


\section{Reliability in Electronic Packaging}

In terms of reliability, the Japanese proactively develop good design, using simulation and prototype qualification, that is based on advanced materials and packaging technologies. Instead of using military standards, most companies use internal commercial best practices. Most reliability problems are treated as materials or process problems. Reliability prediction methods using models such as Mil-Hdbk-217 are not used. Instead, Japanese firms focus on the "physics of failure" by finding alternative materials or improved processes to eliminate the source of the reliability problem. The factories visited by the JTEC panel are well equipped to address these types of problems.

Assessment methods. Japanese firms identify the areas that need improvement for competitive reasons and target those areas for improvement. They don't try to fix everything; they are very specific. They continuously design products for reduced size and cost and use new technologies only when performance problems arise. As a result, most known technologies have predictable reliability characteristics.

Infrastructure. The incorporation of suppliers and customers early in the product development cycle has given Japanese companies an advantage in rapid development of components and in effective design of products. This is the Japanese approach to concurrent engineering and is a standard approach used by the companies the JTEC panel visited. The utilization of software tools like design for assembly allows for rapid design and is an integral part of the design team's activities. At the time of the panel's visit, design for disassembly was becoming a requirement for markets such as Germany. Suppliers are expected to make required investments to provide the needed components for new product designs. Advanced factory automation is included in the design of new factories.

Training. The Japanese view of training is best exemplified by Nippondenso. The company runs its own two-year college to train production workers. Managers tend to hold four-year degrees from university engineering programs. Practical training in areas such as equipment design takes place almost entirely within the company. During the first six years of employment, engineers each receive 100 hours per year of formal technical training. In the sixth year, about $10 \%$ of the engineers are selected for extended education and receive 200 hours per year of technical training. After ten years about $1 \%$ are selected to become future executives and receive additional education. By this time, employees have earned the equivalent of a Ph.D. degree within the company. Management and business training is also provided for technical managers. In nonengineering fields, the fraction that become managers is perhaps $10 \%$.

Ibiden uses "one-minute" and safety training sessions in every manufacturing sector. "Oneminute" discussions are held by section leaders and workers using visual aids that are available in each section. The subjects are specific to facets of the job like the correct way to use a tool or details about a specific step in the process. The daily events are intended to 
expose workers to additional knowledge and continuous training. As a consequence, workers assure that production criteria are met. Ibiden also employs a quality patrol that finds and displays examples of poor quality on large bulletin boards throughout the plant. Exhibits the panel saw included anything from pictures of components or board lots sitting around in corners, to damaged walls and floors, to ziplock bags full of dust and dirt.

The factory. Japanese factories pay attention to running equipment well, to continuous improvement, to cost reduction, and to waste elimination. Total preventive maintenance (TPM) is a methodology to ensure that equipment operates at its most efficient level and that facilities are kept clean so as not to contribute to reliability problems. In fact, the Japan Management Association gives annual TPM awards with prestige similar to the Deming Prize, and receipt of those awards is considered a required step for companies that wish to attain the Japan Quality Prize. No structured quality or reliability techniques are used - just detailed studies of operations, and automated, smooth-running, efficient production.

Safety concerns appeared to the JTEC panel to be secondary to efficiency considerations. While floor markings and signs direct workers to stay away from equipment, few barriers keep individuals away from equipment. In the newest production lines, sensors are used to warn individuals who penetrate into machine space, and the sensors even stop machines if individuals approach too close. Factories provide workers with masks and hats rather than safety protection like eye wear. In most Japanese factories, street shoes are not allowed.

Most electronic firms the panel visited were in the process of meeting new environmental guidelines. Fujitsu removed CFCs from its cleaning processes in October 1993. CFCs were replaced by a deionized-water cleaning process. In the old assembly process, the amount of handling required for inspection reduced the impact of cleaning. The new line had no such problems.

To provide high reliability, Japanese firms create new products using fewer components, more automation, and flexible manufacturing technologies. For example, TDK is striving for 24-hour, nonassisted, flexible circuit card manufacturing using state-of-the-art highdensity surface mounting techniques and integrated multifunction composite chips. It has developed true microcircuit miniaturization technologies that integrate 33 active and passive components on one chip. This will reduce the number of components required by customers during board assembly, thereby reducing potential assembly defects.

In addition, the application of materials and process know-how provides a fundamental competitive advantage in manufacturing products with improved quality characteristics. Nitto Denko, for example, has developed low-dust pellets for use in molding compounds. Ibiden has developed an epoxy hardener to enhance peel strength, thus improving reliability of its plating technology. The new process reduces cracking in the high-stress areas of small vias. Ibiden also uses epoxy dielectric for cost reduction and enhanced thermal conductivity of its MCM-D substrate. At the time of the JTEC visit, the company was also attempting to reduce solder resist height in an effort to improve the quality and 
ease of additive board assembly. It believes that a product with a resist 20 mils higher than the copper trace can eliminate solder bridging. Sony developed adhesive bonding technologies in order to improve the reliability and automation of its optical pickup head assembly. It set the parameters for surface preparation, bonding agents, and process controls. Sony used light ray cleaning to improve surface wetability and selected nine different bonding agents for joining various components in the pickup head. It now produces some $60 \%$ of the world's optical pickup assemblies. The continuous move to miniaturization will keep the pressure on Japanese firms to further develop both their materials and process capabilities.

\section{Quality Improvement Through Comprehensive Waste Reduction}

Fundamental improvement means working to eliminate wastes that can negatively affect product quality, cost, and delivery time. The Japan Management Association published a book describing the activities of Canon Corporation, Canon Production System: Creative Involvement of the Total Workforce, that outlined a number of approaches to improve quality and reliability through "waste reduction" strategies (JMA 1987, 19-22). These include the elimination of waste associated with defective products, systems planning, work-in-process, human resources, equipment, expenses, and excessive startup time for new products. Most Japanese electronics firms now incorporate waste reduction as a central part of their TQM programs.

\section{TQC Management Strategies}

The total quality movement in Japan has lead to pervasive top management involvement. Many companies in Japan have extensive documentation on their quality activities. With Koji Kobayashi, NEC's retired chairman, providing early leadership in Japanese TQC development, NEC has a comprehensive quality strategy. In 1965, NEC initiated its TQC movement under the name of zero defects (ZD). In 1972, the NEC Corporation formally initiated its total quality strategy, which included the following components:

- quality of management is promoted by all executives

- quality of products and services is promoted within all functional departments from purchasing and engineering through sales and transportation

- quality of human behavior is promoted within all human resource activities from personnel and industrial relations through education and training

- quality of working environment is promoted by all operating and support operations concerned with the well-being of the workforce

- quality of community relations is promoted by operational support and environmental control divisions

- quality of business operations is promoted by the comptroller's division

- quality of the corporate image is promoted by public relations and advertising divisions under the guidance of top management (Satoh 1986) 
By the early 1980s, NEC had over 3,000 ZD groups in operation that were generating over 43,000 suggestions, and it had received over 14,000 commendations for goal achievement. One of NEC's major divisions or subsidiaries typically received the Deming Prize each year.

Tadahiro Sekimoto, NEC's current chairman, continues to embrace the TQC philosophy in order to ensure the continuing survival of today's corporation. He argues that such survival requires that companies be thought of as eternal organizations. He was critical of U.S. companies:

In America, the eternal continuity of a company is not always a consideration. If 1 may remark in my own words, it seems that in America, companies are continually subleased. A company is purchased. It is made over, restructured and though purchased at $\$ 10$ billion, it is sold for $\$ 10.5$ billion - this is considered a way of management. Whether this is proper or not is another question. In Japan, however, most companies, and especially NEC, must be eternal (Sekimoto 1992, 220).

Sekimoto further argued that eternal management requires effective management of people - people who have hearts and minds, who must be motivated in the workplace, and who are empowered to accomplish visions of the future. The Deming Prize is simply one method of testing the organization's capability to perform at higher and higher levels in the future.

\section{SUMMARY}

Japan's electronics industry has developed its quality management techniques since the 1940 s, based on the work of American experts like Deming and Juran. Japanese experts have advanced these concepts into peerless total quality management and continuous waste reduction systems; however, Japanese technology is associated with solving problems incrementally. There is nothing particularly revolutionary or strategic about their quality and reliability methodologies. Japanese equipment is very good, very accurate, and very well maintained. When Japanese firms have a quality or reliability problem, they investigate it thoroughly. They do not investigate areas that are not problems unless that is demanded by the customer or unless there are competitive issues. Most of the research is targeted at improving next-generation products, components, materials, equipment, or processes. It is by dominating in materials, equipment, and manufacturing processes that Japanese electronics firms have been able to provide the highest quality and reliability in today's electronics markets.

\section{REFERENCES}

Ishikawa, Kaoru. 1982. Guide to Quality Control. Tokyo: Asian Productivity Organization.

Ishikawa, Kaoru. 1985. What Is Total Quality Control? The Japanese Way. Englewood Cliffs, NJ: Prentice-Hall. 
JMA (Japan Management Association). 1987. Canon Production System: Creative Involvement of the Total Workforce. Stamford, CT: Productivity Press.

Satoh, Yukio. 1986. Challenge to the Quality Revolution. Tokyo: NEC Corporation.

Sekimoto, Tadahiro. 1992. "Perspectives and Directions of Management Strategies in the 1990s," in Advances in Applied Business Strategy. Vol. 3. Greenwich, CT: JA1 Press.

Tsurumi, Yoshi. 1990. "An Interview with Homer M. Sarasohn: The Unsung American Hero of Japan's Total Quality Control System.” In Pacific Basin Quarterly, Winter/Spring: 1-5. 


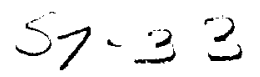

CHAPTER 7

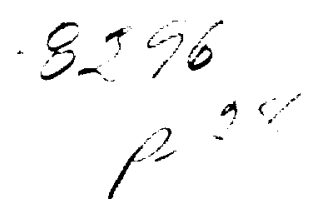

\title{
SUCCESSFUL PRODUCT REALIZATION STRATEGIES
}

\author{
John Peeples \\ William R. Boulton
}

Product realization is the process of defining, designing, developing, and delivering products to the market. While the main thrust of this JTEC panel was to conduct a complete investigation of the state of Japanese low-cost electronic packaging technologies, it is very difficult to totally separate the development of technology and products from the product realization process. Japan's electronics firms adhere to a product realization strategy based on a strong customer focus, a consistent commitment to excellence in design, and a cost-effective approach to technology commercialization. The Japanese product-pull strategy has been a successful driver and influencing factor in every aspect of the product development cycle.

\section{REQUIREMENTS DEFINITION}

Defining product requirements is critical to the product realization process. Incomplete or incorrect requirements nearly guarantee a noncompetitive product offering. In a marketdriven environment, the establishment of product requirements is clearly a job demanding a customer focus. The JTEC panel's site visits provided evidence of an extremely tight coupling between Japanese companies' product realization activities and their targeting of customers' needs. This tight coupling enables the complete and accurate definition of future product requirements. Panelists observed the following examples of Japan's customer focus:

- widely posted customer- and society-based mission statements

- established systems to ensure daily customer contact

- no development programs without identifying a clear customer need 
- early customer involvement, even at the conceptual stage of product design

- standing committees established to solve customer problems

- clearly defined component development strategies that avoid competition with customers' product strategies and simultaneously project future customer requirements

Matsushita's published mission statement provides a clear example of the kind of customer and societal focus found in Japanese electronic firms:

Since its founding in 1918, Matsushita has adhered to the same basic philosophy of product development: contribute to society and improve living standards by providing products of superior quality and functionality. ...In line with this move toward creating a more organic, affluent society, Matsushita is entering new fields and developing the electronic products that will satisfy customer needs in the $21 \mathrm{st}$ century.

\section{Japan's Focus on the Customer}

Among the JTEC panel's most important observations was the tight focus in Japanese companies on the market and the customer. No matter what material, component, or product companies are developing, they are all trying to meet their customers' needs. Suppliers are developing material and component technologies that meet the future miniaturization needs of the end-product companies. Consumer electronics firms are searching for products that will generate new markets or stimulate existing markets with lower prices or more features. This focus affects all levels of Japan's electronics industry. Providing lower prices and improved quality requires better designs and manufacturing systems; improved features require new or improved components and technologies.

Every Japanese electronics firm is looking downstream to meet its customers' future needs; at the same time, many companies are also using their upstream technologies to integrate into component technologies. Murata, for example, is building on its miniaturization strengths in capacitors to develop complete functional radio frequency (RF) modules. Murata is building a gallium-arsenide integrated circuit pilot plant to protect its intellectual property and to improve its competitive position in the microwave and RF module business, with a focus on future personal communication products. By building on its core technologies, the company is following the strategy of other electronics firms in finding new applications or intermediate products whose markets it can dominate. On the consumer side, Sharp is the most creative firm in finding and using what it calls "sense leaders" to supply product direction. A whole industry of suppliers is ready to supply whatever electronic packaging technologies and equipment are needed to meet their customers' miniaturization and next-generation product development needs. Supplier support and availability of components and equipment reduce development and commercialization time.

Murata demonstrates one of the strongest commitments to its customers by providing daily contact with customers. The company so values its customers that it encourages both its 
sales personnel and its application engineers to live within walking distance of key customers. The JTEC panel's hosts at Murata pointed out that accounts are often visited several times daily and/or called as often as six times per day. It would be difficult for another company to penetrate Murata's customer accounts without providing equivalent levels of service and contact. Murata's people are extremely close to their customers.

Customer involvement in defining product requirements is clearly a part of product planning activities. At every phase, customers have input. The customer is involved much earlier than is typical in U.S. firms, participating even at the conceptual phase of the project. Sony and TDK have both dropped their efforts to develop superconductor technologies due to present lack of customer interest. TDK, the firm whose founders invented ferrites, canceled its high-temperature superconduction work after realizing that its target customers would only develop products that operate at normal temperatures. Sony is keeping only a minimal effort in this area for similar reasons. It is important not to confuse the cancellation of work in absence of a customer need with an unwillingness to invest strategically. The JTEC team observed a clear willingness to invest heavily and with great perseverance in technologies where results were not expected for five or even ten years. For example, Sony's investment in the compact disc took thirteen years to matriculate. Long-term investments occur only when customers' needs are clearly understood.

The use of problem-solving committees showed the JTEC team a different approach to customer support than what some U.S. companies use. Where a team may be formed in the United States to address and resolve a particular customer problem, several Japanese companies reported having specific standing committees devoted to helping customers overcome novel application problems. The intent of these committees seems to be heavily biased in favor of collecting requirements for future products as opposed to just resolving current problems. By having such close communications, these companies are able to define the requirements for next-generation products.

\section{DESIGN FOR EXCELLENCE}

A key part of any product realization process is the robustness of the design. In the United States, many "Design for" initiatives such as Design for Assembly, Design for Cost, Design for Manufacturing, Design for Test, Design for Logistics, Design for Performance, and so on are now being referred to as Design for Excellence (DFX). The JTEC panel found that Japanese design emphasizes two key areas: the overall development process and concurrent engineering. As shown in Figure 7.1, there is a strong customer focus at the product planning phase and in the product evaluation phase of the product development process. The overall product development process is rooted in what Japanese firms call the "marketin." Market-in refers to having a clear set of customer-driven requirements as the basis for product development. This is a fundamental requirement for DFX. Concurrent engineering of product design and development activities provides the second main step in achieving DFX. 


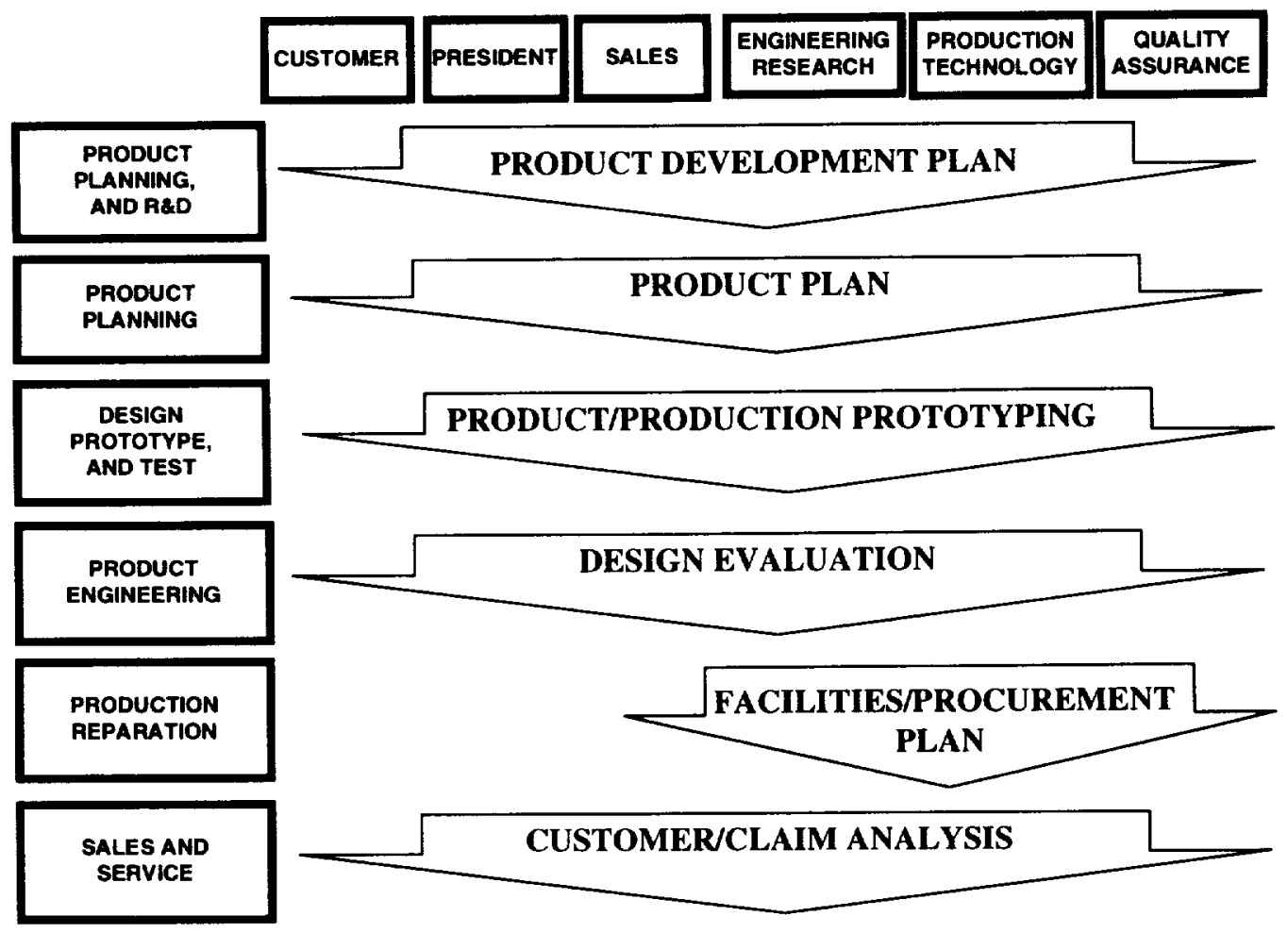

Figure 7.1. Japan's product development activities (Toyoda Machine Tool Co.).

In order to effectively deploy a timely design, thorough testing of the design and process training are considered a must. The JTEC panel members toured a number of training facilities affiliated with process development laboratories. Company employees, often including foreign nationals, receive months of training on specific manufacturing processes before equipment is installed overseas.

A successful DFX process requires carefully managed design of new products. As shown in Figure 7.2, there are numerous activities that must be coordinated in order to develop and implement a successful product realization effort. Information must be gathered and analyzed from regions of the globe in which products will be introduced, and products must be market-tested in those specific regions. An engine controller for use in an American version of a Japanese automobile, would, by necessity, receive its reliability testing in the United States. Products that are targeted globally, however, also get tested in Japan in order to carefully control the products' globalization. Technology development activities must operate in parallel with product technology planning and market development planning to assure timely development and introduction of new products. 


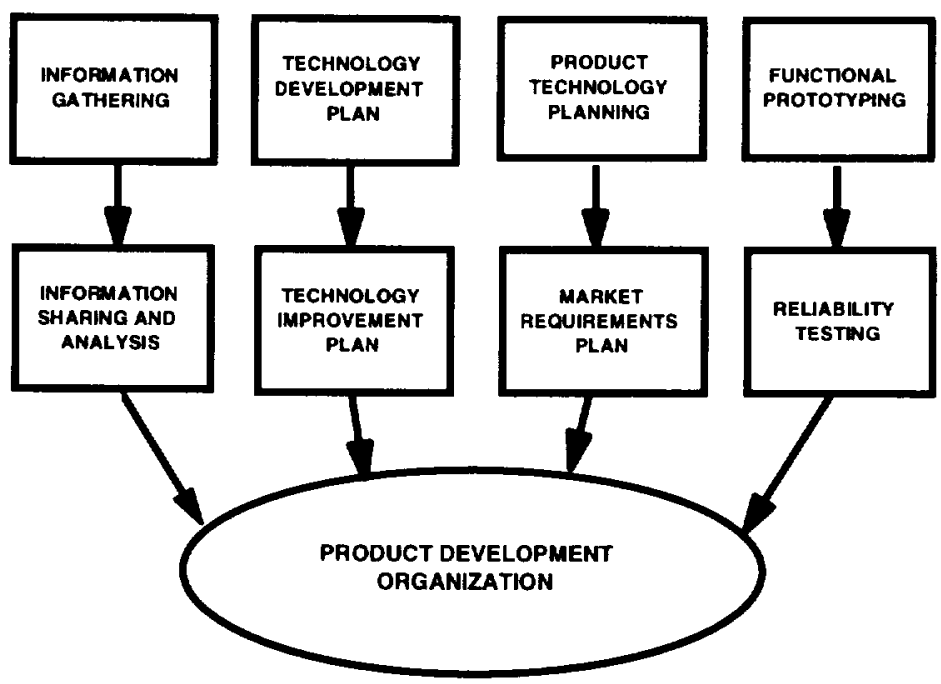

Figure 7.2. Concurrent development requirements (Sony Corp.).

In Japan, product development and market testing is widespread. A visit to the Akibahara, Tokyo's electronics district, introduces the visitor to many consumer products that will never leave the shores of Japan. The strategy of testing products at home differs from the strategy of some U.S. companies that test new products in whatever region of the world is most likely to provide the initial product order. Experience has shown that Japanese consumers are more demanding and also more willing to buy new products than consumers in many overseas markets. As a result, the latest versions are typically found in Japan first. The best-received new products sold in Japan are then exported with expectations of high acceptance in overseas markets.

\section{Concurrent Development Activities}

Focus on concurrent engineering is prevalent in all the organizations the panel visited. The primary objective is to get the overall design right at the lowest cost. This requires making critical decisions as to product features/functions, manufacturability, and most importantly, cost. JTEC panelists saw numerous examples of this focus on concurrent engineering in order to lower product cost. Our hosts at Sony described in detail an effort to develop the adhesives used in the assembly of the CD pickup head in order to achieve cost goals of the product line. Similar stories from other companies abound. Functional boundaries are disregarded once product or cost objectives are specified.

Evidence of Japan's concurrent engineering culture was overwhelming to the JTEC panel. As shown in the following figures, firms use a variety of concurrent engineering 
schematics to depict product, process, and equipment development efforts. For a firm with a core material competence, the product is often a new material, and its schematic would show concurrent development of materials, process, and equipment. Concurrent engineering is a culture in Japan. New products and materials are developed simultaneously with the processes and equipment needed to produce them.

Japanese firms first attempted to break down functional barriers as part of the TQM (total quality management) activities initiated to incorporate quality into product design activities. This was the beginning of what is today referred to as concurrent engineering. The strategic objectives typical of Japanese firms in the mid-1980s were summed up in the quality, cost and delivery (QCD) motto (see Chapter 2). Functional compartmentalization was totally inadequate to effectively meet the cross-functional requirements of these strategic objectives.

MITI described the first functional integration model based on teams, as shown in Figure 7.3. This approach is a minimum requirement for competitive success in product development and for facilitating rapid product introductions. MITI points out that close coordination between functions dramatically cuts time to market. The problem with this model is that any one of the functions can still become a bottleneck to development activities because of shared resources. Sharp utilized this model until 1990, when it moved to what is known today as concurrent engineering. A similar problem now faces producers of electronic products that lack manufacturing capabilities in electronic packaging. Without the capabilities to produce and assemble miniaturized components in-house, firms will be unable to get next-generation products into the market as quickly as their competitors.

BASIC \&
APPLIED
RESEARCH

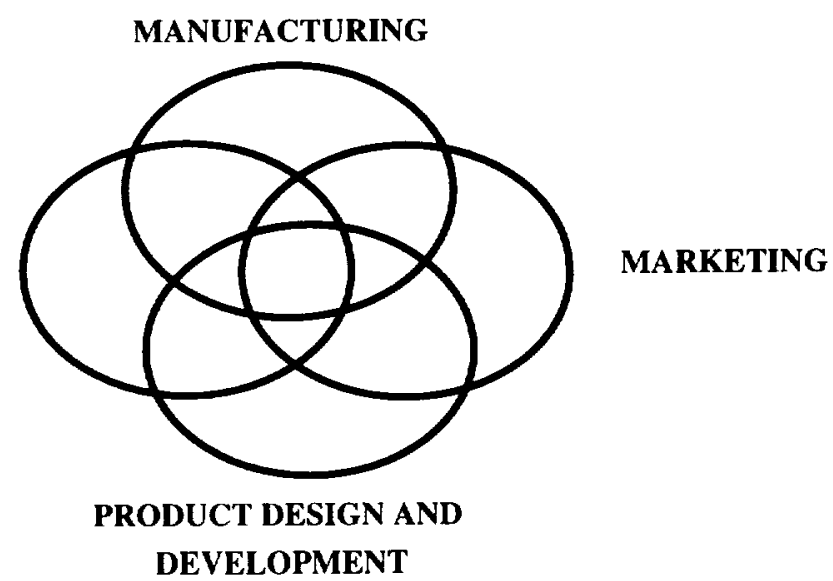

Figure 7.3. Functional integration required for technological innovations (MITI). 
Going beyond team developments, the concept of concurrent engineering is being practiced in Japan under TQM systems. (Sharp changed the name of its practice from TQM to concurrent engineering after U.S. visitors in 1990 described what it was doing as concurrent engineering.) To shorten time to market for new technologies, firms are working simultaneously to develop component and insertion technologies to be introduced at the time the product is prototyped. As shown in Figure 7.4, concurrent engineering requires parallel implementation of all functional activities.

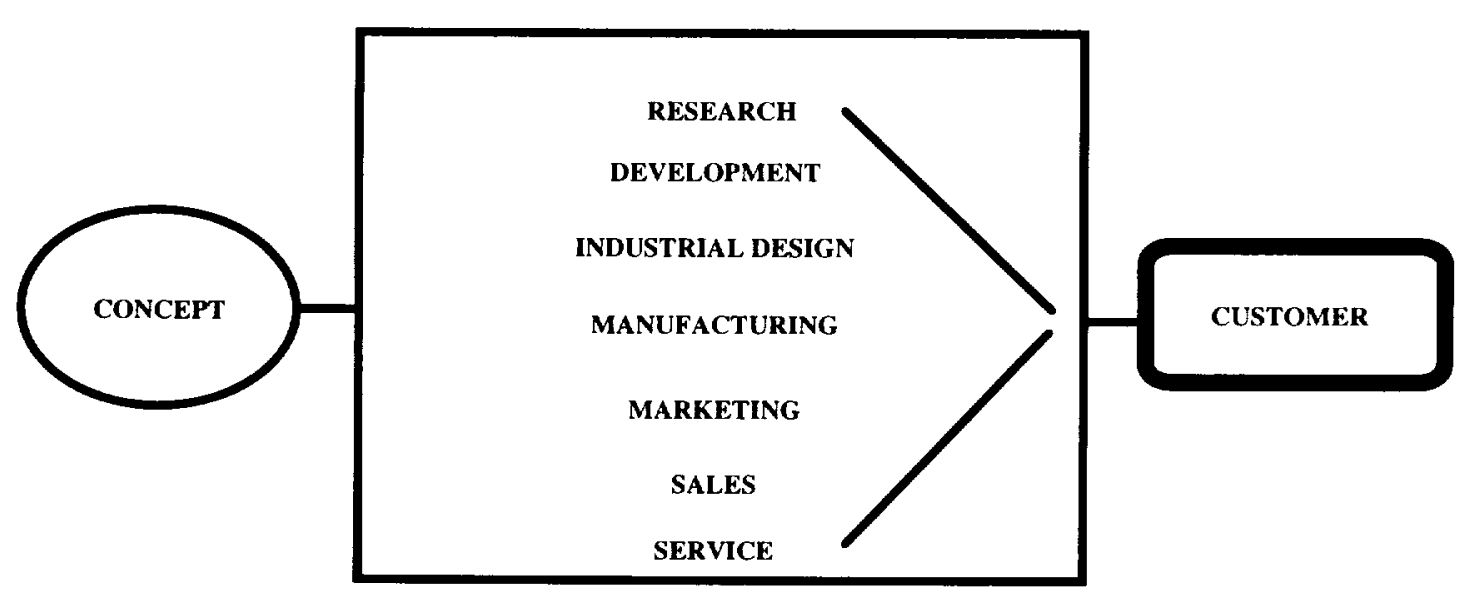

Figure 7.4. Concurrent engineering for product innovation (MITI).

In advanced electronics, U.S. product development is going to be limited by the lack of basic technologies required for successful production of advanced electronic products. Thorndyke (1993) was not very encouraging to small supercomputer firms in the United States. He noted that the lack of high-performance packaging technology and assembly capability was putting them in jeopardy:

The U.S. companies are in danger of being driven out of the market because of the high costs of a broad product line and the multi-billion-dollar revenues required to fund the R\&D and tooling. The only U.S. companies that can compete in such a broad market [are] IBM, and possibly Cray Research.

The MCC/Sandia report (1993) came to a similar conclusion:

The low cost, high technology manufacturing base of Japan qualifies it to gain significant market share in the area of industrial electronics and high performance systems. To defend existing opportunities and to create new avenues for economic growth, North America must develop a similar low cost, high technology manufacturing infrastructure. This can only be accomplished through a commitment to manufacturing consumer products, and in particular, consumer electronics, which can provide the high volume demand necessary to rationalize the cost of investment. 


\section{Innovation and Improvement}

In the area of innovation and improvement, the Japanese focus is on core competencies and on technology. Companies with core competencies in manufacturing and materials include the following:

Miniaturization and Automation

- Sony

- Matsushita

- Nippondenso $\underline{\text { Materials }}$

- Ibiden

- Nitto Denko

- TDK

- Murata

The JTEC panel found that the concept of core competencies is well understood by these companies. For example, an excerpt from a Murata annual report reads, "Superior electronic materials lead to superior electronic components, which lead to superior electronic equipment." The micromachining core competency of Nippondenso is so integral a part of the company's strategy that one recent annual report features a $4.8 \mathrm{~mm}$ long micromachined automobile, complete with rolling wheels and license numbers. A photograph of the car is printed on a page of a dictionary, positioned on top of the word "creative."

Corporate core competencies enable efficient use of technology; furthermore, process technologies enable more rapid product introductions. For example, Ibiden coupled its competency in inorganic materials and in electronic laminates (two separate divisions of Ibiden) to develop Ceracom. Ceracom is a low-cost ceramic-cored printed wiring board for direct chip attach applications that require a substrate thermal coefficient of expansion similar to that of silicon. Another example is the surface mount component mounting density roadmap that Sony uses to drive its HandyCam development. Sony's TR1 palmsized HandyCam required the development of a 20 components per square centimeter process, nearly double the density of previous models. Sony presents this story as one in which the process technology enables the company to achieve its product size objectives for next-generation products.

The JTEC panel found that most companies visited have a base technology strategy that is relentlessly pursued. One panel member had also visited two of the companies in 1990. He said, "In comparing the 1990 and 1993 meetings, I was impressed with the degree of their consistency in their technology development activities. I describe this as 'technoperseverance' as opposed to 'techno-thrashing.' If you visited U.S. firms on 3-year intervals, they would most likely be pursuing entirely different technologies in their search for 'silver bullet' solutions. These Japanese companies covered the identical strategies for fine-pitch SMT development that I had seen in 1990, often using the same identical overheads showing progress along the technology timeline. [Chapter 4 covers many of these developments.] The point to emphasize here is the tireless pursuit of the technology strategy and the accompanying resistance to distraction." 


\section{Increasing Value Added Through Component Development}

Successful product realization efforts demand both product and production strategies that ensure adequate gross margins and successful product or product line deployment. To ensure adequate gross margins, companies focus attention on value addition and product phasing. Companies that JTEC visited showed a clear understanding of present costs and value added for their products, components, or materials. Consumer electronics product firms such as Matsushita increase value added opportunities through vertical integration to supply the value chain for their products. For example, Matsushita provides the substrates and many of the components used in Panasonic VCRs.

For compact disk players' optical pickup heads, Sony developed the design, processes, and equipment necessary to produce them in-house. Today Sony provides $60 \%$ of the worldwide market for optical pickup heads for compact disk units. For the $8 \mathrm{~mm}$ video camera, Sony developed the magnetic pickup head and drum and the CCD (chargecoupled device) components as key parts of the overall program. The value added from key components is about $65 \%$, compared to only about $12 \%$ for final assembly. Since Sony makes about half of its key components, it is able to derive $35 \%$ value added from in-house production of key components, compared to only $12 \%$ for the assembly of $8 \mathrm{~mm}$ camcorder products. The value added contribution of other products like CD players is similar.

Product phasing into next-generation products is clearly understood in Japan. While U.S. companies seek to extend product life cycles and shorten development cycles, Japanese companies seem to more clearly differentiate between product improvements and new product introductions. Product improvements occur annually or even semiannually for the most competitive consumer electronic products. New or next-generation products typically require 1-5 years for development. The Sony Walkman, with 160 model releases since its introduction in 1979, has an average model life of less than 18 months. Typically, annual product improvements are released in response to competition, and the central labs, in conjunction with factory teams, engage in developing 3rd- and 4th-generation products.

\section{Requirements of Production Skills}

The final phase of the product realization process focuses on execution and competition. Keeping product cost low is critical to remaining competitive in the consumer electronics industry. The cost objective can be lost for a myriad of reasons. The Japanese concentrate on a set of requirements that include the following: developing what the customer wants; ensuring that the product is manufacturable; targeting and obtaining the desired value addition; tuning production processes and equipment for maximum yield (automating to reduce defect rates, to produce miniaturized products, to facilitate rapid offshore start-up, and to free up skilled labor); and utilizing global markets to achieve economies of scale.

The panel found that Japanese firms invest heavily to tune production processes for nextgeneration products. Each new product generation is designed for the most efficient 
production techniques and equipment. This includes the reduction of the number of parts and the use of standard parts whenever possible. Industrial engineering techniques are used to optimize velocity and minimize waste in a manual production line. Automation is then applied to maximize efficiency and minimize production cost.

Automation has become an essential element of the product realization process at the electronic packaging level, for several reasons. Increased quality and miniaturization are two reasons cited, but Sony automated its Walkman assembly process in order to rapidly deploy Walkman production to offshore sites. Developing new markets and overcoming currency exchange rate barriers are two of Japan's most pressing challenges. Firms are being forced to move operations out of Japan to less developed countries in order to stay competitive. Sony found that its fully automated production line could be deployed and brought on line in a period of one to three weeks compared to three to six months for a manual assembly line.

Man-machine harmony was also mentioned in most discussions on automation held during the JTEC visits. A stated advantage of and reason to automate is to free up human value for more complex and creative tasks. Some of this discussion is, in reality, a rationalization for the replacement of manpower with automation.

Japanese companies visited by the panel study their competition continuously. They respect and attempt to fully understand their competition at all times, and they appear to relish the "fight." For example, Konosuke Matsushita wrote in My Management Philosophy, "My proverb about management says that if we fight a hundred wars, we should win a hundred victories," and also, "You pray for the survival of your rival because you want another chance to demonstrate your superiority."

\section{JAPANESE TECHNOLOGY COMMERCIALIZATION EFFORTS}

The following four examples provide unique insights into how Japanese companies successfully bring products to the marketplace.

\section{Murata Manufacturing Company}

Murata is a world leader in ceramic capacitors, ceramic filters, and other electronic components. Murata's central technology-driven strategy, shown in Figure 7.5 , includes integrating ceramic materials technology, electronic machinery design technology, and

production process technology to develop downstream products. Its R\&D organization has been set up to carry out this strategy.

Under the corporate-level technical administration division are (1) the fundamental research laboratory for materials, new processes, and HF components, (2) the module and application development laboratory for next-generation communications and sensing 
devices, and (3) the machinery and production engineering laboratory for production line and semiconductor equipment development. Within the product divisions are materials, functional devices, and components laboratories responsible for both product and process developments.

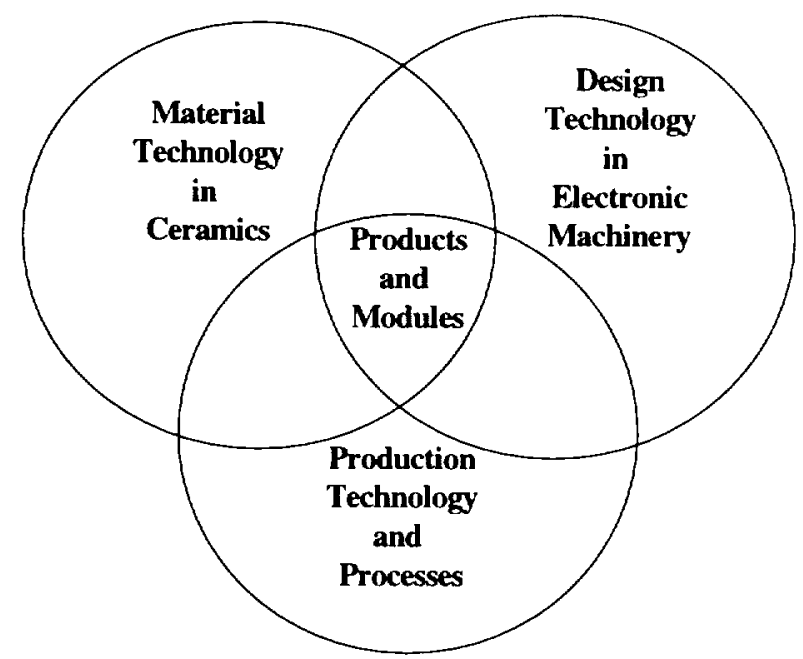

Figure 7.5. Murata's integrated technology strategy.

Murata's R\&D management approach combines technology roadmaps with technology programs targeted at strategic themes. Technology roadmaps identify opportunities for early involvement in new areas of technology that have long-term potential. To gain a position in such technologies requires a strategic technology program that will build a core competence in the company. The commitment to such technology programs requires a long-term vision that fits within the overall direction or business theme for the company. R\&D themes require approval by Murata's board of directors in order that appropriate resources can be allocated. Murata currently has 27 strategic technology programs under development. Each program is reviewed at each phase of its development, starting with surveys, moving through research, development, application design, and preproduction, and finishing with mass production.

\section{Sony Corporation}

Sony has had a balanced strategy for product realization. Its strategy has included the development of product "sets" that use the company's own components (CCDs), devices (semiconductors), and advanced materials. As demonstrated in Figure 7.6, Sony takes concurrency to the most comprehensive level to ensure that the entire product component set offering and infrastructure are being developed in phase. Sony's product-oriented strategy is coordinated by corporate $R \& D$ and includes three critical activities: 


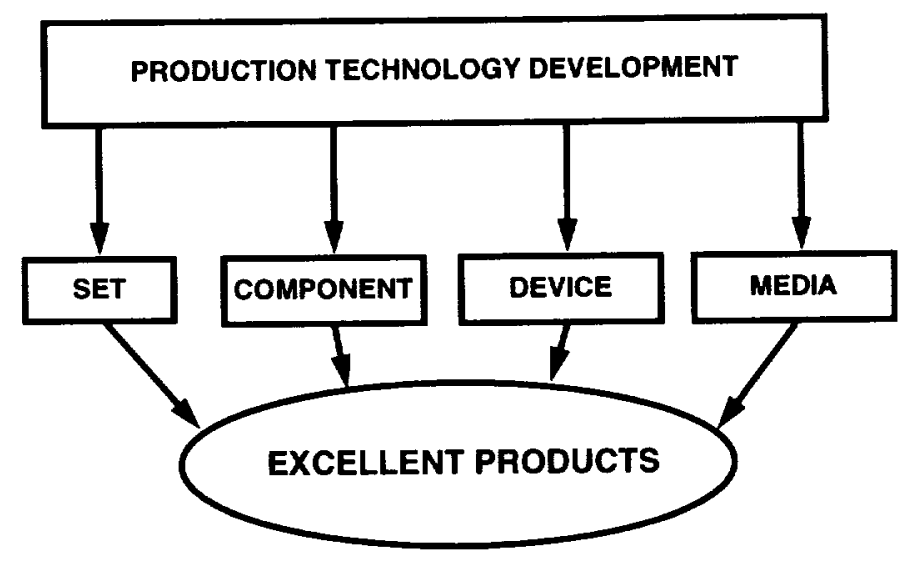

Figure 7.6. Sony's concurrent development model.

1. Deciding on major product targets. This corporate-level function is assigned to the R\&D Corporate Planning Group. Large corporations need multiple projects in parallel. Moving from consumer products to systems that include voice/data/video/graphics makes identification of targets difficult. Such targets include personal communication products, multimedia components, ISDN systems, and next-generation displays.

2. Identifying the mid- and long-term strategic technologies required to achieve product targets. These decisions affect budget allocation and other resource allocation decisions.

3. Establishing an R\&D organization to effectively develop required technologies. This includes clarifying the mission of corporate and divisional laboratories and setting time schedules for project assignments.

The divisional laboratories of Sony's 19 business units are responsible for developing new products in their markets within three-year time frames. Sony has development laboratories for audio, consumer video, displays, business and professional, computer and memory, high-definition recording, components, ULSI, and production technology applications. The semiconductor and production technology groups have in-house support responsibility for product divisions in addition to their business responsibilities. Corporate R\&D funds are used for mid- and long-term R\&D projects.

In January 1993, Sony reorganized its corporate laboratories: The Yokohama Research Center has materials responsibilities; the Corporate Research Laboratory has device development responsibility; the Telecommunication and Information Research Laboratory has networking responsibilities; and a new Development Laboratory has responsibility for new products that do not fall within current divisional domains. All corporate laboratories are responsible for activities with development time frames beyond three years. 
With the continuing recession in Japan, most companies were attempting at the time of the JTEC panel's visit to improve their R\&D efficiencies. Sony was more discriminating in the selection and weighting of research themes. It was also reevaluating its R\&D funding system with a view to reducing corporate funding to $50 \%$ of the total and shifting more of the funding burden to the business divisions. The company had also established a requirement for laboratories to market their technologies in order to more effectively disburse them into the divisions. The corporate development laboratory was set up to help in technology commercialization, especially for new types of products that were outside the domain of current business groups. Finally, R\&D activities were being centralized within specific locations in order to increase the concentration of effort and know-how.

There is no question that Sony is a product-driven company. By focusing R\&D activities at product targets, it is easier to transfer technologies quickly to the divisions. The critical technologies include materials and semiconductors, key devices like the CCD, and automation technologies for packaging technologies that are too small for human assembly. Sony Chemical is also working on advanced printed circuit boards (PCBs) and has developed five-layer boards. Semiconductor developments have a goal of single-chip deployment in order to reduce package size and increase package density. For example, Sony's 1992 TR1 camcorder achieved packaging densities of 20 components per square centimeter, about twice the density of the 1989 TR5 model. The component density target for future products is 30 components per square centimeter.

Sony holds monthly meetings between R\&D and business groups to share information and results. There are also general meetings between groups, and two-day internal electronics fairs are held semiannually. Companies like NEC and Sharp also hold similar exhibitions in an effort to make divisional personnel aware of potential solutions to their customers' problems and to stimulate new product ideas. Sony has a less structured system than NEC, but at the time of the JTEC visit was considering ways to improve its effectiveness.

\section{Sharp Company}

Sharp's market-driven strategy for R\&D began by identifying a group of consumers called "sense leaders" to help the company define customers' needs. Company officials explained

We began to define the market according to the role that people played. For example, we consider the most sophisticated people in a market to be the professionals. The next level of consumer is the sense leader, then comes the sense follower. At the bottom of the market is the no-sense consumer or the mass market. Matsushita and Sanyo are after the mass market. Sony and JVC are after the professional. Sharp is looking for the sense leaders, those that influence others to buy new products (Sharp 1993).

From the sense leaders, Sharp began to understand the needs of customers. The video camera provides one example of Sharp's use of sense leaders. In 1991, video camera sales 
fell $15 \%$ to 1.44 million units, far below still camera sales of 4 million units per year. To understand the reason for this decline, Sharp went back to basics:

We took a sample of ten users of video cameras to find out who was buying, how they were using it, how often they were using it, and for what. From our research, we found two important findings. One major finding was that the time spent using this product was very small. For people paying 150,000 to 200,000 yen for the video camera, they were only using it thirty hours per year. That was awfully little for such an expensive product. Color TVs were viewed 1,200 hours per year, refrigerators throughout a year. Video disc and VTRs, which people didn't use much, were used 500 hours per year. Even air conditioners, which are only used during the summer, are used 900 hours per year. Thirty hours per year for such an expensive product seemed awfully small (Sharp 1993).

The research found that the number one usage of the video camera was to tape the first born child until kindergarten. That limited the age of purchasers to the latter half of the $20 \mathrm{~s}$ age group and then only to those who felt obliged to record their child's growth. To expand sales, customer usage had to be changed:

We identified three kinds of pain associated with this product. One is the pain of having to carry it to the destination where you intend to use it. The second is the difficulty of taking pictures. You are out of the picture and it is difficult to use. The third is the difficulty of seeing the pictures you took. Even if you are tired when you get home, you have to see the pictures. You cannot wait until next week. Our conclusion was that we had to reduce these pains and make the video camera fun to use (Sharp 1993).

Sharp's new concept of the video camera, the ViewCam, incorporated its LCD technology. That required overcoming three technical problems: First was to reduce the weight of the camera, which became too heavy with the addition of the LCD. Second was to increase the brightness of the LCD, because it was hard to see the LCD screen in bright light. Third was to reduce the price, because adding the LCD made an already expensive product even more expensive. That required overcoming both technology and cost problems. With the problems identified, a special corporate project was given the challenge of developing the new product in 18 months. The successful results raised the average use of Sharp's ViewCam to over 300 hours per year, compared to 30 hours for the traditional viewfindertype camera, and Sharp's market share moved from fourth to second in one year. Sharp's newest ViewCam can be used as a portable TV display and allows viewing of instant replays, thereby revolutionizing the camcorder market.

In planning for future product development activities, Sharp's president has encouraged business managers to develop other new products that utilize LCD components. The company's long-term product development will continue to use its competitive advantage in LCD components, as shown in Figure 7.7. 


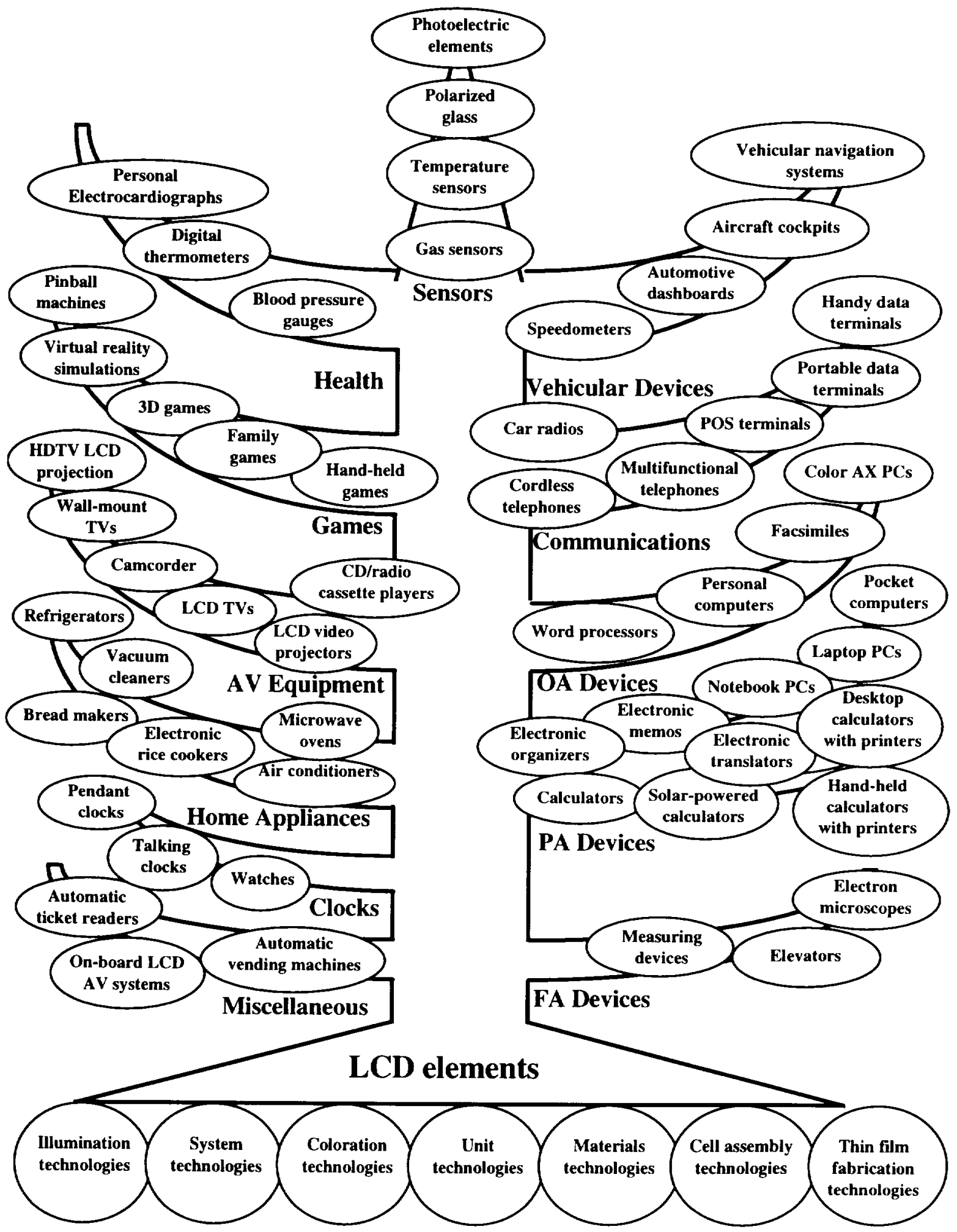

Figure 7.7. Sharp's expanding LCD applications. 


\section{NEC}

Technologically oriented organizations require sophisticated management techniques. As with Murata, Sony, and Sharp, superlative management is a key to NEC's success. NEC's "core technology program," as explained to one JTEC panelist, provides top-down guidance to tell its people what kind of technology is needed. This is renewed every three to five years by determining what core products will be needed in ten years. Technologies that will provide the seeds for growth are also identified. NEC has thirty to forty core technologies that are company secrets. Each core technology includes many subordinate technologies.

For NEC, success requires that its technologies be effectively utilized in products to meet customer needs. For example, NEC has worked since 1965 to develop advanced ceramics technologies. In 1970, a low dielectric material allowed NEC to produce small, highcapacitance ceramic capacitors. By the mid-1970s, a semiconductor ceramic material led to the introduction of ballistors for protecting computers from electric power surges. NEC also introduced new process technology for materials used in packaging, called green sheet technology. This process was applied in 1980 to make a multilayer substrate used in highperformance and high-speed large computer systems. In 1985, NEC introduced a multilayer ceramic substrate for increasing circuit density by four times. It reduced media delay by one-half, for improved computer performance.

NEC's most advanced green sheet technology application was in a high-performance MCM (multichip module) used in its 3900 series large, high-speed computer. The green sheet technology used polymer, binder, ceramic glass, and powder. The sintered substrate then used I/O PGA with 11,540 pins and 40 layers. This included the 14 conductive layers; the remainders were used as grounds to reduce noise. The total number of connection alternatives was the 40 layers times the 11,540 holes per layer $(461,600$ alternatives, total). NEC had worked on this technology for about fifteen years and finally completed its development in 1991. The development of this material and process technology has been applied to NEC's fiberoptic interconnect. The new, moderate-priced application allowed NEC to reduce the size of the new component by $70 \%$ and reduce the power consumption by $30 \%$. Future applications will be in NEC's consumer products.

Managing NEC's distributed R\&D system requires the matching of market needs with technology developments. Contact between central $R \& D$ and production $R \& D$ is considered essential if technology is to be introduced in a timely fashion. Market-oriented business units take the lead in responding to market needs. To facilitate rapid technology commercialization, NEC uses exhibitions, contract research, and technology strategy meetings. An Exhibition Fair is held yearly to give over 5,000 business unit personnel exposure to NEC's technical capabilities. The exhibitions last for a week and include over 2,000 participants. After such exhibitions, R\&D personnel contract with the business group to carry out product-related development. At NEC, $30 \%$ of the R\&D budget is paid for from such contracts, thereby providing an incentive for cooperation. 
According to NEC's former Executive Vice President, Yasuo Kato (1993), NEC limits the amount of research work it contracts out in order to keep the pace of internal technology transfer high:

We have found that contract research works best at about 30 percent of the budget. We lose flexibility if the percent of contracts goes up. Bellcore said 100 percent of their research was supported by operating companies. If customers lose interest, you lose research people and can't maintain your research efforts. Thirty percent is a good number to keep up your research flexibility. I am pressured to increase the percent, but I resist. This is not for money, it is for the spirit of accelerating technology transfer and engineering. It makes for more effective $\mathrm{R} \& \mathrm{D}$ activities.

NEC holds technology and strategy meetings each year. Senior people from technology and business areas meet to discuss the technology strategy for the next four to five years or even ten years out. They establish the long-term business plans, outline technology trends, discuss the types of technology that will be critical in the future, and decide what actions to take. This sets a framework for starting the internal contracting process. The procedure is repeated in smaller discussions with specific businesses and product managers. To overcome the complexity of managing so many technologies, NEC has developed a special technology management organization. Kato continued:

To help in tracking and communicating these technologies, we have grouped them into six strategic technology domains or STDs. Currently we use materials/ devices, semiconductor materials/devices, functional devices, communication systems, knowledge/information systems, and software to show where these core technologies will have the greatest impact. We then show where each of the core technologies have the greatest impact in each of these six domains. We communicate these with a matrix like this:

\begin{tabular}{|lccc|}
\hline Strategic Technology Domains & Technology 1 & Technology 2 & Technology 3 \\
Materials/Devices & $* *$ & $*$ & \\
Semiconductor Materials/Devices & $*$ & $* *$ & \\
Functional Devices & $*$ & & $*$ \\
Communication Systems & & & $* *$ \\
Knowledge/Information Systems & & $*$ \\
Software & & & \\
\hline
\end{tabular}

For each STD, we identify the core technologies and the laboratories that have responsibilities for technology developments....Each lab has its own responsibility for technologies in specific areas. Individual researchers learn what projects there are and what people are doing as a way to get new ideas. Individual researchers can then propose their own research projects. 
NEC's R\&D Planning Process. NEC's planning system for technologies is made up of topdown guidelines and bottom-up proposals, as shown in Figure 7.8. Management makes a clear distinction between the setting of policy guidelines and the initiatives of individuals to come up with programs to achieve the company's objectives. These two perspectives are brought together through joint planning meetings between R\&D and operating groups. Yasuo Kato explained:

We have a research proposal system with a history of over 25 years of execution. In October, we have strategy meetings between the top managements of the R\&D groups and each operating group. During these meetings, each group explains their long range plan for their business, makes predictions about their markets, and discusses the technologies and $R \& D$ requirements that will be needed. $R \& D$ will explain the new technologies and R\&D trends and the competition coming from other companies. At these meetings, group and R\&D managers will attempt to gain a consensus on what projects are needed, the size of those projects, and the amount of resources needed. An internal contract system is then available so that product groups can contract $R \& D$ with the central labs. The average central laboratory has 30 percent of its budget paid for by contract $R \& D$. In the $C \& C$ labs, 40 percent of the budget is paid for by contract research (1993).

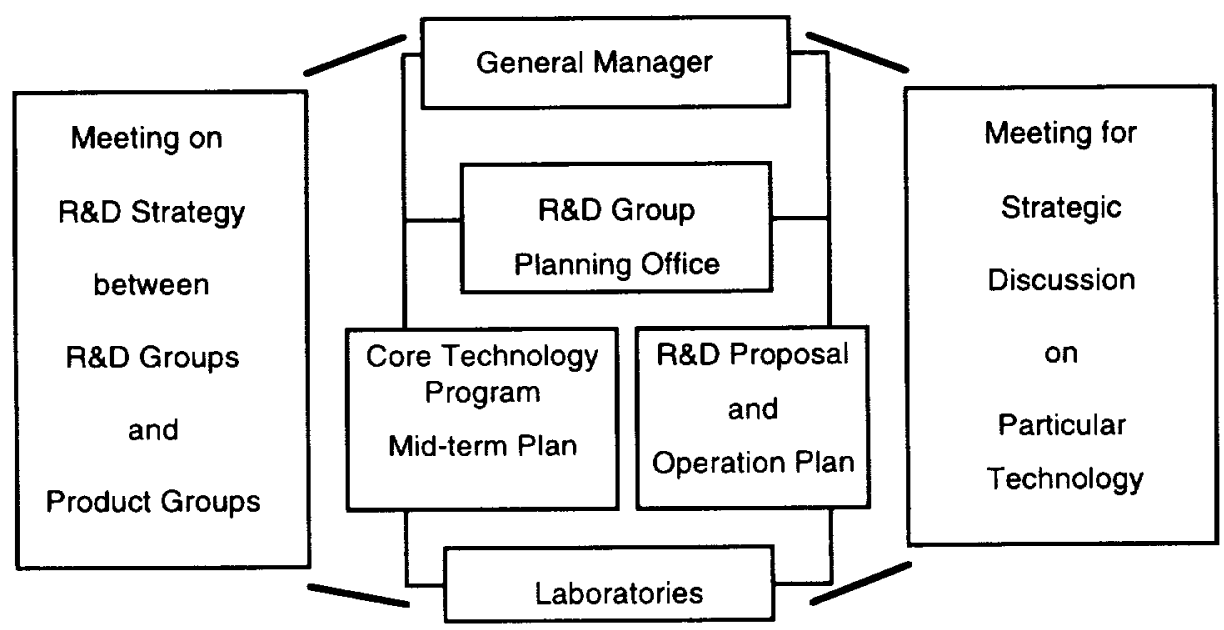

Figure 7.8. NEC's technology planning process.

Once the basic strategies have been decided, the implementation begins with actual development of research contracts between the R\&D and operating managers, as shown in Figure 7.9. According to Kato there is a clear framework:

In December, the $R \& D$ proposals are made and screened through the end of December. They are read and refined during this time, priorities are set, and the proposals are then linked to the budget. Within this process, we have both continuing project proposals and new project proposals. 
Once projects are determined, contracts are negotiated and signed between the R\&D organization and the operating groups. Kato further explained:

The internal contract system forces operating groups to be serious about the research they want done. It is economical for the operating groups to use the central labs. They pay only a part of the R\&D costs, but they pay a negotiated amount. This expenditure gives an operating group stronger motivation for use of the research results. The number of them and the amount of requests from the operating groups are increasing each year.

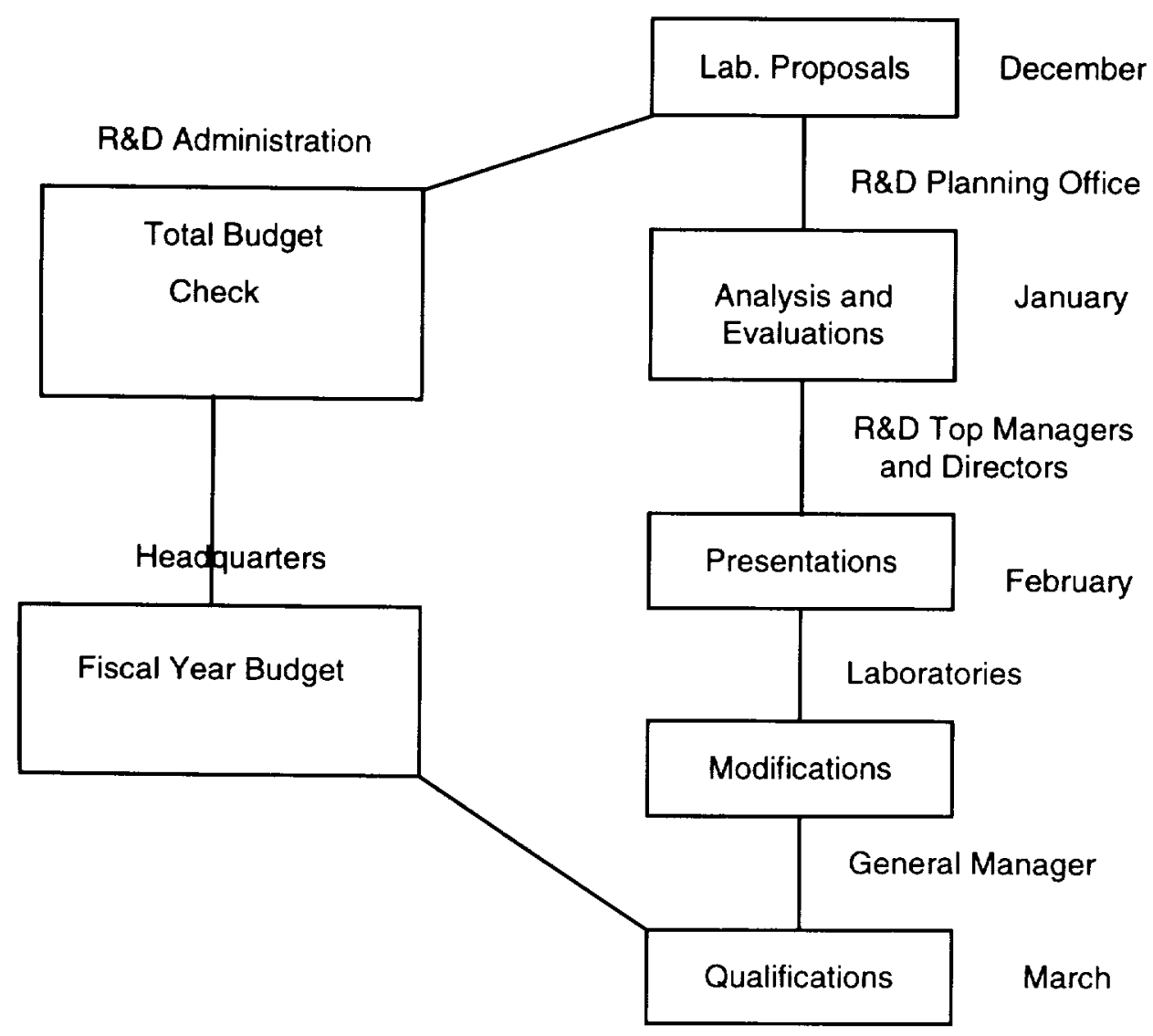

Figure 7.9. NEC's contract and budget process. 


\section{SUMMARY}

Successful product realization in low-cost electronic products in Japan appears to derive from a strong corporate focus. Each phase of product realization is supported by critical activities that include focusing on the following:

$\begin{array}{ll}\text { - } & \text { customer } \\ \text { - } & \text { process } \\ \text { - } & \text { concurrent engineering } \\ \text { - } & \text { technology } \\ \text { - } & \text { value added } \\ \text { - } & \text { product phasing } \\ \text { - } & \text { execution } \\ \text { - } & \text { the competition }\end{array}$

There is no obvious barrier to U.S. companies adopting a similar approach to low-cost electronic product realization. Most of these activities are understood and practiced to some degree by U.S. companies today. The main challenges come from developing the proper focus and perseverance required for long-term success.

\section{REFERENCES}

Kato, Yasuo. 1993. Personal interview with William R. Boulton in Tokyo.

Microelectronics and Computer Technology Corporation and Sandia National Laboratory (MCC/Sandia). 1993. Industrial Competitiveness in the Balance: A Net Technical Assessment of North American vs. Offshore Electronics Packaging Technology. (U.S. Department of Energy Contract \# AD-3474.)

Sharp Company officials. 1993. Personal interview with William R. Boulton in Tokyo.

Thorndyke, Lloyd M. 1993. "Supercomputer Packaging Technologies Compared." SIB, 18 Feb. 


\section{APPENDICES}

\section{APPENDIX A. PROFESSIONAL EXPERIENCE OF PANEL MEMBERS}

\section{Michael J. Kelly (Chairman)}

Dr. Michael Kelly is Director of the Manufacturing Research Center at Georgia Institute of Technology. Prior to accepting that position in October 1991, he was Director of the Defense Manufacturing Office at Defense Advanced Research Projects Agency (DARPA), during which time he was also Executive Director of the National Advisory Committee on Semiconductors. He came to DARPA in January 1989 from the New Jersey Institute of Technology, where he was Director of Computer Integrated Manufacturing and Technology Transfer.

Dr. Kelly's career includes seventeen years with IBM. His IBM experience included ten years in East Fishkill, where he had management responsibilities for designing and developing computer-aided design tools, electron beams and related lithography tools, and manufacturing system architecture. From 1979 to 1984, he was manager of IBM's Manufacturing Technology Center in Boca Raton, Florida, with responsibilities for establishing the architecture and specifications for computer-integrated manufacturing systems and continuing support through implementation at IBM facilities. During that same period, he initiated the multimillion dollar IBM support of manufacturing-oriented curricula development at universities and two-year colleges. In 1984, he accepted a special assignment to assist in preparation for the move of the Corporate Technical Institutes to a new facility in Thornwood, New York. During that same year, he became director of the Quality Institute, where he organized the program to educate and train all IBM employees on the principles of total quality management. Following his one-year assignment as Director of the Quality Institute, he transferred to the IBM Systems Technology Division as Manager of Quality Improvement and Professional Development programs, where he worked for the establishment of quality programs in two IBM plants in the United States (Endicott, N.Y. and Austin, TX) and two IBM plants in Canada (Bromont and Toronto).

Prior to joining IBM, Michael Kelly was an associate professor of electrical and mechanical engineering and Director of the Engineering Case Program at Stanford University. His other academic experience includes three years of teaching at the University of Detroit, where he also served as director of the university's computer center, and four years of teaching and administration at Marist College. Dr. Kelly holds a B.A. degree from Marist College, B.E.E. and M.E.E. degrees from Catholic University, and a Doctor of Engineering degree from the University of Detroit. 


\section{William R. Boulton (Editor)}

Dr. William Boulton is the Olan Mills Professor of Strategic Management and was the Director of the Center for International Commerce at Auburn University. He completed his doctorate at Harvard Business School in 1977 and taught at the University of Georgia for thirteen years prior to moving to Auburn in 1990.

Dr. Boulton has published extensively on topics related to Japan, competitive strategy, and technology management. In an attempt to encourage business schools to teach technology management, he recently completed $A$ Resource Guide on the Management of Innovation and Technology for the AACBS, the accrediting organization for business schools.

He has lived over six years in Japan since his first visit in 1961. He has worked and conducted research in such firms as Hitachi, Sharp, Matsushita Electric, NEC Corporation, GTE International, and Singer Corporation. In 1986, he was a Fulbright Scholar in Japan researching the robotics and factory automation industries. In 1991, he was a visiting scholar at the prestigious Institute for Fiscal and Financial Policy, part of Japan's Ministry of Finance. In 1992 he was a visiting professor at Keio University's business school, where he returned in August 1993. He continues to research technology management issues in the United States and Japan.

\section{John A. Kukowski}

John Kukowski currently holds the position of Corporate Fellow at Universal Instruments Corporation. Presently he is completing a fellowship at Rochester Institute of Technology, where he is working as a research associate in electronics manufacturing and is enrolled in the master's program for computer-integrated manufacturing. Mr. Kukowski is a co-leader of the Electronics Industrial Advisory Board and is an active participant in the establishment of an interdisciplinary electronics design and manufacturing curriculum at RTT.

Mr. Kukowski has been employed with Universal Instruments for 23 years and has served in various capacities, including tool and die maker, manufacturing engineer, design engineer, Manager of Design Engineering, Manager of Manufacturing Engineering, Operations Manager, Vice President of Engineering, and recently, Vice President of Advanced Technology. Mr. Kukowski was the project leader for the first vision-guided placement machine developed by Universal Instruments and led the implementation of flexible manufacturing for the assembly of automated placement machinery.

He holds two patents in automated assembly machine design and has conducted research in the fields of surface mount assembly of printed circuit boards, tape automated bonding, and flip chip attach. He is a member of the Industrial Advisory Board at Broome Community College and is the recipient of the Universal Instruments Dale Chubb award for outstanding technical contribution. 


\section{Eugene S. Meieran}

Eugene S. Meieran received his B.S. degree from Purdue University in 1959 and his M.S. and Sc.D. degrees from the Massachusetts Institute of Technology in 1961 and 1963, respectively, in the field of material science.

He then joined Fairchild Semiconductor Research and Development Laboratories in Palo Alto, $\mathrm{CA}$, as a member of the technical staff, where he assumed responsibility for the materials analysis laboratories. In 1973 he joined Intel Corporation in Santa Clara, CA, as Manager of Package Development, with responsibility for developing new lines of plastic and hermetic packages for emerging memory and microprocessor products. In 1977 he transferred to the Quality and Reliability staff, with responsibility for all Intel materials, for the newly established Analysis and Characterization Laboratory, and for key elements of the wafer fab and assembly reliability functions. For seven years Dr. Meieran was responsible for all the quality and reliability functions for the East Asian and Caribbean assembly plants. In 1985 he was appointed Intel Fellow, the second in the company's history. He has been working in the fields of statistical process control (SPC) and artificial intelligence in Intel's Manufacturing Systems Technology Group, with responsibility for introducing advanced computer and system technologies into Intel's component manufacturing facilities. Dr. Meieran is a member of the Intel Museum Committee, the Intel Research Council, and the Intel Academic Relations Council. He has received two Intel Achievement Awards for his contributions to Intel.

Dr. Meieran has taught at Stanford University and the University of California at Berkeley and has given seminars and invited talks to many universities throughout the world. He has published extensively in the fields of SPC, materials analysis, process and product reliability, and more recently, AI applications, with about 50 technical papers published in international journals. He has been awarded three international awards based on technical presentations on his work in semiconductor device reliability, with emphasis on the phenomena of electromigration in thin films, soft error upsets in DRAM devices, and material analysis technology. Dr. Meieran founded in 1973 and has actively participated in the Electronic Materials Symposium.

In 1987, Dr. Meieran was made Distinguished Engineering Alumnus by Purdue University. He has been on the Scientific and Education Advisory Board for Lawrence Berkeley Labs and is currently on the Advisory Board for the Department of Electrical Engineering/Computer Science at U.C. Berkeley. He was appointed Codirector for the MIT Leaders For Manufacturing Program in 1993.

\section{Michael Pecht}

Dr. Michael Pecht is a professor at the University of Maryland with a joint appointment in systems research and mechanical engineering. He is also Director of the Computer-Aided Life Cycle Engineering (CALCE) Electronic Packaging Research Center at U.M., which is supported by the National Science Foundation. 
Dr. Pecht has a B.S. in acoustics, an M.S. in electrical engineering, and a Ph.D. in engineering mechanics from the University of Wisconsin. He is a professional engineer and an IEEE Fellow. He serves on the board of advisors for various companies and was a Westinghouse professor.

$\mathrm{He}$ is the chief editor of IEEE Transactions on Reliability, a section editor for the Society of Automotive Engineering, and is on the advisory board of IEEE Spectrum. He has edited five books on electronics design, reliability assessment, and qualifications.

\section{John Peeples}

Dr. John Peeples is an assistant vice president of manufacturing for AT\&T Global Information Solutions (formerly NCR) and Director of the Manufacturing Technology Research Center (MTRC) located in West Columbia, SC. The center identifies, develops or coordinates the development of and deploys technology to company manufacturing sites worldwide, with particular emphasis in the area of electronic module assembly and test technology. The center is a key concurrent engineering element within the company and owns the corporate design rules for electronic module assembly and test.

Additionally Dr. Peeples is the leader of the Director of Engineering Peer Team for the General Purpose Product Group. This team's mission is to enhance development productivity through continuous improvement of the development infrastructure.

Dr. Peeples was with NCR for 17 years prior to becoming part of AT\&T management, and he has served in various capacities within the departments of component engineering, design engineering, management of reliability engineering, product evaluation engineering, and advanced systems development. He served as director of operations and, prior to his current job, as director of engineering for the West Columbia NCR facility.

Dr. Peeples received his B.S. in electrical engineering from the Citadel in 1970 and his M.S. and Ph.D. degrees from the University of South Carolina in 1976 and 1978, respectively.

Dr. Peeples is a member of the IEEE and has served in various capacities, including those of general chairman and chairman of the board of directors for the IEEE International Reliability Physics Symposium. He is currently the only nonteaching professional on the Science Framework Writing Team for the state of South Carolina. Dr. Peeples serves on industrial advisory boards for the University of South Carolina and Georgia Tech.

\section{Rao R. Tummala}

Rao R. Tummala is a chaired professor in the Electrical Engineering Department at Georgia Tech. Previously, he was an IBM Fellow at IBM East Fishkill Packaging Laboratory in New York. After joining IBM in 1968, he invented a number of thick film materials and processes for IBM's products for magnetic storage, displays, printers, and packaging. In the 
process, Dr. Tummala was awarded 21 U.S. patents, made 45 other inventions, published 60 papers in professional society journals, and presented over 70 keynote, invited, and other talks throughout the world. He coedited a book entitled Microelectronics Packaging Handbook, which was recently translated into Japanese.

Dr. Tummala received a B.S. in mathematics, physics, and chemistry, and a B.E. in metallurgical engineering from universities in India, an M.S. in metallurgical engineering from a Canadian university, and a Ph.D. in ceramics from the University of Illinois. Dr. Tummala is a member of the National Academy of Engineering, a Fellow of the American Ceramic Society, the Technical Vice President of the International Society for Hybrid Microelectronics (ISHM), and a member of the Board of Governors of the IEEECHMT.

Dr. Tummala received nine IBM Invention Awards, three IBM Divisional Awards, one IBM Corporate Award, and three IBM Publication Awards. He also received the John Wagnon Technical Achievement Award from ISHM, a Best Paper Award from IEEE, the Engineering Materials Award from the American Society for Metals, the Distinguished Alumni Award for outstanding service in engineering from the University of Illinois, and the David Sarnoff Award from IEEE. 


\section{APPENDIX B. PROFESSIONAL EXPERIENCE OF OTHER TEAM MEMBERS}

\section{Phillip R. Barela}

Mr. Barela works at the Jet Propulsion Laboratory in Pasadena, CA. He began his career at JPL as a failure analyst. Currently he is Technical Group Supervisor for the Applications Engineering Group within Quality Assurance. Mr. Barela is chartered with participating in design, manufacture, and test of space flight hardware. He actively participates in numerous research and development activities that deal with advanced packaging applications for space flight hardware. He evaluates packaging designs and develops process controls for lowvolume manufacturing with a focus on placing quality assurance in a proactive posture during design and manufacturing.

Mr. Barela worked as an RF electronic systems technician while still an undergraduate. Since receiving his B.S. degree in manufacturing engineering, he has filled numerous packaging design, failure analyst, and manufacturing positions at Gould Electronics, NavCom Defense Systems, Loral Electro-Optical Systems and the Jet Propulsion Laboratory. Mr. Barela has served as lead manufacturing engineer in hybrid (thick and thin) MCMs, COB, through-hole, surface mount, and mixed assembly facilities. In this capacity, Mr. Barela started numerous product lines for low- to medium-volume military and space products. He has extensive experience with producibility issues relating to new and mature product lines (e.g., DOE, QFD, DFM, DFI, DFR, SPC, etc.).

Mr. Barela is a certified manufacturing technologist through the Society of Manufacturing Engineers (SME). He is a member of SME, ISHM, SMTA, SOCE, EOS/ESD Assoc. and the IPC. Mr. Barela is currently attending UCLA, working towards his master's degree in manufacturing engineering.

\section{George Harman}

George Harman is a Fellow at the National Institute of Standards and Technology (formerly NBS), Chair of the IEEE CHMT's Fellows Committee since 1988, and President of ISHM (1994-1995). He was a Trustee of the Federation of Materials Societies (1988-1990) as well as the Chair of the IEEE CHMT society's nominating committee (1982-1988). Mr. Harman is a Fellow of the IEEE and ISHM, Member of IEPS, American Physical Society, ASTM, Sigma Xi, and Sigma Pi Sigma.

Since 1984, Mr. Harman has traveled to East Asia (Singapore, Malaysia, Taiwan, Hong Kong, Philippines, Korea, and Japan) lecturing and consulting at 17 American-owned facilities. 
Mr. Harman has received numerous awards. The Department of Commerce awarded him the Silver Medal (1973) and the Gold Medal (1979). NIST awarded him the E.U. Condon Award for best publication in 1990. He received the Centennial Medal (1984), CHMT Outstanding Contributions Award (1992), and the ECTC Sustained Distinguished Service Award (1993) from IEEE. ISHM has also conferred several awards on Mr. Harman, including its Technical Achievement Award (1981), Lewis F. Miller Award (1984), Daniel C. Hughes Award the society's top award, (1988), and the ISHM Foundation Distinguished Service Award (1990).

Mr. Harman received a B.S. in physics from VPI \& SU, and an M.S. in physics from the University of Maryland. He was a Research Fellow at the University of Reading (England). He has published 40 papers, one book (a second is under contract), and has been granted 4 patents.

\section{Gene Lim}

M. Gene Lim is President of SEAM International Associates and a member of the Industry Advisory Board for the Rochester Institute of Technology. He is a consultant for the Institute for Defense Analyses (IDA) and Systems Planning Corporation (SPC) for the U.S. Department of Defense. Dr. Lim previously was President of Westinghouse Nuclear, Korea, in Seoul, Korea. Prior to that he was Manager of Japan Operations for Westinghouse in Kobe, Japan.

Gene Lim has 17 years of overseas-based experience in government affairs, technology transfer and license administration, marketing, and project implementation for international projects in Japan and Korea. Dr. Lim received his Ph.D. in nuclear science and engineering from the University of Virginia.

\section{Nicholas J. Naclerio}

Nicholas J. Naclerio is a program manager in the Electronic Systems Technology Office of the Advanced Research Projects Agency (ARPA). In that capacity, he manages several major electronics manufacturing initiatives including SEMATECH and ASEM. ASEM is a new ARPA program aimed at developing a merchant supplier infrastructure for applicationspecific electronic modules. He also serves as executive director of two federal advisory committees: the National Advisory Committee on Semiconductors (NACS) and the Advisory Council on Federal Participation in SEMATECH. Prior to joining ARPA he held positions at the Air Force's Wright Laboratories as Chief of the Manufacturing Technology Directorate's Information Management Branch and earlier as a research program manager in the Design Branch of the Electronic Technology Laboratory. 
Dr. Naclerio holds a bachelor's degree in electrical engineering and computer science from Duke University, a master's degree in material science from the University of Cambridge (England), and a Ph.D. in electrical engineering from the University of Maryland. He has published numerous articles in areas such as microcircuit fabrication, computer-aided design algorithms, and engineering information systems.

\section{Linton G. Salmon}

Dr. Salmon recently completed a tour as the director of the solid state and microstructures program for the National Science Foundation. In that capacity, he directed NSF funding of research in electronic materials, semiconductor manufacturing, advanced processes, electronic packaging, and microelectromechanical systems (MEMS). Dr. Salmon came to NSF from Brigham Young University, where he has now returned to his position as Associate Professor. His current research interests include MEMS applications and packaging, multichip module packaging, and high-speed VLSI integrated circuits. Previously, he was Director of GaAs Engineering at Rockwell International, where he directed the development of advanced designs and processes for III-V integrated circuits and multichip packaging. Earlier he was head of GaAs Technology and Molecular Beam Epitaxy Sections at Hughes Research Laboratories. He received his B.S. degree in Physics from Stanford University, M.S. and Ph.D. degrees in Applied Physics from Cornell University.

\section{R. Duane Shelton}

Robert Duane Shelton has led international technology assessments since 1984, as science policy analyst at NSF, and now as ITRI Director. He is currently on sabbatical from Loyola College in Maryland, serving as IEEE Congressional Fellow in the office of Rep. Lloyd Doggett (D. TX).

Dr. Shelton's degrees are in electrical engineering from Texas Tech (MCL), MIT (as NSF Fellow), and the University of Houston. Dr. Shelton worked at Texas Instruments on electronics R\&D and at NASA in performance analysis of the Apollo space communications system and of TDRSS - the system currently used for Shuttle communications.

He has been a professor at the University of Houston, University of Louisville, Texas Tech University, and now Loyola College. During this time, he has served as principal investigator on 35 grants, has written 58 technical papers and one book, and has chaired 57 M.S. and 3 $\mathrm{Ph} . \mathrm{D}$. thesis committees. He has chaired academic departments of applied mathematics, computer science, and electrical engineering. His current research interest is science policy analysis: international technology assessment, high-technology trade problems with Japan, and national strategies for engineering education. 


\section{APPENDIX C. SITE REPORTS}

Site:

\section{Fujitsu (Yamagata Plant) 1-6-1 Marunouchi, Chiyoda-Ku, Tokyo 100, Japan}

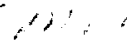

3

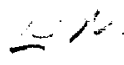

Date Visited:

October 6, 1993

Report Author:

M. Pecht

\section{ATTENDEES}

JTEC:

P. Barela

W. Boulton

G. Harman

G. Meieran

M. Pecht

HOSTS:

C. Handa

T. Tsuchimoto

M. Nakazono

\section{BACKGROUND}

Fujitsu manufactures and automates to the level needed to reduce costs and improve quality incrementally; nothing more, nothing less.

Our JTEC group spent a half day at Yamagata Fujitsu (Fujitsu's Yamagata plant). The main technology that we came to see was Fujitsu's high-volume surface mount operations that are part of its manufacturing process for hard disk drives used in PCs and workstations. We were greeted by Chiaki Handa, President of the Yamagata plant, and by T. Tsuchimoto, Board Director and General Manager of the Technology Group at the Kawasaki Facility, who gave a general overview of the operations of Fujitsu. Then M. Nakazono, Director and General Manager of the Yamagata plant, gave the Yamagata plant overview. Altogether there were 12 managers from three different Fujitsu facilities (Yamagata, Kawasaki, and Atsugi).

Fujitsu has some 71 overseas manufacturing and assembly-and-repair subsidiaries, in addition to numerous sales and other offices. It currently lists 161,974 employees worldwide. 
(This number does not include employees from Amdahl and other similar affiliates in Europe.) In addition to manufacturing computers, Fujitsu has entered the multimedia market and has been chosen by U.S. common carriers for broadband ISDN equipment, switching systems, optical transmission systems, and cellular mobile phones; it is offering similar equipment in parts of Asia, Australia, and Europe. It is also moving into software and other computer services around the world.

\section{YAMAGATA FUJITSU}

Yamagata Fujitsu is located in Japan's industrial district. Established in 1983, it had 100\% investment by Fujitsu; $70 \%$ of sales go overseas. As of the JTEC visit, approximately 300 of 1,000 employees were staff, approximately 700 were operators; about $60 \%$ were male and $40 \%$ female; their average age was 24 . The plant developed, produced, and managed sales of disk drives. The JTEC group toured the printed circuit board (PCB) assembly line (PCA) for 3-1/2 inch disk drives and the 2-1/2 inch hard disk drive assembly line (HDA).

\section{Printed Circuit Assembly Line for 3-1/2 Inch Disk Drives}

Yamagata Fujitsu's PCA line incorporates traditional semiautomatic component placement, soldering, and cleaning equipment with manual part and assembly feeding of machines. There was some manual part soldering and a lot of manual inspection, testing, and repair. The reasons given for all the manual work were (1) it was the most cost-effective considering the mix of PCA technologies they needed to handle, (2) there were many odd parts, such as special connectors and heat sinks that didn't easily lend themselves to automation, and (3) product demand was low, so that only two shifts were needed and further automation would not pay off. Over 600 pieces per minute could be manufactured. The components were predominantly plastic. Generally $60 \%$ of the boards were composed of SMT; $20 \%$ of these were single-sided and double-sided boards, $45 \%$ were four-layer, $30 \%$ were six-layer, and $5 \%$ were eight layers and up. In general the PCA process line was not by any means state-of-the-art and may not even be highly profitable. It was stated that the demand for these products was down.

The 3-1/2 inch drive had a lot of manual handling: for insertion of some components, for rework, and for inspection. Burn-in equipment at the plant operates under the following conditions:

- There are some fans covered with stainless steel mesh at the bottom of this equipment to circulate the inside air.

- There are no heaters inside the equipment. As a number of hard disk drives are operating within a closed box, temperature inside the box increases significantly because of heat radiation from the disk drives. As a consequence, all hard drives kept in the box are burned-in under this high temperature even with no heaters.

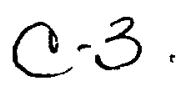


- In case of a perfectly sealed system, temperature becomes too high, so, a slit is put on the top side to maintain the hard disk drive's temperature at a range between $67^{\circ} \mathrm{C}$ and $73^{\circ} \mathrm{C}$. The location and size of this slit are based on Fujitsu's know-how.

The cleaning operation was $\mathrm{OK}$, but there was so much handling after the cleaning with bare hands that it seemed as if the cleaning was somewhat superfluous. Of some special interest in the PCA manufacturing line was the removal of CFCs in October 1993 and the subsequent use of non-CFCs, replaced by a deionized water cleaning process. While there was no research being conducted in leadless solder, management was aware of efforts in Germany and did look at InSn, but considered it too expensive.

The small FR-4 boards (to be mounted in hard drives) were demarked and partially cut out but remained in the larger mother boards for handling. Each mother board contained four or six smaller active boards. They were loaded with pick-and-place machines (said to have a placement accuracy of $50 \mu \mathrm{m}$ - at other sites we saw machines that were more accurate, but $50 \mu \mathrm{m}$ was apparently adequate for the purpose). The boards were reflow soldered.

In summary, the printed circuit line for 3-1/2 inch discs was "low tech": the machinery was old; the process was a combination of automated and manual assembly; there was lots of inspection; cleanliness was minimal; the burn-in was primitive. It was clear, however, that the important processes were well developed, and all the things we saw that seemed "lowtech" were indeed relatively unimportant (e.g., the burn-in caught what it needed to catch, and having a more sophisticated burn-in system was unnecessary, and hence no attention was paid to it). Thus, the operation appeared efficient for what it was doing, even though it was not elegant. It was obvious that Fujitsu has no intention of significantly improving this line. It was also obvious that Fujitsu was going to use what it learned on this line to make a step-wise improvement on its $2-1 / 2$ inch drive assembly.

It should be noted that the Yamagata plant is dedicated to manufacturing products for personal use, different from any other Fujitsu plant, such as its Numazu plant, which manufactures high-technology products. The main focus of the Yamagata plant is to utilize the existing equipment to a maximum extent to promptly manufacture high-quality products and at the same time to seek better production efficiency at a lower cost.

As pointed out to the JTEC team, the Yamagata plant uses traditional manufacturing methods through semiautomated equipment and manual work on its printed circuit board assembly lines. While installed machines at the Yamagata plant such as screen-printer, parts-mounter, and air-reflow oven may be obsolete from the technical point of view and give the impression that the Yamagata plant continues to use old equipment, our hosts noted that the use of this equipment is optimal from the point of view of efficient investment.

The plant does utilize an automatic appearance inspection tester for any minimum-size parts such as QFP (quad flat package) with 0.5 lead-pitch and 1005 chips, which are almost impossible to inspect manually. On the other hand, inspection and repair of any parts other 
than those minimum-size ones are carried out by manual tasks to maintain efficiency in capital investment.

\section{Hard Disk Assembly Line}

The hard disk drive assembly (HDA) line was highly automated and the equipment was modern and sophisticated. The environment was a 100-class clean room (not great by semiconductor standards, but certainly sufficient for the operation, especially since extra precautions were taken on the equipment where the magnetic heads were physically present), with automated testing of over 100 drives simultaneously. There was complete robotic handling of parts. The operators all wore appropriate clean-room clothing. This line was being prepared for high-volume production. The hard disk assembly operation was a model of efficiency. The entire operation was automated using Fujitsu-built robots and required attention to technology and detail. The striking difference between the PC board assembly area and the hard disk area was attributed (by us) to the fact that the disk was the guts, the family jewels, of the Fujitsu system; hence, no expense was spared to make this as efficient and low-cost as possible.

\section{New Technology}

We saw very little in terms of new technologies, but our hosts did mention various technical activities in other parts of Fujitsu, including 16-to-42-layer PC boards, 60-layer ceramic laminates used in its supercomputers, and the newest parallel supercomputer using GaAs chips. (These are mounted in single-chip packages that are then mounted on ceramic boards in order to get around the known-good-die problem.) Fujitsu was using opto-connections for external connections but using electrical connections inside. It developed its own router for these boards.

Our hosts also mentioned a new (but published in MRS in 1992) photosensitive dielectric film using a blend of polymers that can be used for cheap MCM-D circuit boards. Line widths were $30 \mu \mathrm{m}$, and vias were claimed to be about $20 \mu \mathrm{m}$ in diameter. They used Al metal lines and made up to four metal and four dielectric layers. They said this might be in production within two to three years.

Our hosts said they were following the work in BGAs including the OMPAC by Motorola and some products by AMD. They were conducting some work in flexible PCB manufacturing and assembly, flip chip mounting and TAB mounting, with plans for bare chip assembly on a computer product (server) in 1994.

\section{Quality and Reliability}

Quality and reliability were assumed, but never initiated as a topic of discussion by our hosts. Their policy is summed up as "quality built-in," with cost and performance as prime 
considerations. Our hosts noted that today's components do not require burn-in, although at the board level there was some concern for solder bridges.

In February 1993 Yamagata Fujitsu became ISO 9002-certified and at the time of our visit was expecting to be 9001 -certified later in 1993 - the purpose is to be able to sell products in Europe.

\section{Management Philosophy}

As in other Japanese factories the Yamagata plant management paid attention to running equipment well, to continuous improvement, to cost reduction, and to size reduction. No magic technology was employed; just fruits of a detailed study and execution of automated processing and smooth-running, efficient operations.

\section{SUMMARY}

Fujitsu is motivated to improve circuit board density and reduce cost. The improvement in density had several implications; for example, to reduce package thickness, to improve mounting location, and to reduce weight. Reducing cost was the prime driver after functionality and customer needs were accounted for.

To meet the objectives, Fujitsu was going to use flexible printed circuits, improved soldering technology, design of thinner packages, and specially plated through-holes. None of the technologies are revolutionary; rather, they are the straightforward application of continuous improvement to Fujitsu product lines.

A Fujitsu representative aptly stated, "Indeed, we are still using an old-type equipment for the printed circuit board assembly line for 3.5 inch disk drives. We would like to stress, however, that the use of the fully automated equipment does not always represent "high technology.' Through our experience over years, we have come to the conclusion that in certain cases manual work is sometimes more efficient rather than automated machines, as other vendors do in some cases." 
Site:

Hitachi PERL and HIMEL 292 Yoshida-cho, Totsuka-ku Yokohama-shi Kanegawa-ken 244, Japan

Date Visited:

October 6, 1993

Report Author:

L. Salmon

\section{ATTENDEES}

JTEC:

P. Barela

J. Kukowski

L. Salmon

R. Tummala

HOSTS:

Dr. Hiroyoshi Matsumura

Mr. Ikuo Kawaguchi

Mr. Toshiro Kinugasa

Mr. Ryugi Nishimura

Mr. Masahiko Yatsu

Dr. Norikazu Tsumita

Dr. Toshio Asano

Mr. Takanori Ninomiya

Dr. Hisashi Sugiyama

Dr. Makoto lida

\section{BACKGROUND}

Hitachi has nine corporate research laboratories with approximately 5,700 employees. The corporation spends approximately $\$ 3$ billion per year on research and development. This amount corresponds to approximately $10.5 \%$ of total sales for the company. The first corporate R\&D laboratory, the Central Research Laboratory, was established in 1952. We visited two of the corporate research laboratories, the Production Engineering Research Laboratory (PERL) and the Hitachi Image and Media Systems Laboratory (HIMEL), which are both situated at the Yokohama site together with the Systems Development Laboratory.

PERL is a corporate research laboratory and has as its major goal research in the areas of advanced packaging, precision machining, factory automation, high-density magnetic media, 
and advanced semiconductor materials and processing. The laboratory has approximately 600 employees and was established in 1971.

HIMEL is also a corporate research laboratory and is chartered to perform research in technology areas of importance to camcorders and other optical consumer products. The laboratory has approximately 400 employees and was established in 1972. The laboratory was originally an associated division of the Consumer Products Group, but was designated as a separate research laboratory in February of 1993. Its purpose is to work closely with the production divisions to provide technology required for new products. HIMEL is divided by products into four departments: projection displays, range finder video cameras, LSI design and fine mechanism development, and fax/word processors.

Hitachi's philosophy regarding research is called Tokken and is based on tight coupling between production and $R \& D$ efforts. Connections between production and $R \& D$ groups include personnel exchange, common planning, and frequent meetings to assure coordination. The charter of each of the organizations in Hitachi is summarized in Table PERL.1. This chart is idealized and is not always rigidly followed. Research staff will sometimes work at the development facility for extended periods during technology transfer. In other cases, the development staff may come work at the research facility for an extended period.

\section{Table PERL.1 \\ Summary of Organizational Responsibilities}

\begin{tabular}{||c|c|c|c||}
\hline $\begin{array}{c}\text { Central } \\
\text { Research }\end{array}$ & $\begin{array}{c}\text { Production } \\
\text { Research }\end{array}$ & Development & Production \\
\hline 2nd Generation & Next Generation & Prototype & Current Product \\
\hline
\end{tabular}

Mr. Kinugasa from HIMEL first gave a presentation on Hitachi's design and manufacture of camcorders. He began with presentation of a roadmap for reduction in camcorder size through integration of camcorder functions into fewer LSI and fewer discrete components. The path he outlined shows an evolutionary approach to reducing the number of components and does not hope for revolutionary changes in IC technology for at least the next four years. He projected continued use of hybrid and PCB technology to package the components and exploitation of shrinking feature sizes in IC technology. TAB and bare chip technology are not part of the current packaging plan because these technologies are more expensive to produce. Current PCBs are designed with a $0.5 \mathrm{~mm}$ pitch. Efforts are under way to decrease pitch size to $0.4 \mathrm{~mm}$ and $0.3 \mathrm{~mm}$, and the technologies will be included in products if the cost is not too high. Hitachi is developing optical inspection techniques for $0.3 \mathrm{~mm}$ technology because $\mathrm{x}$-ray inspection is blocked by the large number of metal layers on the PCB. Inspection for $0.3 \mathrm{~mm}$ is currently performed manually. The most advanced SMT process 
Hitachi has developed is $0.3 \mathrm{~mm}$ pitch on a six-layer PCB that is $1.6 \mathrm{~mm}$ thick. The solder paste screen is made using an $\mathrm{Ni}$ additive process. Super solder is not used because solder deposition was found to be too uneven.

Mr. Kinugasa indicated that packaging accounts for $20 \%$ of IC production cost, and he anticipates that the percentage cost will continue for new products. The major impediment to dramatic reduction in camcorder size is the size of the recording tape and associated mechanical parts required to read and write to the media. During a tour of HIMEL facilities, our hosts indicated that HIMEL is seeking to reduce discrete component size below the 1005 size part. They also indicated that the plan for HIMEL includes development of the technology required to build a pocket-size, all-solid-state camcorder. Our hosts suggested that some effort is being expended to investigate bare chip technology using conductive adhesives in order to address environmental concerns regarding lead-based solders.

The JTEC team was given a tour of the clean-room facility used to pursue research in the areas of advanced disk drive media and thin film MCM development. The facility is approximately $10,000 \mathrm{ft}^{2}$ and is class $100 / 1,000$. PERL is also investigating high-density magnetic media and advanced thin diamond-like coatings to protect hard disk media. Research on magnetoresistive magnetic storage is carried out at a separate Hitachi laboratory.

The thin-film-on-ceramic MCM process is being pursued to support high-performance supercomputer applications. The technology provides excellent thermal properties and is designed to dissipate heat from high-power ICs. Dr. Inoue indicated that the technology will be used for the next generation of high-end supercomputer, but that it is unclear what technology will be used for packaging for the generation after that. He stated that thin-film MCM technology may be important for workstations, but that the cost of the process will have to be decreased significantly before the technology can be used in that area. Current research efforts are concentrating on cost reduction in the process, but there are no immediate plans to use the technology in Hitachi workstations. We were told that this technology would not be used for consumer applications due to its high cost.

We were given a tour of the facilities for several projects at PERL. There is a strong effort to develop the technology and equipment required to automatically inspect and evaluate the quality of products and processes. Successful equipment and techniques developed in the laboratory are immediately implemented in the manufacturing line. PERL makes extensive use of image processing to decrease highly accurate inspection of high-definition CRT screens. PERL is also active in developing systems to automatically inspect green sheets for multilayer ceramic packaging and solder quality in SMT reflow processes.

Scientists at PERL have developed an advanced PCB that they call TAF-II. The process uses an additive metalization process that results in improved resolution: line widths as small as 140 microns in 35-micron-thick copper. The process flow for the TAF-II process is shown in Figure PERL.1. The lamination, drilling, and catalyzation steps are similar to those in standard PCB processes, but the following steps differ from standard processes: Solder resist 
is formed through an etched stencil; the plating process is an electroless plating step in a bath with a pH of 12. The PCB typically contains 4-6 layers, but the PERL researcher claimed that the process would support as many as 12 layers. He also claimed that the TAF-II process is $20 \%$ less expensive than the standard PCB process because less plating solution is used in the selective plating process. The TAF-II process was licensed to several companies in 1989, and a new process, TAF-III is in development. TAF-III will use lithography to define the solder resist layer and will have line widths as small as 80 microns.

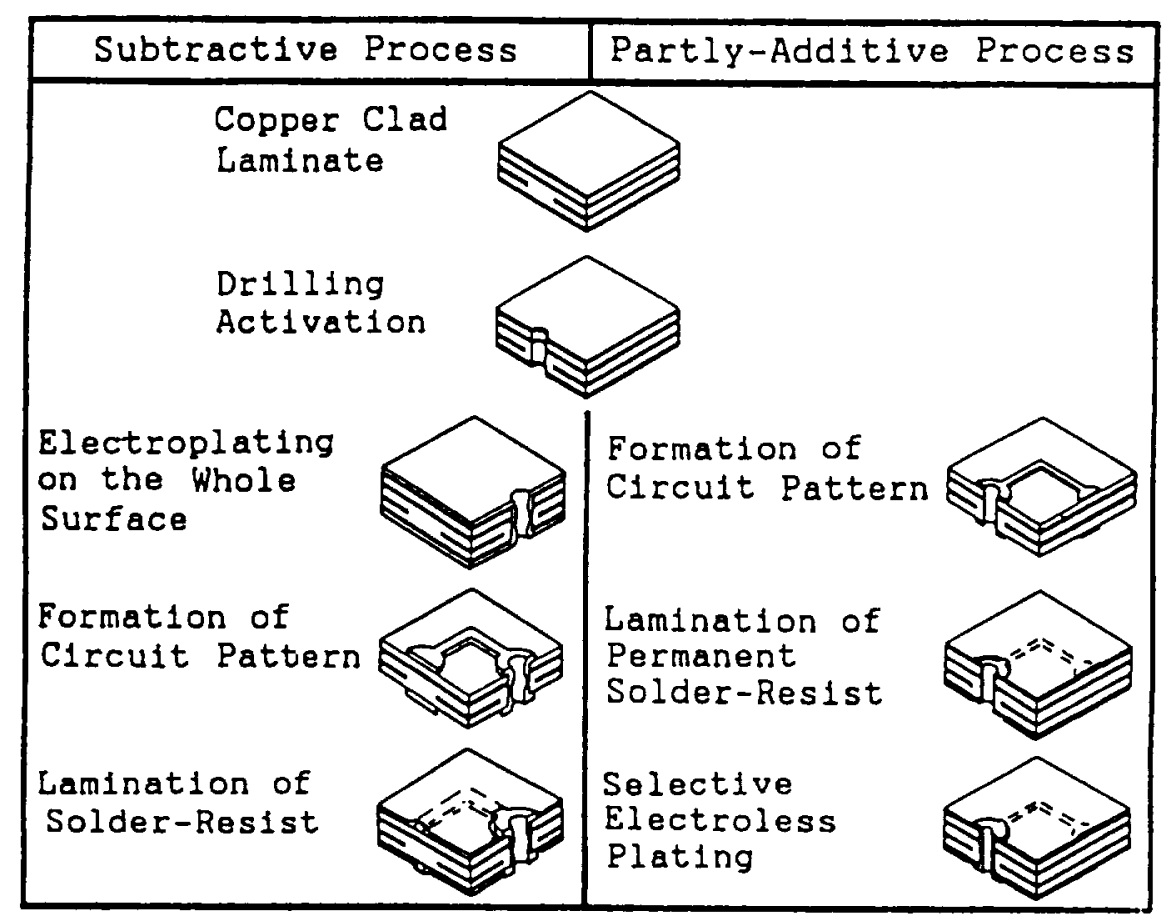

Figure PERL.1. Brief process flow.

Dr. Makoto lida presented work on thin molded plastics for laptop computer cases. He showed research on methods to reduce the thickness and mass of the plastic required for a domestic Japanese portable PC product, describing a roadmap for thinning body plastic thickness from $3 \mathrm{~mm}$ in 1985 to $1.5 \mathrm{~mm}$ in 1993. PERL researchers are currently working to reduce the size of the plastic case by improving structural design of the case, the polymer material used in the case, and mold design. Hitachi has developed its own polymeric material, together with an associated company. One of the greatest challenges is to control flow of the resin during filling of the mold. PERL researchers have analyzed resin flow using 
a simulation program to predict the best method to inject resin into thin molds. Dr. lida stated that although composite materials can be made thinner, they are only used in highervalue products such as computer pen pads, due to the high cost of the material. Composite materials can be molded as thin as $1 \mathrm{~mm}$ and weigh less than conventional plastics. Overall thickness of the portable product was also reduced by using the LCD display as a structural member. A shock-absorbing material was used to assure that $L C D$ reliability remained high. Dr. Iida indicated that PERL is investigating molded circuit boards, but present cost of materials is very high. He indicated that the thermal expansion characteristics of the molded circuit board material are very important.

Dr. lida then described a rework tool that has been developed to add or remove solder from SMT parts with a pitch as small as $0.3 \mathrm{~mm}$. The tool removes excess solder using a braided wick, and adds solder using a novel technique. A droplet of solder is held by surface tension to the end of a heated point and the solder is placed on the unsoldered joint. The solder and the lead are heated in a single step.

There were several general comments made during the JTEC visit to Hitachi that are worthy of note. First, although a high level of automation is evident in the production philosophy of Hitachi, individuals at PERL emphasized the importance of an "appropriate" level of automation. They stressed that overdependence on automation is as detrimental as underdependence on automation. They further stressed the importance of the skilled individual to improve production yield and to retain production flexibility. The managers at PERL indicated that process floor workers should have a college education. When asked, they agreed that it is difficult to attract high-caliber people to production tasks, but indicated that showing employees the importance of their contribution to production is the best method to attract them.

A second theme was the importance of cost in all decisions regarding technology. Cost was clearly a critical consideration in every discussion regarding proposed technology. There was always a clear product path, and the cost of a technology was compared to a projected, required production cost. One statement made by Dr. Matsumura summarized this attitude. He said, "We used to determine the price of a product by adding an acceptable profit margin to the projected cost to produce a product. Now the price is a predetermined quantity, and we add an acceptable profit margin to arrive at the required product cost." 
Site:

Ibiden Co., Ltd.

3-200, Gama-Cho, Ogaki City

Gifu Prefecture 503, Japan

Date Visited:

October 5, 1993

Report Author:

J. Peeples

\section{ATTENDEES}

JTEC:

M. Kelly

G. Lim

N. Naclerio

J. Peeples

HOSTS:

Mr. Hidetoshi Yamauchi

Mr. Kazuhisa Ohno

Mr. Osamu Fujikawa

Mr. Koji Hosada

Mr. Keiji Adachi
Corporate Overseas Planning Office Manager of Sales and Marketing for the Overseas Affairs Division Director of Technology and Development General Manager of Overseas Marketing and Sales of Electronics Sales Engineer, Overseas Marketing and Sales of Electronics

\section{BACKGROUND}

Ibiden began life as a power company and is now a manufacturer as well. It offers products in the following three areas:

\section{IBI Electronics Branch}

- double-sided/multilayer/special boards (small)

- IC packaging based on the special board technology

- continuous processing

- up to 12 layers

- width traces in the lab

- small vias and blind/buried vias

- flip chip on board (COB) for one customer

- aluminum core substrates for power dissipation 


\section{IBI Inorganic Chemical Branch}

- calcium carbide/carbon/acetylene for the steel industry

- fine-grain graphites - electrodes/fixtures

- ceramic fibers - IBI, wool, insulator

\section{IBI Building Materials Branch}

- IBI board - laminate material for home construction and decor

- nonflammable construction materials

Ibiden shares its product branches between manufacturing plants. Any given plant may be involved in the production of electronics, building materials, inorganic chemicals, and/or new products. Generally, however, one or two plants specialize in production for a particular branch.

\section{R \& D ACTIVITIES}

IBI-Techno is the calling card of Ibiden's R\&D activities. Advanced product development is conducted in the New Products Development Branch. When ready, the technology is fused into one of the major product branches. The development of plastic pin grid arrays (PGAs) and application-specific integrated modules (ASIMs) were discussed as examples of this advanced product development process. Ibiden discussed the ASIM concept with me during my April 1990 visit. I could not detect that the concept was any closer to product at the time of the JTEC visit in late 1993.

Fundamental technology development is the charter of the Technology and Development Department. Activity in this area includes investigation of biotechnology, superconduction, ceramats, and optical materials.

Ibiden Electronics is working mainly in two product areas: IC packages and printed wiring boards (PWBs).

\section{IC Package Products}

Ibiden has leveraged its competency in laminate substrates technology into an IC package business. It makes small interposer substrates with facilities for chip attach (plated wirebond pads, semi-cavities, etc.) and add pins. Its major product line, by far, is the plastic pin grid array (PGA). It is very intense in this product development area, which is driving performance as well as costs. Our hosts showed examples of plastic PGA substrates in the $2 \mathrm{nH}$ inductance range.

Ibiden has chosen to get out of the TAB package business because it feels that it was unable to compete with the major suppliers of $\mathrm{TAB}$ packages. It has just begun prototype production of BGA; it has one package of over 500 pins. Our hosts characterize this program as being very U.S.-centric but realize that some devices may have to be provided to U.S. end users by Japanese semiconductor vendors, and it therefore must do the package development. 


\section{Substrate Products}

Ibiden is a major supplier of PWBs. It produces subtractive laminate substrates at a rate of 25,000 square meters per month of double-sided substrates and 15,000 square meters per month of multilayer substrates. It is also active in several more advanced substrate areas, alternate materials for CTE and power dissipation, and additive processes for higher routing densities. Topan, which began life as a printing company, is a very important Ibiden competitor in laminate substrates. Yamamato and Compaq are also viewed as important competitors, especially for U.S. business. Samsung is a licensee of IBI-Techno.

Ceracom is a ceramic-cored PWB and is Ibiden's "low-cost," low-expansion substrate for flip chip. Ibiden currently single-sources Ceracom substrates but is interested in supplying the raw material and technology to U.S. substrate suppliers. It is not interested in supplying end products (substrates) of Ceracom to the United States. Ceracom currently has two major Japanese customers and few applications. Ceracom costs are between thin film metalized ceramic and FR-4 at the finished circuit board. Material cost is higher than ceramic substrate and FR-4.

Ibiden's additive process is still in the prototype stage of development. Development seems focused in the areas of adhesives, dry film plating resists, and plating technology. Plating technology is critical to the additive strategy. Ibiden is doing the work to ensure thickness consistency and peel strength. Thickness consistency is not a given, even in the electroless process. Peel strength is the major reliability concern. Ibiden's adhesive resin for additive process consists of two different epoxy resin systems (one is solid and the other is liquid). These resins show different strength against some chemicals by having different hardeners (e.g., acid and amine). This process additionally mitigates cracking in the high-stress regions of small vias.

Peel strength is also a bit of a "specsmanship" issue in that strength levels have been characterized as appropriate to the older, much more macroscopic technologies, which may not extrapolate reasonably to the very-fine-pitch additive products. Ibiden is also investigating what can be done with solder resist height to make assembly of additive boards easier. Its researchers think that a product with a resist 20 mils higher than the copper trace can eliminate solder bridging.

Ibiden's build-up multilayer PWB product is still in development. Build-up is intended to be similar to IBM's surface laminar circuit (SLC). It is anticipated to be a double-sided subtractive core with two build-up fine-line layers on each side of the core (a total of six layers). Build-up will have a very high routing density due to the $50 \mu \mathrm{m}$ conductor widths and the $100 \mu \mathrm{m}$ vias. It is currently about five times the cost of a normal laminate substrate but about eight times less than an MCM-D substrate. Laminate substrates are the cost target for this technology.

The major changes in Ibiden's MCM-D substrate technology are the move away from polyimide to an epoxy dielectric for cost reduction and the deployment of a "hot press" aluminum nitride core for enhanced thermal conductivity and dimensional stability. This extra stability results in a $1 \mathrm{mil}$ line and $1 \mathrm{mil}$ space capability for wiring. Ibiden feels that 
the $\$ 6-8$ subtractive board of today would cost $\$ 40$ in the MCM-L build-up technology, but sees a path to drive that to $\$ 15$. The same circuitry would cost $\$ 300$ today in a copper/polyimide MCM-D substrate or $\$ 120$ for a copper/epoxy implementation.

\section{GAMA PLANT TOUR}

Mr. Fujikawa gave us a tour of the package production at the Gama plant. He feels that the current staffing level may be too high at about 300 persons, of which $20 \%$ are considered indirect. The plant was somewhat eclectic in layout and was literally covered in paper: SPC control charts with goal lines extended into 1995 were everywhere. There were safety and "one-point" displays in every section, as well. The "one-point" concept is an interesting one. A cache of visual aids is kept in each section from which the section supervisor or engineer can present a "one-point" discussion daily to the workers. The subject will be a very specific commentary on some facet of their job, like the correct way to use a tool or the details of why a particular process step is performed. There is no effort to tie the daily events together; the intent is rather to expose the workers daily to some level of very specific training.

The IC plastic package substrates and the Ceracom substrates are processed on very similar, if not the same, production lines. Drilling and routing of the package substrates takes place in a single room. Production control appears to be totally paper-based. There were paper travelers with every lot of material, and no bar code readers were seen to be integrated into any of the production steps. The design area was a large, well-lighted open office space that housed about 50 uniformed Ibiden and contract designers. Mr. Fujikawa again mentioned his concern that overhead support was duplicated within the various departments of the facility.

A major distinction between the package business at Ibiden and its substrate business is that the package business can focus on a relatively small customer set: the Gama plant deals with tens of customers, whereas the substrate plants must deal with five hundred to a thousand customers.

\section{AOYANAGI PLANT TOUR}

Ibiden manufactures laminate printed wiring boards at its Aoyanagi plant. It provides layout services for about $60 \%$ of its printed wiring board orders. This plant employs about 1,500 persons and exports about $30 \%$ of its production to Europe, the United States, and Singapore. This is the most active of all the IBI plants. It seemed busier, more disorganized, and a bit dirtier during this visit than it did during my visit in 1990 . There were definitely more people in areas that were essentially fully automated during my last visit.

\section{Work Environment}

While safety awareness was apparent, there was no evidence of safety requirements. The smocking that did exist seemed much more focused on protection of the product (e.g., hats 
and masks to keep the product clean) than on human safety (e.g., lack of eyewear). The factory is by no means a "smoke-free environment." As in all Japanese factories, no street shoes are allowed.

\section{GENERAL OBSERVATIONS AND CLOSING REMARKS}

Below is a list of general observations and impressions:

- Primary electronic products are PWBs and IC packages.

- Package products include COB, PGA, and plastic leadless chip carriers.

- Product focus is on higher performance through higher density.

- Ibiden is keeping R\&D investment flat in spite of the Japanese economic slowdown.

- $R \& D$ focus is on alternative materials and processes.

- Ibiden provides product design service or can receive design data from its customers.

- Ibiden provides low-volume or high-volume products and services.

- Cost per product is volume-dependent.

- Significant growth is expected in fine ceramics.

- Ibiden designs and builds much of its own production equipment.

- Environmental impact is a stated concern.

- Some waste is managed on-site; some is transferred to specialty companies.

- Economic slowdown resulted in excess capacity and underutilization.

- While Ibiden does not expect to be fully utilized for some time, it is optimistic that it has a bright future due to its investment in technology.

My summary impressions of Ibiden are very aligned with my overall impression of the visit to Japan. Having visited some of the same facilities and having met with some of the same people three years prior to this trip, I was very impressed with the company's consistency of technology and product strategy. Ibiden seems to understand its core competency very well, although our hosts never spoke in those terms.

Ibiden Electronics does laminate PWB well. It is willing to drive that technology to new product opportunities (plastic PGAs), align it with other lbiden technologies for new product opportunities (with ceramic for Ceracom), augment it for new product opportunities (with novel surface science for additive processes), and repeat the process (new ceramic cores and additive processes for the build-up MCM-D products).

I did sense a lack of visible progress. The laminate facility appeared very much as I had seen it three years earlier. Process control and worker communications technology seemed stagnant as well; however, neither of these seemed to limit the capability of the plants. 
170

Site:

Date Visited:

Report Author:
Appendix C. Site Reports

Matsushita Electric Industrial Co., Ltd. 3-1-1 Yagumo-Nakamachi, Moriguchi Osaka 570, Japan

October 6, 1993

J. Peeples

\section{ATTENDEES}

JTEC:
M. Kelly
G. Lim
N. Naclerio
J. Peeples

HOSTS:

Keith Nishitani

GM-Business Coordination, Overseas Dept. of the Corporate Technology Mgmt. Office

Dr. Yamazaki

Shunichi Murakami

Director, Circuit Manufacturing Technology Lab., Corporate Production Engineering Division GM, Process and Materials Development Dept., Corporate Production Engineering Division

Mark Kawai

Hiroaki Fujimoto

Yoshihiro Bessho

Hiroshi Asai GM, Control and SW Development Dept., Corporate Production Engineering Division Senior Engineer, VLSI Technology Lab, Semiconductor Research Center Engineer for Materials and Components Research Lab, Components and Devices Research Center Manager, Marketing Department

\section{BACKGROUND}

Our visit was divided into three distinct sessions: a tour of the Circuit Manufacturing Technology Lab of the Corporate Production Engineering Division, a tour of a chip size inductor factory, and a discussion on chip mounting technology. The JTEC visit began right where my visit in 1990 had ended, in the Circuit Manufacturing Technology Lab, one of five subdivisions of the Corporate Production Engineering Division.

Mr. Murakami discussed the process development plans. Some of his handouts were identical to those I had been shown in 1990, only updated to show progress. Panasonic, like most of the Japanese companies I visited, seemed to have a remarkable degree of strategic 
technological consistency. My opinion is that similar U.S. companies are less likely to invest long-term in specific technologies, but would rather jump to new "promising" alternatives.

Mr. Hiroshi Asai, Manager of the Marketing Department, gave us a rough sketch of Matsushita:

- $\$ 60$ billion company composed of 252,000 people

- R\&D budget of about $\$ 3$ billion $(5.8 \%)$ - flat for five years

- 17 Japanese locations housing 30 organizations

- 12 Divisions (including Panasonic FA)

- 22 overseas manufacturing plants

- component group revenue is $\$ 300$ million/month from 80,000 product types

We were each presented a copy of My Management Philosophy by Matsushita's founder, Konosuke Matsushita. It is 66 pages full of gems of wisdom. Following are some of the quotables:

- Good times are good but bad times are still better.

- It is my hope that managers would use their knowledge as expert economists [to] work for measures that would be in the best interests of the people and the nation.

- Foreign expertise may still have a role to play but more important now is that Japan develop its own technologies.

- My proverb about management says that if we fight a hundred wars, we should win a hundred victories.

- You pray for the survival of your rival because you want another chance to demonstrate your superiority.

\section{R\&D ACTIVITIES}

The Circuit Manufacturing Lab is the process and equipment development arm of Panasonic Factory Automation. It develops whatever is necessary to service new products. Much of the work in process is for palmcorder or for flat panel applications. We were told that about 20 engineers may be involved for three months to transfer a new FA line into production.

The lab we visited is set up for touring. A graphic arts display emphasized the importance of the Panasonic solder paste development to its fine-pitch $(0.3 \mathrm{~mm}$ in production) stencil, place, and reflow process. The key point was that Panasonic has achieved a more spherical solder particle shape than normal, allowing the paste to have more predictable flow characteristics. Our hosts were excited about this and were similarly excited about their 
in-house-developed conductive epoxy; neither of these formulations are available for sale in the United States.

This lab exhibited the latest equipment technology for FA. New since my 1990 visit is the emphasis on lower-cost methods of direct chip attach and an increased involvement with glass substrates. Panasonic is using normal wirebonders with a special shear cycle to attach a gold ball bond to an IC pad and immediately shear the wire at the top of the ball. This leaves a small tail (like a Hershey's Chocolate Kiss), which is then flip-mounted into conductive adhesive sites on a glass substrate. The process requires no tooling or wafer-level processing.

Another area that has developed dramatically since my last visit is the film area. Panasonic has put $\mathrm{TAB}$ into full use as a glass and $\mathrm{PC}$ board interconnection media. It has special equipment for what our hosts refer to as FOG (film on glass) and FOB (film on board). Both technologies are demonstrated as applied to flat panel display production. LCD drivers are mounted to a sliver of PC board material. A TAB interconnection is first hot bar bonded to the glass flat panel using anisotropically conductive adhesive tape. The other end of the TAB is then pulse laser bonded to the driver PC boards. With FOG and FOB, Panasonic has in place the first fully automated LCD assembly line in the world. The current line does a single edge of the LCD per cycle. The new generation will assemble all three edges simultaneously.

The Circuit Manufacturing Technology Lab, as a corporate staff function, provides assistance to all system divisions across the Matsushita group on SMT fine-pitch process and equipment development. It is primarily intended to enhance Matsushita Electric's manufacturing capability in order to increase its competitiveness. Membership is $¥ 600,000$ annually, open only to Matsushita's system divisions, its subsidiary companies, and its affiliated companies, not to any party outside of Matsushita, regardless of whether it is a domestic or overseas entity.

Almost as an aside, we were given a tour of a factory of SMT mountable inductor coils. This facility was extremely noisy. Wireless headsets must be worn in order to hear the tour guide. Fine wire is automatically wound on a core that is terminated to a continuous leadframe and encapsulated. These are moved around on reels of 40,000 parts each. Parts are marked and visually inspected by computer, then excised from the lead frame and tested and binned. Velocity and quality are very high. Relatively large numbers of people are involved in this production.

Process improvements seem targeted at further integration of processes. The current process demands loading the test station from a parts feeder after excising from the continuous leadframe. After testing, parts are once again binned into parts feeders for final packaging. The new process will trim and test the parts and put them directly into rails to be packaged without the parts feeders. This new method reduces the space required for trimming, testing, and packaging by 10 square feet; floor space reduction was mentioned as a key reason for the improvement. As this station is replicated many times, this results in a significant utilization opportunity. One-fourth or more of the floor space appeared to be dedicated to test stations. 
Mr. Hiroaki Fujimoto, Senior Engineer of the VLSI Technology Research Lab, discussed transfer bump, micro bump, stud bump, and new bonding methods for chip assembly to substrates. Transfer bump is a method developed by Matsushita to displace the need for wafer scale processing to form the gold bumps required for TAB inner lead bonds. Gold bumps are formed on a glass substrate and transferred to the inner lead of the TAB frame via thermo-compression prior to inner lead assembly. Matsushita has marketed transfer bump worldwide for several years now.

Micro bump technology is a flip chip method that uses adhesive shrinkage to electrically and mechanically connect the interconnection bumps to a typically glass substrate. Micro bump uses glass and ceramic substrates. The adhesive is photo-curable; thus a more transparent substrate is naturally preferred, but edge-wise illumination will work with opaque substrates. Micro bump is currently in use in thermal print head assembly and is capable of $10 \mu \mathrm{m}$ lead pitch.

Mr. Yoshihiro Bessho, Engineer for the Materials and Components Research Laboratory spoke on the stud bump bond (SBB) method of attachment. SBB employs the sheared gold ball bonds mentioned earlier to adhesively mount the chip to a variety of substrates. This technology is limited to pitches greater than $100 \mu \mathrm{m}$ but is extremely flexible and simple in application. The ball bond studs are dipped into conductive adhesive and then glued to substrate. The wire bond "tails" are allowed to set the conductive paste penetration depth and apparently can do so accurately enough that bridging between bonds is not a problem. An undercoat adhesive more firmly secures the overall system.

Similar to what we saw and heard at Sony, Matsushita views process development on a par with product development. The Corporate Production Engineering Division (Circuit Manufacturing Technology Lab), reports at the highest level of the company and appears to be marketing what is considered a corporate core competency. As mentioned earlier, the consistent pursuit of a technological strategy is striking. The laboratory's dedication to fine pitch or to transfer bump or other low-cost flip chip technologies is long-term and not likely to be redirected or curtailed short of the set objectives. The Matsushita strategy seems to be a familiar one: make it small and cheap! 
174

Site:

Date Visited:

Report Author:

\section{ATTENDEES}

JTEC:

P. Barela

W. Boulton

G. Meieran

G. Harman

M. Pecht

R. Tummala

HOSTS:

Norio Meki

Hideo Sakai

Hiroshi Yamauchi

Yasuyuki Baba

Yasuhisa (John) Kobayashi
Appendix C. Site Reports

Matsushita-Kotobuki Electronics

Saijo Division

247 Fukutake, Saijo

Ehime, Japan

October 5, 1993

R. Tummala
Director, Research \& Development Laboratory

Assistant General Manager, Sales Department

Manager, HIC Manufacturing Section

Chief, Development Dept \#5, R\&D Laboratory

Coordinator, Semiconductor and Appliance Section

\section{BACKGROUND}

Matsushita-Kotobuki Electronics Industries (MKE), Saijo Division, located in Saijo, Ehime Prefecture, on Shikoku Island, is one of the affiliated companies of the worldwide company Matsushita Electric Industries ( $\$ 43.75$ billion in FY 92), famous for the brand name "Panasonic." MKE, established in 1969, has several divisions in each prefecture on Shikoku and also subsidiaries in the United States, Singapore, Indonesia, and Ireland. Total 1992 sales were $¥ 308.9$ billion (about $\$ 3$ billion); annual investments were about $¥ 14$ billion ( $\$ 130$ million).

\section{MANAGEMENT, ORGANIZATION, AND PRODUCT CYCLES}

The organization chart, Figure Pan.1, shows corporate functions including planning, personnel, general affairs, accounting, finance, administration, components purchasing and legal/patent section, and divisional arms that are independently managed. Each division is responsible for its own manufacturing, development, design, factory automation, and quality assurance with corporate support from R\&D Laboratory, Design Center and Quality Assurance Center. 


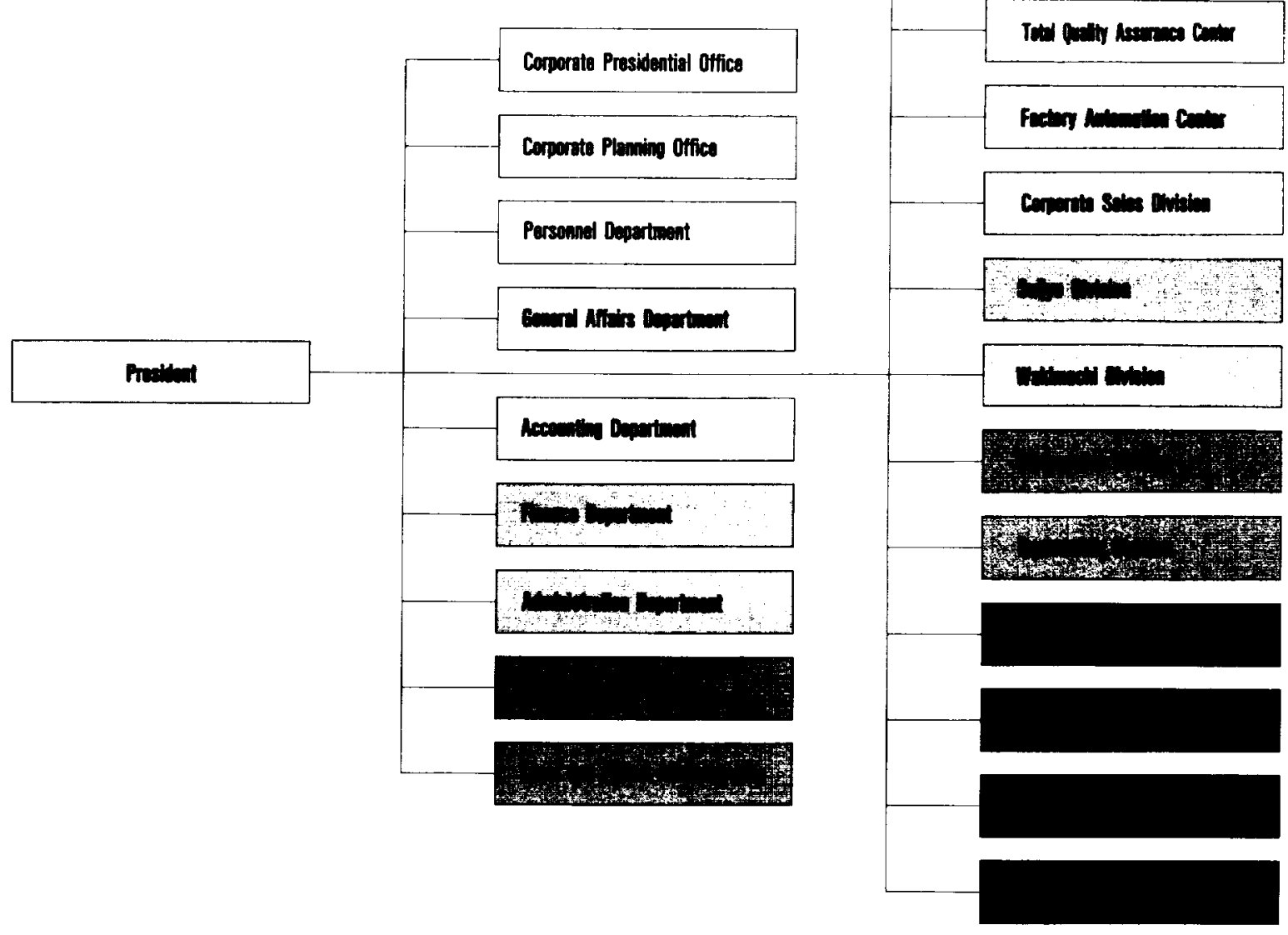

Figure Pan.1. Organizational chart.

MKE has about 5,200 employees; the total number of engineers and personnel in manufacturing are 600 and 3,100 , respectively.

The divisions work specifically to improve current technology for the products to be released within a couple of months while continuing to manufacture existing products. The corporate R\&D Laboratory works to develop next-generation products together with the design section of each division. MKE creates new technology every two or three years that results in new products being introduced.

At the Saijo Division, 300,000-500,000 VCRs are manufactured per month. This high productivity is achieved by a high degree of factory automation. 


\section{TECHNOLOGY}

There are two packaging technologies in use at MKE, one using conventional PWB and the other using a ceramic substrate. MKE is perhaps one of very few companies using ceramic technologies in consumer products and pushing the leading-edge aspects of these technologies in achieving (1) miniaturization, (2) design standardization, (3) low cost, and (4) high reliability. MKE is using QFP with about 100 to $168 \mathrm{I} / \mathrm{O}$ at $0.5 \mathrm{~mm}$ lead pitch currently and is expected to migrate to $0.4 \mathrm{~mm}$ with forced air $\left(\mathrm{N}_{2}\right)$ convection reflow.

The sophistication of MKE at Saijo is in ceramic technology based on hybrid IC (HIC) introduction in the late ' $70 \mathrm{~s}$ and low-temperature co-fired ceramic (LTCC) technology used since 1990. MKE's ceramic strategy during the last decade has been as follows:

$\begin{array}{lr}\text { Hybrid IC with } \mathrm{Ag} / \mathrm{Pd} & 1981 \\ \text { Hybrid IC with } \mathrm{Cu} & 1988 \\ \text { LTCC with Cu} & 1990\end{array}$

The MKE plant had shipped about 60 million HICs and 170,000 LTCC modules as of the time of the JTEC visit. It has the capacity to manufacture about $1 \mathrm{million} / \mathrm{month}$ HICs and $10 \mathrm{~K} /$ month LTCCs. Each handling size is roughly 4 inches square.

MKE's LTCC technologies with Ag/Pd and copper are schematically illustrated in Figures 4.8 (p. 74) and 4.10 (p.75), respectively, showing the substrate characteristics that include the capacitors, resistors, and conductors. The current design ground rules being practiced are indicated in Figure Pan.2. Electrode pin allocation technology, such as lead frame, lead array, and BGA, is used for connecting LTCC and PWB. $\mathrm{Pb}\left(\mathrm{Mg}_{1 / 3} \mathrm{Nb}_{2 / 3}\right) \mathrm{O}_{3}-\mathrm{PbTiO}_{3}-\mathrm{PbO}$ is the principal ingredient for embedded capacitors.

The LTCC is being used currently in peripheral application - tape memory systems - and is expected to be applied in cellular, automotive, camcorder, and computer applications. The LTCC has proven to be more advantageous than equivalent PWB process/materials relative to the application at system level.

MKE's LTCC process involves manufacturing the green sheet and producing approximately 0.10 to $0.15 \mathrm{~mm}$ diameter via holes on the green sheet by numerically- and mechanicallycontrolled punching equipment. After filling up and drying copper oxide paste into the via hole, conductor pattern is also applied on the green sheet by the copper oxide paste. These printed green sheets are laminated together under a heat pressure and fired at $550^{\circ} \mathrm{C}$ in air to remove organic components sufficiently. Then copper oxide is reduced to copper at $350^{\circ} \mathrm{C}$ in nitrogen atmosphere containing $10 \%$ hydrogen, and the copper and ceramic substrate are sintered at $900^{\circ} \mathrm{C}$ in nitrogen. This unique process provides highly reliable LTCC with copper electrode. 


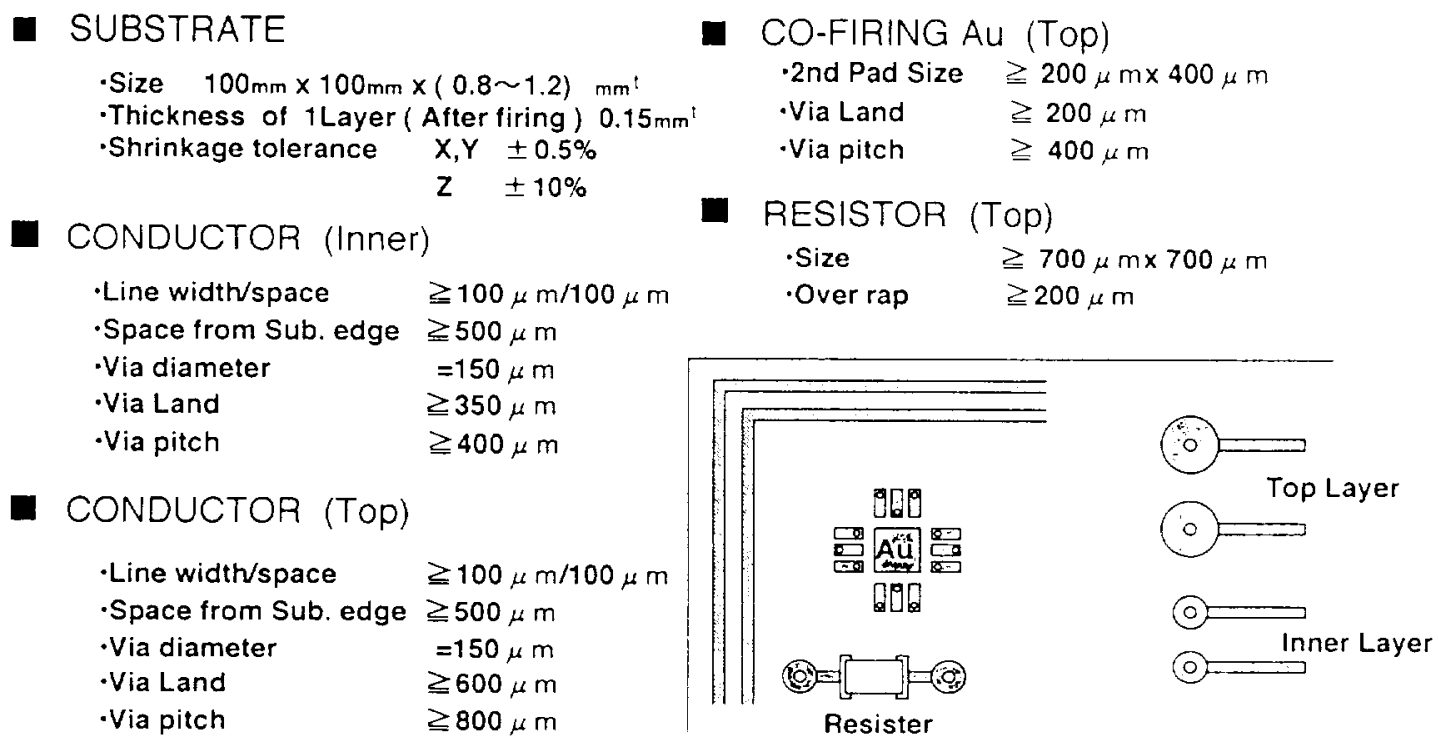

Figure Pan.2. Design rule (typical).

\section{FUTURE TECHNOLOGY DIRECTIONS}

Table Pan. 1 shows the directions MKE is expected to take. The future directions include (1) upgrading LTCC by buried CR, (2) fine line by photo process, (3) BGA technology, (4) highprecision LTCC by nonshrinking process, and (5) flip chip.

Table Pan.1

Future MKE Directions

\begin{tabular}{|c|c|c|c|}
\hline Substrate Functions & Future Technology & Technology Elements & \\
\hline \multirow[t]{6}{*}{ Substrate } & \multirow[t]{2}{*}{ o Ag System } & & Target \\
\hline & & Internal Capacitor (Ag) & 1994 \\
\hline & \multirow[t]{4}{*}{ o $\quad \mathrm{Cu}$ System } & Non Shrinkage Substrate $(\mathrm{Ag}, \mathrm{Cu})$ & 1994 \\
\hline & & Internal Resistor $(\mathrm{Ag})$ & ---- \\
\hline & & Photo Conductor $\mathrm{L} / \mathrm{S}=50 / 50 \mathrm{~mm}(\mathrm{Cu})$ & 1994 \\
\hline & & $\mathrm{NI} / \mathrm{Au}$ plating $(\mathrm{Cu})$ & 1994 \\
\hline \multirow{2}{*}{$\begin{array}{l}\text { Bare Semiconductor } \\
\text { Device Attachment }\end{array}$} & \multirow[t]{2}{*}{ Wire Bonding } & Flip Chip ( $\mathrm{Ag}, \mathrm{Cu})$ & 1995 \\
\hline & & $\mathrm{TAB}$ & $-\cdots$ \\
\hline V/O Connection & $\begin{array}{ll}\text { o } & \text { Lead Frame } \\
0 & \text { Lead Array }\end{array}$ & $\mathrm{BGA}$ & 1994 \\
\hline
\end{tabular}


Site:

Meisei University 2-590 Nagafuchi, Ome-shi Tokyo 198, Japan

Date Visited:

October 8, 1993

Report Author:

W. R. Boulton

\section{ATTENDEES}

JTEC:

P. Barela

W.R. Boulton

HOSTS:

Dr. Otsuka

\section{BACKGROUND}

Dr. Otsuka recently retired from Hitachi to assume a position at Meisei University, where he teaches a course on advanced information technology. He is affiliated with IEEE and chaired the VLSI workshop held in Kyoto December 1994. He teaches computer and computer packaging technology. Through workshops, he teaches engineers from Japanese companies. He has research contracts on electrical characterization of packages.

\section{PACKAGING TECHNOLOGY IN JAPAN}

Dr. Otsuka limited his formal remarks to the topic of "Main Packaging Technology in Japan (Single Chip Packaging)." He provided a number of important insights into the future developments of electronic packaging technology in Japan.

\section{Korea or America is expected to take over long-term leadership in LCD packaging technology.}

Dr. Otsuka made it clear that LSI packaging technologies have a different origin and core competence than LCD packaging technologies. The development of LCD technologies has come from the merging of TV cathode tube and silicon wafer process technologies, which gives Koreans and Americans the potential to take leadership in this area. Korea has made a strong commitment to LCD development, and recently, Samsung and Gold Star have announced massive investments of $\$ 400$ million and $\$ 300$ million, respectively, in TFT technology development programs through 1995. 
Dr. Otsuka was not optimistic about Japanese companies maintaining leadership in CD technology. He didn't feel that large Japanese companies could work with small companies to develop such a new infrastructure. At the time, large companies were worried about small companies competing with them. Dr. Otsuka believed that Japanese companies' departmental structures were too competitive with each other to cooperate on merging new technologies. He felt that presidents cannot control their department heads. That means that they cannot develop large-scale systems like Apple did with Macintosh.

Small companies also provide a threat to large companies by their dedication to a single technology. While big companies are investing in CRT technology, they cannot give the same effort to new LCD technology. The large companies are worried about the potential of small companies. Active matrix LCDs by Japan Hosiden are a threat to Sharp because they are selling to Apple and other U.S. companies like Boeing. Companies like Sony are integrating backwards into their own components to increase profitability. That is causing a breakdown in supplier relationships and causing less coordination on new development.

In the future, Dr. Otsuka sees the United States maintaining strength in high-frequency devices like computers and microprocessors. He expects Korea will be strong in memories and LCDs in the future. Low-cost micro assembly applications will remain the strength of Japan in the future. If Japan loses low-cost QFP packaging technology, then he expects that Japan will be in trouble. Since plastic molded lead frame packages represent $85 \%$ of electronic product applications, Japan's electronic industry must continue to lead in this area.

\section{Japan will remain the leader in LSI packaging technologies.}

Dr. Otsuka said that over $85 \%$ of electronic packaging uses plastic molded lead frame technologies. Because these packaging technologies are so pervasive in Japanese industry and because so many companies are committed to them, he argues that Japan will continue to dominate in low-cost packaging technology. LSI packaging technologies include materials, parts, subassemblies, and assembly process. Most companies have specialized in specific areas of plastic packaging technology, which provides Japan with the strongest low-cost packaging infrastructure. This infrastructure is distributed across both large and small companies in Japan and, because it is pervasive, is unlikely to change its technological direction. He pointed out that it would be virtually impossible for any one company or group to change the technological focus of this infrastructure. Dr. Otsuka argued that, as a result, the low-cost electronic packaging industry in Japan will continue to develop current plastic packaging technology, because it is the easiest direction for all industry participants to continue in.

\section{Low cost is top priority in the Japanese industry, which requires mass production technologies.}

Because of Japan's cost requirements, Dr. Otsuka argued that LSI plastic packaging technology has to utilize mass production technology. This mass production orientation will 
continue to utilize existing packaging technologies. New technologies will require new mass production technologies, which would be expensive to develop and lead to higher costs. To keep from incurring such added costs, Dr. Otsuka argued that companies will continue to push existing packaging technologies to their limits rather than add new high-cost technologies. This strategy means that Japanese companies seek to solve performance problems related to current plastic packaging technologies.

\section{Current plastic molded package technologies will meet future miniaturization requirements.}

Dr. Otsuka feels that QFP packages can be designed with $0.15 \mathrm{~mm}$ pin pitch. Such fine pitch will allow 800 pins on a $32 \mathrm{~mm}$ package, or 1000 pins on a $40 \mathrm{~mm}$ package, or 384 pins on a $16 \mathrm{~mm}$ package. To support his argument, Dr. Otsuka gave examples of developments that are currently under production or development in Japan. He provided an example of 344 pins on a $28 \mathrm{~mm}$ package using $0.3 \mathrm{~mm}$ pin pitch that is currently in production at Hitachi.

Dr. Otsuka argued that Japan's strength is due to the extensive infrastructure of companies involved in plastic electronic packaging technology. Japanese companies have developed QFP packages with 500 pins, available from Nippon Printing Company by 1996, using 0.3 $\mathrm{mm}$ pin pitch. Some firms are currently developing this process using $0.2 \mathrm{~mm}$ pin pitch chips. This will allow plastic QFP packages to surpass ceramic PGA packages in pin density. Such strong development power comes from Japan's massive investment in all areas of plastic packaging technology. Nikkei Electronics described these developments in its August 2, 1993 issue (p. 94).

Dr. Otsuka also described Kyushu Matsushita's $0.15 \mathrm{~mm}$ pitch soldering process that he expects to be commercialized within several years. This process uses a solder precoat (super solder) with the body being pushed down as infrared heat is applied. The company uses solder bumps to ensure contact, but staggers the bumps to minimize shorting. This process would not require new machine technology for production utilization. Kyushu Matsushita is planning to use this approach in its next-generation camcorder production. While it is currently using TAB technology, Dr. Otsuka believes that the approach will be used with SMT in the future. Hitachi is currently producing circuits with 90 micron wire bonding on chips with spaces between the wire of 120 microns. Oki and Nippon Steel have demonstrated wire bonding with 40 micron pitch. Dr. Otsuka believes that we will see this in production in the future.

Fine pitch requires materials with higher resistivity. Fine pitch creates additional soldering problems by causing high current on the printed circuit board. Dr. Otsuka suggested that new materials will be used on fine-pitch boards. For example, conventional FR-4 through-hole resistivity is too low at $130^{\circ} \mathrm{C}$ to be used on fine-pitch boards. High Tg epoxy provides better resistivity, but for fine-pitch boards, the high resistivity requirements can be met with BT resin. Mitsubishi Gas Chemical has used BT resist (BTM 450) on contacts with $1.27 \mathrm{~mm}$ separation. 
Japan will overcome low yield problems caused by fine pitch packages. Dr. Otsuka agreed that the move to fine pitch production will cause higher reject rates in the beginning. However, he argued that Japan has a long history of taking lower yield technology and improving it. In the United States, he believes that companies change technologies if they have low yields, but not in Japan. In addition, QFP is more inspectable than BGA even in low yield situations. Inspectability is very critical to ensuring quality products.

\section{Finer pitch packages will automatically improve operating characteristics.}

Fine pitch will increase product design flexibility. Since height is very important, singlelayer boards are preferred in package design. Also, single boards are simpler to produce and are therefore cheaper to produce. Fine-pitch soldering would mean that we do not need twolayer bonding systems. Two-layer bonding has lower reliability because it depends on the solder connections. Simple packages are the best in every characteristic. For $0.3 \mathrm{~mm}$ pin pitch, a $40 \mathrm{~mm}^{2}$ QFP package can have over 500 pins. With $0.2 \mathrm{~mm}$ pin pitch, $34 \mathrm{~mm}^{2}$ packages can have 600 pins. At $0.15 \mathrm{~mm}$ pin pitch, we can have 600 pins on a $28 \mathrm{~mm}^{2}$ package, comparable to a $1.0 \mathrm{~mm}$ pitch bump BGA chip. Dr. Otsuka used the previous examples to argue that these dense packages will be available within this decade.

Fine-pitch packages will provide additional advantages. Dr. Otsuka pointed out that finer pitch allows the use of three-set wiring design instead of two-set wiring between ground and power leads. Three-set wiring can increase output from $80-90 \Omega$ to $95-105 \Omega$ at $200 \mathrm{MHz}$ and above. Finer pitch allows use of three-set packages for high-power packages. At the same time, impedance can be reduced once pin pitch falls below $0.3 \mathrm{~mm}$. Japanese researchers have simulated $0.05 \mathrm{~mm}$ pin pitch designs and found that impedance drops $50 \%$. Coupling capacitance can be further reduced in fine-pitch applications by using shorter wires. Shorter wires also means that multilayer wiring in single-chip packages is not essential. As long as power consumption stays below three watts per chip, chip scale packaging with short wires and fine-pitch provide the best design solutions. This has already been utilized in memory DRAM developments and should be viable in LSI packaging. As long as power consumption stays under 3 watts, natural cooling systems can be used and costs kept lower.

Dr. Otsuka also pointed out that reduced voltage requirements and reduced load capacitance can save power consumption $\left(\mathrm{P}=1 / 2 * \mathrm{CV}^{2}\right)$. Lower voltage reduces coupling noise. He then argued that as we reduce package size, everything improves: "If we can communicate $\mathrm{MHz}$ at 3.3 volts, then the same package using 1.5 volts can operate at $400 \mathrm{MHz}$." He believes that QFP chip scale packages will be able to pass $200 \mathrm{MHz}$ in the future.

QFP will be competitive with BGA on price-performance measures. Dr. Otsuka believes that QFP packages are better than BGA packages because they are inspectable and don't require new assembly technology. While the U.S. is interested in BGA because of its high pin count, Dr. Otsuka believes that $0.15 \mathrm{~mm}$ pin pitch on QFP packages will make them competitive with BGA alternatives. Since most Japanese companies do not have BGA capabilities, he expects continued QFP design and technology improvements to keep QFP packages cheaper than BGA packages. 
Figure Meisei.1 shows the competitiveness of different packaging technologies, and additional insights offered by Dr. Otsuka are shown in Figure 4.5 (p. 64). Dr. Otsuka pointed out that ceramic substrates are cheaper in high-performance applications, but he believes that improvements described in the above statement will make QFP boards cost-competitive in future high-performance applications. The critical improvements are in the soldering process for wire bonding systems and in reducing popcorn problems of chips. If these problems can't be overcome, Japan will not be competitive in the future. But if Japanese firms can meet future miniaturization requirements with QFP technology, they will continue to be the lowcost producers of high-volume electronic packaging.

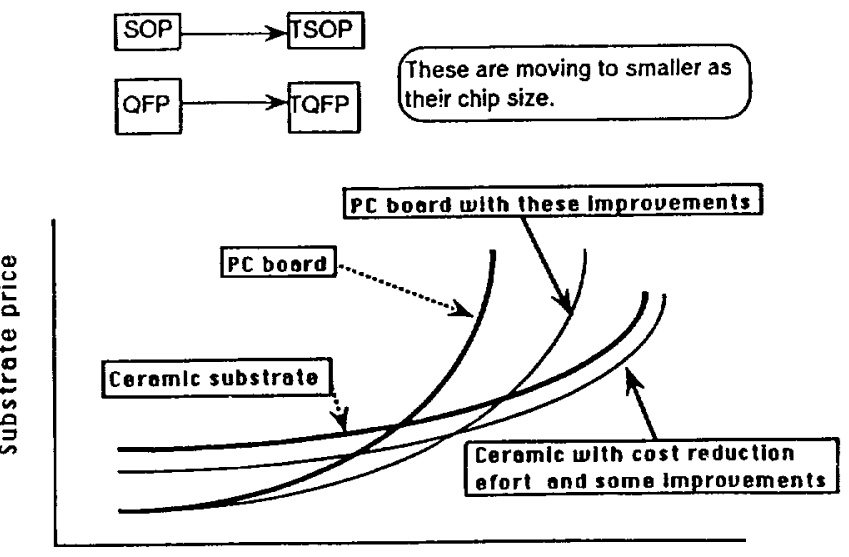

Performance (wiring density, layer count etc.)

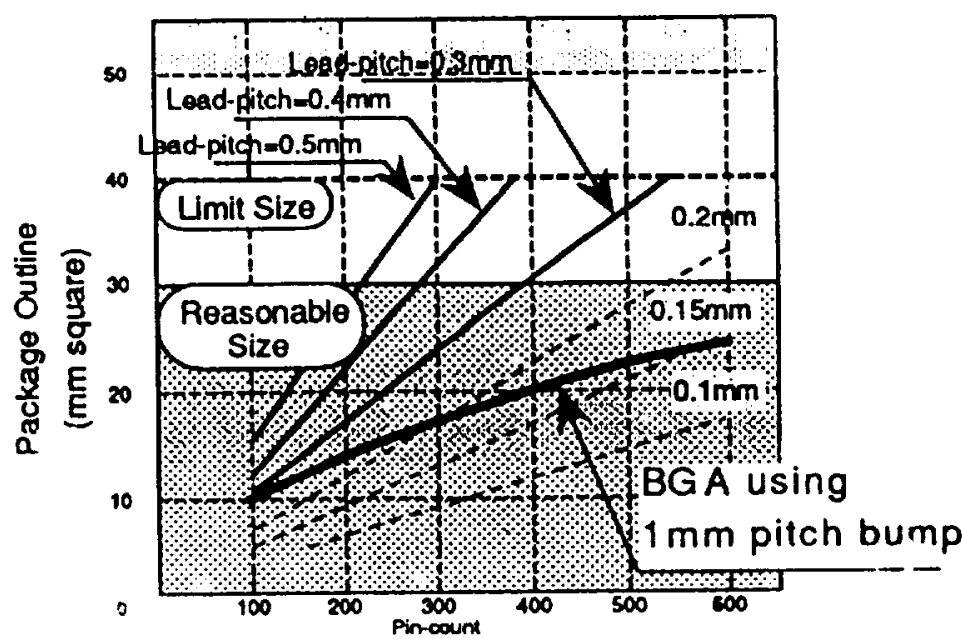

Figure Meisei.1. Competitiveness of different packaging technologies. 
Dr. Otsuka believes single-chip packages will be cheaper than integrated chips on a substrate. He believes pushing the current technology to the limits will be cheaper than introducing new technology. Japan has alternative technologies, but low-cost plastic package technology is much cheaper. However, if package technology cannot achieve its improvement objectives, then its cost will cross over, and multichip technology will be cheaper.

Several technologies are unlikely to become dominant. Dr. Otsuka felt that adhesive conductors create too much noise and are too low in quality to replace solder connections. He continued to argue that the simple technology will survive. Reduction in size will reduce the problems of solder pollution and allow high-quality alternatives to be used. Because miniaturization will require less solder, it will be cost-effective.

Japanese companies guarantee everything about their products. Dr. Otsuka believes that they will continue to provide complete packages instead of bare chips. They want to control the assembly of their components to ensure their performance.

\section{SUMMARY}

\section{Cost is the First Objective}

There are three strategic objectives in Japanese competitive strategy. Since the mid-1980s the acronym "QCD" has been pervasive among Japanese companies: it stands for quality, cost, delivery.

All Japanese electronics suppliers are forced by their customers to keep lowering their costs. At the lowest cost, the company that provides the highest quality with the best availability or delivery wins sales. This puts great pressure on firms to reduce costs and improve quality as a daily activity. It also makes it extremely difficult for Japanese suppliers to make a high profit.

\section{Miniaturization is Driving Automation}

Sony has been driving consumer products technological development in Japan since the mid1980s when it introduced the minicamcorder. It has set the rules of the game for development by projecting that the next model be half the size and half the cost for the same function. For example, its first minicam was $1.6 \mathrm{~kg}$, its second was $0.8 \mathrm{~kg}$, and the most recent was $0.4 \mathrm{~kg}$. The current technology driver is the cellular telephone at $0.2 \mathrm{~kg}$. These small-sized products are pushing product components and packaging technologies to smaller sizes.

Continued commitment to the miniaturization of products and component technologies requires increased investment in production technologies and factory automation. As part sizes shrink, human assembly is no longer feasible. This has pushed assembly technologies to become more precise and faster. For example, precision robots have improved 
repeatability precision from $0.05 \mathrm{~mm}$ to $0.01 \mathrm{~mm}$ since the mid-1980s. Matsushita's new SMT machine has 11 placement heads with $0.01 \mathrm{~mm}$ repeatability. Sony's high-speed robots are now working at 0.012 repeatability placement.

\section{Miniaturization and Automation are Increasing Competitive Advantage}

Japanese companies have been committed to miniaturization for nearly a decade. Product miniaturization is leading to improved product operating characteristics. Smaller component sizes lead to lower power usage and heat generation and longer battery life. Automation has led to improved quality and faster delivery of new products. Sony's factory automation activities have caused defect rates to drop to $20 \mathrm{ppm}$ and have reduced ramp-up time to half that of manual assembly facilities. The goal of miniaturization has been supported by concurrent engineering in both product and process technology development. Companies have invested heavily in process technologies to achieve the miniaturization goals that can no longer be achieved through manual production techniques. By developing existing technologies rather than investing heavily in new technologies, they have been able to keep overall costs down and have stayed competitive in advanced consumer products.

\section{High Technology is Only Used When Required}

Japan's electronic packaging industry is heavily committed to plastic molded packaging systems. Cost as a competitive objective leads Japanese electronics suppliers to avoid hightechnology solutions to their miniaturization problems. Current QFP packaging technologies are being pushed to their limits. Miniaturization of all components appears to be the strategy, not the movement to new technologies. New packaging technologies such as MCM are used when needed, but are considered higher-cost than established technologies. The miniaturization of current packaging technologies appears to be meeting the needs of most product requirements.

At the same time, high-technology packaging solutions are available in Japan in highperformance products such as supercomputers. A recent study of supercomputers found that Hitachi had the most advanced design for future MCM applications. This suggests that costs will limit the use of such technologies except where current technologies fail to meet the functional or size requirements of the package.

\section{GROUP COMMENTS MADE DURING THE DISCUSSION AT NCR}

- Japan is using simple, low-cost technologies to win the market.

- Japan is committed to those simple technologies.

- Concurrent engineering is required for simultaneous product and process developments.

- Defense industries are driven by reliability and quality, and cause the cost to be high. 
- Firms would be able to compete with Japanese firms if they were willing to make the investments. There are some production technologies that are not available in the United States. The equipment required for one micron of accuracy in miniaturized mechanical component production is probably outside of the U.S. capabilities today. We lack the required skills. Japan does not have the technology required to make advanced microprocessors.

- The U.S. believes that it can go to the moon if the commitment is made. It would require a number of years to rebuild the infrastructure and educate the people.

- The basic questions are, "What skills do we have? What do we want to do? What actions do we need to take to achieve those objectives?"

- All new products at the electronics show are smaller than the previous models. The only way that the U.S. will compete is to get into the market.

- The U.S. dominates the market in design tools and microprocessors. This should provide some opportunity for development. U.S. firms have designed but not exploited technologies.

- Most firms produce their own equipment and plan to build even more of their equipment in the future. The ability to produce is a constraint to getting into the business. Some firms have developed their own equipment to sell their components. They use other makers' equipment, but build their own when equipment is not available to meet their own needs. So why is TI selling off its equipment business?

- The companies we visited build a high portion of their own equipment and place a high priority on production technology.

- Most firms said they were not going to get into BGAs, but would push today's technology to the limit. Those firms going to TAB may be taking a high-cost alternative. 
Site:

Murata Manufacturing Co., Ltd. 2-26-10 Tenjin, Magaokakyo-shi Kyoto 617, Japan

Date Visited:

October 6, 1993

Report Author:

M. Kelly

\section{ATTENDEES}

JTEC:

M. Kelly

G. Lim

N. Naclerio

J. Peeples

HOSTS:

H. Kuronaka

Manager, R\&D Management Section

H. Iwatsubo

Assistant Chief, R\&D Section

\section{BACKGROUND}

Murata is a leader in the production of discrete electronic components. The primary market for Murata products is Japan (63\%), followed by the United States (11\%), Europe (10\%), and Asia (most of the remaining $16 \%$ ). The company strategy is to pursue manufacturing within the geographical spheres of its primary customers. The Murata group includes 23,000 employees and 47 affiliates, including 23 overseas; Murata Erie North America, for example, has two plants in Georgia, one of which makes capacitors and the other of which makes passive electronic components. Based on information contained in the 1993 annual report, the primary product groups in Murata are the following:

- Capacitors. This group produces monolithic disk-type and semiconductor ceramic and trimmer capacitors.

- Resistors. This group produces PTC thermistors, potentiometers, R-networks and highvoltage resistors. Demand comes primarily from Japanese display manufacturers.

- Piezoelectrics. This group produces ceramic filters, ceramic resonators, piezoelectric buzzers, and surface acoustic wave filters.

- Coils. This group produces flyback transformers, deflection yokes, and various types of coils. The major expansion was in sales of high-definition and microwave deflection yokes for computer displays in the Japanese and Asian markets. 
- Electronic Modules. This group produces circuit modules and power supplies. There has been a high demand in overseas markets for voltage controlled oscillators for mobile and portable telephones.

- Other Products. There is a wide variety of "other products" that include EMI suppression filters, microwave filters, sensors, piezoelectric vibrating gyroscopes, thermal cutoffs, and production equipment. The most attractive markets are in the areas of EMI suppression filters for computers, piezoelectric vibrating gyroscopes for camcorders, and in the future, compact switching regulators $(2 \mathrm{MHz}$ ) for notebook PCs.

Murata sales total about $\$ 2.7$ billion annually, with capacitors representing $38 \%$ and piezoelectric components $20 \%$. We were told that Murata dominates world market share of ceramic filters/ceramic resonators $(85 \%, \$ 100 \mathrm{million} / \mathrm{mo})$, capacitors $(50 \%)$, thermistors $(40 \%)$, and EMI suppressors (30\%).

Murata's product strategy is to continue to build on its strengths and move aggressively to be a supplier of complete functional modules. In pursuit of future objectives, Murata is spending $6.5 \%$ of sales, about $\$ 176$ million, on $R \& D$.

Murata's primary R\&D domains include

- microwave modules (for digital cordless telephones): oscillators, mixers, synthesizers, antennas, filters, GaAs MMICs

- power supplies ( $S W$ frequency $2 \mathrm{MHz}$ ): CAD, substrates, packaging, transformers, capacitors

- functional sensor modules: gyro sensors, IR sensor arrays, signal processing, technology integration

- capacitors (miniature, high capacitance): thin film multilayer, ceramic, reliability, electrode materials

- filters (for communications): piezoelectric ceramic products, high-Q ceramics, thin-film process

Murata's strategic technologies are identified in Figure 7.5 (p. 137). Other areas considered important by Murata include module circuit application-specific components and vertical technology integration within the company.

As of the JTEC visit, recent capital investments had been made for the production of ceramic materials, monolithic ceramic capacitors, components for imaging equipment, chip components, microwave components, and electronic modules. Aggressive capital investments were also made for thin-film processing technology and the development of equipment for gallium-arsenide semiconductor devices. 
At the time of the JTEC visit, Murata planned to have a gallium-arsenide integrated circuit pilot line in production by the end of 1994. The motivation for establishing the line, as expressed by our hosts, is to protect intellectual property and to improve Murata's competitive posture in the microwave and RF module business by focusing on future personal communication products.

Murata is doing extensive work in sensor development. Present applications for sensor products include engine knock detectors and fire and burglar alarms. An advanced sensor application that was discussed is a piezoelectric gyro for sensing angular accelerations. The current product measures $21.5 \times 8 \times 8.5 \mathrm{~mm}$ and is used in the Sony TR2 and TR3 palmsized camcorder for vibration stabilization. A larger, more accurate version $(24 \times 24 \times 58$ $\mathrm{mm}$ ) is used in Pioneer's automobile GPS navigation systems. Future markets for Murata sensors include accelerometers and chemical/gas detection.

A new silicon micromachining program has been initiated at the Yokohama R\&D Center to develop microminiature accelerometers, sensors, and oscillators.

The manufacturing lines JTEC panelists toured in Kyoto are most impressive. The total process is automated. The equipment appears to be very robust and capable of handling very high-volume throughput. Over $80 \%$ of the equipment being used was designed and built by Murata. Much of the equipment is customized to meet specific product requirements, which justifies the in-house development; however in more general terms, Murata recognizes the importance of internal equipment development in order to protect its competitive advantages. There was evidence of continuous improvement in the manufacturing processes, with particular emphasis on equipment improvements.

Murata has evidently mastered the manufacturing process for high-volume, miniaturized discrete components. Perhaps this explains its dominance in the world market. There was nothing magic about what we saw: outstanding equipment designed for automation, meticulous attention to detail, continuous improvement, qualified personnel, and a committed management team.

It became very evident during our discussions that Murata places a very high priority on customer interactions. It was pointed out that in some cases Murata people visit customers once or twice a day. Procurement planning is regularly updated, and Murata can expect at least a three-year lead time from customers for new product requirements. It was likewise evident that the needs of suppliers were taken into account when negotiating reduced costs. Suppliers, it was stated, are no good to us if they are driven into bankruptcy. Suppliers are considered part of the team and expected to contribute to the competitiveness of the product.

The visit to Murata substantiated much of what has been identified as Japanese strengths:

- Focus on the fundamentals

- Pursue continuous improvements 
- Drive continuously to miniaturize components

- Work closely with suppliers and customers

- Design and build your own equipment

- Eliminate waste

- Make cost reduction a primary objective in design and manufacturing

- Automate whenever it is cost-justified

- Build on core competencies

- Follow an evolutionary product strategy

- Move increasingly to integrate components to produce functional modules

Murata, like other Japanese companies visited, was concerned about the effects of the recessionary period that industry was experiencing at the time of the JTEC visit. The attitude of our hosts, however, was very positive about the future of Murata. If anything, I expect that the present economic climate will strengthen the company and better prepare it for the competitive challenges of the future. 
Site:

\section{Nippondenso Kota Plant Nippondenso Co., Ltd. 1-1 Shawa-cho, Kariya-shi Aichi-ken 448, Japan}

Date Visited:

October 7, 1993

Report Author:

N. Naclerio

\section{ATTENDEES}

JTEC:

M. Kelly

N. Naclerio

J. Peeples

HOSTS:

Mizutani Shuji

Director, Automotive Electronics Division

Shigehiko Ito

Mark R. Hunter

General Manager, Electronics Manufacturing Dept.

Public Affairs Department

\section{BACKGROUND}

Nippondenso is a leading manufacturer of automotive components and electronic systems. In 1992 , Nippondenso had sales revenues of about $\$ 12$ billion. Approximately $9 \%$ of sales was invested in capital and another $7.3 \%$ in R\&D. About 56,718 people were employed by Nippondenso in 1992. (The above figures are based on consolidated 1992 data.)

Some of the themes that drive Nippondenso's business strategy are high performance, safety, and fuel efficiency. In-house research ranges from semiconductors to micromachines to materials, and from AI to telecommunications to control theory. Fuzzy logic systems have been developed and are in use for anti-lock braking systems (ABS), cruise control, and suspension systems. Nippondenso uses its micromachine technology to manufacture accelerometers and other sensors for automotive applications. As a demonstration of its micromachine prowess, it built a miniature car, barely $5 \mathrm{~mm}$ long, complete with electric motor. Nippondenso plans to fuse automobile technology with state-of-the-art electronics to generate new products in many fields. Examples of nonautomotive products we saw included portable cellular phones, hand-held bar code scanners, and factory automation systems.

Nippondenso manufactures components and systems for nearly every automobile manufacturer in the world. While Toyota is its largest shareholder and customer, it also sells components to most of the other Japanese auto makers, the Big Three U.S. companies, and 
most European companies. Nippondenso claims to be a leader in 14 product areas including electronics, fuel injection systems, braking control, navigation, air conditioners, fuel pumps, and radiators. Nippondenso product groups do their own product development and manufacturing but do not have their own sales forces since most of their products are sold to a few automobile companies.

\section{THE KOTA PLANT}

Activities at the Kota plant include manufacture of automotive ICs, electronic control units (ECUs), and communications equipment. This plant is located in Aichi Prefecture on $274,000 \mathrm{~m}^{2}$ and was dedicated in April 1987 after one year of construction. The site is about $50 \%$ developed, with three main buildings. A new wafer fabrication facility occupies about $18,000 \mathrm{~m}^{2}$ of floor space, and a four-floor electronics factory occupies $173,000 \mathrm{~m}^{2}$. The total value of the products manufactured in the Kota plant in 1992 was about $\$ 160$ million per month. There are approximately 5,000 pieces of equipment and 3,700 employees.

\section{IC Manufacturing}

Nippondenso's IC production is being transferred from a $5^{\prime \prime}$ line at the head office in Kariya to a new 6" line at the Kota plant. Nippondenso has been in the IC business for 25 years. While its people recognize that they cannot compete with large merchant IC companies in products like general purpose microprocessors or memories, they still feel that in-house IC manufacturing gives them a competitive advantage. Two advantages of building devices inhouse cited by Nippondenso are (1) the ability to produce specialized products not available on the market, and (2) the ability to avoid sharing proprietary designs with potential competitors. Nippondenso manufactures complex, more expensive VLSI chips that are specially designed for automotive applications.

\section{Engine Control Unit Assembly Line}

The main four-story building at the Kota site houses chip assembly, hybrid manufacture, SMT board, and final assembly. Five different engine controller product families including over 120 different engine controllers are made on a single assembly line. The line begins with traditional surface mount assembly including adhesive application, component pick-andplace, add form component assembly, and test. After testing, a conformal environmental coating is applied to the boards. The boards are then assembled into metal enclosures that are sealed and marked. The completed modules go through high-temperature burn-in before final outgoing test. After testing, the modules go into a stocker on the factory floor to await a daily shipment to nearby Toyota automobile assembly plants.

The entire 1,170-meter manufacturing line, including assembly, burn-in, and test, has only one direct labor worker who folds multiple rigid boards connected by flex cables into a metal enclosure. We were told that this operation had not been automated because the necessary machine would be too expensive. There is zero changeover time between products on the 
line. In fact, we were told that complex and relatively simple engine controllers were intentionally mixed to balance the throughput of the line. As a practical matter, controllers are usually made in batches of 16 since that is the size of the cassettes used to transport boards on AGVs. In order to simplify material handling, all of the products have a common width, but appeared to vary in length by as much as a factor of three. Every board type is identified by a bar code, and every piece of equipment on the line has its own bar code reader. As a result, the number of different components that must be simultaneously loaded on the pick-and-place machines is probably higher than on most lines producing only one product at a time.

\section{Production Systems}

Almost all of the manufacturing equipment we saw at the Kota plant was produced internally by Nippondenso. Our hosts claimed that because of the company's unique needs, it is actually cheaper to develop equipment in-house rather than purchase more general-purpose tools. One tool for visually inspecting solder joints reportedly took over two years to develop internally. Over 200 people at the Kota site are involved in the development of production equipment and processes. The average piece of equipment on the manufacturing line is either replaced or upgraded every three to four years. Some of the larger pieces of factory equipment are developed at another Nippondenso site dedicated entirely to that purpose, but many of the smaller pieces of equipment are developed and manufactured on-site. In all cases, customization of the equipment, fixture development, and programming is the responsibility of the manufacturing site. Nippondenso is just beginning to market production equipment such as robots to external customers. Factory equipment and production processes are designed by teams that include both hardware and software engineers. The Kota plant was the first to implement a factory-wide CIM system, now in place at all other plants. This system unites data from the head office and all the factories to meet quality standards and delivery times. (In addition to factory-level data, information from design and sales is also included.)

\section{Multichip Modules}

We saw some ceramic MCM modules or hybrid assemblies built at this plant using flip-chip assembly. The flip chip used is similar to that employed by some U.S. automotive manufacturers and involves plated copper bumps with solder. The main Japanese concern with the wider use of MCMs is reportedly cost. Nippondenso says that MCM-L is very close to introduction in some of its automotive applications. Its automotive customers are not too anxious to have risky "new" technologies used in their cars; however, Nippondenso thinks that MCM-L will be the lowest-cost solution for many ECU products.

Another driver for the use of MCM technology will be miniaturization of engine control functions so that they can be mounted directly on sensors and/or actuators. Nippondenso representatives feel that by 1998 multiple functions will be combined into modules

containing sensors, processors, and actuators. These distributed processors will share data across a vehicle-wide network. 


\section{Impact of Automation on Productivity}

The highly automated production line at Kota results in a high degree of flexibility, very high manufacturing quality, and the elimination of most direct labor. During the time the JTEC team spent in the ECU assembly plant, we did not see any modules in reject bins. According to one host, only a couple of modules per month fail final test. In five years Nippondenso expects to have added a second wafer fab and 50\% more assembly area while also hoping to reduce by half the total number of people on the site to less than 2,000 from the current 3,700 .

\section{Customer Relationships}

Nippondenso has close ties to its automotive customers. Large customers provide regularly updated five-year production requirements. Engine control units are essentially built to order and delivered to customers every day. In order to provide similar service to North American auto makers, Nippondenso operates a similar assembly line in the United States.

\section{Engineer Training}

Nippondenso runs its own two-year college for training engineers. Managers tend to hold four-year degrees from university engineering programs. Practical training in areas such as equipment design takes place almost entirely within the company. During the first five years of employment, engineers each receive about 100 hours per year of formal technical training resulting in the equivalent of a master's degree. In the sixth year, about $10 \%$ of the engineers are selected for the management track and receive another 200 hours of technical training. After ten years about 2-3\% are selected to become assistant managers and receive additional training. By this point, the assistant managers have earned the equivalent of a $\mathrm{Ph} . \mathrm{D}$. within the company. Management and business training is also provided for those technical managers. The fraction in nonengineering fields who become managers is perhaps $10 \%$.

\section{Display Technology}

Nippondenso manufactures passive liquid crystal displays (LCDs) for black-and-white instrument displays. It also manufactures a holographic display produced for the Lexus automobile that projects the vehicle's speed two meters in front of the windshield. Nippondenso's R\&D labs have very recently developed a color anti-ferroelectric LCD display technology that offers a wide viewing angle and the potential to be very low-cost. A ten-inch diagonal display suitable for personal computer applications has already been demonstrated.

\section{Future Directions}

Nippondenso believes that future automobiles will contain highly integrated, but distributed, electronic systems composed of sensor/processor/actuator modules that share data over a vehicle network. When asked about the role of fiber optics in those automobiles, our hosts responded that the company's experience putting optical fiber links in the Toyota Sentry door lock system taught them that optical data links are too expensive for automobile applications; Nippondenso was no longer pursuing them at the time of the JTEC visit. 
Nippondenso is already shipping highly integrated communication/navigation/entertainment systems for luxury automobiles. A demonstration at the plant showed a new system being manufactured for the Lexus automobile. A color flat-panel display built into the automobile's console can display television when the car is parked. While driving, it can be used to display map information or travel guides from CD ROM. The system can also display position information obtained from an automotive navigation system that includes both GPS and dead-reckoning. The dead-reckoning system uses wheel rotation information from the ABS sensors in the front wheels of the car. When the car is put in reverse, a CCD camera shows what is behind the car. If the car gets too close to another vehicle or obstacle, a warning is flashed on the screen. An FM-broadcast traffic information system was scheduled to begin pilot operation in Japan in 1994, allowing the car navigation system to also display traffic congestion information. Aftermarket GPS/navigation/entertainment systems are also being produced by a number of other Japanese electronics companies including Sony, Matsushita, and Pioneer, and they are reportedly very popular with young Japanese.

\section{SUMMARY}

Nippondenso is a best-of-breed automotive electronics manufacturer. It manufactures vehicle electronic systems for sensing, control, communications, and navigation. Perhaps as a result of its close relationship to Toyota, it has embraced a flexible manufacturing approach that enables it to manufacture engine control units with a lot size of one and zero changeover time. This flexibility does not appear to cost the company in-line throughput or manufacturing quality, both of which appear to be world class. Like other large Japanese electronics companies, Nippondenso is vertically integrated, and it designs and manufactures most of its own production equipment. Because of its unique approach to flexible manufacturing, it is possible that in-house development of production equipment such as SMT assembly is actually cheaper than purchasing full-featured machines on the open market. Nippondenso manufactures key components such as semiconductors and micromachined sensors because of the view that doing so gives it a proprietary advantage. The use of MCM technology at Nippondenso will be driven by cost reduction and the desire to integrate sensors, processors, and actuators into compact modules that can be located directly on engine and drive train systems.

Most formal training of engineers takes place in-house, with all engineers receiving 100-200 hours of formal technical training per year. The company's skills as a low-cost producer of very high-quality electronic systems is enabling it to branch out into other markets such as personal communications and mobile point-of-sales terminals.

Nippondenso believes that total manufacturing efficiency can only be achieved by closely coordinating product development with production engineering. To achieve this, Nippondenso has long been developing specialized manufacturing equipment and methods in-house. 
Site:

Nitto Denko Corporation

61-7, Aza-Sasadani, Yamadera-cho

Kusatsu

Shiga 525, Japan

Date Visited:

October 6, 1993

Report Author:

G. Harman

\section{ATTENDEES}

JTEC:

W. Boulton

G. Harman

G. Meieran

M. Pecht

D. Shelton

HOSTS:

M. Takemoto

General Manager

Y. Takashima

Manager

M. Sano

S. Omori

Manager, Design Section

Manager, Quality Assurance

H. Tabada

T. Mitarai

Chief Researcher, Reliability Evaluation Center

Assistant Manager, Overseas Department

M. Kaneto

Researcher

\section{BACKGROUND}

Nitto Denko is a diversified materials company with headquarters in Osaka. Nitto Denko's philosophy is to listen to the customers who are on the leading edge of technology and to develop or improve products for their use.

The company was founded in 1918 to produce electrical insulating materials in Japan. Each product center has its own development group and profit center and issues its own financial report. Nitto Denko is an independent company, not part of any keiretsu. About $30 \%$ of its business is semiconductor- and electronics-related. Other areas include industrial products, packaging products, engineering plastics, medical products and membrane products. Nitto Denko is a major plastic molding-compound supplier for semiconductor chip encapsulation. Our hosts also indicated that Nitto is the major producer of polarizing films (used in flat panel displays) and low friction rings (used in floppy disks). The company's newest venture is to produce cultured (fermented) ginseng soft drinks to help improve its profit margin. Nitto 
Denko has manufacturing plants for various products located all over the world, including three in the United States that will be expanding soon as the firm moves more production off shore.

Nitto Denko's philosophy emphasizes that it listens to its customers - a lesson that many American companies could learn. It has a standing committee to help solve applications problems of companies using its products. Planning for future growth is exceptional. Company personnel have outlined the entire semiconductor assembly and packaging process and would like to develop products that will contribute to or simplify each step. A diagram showing this approach is given in Figure Nitto 1. A further example of Nitto's exceptional planning is its development and fitting of future products into the U.S. SIA roadmap for semiconductor development by the year 2000. Our hosts at Nitto Denko stated that they have a department of "Research on New Basic Technology," but nothing we saw was identified as coming from that. In fact, when asked how many Ph.D.s they have in this particular plant, their response was "only one." Before a recent reorganization they had four.

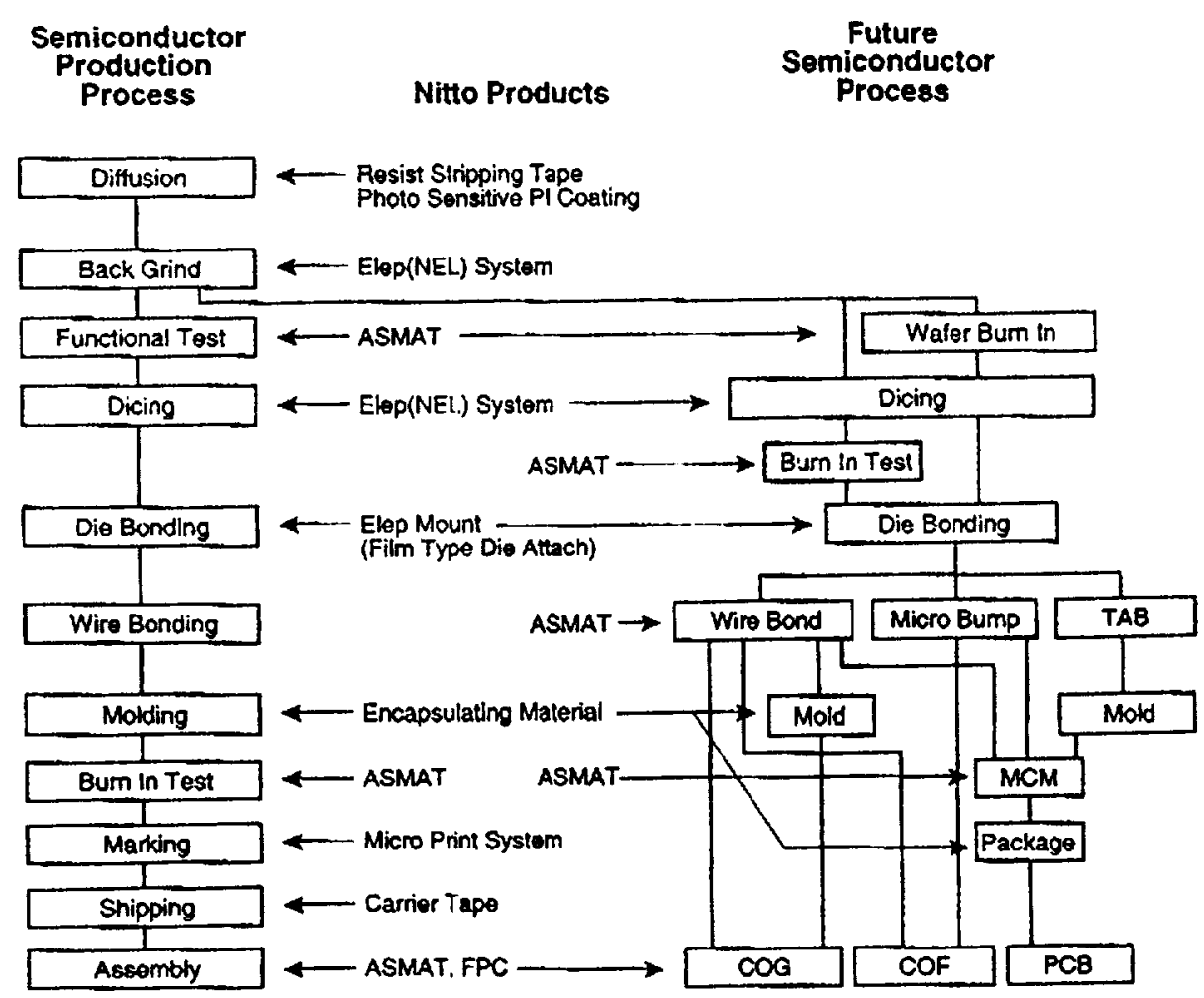

Figure Nitto.1. Nitto's technical development plan for semiconductor related materials. 
Nitto's Kameyama plant is highly goal-oriented. It has a product line that primarily consists of adhesives and packaging and encapsulation materials. The company then looks for ways to apply these products and expertise to the field of electronics materials. The JTEC team discerned no fancy gear or advanced research projects; just a strict "improve the product and look for new areas to apply products," no-nonsense approach. The company is quite creative in looking for new applications, but in the electronics areas, it is not trying to expand its product line into ceramic packaging. It is the company's understanding of the characteristics of plastic materials that separates it from its competitors. Nitto appears to be a world leader in this area.

\section{Finances}

Nitto had net sales of $\$ 2.187$ billion with a net income of $\$ 34.3$ rilillion in 1993 . This compared with a net income of $\$ 55.7$ million in 1992 , and $\$ 71.3$ million in 1988 . The sharp decline in 1993 resulted from the increased value of the yen, coupled with downward cost pressure from its Japanese customers. It is planning to expand production overseas to help overcome the effects of the increasing value of the yen.

The biggest problem facing Nitto is the flat sales volume for plastic molding compounds. The volume of molded plastic packages continues to increase, but the thinner package dimensions, e.g., small outline devices, may be only $0.5 \mathrm{~mm}$ thick, and improved mold design leading to reduced loss of plastic during the molding operation has led to flat sales. It seems that both of these trends will continue in the foreseeable future. However, it is not obvious what can be done to improve this situation. Nitto has been a leader in developing low-stress molding compounds as well as in low alpha particle filler materials, and it is well positioned to maintain leadership in these various technical areas, as well as in the new products mentioned below. Company officials hope that increased overseas production will overcome the flat sales and profits in the older product areas.

\section{Specific Products}

Nitto is developing a number of new products based on its core technologies. One such product is a new die attach material for application to the whole wafer called "Elep Mount." This is a conductive epoxy film applied to the backside of the wafer before sawing. This application can save several assembly steps and thus time and money. (Note: This is an old idea originating in the ' $70 \mathrm{~s}$ at Fairchild. Early in the ' $80 \mathrm{~s}$, such films were unsuccessfully marketed by Stauffer Chemical, a U.S. company, which sold that division to Ablestick. The film is apparently not marketed now. Amicon also tried to market a conductive epoxy screened-on-wafer variation of the system in about 1985. Both had technical problems relating to water pickup in the uncured resin during sawing, even if the wafer is not sawed through, which assembly people prefer to do. A water-repellent uncured epoxy film with new specialized equipment, with IC manufacturing cost pressures, may make it successful for Nitto.) 
Other semiconductor-related products were discussed. We requested information on a product called ASMAT. This is being developed by Nitto for an ARPA contractor (U.S.) who is planning to use it as area-array contacts for whole-wafer test and burn-in, to obtain known-good-die. The contacts are hemispherical bumps, precisely electroplated (and/or etched) $48 \mu \mathrm{m}$ in diameter on large two-metal layers of polyimide films. Nitto has a tough job ahead to cover all of the obvious problems inherent in placing a contact-covered polymer thin film on hundreds/thousands of bond pads in a wafer, e.g., no metallurgical interaction with the bond pad is permitted at burn-in times and temperatures, and the film contacts must be position-stable at all times and temperatures. Also, the contact resistance varies with applied force, so each one of thousands may require its own, or at least regional separate spring loading. Nitto is considering plating the bumps with nickel, gold, rhodium, osmium, etc. It expected to publish a full paper on ASMAT at the ISHM symposium held in November 1993.

Other products in development included improved molding compound adhesion to palladium plated leadframes, high-thermal-conductivity molding compounds for power devices, and others that need lower thermal resistances. Ideally, these materials could be developed to replace ceramic packages. Nitto is also working on recyclable molding compounds (presumably thermoplastics) and low-viscosity compounds intended to go under flip chips (a process developed by IBM). Nitto is also developing mold compound pellets that are dustfree for use in the future (class 100) clean-room assembly and packaging areas. Nitto is also studying trapping agents that can slow the migration of bromine ions (fire retardants) in molding compounds and thus increase gold wire bond reliability. It is developing compounds that are stronger, have greater leadframe adhesion, and have lower moisture absorption, for use in TSOPs (thin small-outlined packages). In addition, Nitto is developing materials that require no post mold cure (currently such cure takes five to six hours at $175^{\circ} \mathrm{C}$ ). It is using the Cornell University software for modeling its thermosetting plastics. Also being developed are lines of adhesive contacts and adhesive tapes for die attach, TAB assembly, flexible mounting for chip carriers, etc. It seems to have a well thought out strategy for applying its specific technologies to the entire range of assembly and packaging needs of the industry.

\section{PLANT TOUR}

The Nitto Denko plant and much of the equipment was not new, but certainly appeared to be adequate for the job. The failure analysis and other materials analysis lab facilities appeared adequate, but by no means grandiose. There were all the important analytical and environment test facilities needed for evaluation of plastic packaged devices: $\mathbb{R}$ microscope, SEM, radiography, EDX and WDX, TMA and TAG, pressure cookers, thermal cycle and thermal shock, etc. There were no super advanced capabilities such as advanced surface analysis (Auger, STEM, ESCA, etc.), but the company seems to have access to those capabilities if needed. Our main impression of the analytical facilities is that they are extensively used. Work was going on in most of these facilities (which are located in one 
large room.). Each piece of equipment was clearly labeled in English, apparently for the benefit of the many visitors who come to the facility.

A large area is devoted to lead frame plastic molding equipment for running the many experiments necessary to develop new molding compounds. These experiments are designed by finite-element-modeling of the mold compound during molding to minimize wire-sweep and air bubbles. (Nitto may use some of the Cornell software imbedded in its own). There was considerable QA equipment available for testing the molding compounds (gelling time, rheology tests, spiral flow testing, etc.). We saw several examples of QA processes during our tour.

The plant was typical of a chemical manufacturer rather than an electronic (clean-room environment) manufacturer. This was especially evident in the areas where the mold compound was formulated and pelletized. However, it should be emphasized that there was sufficient cleanliness for the products, and if more is needed, it will be supplied. The level of automation in the preparation of molding compound is not particularly high, but adequate for the job. 
Site:

Oki Electric Industry Co., Ltd.

Honjo Plant

1-1, 4-Chome, Ojimaminiami

Honjo-shi

Saitama 367, Japan

Date Visited:

October 7, 1993

Report Author:

J. Kukowski

\section{ATTENDEES}

JTEC:

P. Barela

J. Kukowski

L. Salmon

R. Tummala

HOSTS:

Tohru Handa

Yoshinobu Tateishi

Yoichi Kohara

Saburo lida

Yasuhide Ohnuki

Executive Mgr, New Business Development Div., Telecommunications Group

Gen. Mgr, Honjo Plant, Tele. Group

Gen. Mgr, LSI Packaging Eng. Dept., LSI

Assembly Eng. Div., Electronic Devices Group

Gen. Mgr, Tele. Devices Devt. Div., Tele. Network Gp.

Mgr, Functional Devices Devt. Dept., Tele.

Devices Devt. Div., Tele. Network Group

Jiro Utsunomiya

Mitsuhide Yamada

Manager, Functional Devices Devt. Dept. Tele.

Devices Devt. Div., Tele. Network Group

Manager, Functional Devices Devt. Dept. Tele.

Devices Devt. Div., Tele. Network Group

Yasuo Iguchi

Toshiyasu Takei

Akihisa Yamada

Hitoshi Shibuya

Research Manager, Microelectronics Dept. Research

Lab. R\&D Group

Manager, P.C.B. Eng. Dev. Sect. Takasaki Plant

Computer and Network Systems Group

Manager, Eng. Relations Dept., Eng. Admin. Div.

Assist. Mgr, Functional Devices Devt. Dept. Tele.

Devices Devt. Div., Tele. Network Group

\section{BACKGROUND}

Oki Electric, Japan's first telecommunications manufacturer, was founded in January 1881 . It is developing its business globally, pursuing all aspects of research and development, 
production, marketing, and service from an international perspective. The company's business sectors are telecommunications systems, information processing systems, and electronic devices. The company produces a wide range of products that include switching systems, transmission systems, telecommunications terminals, data communications systems and peripherals, underwater acoustic systems, telemetry and telecontrol systems, automotive electronics systems, and electronic devices. The company's vision is to capitalize on the technical strength of the three business sectors to be successful in the coming multimedia age.

\section{HONJO PLANT}

The Honjo manufacturing plant produces products for the telecommunications systems business sector. The products being produced at this site include asynchronous transfer mode (ATM) switching systems, modems, facsimiles, telephones, and other peripherals.

\section{Technical Presentations}

Detailed technical presentations were given on the following subjects:

- multichip modules

- polyimide-copper thin film multilayer substrate

- development of post-CFC cleaning technology defluxing

- development of single-PPM soldering systems

- LSI packaging technology

- packaging technology for fiber-optic devices

Multichip Modules (MCM). The subject of MCM was presented by Mr. lida. The topics covered were benefits, Oki development direction, MCM structures, design specifications for LTCC and copper polyimide thin film multilayer substrate, Oki's implementation schedule, and identified applications.

\section{Benefits}

The benefits for creating a MCM are high speed, miniaturization, high reliability, and low cost. The driving forces are low cost and high speed. The key issues in achieving low cost and high speed have been identified as

- miniaturization, as well as monolysic LSI (large-scale integration)

- very fine pattern of substrate

- flip chip bonding

- assurance of known good die (KGD)

- concurrent design (board/module/LSI) 


\section{Directions of MCM development at Oki}

1993 MCM-C (multichip module-ceramic)

- Substrate: Low-temperature co-fired ceramic (LTCC)

- LSI: $\quad$ Wirebond / flip chip

- I/O: $\quad$ Quad flat pack type (QFP).

1994 MCM-D/C (multichip module-deposited/ceramic)

- Substrate: Modified Cu/Pl on LTCC

- LSI: $\quad$ Flip chip

- VO: $\quad$ BGA/QFP type (ball grid array)

- High power LSI and high reliability

1995 MCM-D/L (multichip module-deposited/laminate)

- Substrate: Cu/BT resin on BT base

- LSI: $\quad$ Flip chip

- VO: $\quad$ BGA/QFP type

- Low power LSI

\section{Applications}

The ATM SW module, optical interface module, digital LSI tester module, clock recovery module, and super multi pins LSI package have been identified for potential applications to incorporate MCM technology. During the technical presentation on MCMs the key features of the LTCC substrate and the copper polyimide substrate were reviewed.
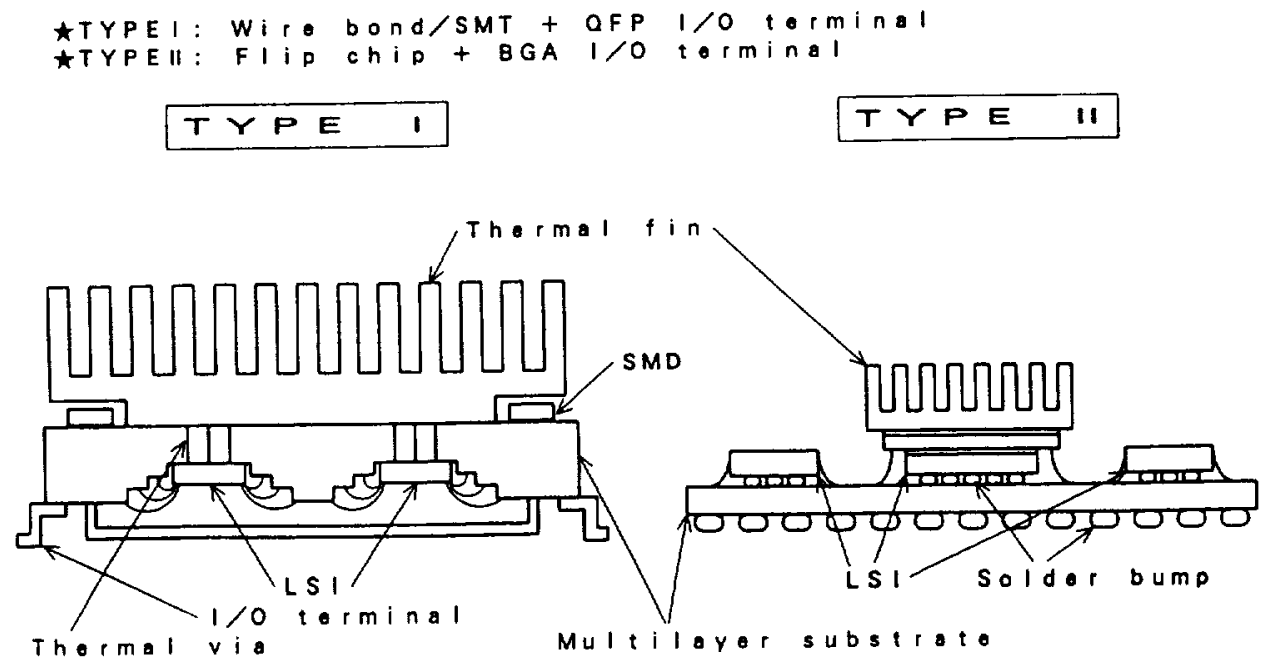

Figure Oki.1. MCM structures. 
Table Oki.1

Design Specifications of MCM Substrates

(Low Temperature Co-Fired Multilayer Ceramic Substrate)

\begin{tabular}{|c|c|c|}
\hline Item & First Stage (1993) & Second Stage (1994 ) \\
\hline \hline Maximum Size & $80 \mathrm{~mm}$ square & $150 \mathrm{~mm}$ square \\
\hline Conductor Material & $\mathrm{Au} / \mathrm{Ag}$ & $\mathrm{Cu}$ \\
\hline Line Width/Space $(\mu \mathrm{m})$ & $100 / 100$ & $50 / 50$ \\
\hline Via Diameter/Pitch $(\mu \mathrm{m})$ & $200 / 600$ & $100 / 250$ \\
\hline Shrinkage Variability $(\%)$ & $0.2 \sim 0.3$ & 0.1 \\
\hline Others & Cavity/Thermal Via & Buried Components C\&R \\
\hline
\end{tabular}

Table Oki.2

Design Specifications of MCM Substrates

(Copper Polyimide Thin Film Multilayer Substrate)

\begin{tabular}{|c|c|c|}
\hline Item & First Stage (1993) & Second Stage (1994 ) \\
\hline \hline Maximum Size & $75 \mathrm{~mm}$ square & $150 \mathrm{~mm}$ square \\
\hline Layers & 4 & $6 \sim 8$ \\
\hline Line Width/Space $(\mu \mathrm{m})$ & $15 / 15$ & $10 / 10$ \\
\hline Via Diameter/Pitch $(\mu \mathrm{m})$ & $40 / 200$ & $20 / 100$ \\
\hline Via Structure & Via Hole & Via Pillar \\
\hline Foundation Substrate & LTCC Alumina & (AIN) \\
\hline
\end{tabular}

Table Oki.3

Implementation Schedule

\begin{tabular}{|c|c|c|c|}
\hline & 1992-1993 & 1993-1994 & 1994-1995 \\
\hline $\begin{array}{c}\text { LTCC } \\
\mathrm{Au} / \mathrm{Ag} \text { System }\end{array}$ & $\begin{array}{c}\text { Trial } \\
\text { Production }\end{array}$ & Production & Production \\
\hline $\begin{array}{c}\text { LTCC } \\
\text { Cu System }\end{array}$ & & $\begin{array}{c}\text { Trial } \\
\text { Production }\end{array}$ & Production \\
\hline $\begin{array}{c}\text { LTCC+ } \\
\text { CU/PI System }\end{array}$ & $\begin{array}{c}\text { Trial } \\
\text { Production }\end{array}$ & Production & Production \\
\hline
\end{tabular}

Note: Oki's LSI interconnection roadmap is shown in Table 4.12 (p. 87). 


\section{Polyimide-Copper Thin-Film Multilayer Substrate}

Oki's developments and research in polyimide-copper thin-film multilayer substrate were presented by Mr. Iguchi, who gave us technical details on the following topics:

- $\quad$ properties of the polyimide resin (thermal, physical and electrical)

- manufacturing process flow of polyimide-copper thin film multilayer substrate (TFML)

- comparison of ground configurations (solid, gridiron, biased gridiron, shifted+biasgridiron)

- test results for characteristic impedance, propagation delay, transmission loss, cross-talk, and temperature cycling for connection resistance

- $\quad$ planarization process

Oki Development of a Single-PPM Soldering System. Mr. Takei presented Oki's challenges and accomplishments with respect to the goals of CFC elimination and single-PPM soldering.

CFC Elimination. Our hosts reviewed the utilization of CFC materials at the Honjo plant and the conventional reasons for CFC cleaning of PCBs. The presentation detailed the development process undertaken to meet the goal of CFC elimination. The process consisted of defining the development target/specifications, defining alternative approaches to eliminate CFCs, the development of experimental fluxes, and testing of the fluxes. Details of the reliability test specification, solderability test specification, contact resistance test specification, and final test results were reviewed. Oki has completed a successful development of a flux with RMA reliability, RA solderability, and ease of test pin contact. The Oki Honjo plant manufactured PCBs for 10 months using the new flux without any major problems reported, and it eliminated the use of CFCs in March 1992.

Nitrogen Flow Soldering System. The nitrogen flow soldering system required development of 3 major subsystems: swing spray fluxer for application of low solid flux; low-consumption nitrogen and flux fume chamber for management of nitrogen gas and flux fume flow; and cover plate over the solder bath to eliminate micro solder balls. Technical details and test results were reviewed. Results indicated a failure rate of $.02 \%$ on a sample size of 21,002 PCBs assembled. The smallest component lead pitch on the PCBs tested was $0.5 \mathrm{~mm}$.

Semiaqueous cleaning. The presentation on the development of semi-aqueous cleaning technology was given in two parts. Part one discussed the development of alternative solvents, and part two discussed the development of a cleaning machine.

Solvent development. Mr. Takei defined the basic criteria for selecting an alternative solvent:

- rosin-based solder paste and fluxes can be used

- cleanliness (ionic contamination) is equivalent to CFCs

- chemical residue does not damage PCB reliability 
- no attack upon the parts and PCBs

- safety (no poison and no flash point)

- low running cost

- no damage such as bubbles to cleaning machine

A detailed matrix for three alternative semiaqueous solvents was reviewed. The review covered the topics of solvent properties, damage to other materials, bubble height and elimination time, and drying ability.

Cleaning Machine Development. There are several basic development criteria for a cleaning machine:

- $350 \mathrm{~mm} \times 400 \mathrm{~mm}$ size PCB to be cleaned

- in-line type and max loading of PCB is $3 / \mathrm{min}$

- no problem for operational reliability

- pure water to be used for rinse

- lower ionic contamination than CFCs

- immersed water of PCB to be dried up

- waste water process to be closed system and low process cost

- lower machine cost than other commercial cleaning machines

Detailed technical matrices were reviewed, covering cleaning methods, waste water process, influence of liquid quantity taken out by passing PCB concentration, cleanliness of PCBs, machine stability, and reliability and quality of post-CFC cleaning methods.

\section{LSI Packing Technology}

Mr. Kohara covered the following topics on the subject of LSI packaging technology:

- Logic LSI Packaging

- logic LSI package roadmaps

- high pin count future direction

- wire bond technology improvement

- comparison of high-power package cross-sections

- thermal resistance

- high-speed packages

- Memory LSI Packaging

- technology roadmap for memory-SOJ

- technology roadmap for memory-TSOP

- heat resistance in reflow soldering

- concerns of thin plastic package TSOP

- package outlines 
- TAB Package (TCP - Tape Carrier Package)

- technology roadmap for $\mathrm{TAB}$

\section{Packaging Technology for Fiber-Optic Devices}

Mr. Ishii presented a technical overview on packaging for fiber-optic devices and reviewed the specifications and block diagram for the optical parallel transmission module. Also included were the topics of coupling efficiency for photo diode and laser diode array modules and bit error rates.

\section{FACTORY TOUR}

The first area we toured was a pilot production area to produce LTCC. The manufacturing process is enclosed in a class-10,000 clean room. This process was in the technology development stage at the time of our visit. The equipment being evaluated for this process consisted of screen printers, inspection stations, NC hole punch, lamination, ovens, laser trim, laser solder for outer lead bond, and thermode bonding for inner and outer lead bonding. The process included screen printing of resistors and capacitors.

Table Oki.4

Memory Package (TSOP) Technology Roadmap

\begin{tabular}{|c|c|c|c|c|c|c|}
\hline & & 1990 & 1993 & 1995 & 1998 & 2001 \\
\hline \multirow{2}{*}{$\begin{array}{l}\text { Device } \\
\text { Configuration }\end{array}$} & Density & $4 \mathrm{M}$ & $16 \mathrm{M}$ & $64 \mathrm{M}$ & $256 \mathrm{M}$ & $1 \mathrm{G}$ \\
\hline & Die Size $\left(\mathrm{mm}^{2}\right)$ & 90 & 130 & 190 & 280 & 400 \\
\hline \multirow{2}{*}{$\begin{array}{l}\text { Customer } \\
\text { Usage Condition }\end{array}$} & Storage & $\begin{array}{l}\text { Dry Pack and } \\
1 \text { Day Usage }\end{array}$ & Dry Pack Free & $\longleftarrow$ & $\longleftarrow$ & $\longleftarrow$ \\
\hline & Reflow Condition & IR $\left(240^{\prime \prime} \mathrm{C}\right)$ & IR $\left(240^{\circ} \mathrm{C}\right)$ & $\longleftarrow$ & $\longleftarrow$ & $\longleftarrow$ \\
\hline \multicolumn{2}{|l|}{$\begin{array}{l}\text { Ratio of Die Size } \\
\text { and Package Size }(\%)\end{array}$} & 64 & $72 \sim 75$ & 79 & 80 & 80 \\
\hline \multicolumn{2}{|c|}{$\begin{array}{l}\text { Spacing between Package Edge } \\
\text { and Die Edge ( } \mathrm{mm} \text { ) }\end{array}$} & 1.0 & 0.5 & 0.4 & $\leftarrow$ & $\leftarrow$ \\
\hline \multicolumn{2}{|c|}{ Package Technology Minimization } & Conventional & LOC & LOC & $\longleftarrow$ & $\longleftarrow$ \\
\hline \multirow{2}{*}{$\begin{array}{l}\text { Reliability } \\
\text { (Reflow Resistance) }\end{array}$} & Lead Frame Design & Conventional & $\begin{array}{l}\text { Vent Effect } \\
\text { Lead Frame }\end{array}$ & $\leftarrow$ & & $\longleftarrow$ \\
\hline & $\begin{array}{l}\text { Molding } \\
\text { Epoxy Resin }\end{array}$ & $\begin{array}{l}\text { Conventional } \\
\text { (EOCN) }\end{array}$ & $\begin{array}{c}\text { Biphenyl } \\
\text { (High Adhesion) }\end{array}$ & Biphenyl & \multicolumn{2}{|c|}{$\begin{array}{c}\text { Imid Modified Epoxy } \\
\text { (High Tg) }\end{array}$} \\
\hline
\end{tabular}

EOCN: Epoxy Ortho Cresol Novolak. Source: OKI.

Note: See Table 4.5 (p. 71) for Oki's memory package (TSOP) roadmap and Table 4.13 (p. 88) for its TAB package roadmap. 
The second area the JTEC team toured was a production facility for the assembly of printed circuit boards and end products. Our tour was focused in the area of the printed circuit board assembly. The manufacturing facility was organized into islands of automation; their manufacturing operations are controlled by a central host computer. The operation begins with an automated storage and retrieval system. The management information system (MIS) defines whether or not incoming material, received from a vendor, requires inspection before being placed into the storage area. Components are automatically identified and retrieved by the use of computer control in combination with a bar code system. An automated guided vehicle is used to deliver material to the process lines; this includes magazines of printed circuit boards and prekited component feeders for the placement machines. The standard screen, place, and reflow manufacturing process is being used for surface mount assembly. Bar code labels are applied to bare printed circuit boards, and automated in-line inspection is performed immediately after screen printing of solder paste, component placement, and solder reflow. Automated inspection and test of individual components is performed within the placement machines. Solder reflow profiles are downloaded from the host system. Presently Oki is using vision for solder reflow inspection but is developing a 3-D laser inspection station. A warp prevention robot was developed for processing of large printed circuit boards through the reflow oven. Design rules have been established to obtain optimum yields within the manufacturing process. The rules define the placement location of components onto the printed circuit boards

\section{SUMMARY}

Oki is organized into three business divisions that are highly integrated. The company possesses the technological capabilities required for success in the coming multimedia age. The organization is involved in development and production of products, systems, materials, automated equipment, and manufacturing processes. Oki gives credit to automation as the key in obtaining product yield improvement with high quality and reliability. The driving forces for its development of new products are cost, weight, and miniaturization.

During the JTEC visit our hosts were open in technical discussions and extremely hospitable. 
Site:

Sony Corporation

6-7-35, Kitashinagawa

Shinagawa-ku

Tokyo 141, Japan

Date Visited:

October 4 and 5, 1993

Report Author:

N. Naclerio

\section{ATTENDEES}

JTEC:

P. Barela

W. Boulton

N. Naclerio

HOSTS:

Yoshiyuki Kaneda

Yoshiyuki Yamada

Takehisa Okada

Junzo Wachi

Yunosuke Hayakawa

Yoshiko Numata

Koichi Motegi
Senior Managing Director

Member, Board of Directors, Dir. of Research Center

Senior General Manager, FA and Precision Products

Deputy Senior General Manager, Marketing, FA and Precision Products

General Manager, Production Technology Coordination

Div. Production Technology Development

Systems Engineering Div., FA

Government and External Relations Div., Trade and

External Relations Group

Manager, Government \& External Relations Div., Trade \& External Relations Group

\section{BACKGROUND}

Sony Corporation has $\$ 34.4$ billion in worldwide sales, of which $\$ 10.5$ billion is in the U.S., $\$ 8.9$ billion is in Japan, $\$ 9$ billion is in Europe, and $\$ 6$ billion is in Asia and other areas. Sony has 126,000 employees with 35 manufacturing plants in Japan, 13 in North America, 14 in Asia, and 14 in Europe. The company is organized around business sectors including audio products (audio components, general audio, automotive, and personal communications); video products (personal video, home video); television; personal information systems; and business and professional products. Our host, Mr. Kaneda, was responsible for component technologies (including semiconductors, electronic devices, batteries, and recording media) and factory automation. 
Mr. Kaneda described the borderless, global marketplace in which Sony competes for new and existing markets. He stated that in addition to building creative products, it is necessary to develop production innovations and equipment for advanced assembly and ultraprecision in order to maximize the company's value added and profits.

\section{SONY'S COMPETITIVE STRATEGY}

\section{Precision Manufacturing And Concurrent Engineering}

Mr. Hayakawa stressed the importance of precision manufacturing and concurrent engineering in order to produce compact, lightweight, and highly reliable products. As an example, for the TR5 camcorder (introduced in 1989), product planning began with a vision of a video recorder that would fit in the palm of one hand. This fixed the external dimensions of the recorder and drove the size of the circuit board and recording head. Development work began concurrently at the design divisions for issues of high-density component packages, assembly, PCB, IC, tape transport mechanism, recording cylinder and head, lens, and highdensity recording tape. Simultaneously, development began in the respective production technology organizations.

In the area of printed circuit board technology, the product requirements meant the use of the very latest surface mount technology. Subsequent versions of the TR5 reduced the PCB size by $75 \%$. In order to achieve $100 \mu \mathrm{m}$ solder lands with $100 \mu \mathrm{m}$ spaces, Sony developed a low melting point solder with more uniformly shaped and sized solder particles and a new metal screen technology for more uniform printing. The TRl camcorder introduced in 1992 achieves 20 components $/ \mathrm{cm}^{2}$, or about twice the component density of the TR5. Sony feels that future products will require 30 components $/ \mathrm{cm}^{2}$. Discrete surface mount components as small as $1.0 \mathrm{~mm}$ by $0.5 \mathrm{~mm}$ are currently being used. Surface mount technology is also used in Sony's larger products because it is less costly, higher performance, and can be manufactured with higher quality and reliability than through-hole technology.

Another example of the need for precision manufacturing in the camcorder is in the recording head. In the manufacture of the very narrow head with $0.3 \mu \mathrm{m}$ head gap, it was necessary to cut ferrite material to a thickness of $2 \mu \mathrm{m}$ and a height of $110 \mu \mathrm{m}$. This required the development of a spindle to precisely control a diamond blade. The head is wound 55 times with $30 \mu \mathrm{m}$ wire that must pass through small slots in the head. This required the development of a precision winding machine. The development of these machine tools proceeded concurrently with the design of the product which could not have been built with production equipment available in the marketplace. Therefore, according to Mr. Hayakawa, "manufacturing of the required production equipment must be done in-house. This has become a truly creative activity because it makes the manufacturing of creative products possible."

Sony has turned its expertise in factory automation into a new product area. Sony sells most of the equipment it develops to outside customers. We toured the FA demonstration center 
and surface mount (SMT) assembly training center where customers come to learn how to operate an SMT line. Sony's FA group has grown to about $\$ 500$ million a year in revenue, with $80 \%$ of that still coming from internal Sony customers.

\section{Materials And Process Technology}

Also cited as important were materials and process expertise. As an example, the design of the compact disk player was cited. The heart of a compact disk player is the optical pickup head. In designing the head, Sony considered alternative methods of precision assembly with regards to suitability for automation, reliability, and contribution to size, weight, and cost reduction. Adhesive bonding was the best method for size, weight, and cost reduction, but was poor in the areas of reliability and automation. Because it offered significant product advantages, Sony decided to focus on improving the productivity of the bonding technique. Key parameters to optimize were surface preparation, bonding agent, and process control technique. Sony developed a light ray cleaning method to improve surface wetability and selected nine different bonding agents for joining various components in the pickup head. Sony now manufactures $60 \%$ of all the world's optical pickup assemblies.

\section{Added Value and the Importance of Manufacturing Key Components}

Mr. Hayakawa stressed the importance of manufacturing key components of a product from the viewpoint of value added. In the case of a compact disk player manufactured by Sony, only $10 \%$ of the value added comes from assembly. In contrast, the key devices (optical pickup, semiconductors, lenses, motors, transformers, and PCBs) account for 55\% of the total product cost. Similarly in the case of the $8 \mathrm{~mm}$ camcorder, assembly is about $12 \%$ of the added value, and key devices (CCD, ICs, drum, PCB, magnetic head, motor, lenses, viewfinder, and sensors) make up about $60 \%$. Sony manufactures about $60 \%$ of the key devices for the compact disk player and about $45 \%$ of the key devices for the $8 \mathrm{~mm}$ camcorder, and it intends to increase both percentages in order to increase profitability.

In the case of the Video Walkman, Sony's palm-sized TV/VCR, Sony procures the display from an "associate" company. According to Mr. Kaneda, the miniaturization technology for the electronics and tape transport mechanism was more important than the display technology in realizing the products. The only flat panel displays manufactured by Sony are for use in camcorder viewfinders. Sony feels that LCD technology is only applicable to moderate-sized displays and that its Trinitron CRT technology is superior for wide-screen, high-definition applications.

\section{Effectiveness of Automation}

In addition to processes that require automation in order to achieve precision that cannot be achieved with human hands, Sony cites several other benefits from its use of automation. These include reductions in factory start-up time, in manufacturing defects, and in manpower requirements. 
In the case of the optical pickup head for the compact disk player, early manufacturing involved manual assembly and adjustment by highly skilled technicians. Worker training limited Sony's ability to ramp production and expand overseas. Automation of the line took a lot of preparation, but was accomplished in four months. Replicated lines in Singapore and France took only two to three weeks to bring up to speed. The operators got one month of training in the Japanese factory prior to startup of the overseas plants.

In the case of color television production, robots were introduced to replace $99 \%$ of the manual parts insertion. In addition to the reduction in labor costs, the defect ratio was reduced by $90 \%$, the PCB rework rate was reduced by $75 \%$, and the increased product uniformity allowed Sony to greatly simplify final product adjustments.

In the case of the Walkman a completely automated assembly and adjustment system was installed. Defect levels during initial manual assembly were $0.2 \%$ in the first week and $0.1 \%$ in three months. However, during the first week of automated assembly, the defect rate dropped to a steady 20 PPM. The introduction of subsequent Walkman models into the same factory required additional investments of $9.1 \%, 3.5 \%$, and $1.5 \%$, respectively, for the product changeovers. In addition, the time to bring up the new systems dropped from six weeks to five weeks, then to three weeks, and finally to one week.

As a result of Sony's skills in automation, coupled with its focus on design for manufacturability, it was able to increase sales by $121 \%$ between 1987 and 1990 with only a $35 \%$ increase in the number of direct operating employees. Manufacturing processes are first established and streamlined in terms of manpower, equipment, and materials, then the final system is automated. Because of the heavy use of automation, an increasing fraction of the operators at Sony are involved in maintenance and indirect operations. Sony employs over 1000 people in its factory automation and precision products group and 300 in production technology within Mr. Kaneda's organization.

\section{Quality and Reliability}

According to Mr. Kaneda, any product introduced into the marketplace must have high quality and reliability. Sony tries to reuse well characterized components from previous products in order to achieve high quality in newly introduced products. As much as possible, basic failure mechanisms are identified in the prototyping stages. Once failure mechanisms are understood, stress tests can be designed using heat, environment, or time.

\section{Product Lifecycles}

Product lifecycles are determined by market conditions. On average, minor product changes occur about once a year. However, in the case of the Sony Walkman, new models are introduced every six months or less. Major model changes that require the introduction of new technology occur only once every three to five years. Sony is working to prolong the product's life in the marketplace. 


\section{Advanced Packaging Technology}

Sony has a $3 \mathrm{~dB}$ theory. That means that the next generation of any product should cost half as much and be one-third the size and weight. In order to reduce the size of the next generation of products by $30 \%$, multichip module technology will be required. At the time of the JTEC visit, Sony was not using MCMs in any products because they were too expensive. However, Sony was planning to develop the equipment and processes necessary to manufacture them more cheaply.

\section{Product Design}

A standard design system is used within Sony. The company does not enforce this on external suppliers; they can maintain their independent design styles. Internal and external suppliers are both generally part of the product team from very early in the product life cycle. External suppliers are expected to make investments in new production technology. FA people are always an integral part of the product team. Product design includes reducing the number of components and standardizing components as well as manufacturing methods. Design for assembly difficulty is measured by design and production engineers using a standardized methodology. Design for assembly software was in use at the time of the JTEC visit, and design for disassembly software was expected to be available within one year. The focus on disassembly is driven by end-use markets such as Germany where some stringent requirements are already being discussed. Full 3-D modeling is available for design of products.

\section{SONY RESEARCH CENTER, YOKOHAMA (10/4/93)}

Sony invests about $\$ 2$ billion per year in R\&D, two-thirds of which is product development. It has four corporate laboratories and nine development groups located within the product groups. Sony maintains R\&D labs around the world. In the United States, there are two major technology centers - one in San Jose, CA, and one in Montvale, NJ - and several small laboratories, some of which are collocated with manufacturing operations. The research center in Yokohama consists of five departments: Semiconductors, Materials, Materials Characterization, Computational Materials Science, and Seeds Laboratories. The Seeds Laboratories focus on specific new materials or devices. The center has recently developed a blue laser diode for optical recording, new materials and devices for magnetic recording, and lithium ion batteries

As technologies mature, they are transferred to manufacturing organizations. For example, CCD imaging was a top priority in the early seventies. Once the first CCD camera was demonstrated, the group was transferred to a semiconductor production site to begin designing the pilot and production lines. Battery technology, MOCVD GaAs, and magnetic recording-related technologies have also been spun out to product groups, as was the plan for the blue laser diode in the near future. The main vehicle for technology transfer seems to be 
the movement of people. Researchers generally come to the research center directly from universities. After working at the research center for a number of years they go out to the product groups and remain there so that they can develop and modify the technology in the field of their expertise. From there, they go on to implement the technology in manufacturing. As a result, very few of these people return to the Research Center.

Most R\&D is "needs"-oriented. Product ideas evaluated and selected by top management, at times by the chairman himself, necessitate specific technology development. For example, the palm-sized camcorder required a small sized CCD, a small lens, a high-density printed circuit board, and other key technologies. By specifying timetables and clear targets, R\&D funds are allocated to those areas requiring the most acceleration. Currently, $20-30 \%$ of the center's R\&D is funded by the product groups, and the corporation is trying to increase that amount to $50 \%$. One engineer in every research group is assigned the responsibility for marketing the technology to the product groups. In addition, annual technology fairs are held to showcase ongoing $\mathrm{R} \& \mathrm{D}$ products to the product groups. A new corporate "development laboratory" has been established to further develop new products that might not fit into any existing product group.

We did not see any advanced packaging $R \& D$ being conducted at the Research Center. MCM development is reportedly underway within the semiconductor division and within the Production Technology Development Group's High-Density Mount Laboratory located in Tokyo. Sony Chemical, a subsidiary, is reportedly doing advanced PWB research.

One complex new piece of materials analysis equipment was being operated by an American who recently earned a Ph.D. at a leading U.S. research institution. He said that he came to the research center because it was the best equipped in the world for the work that he wanted to do.

\section{SONY'S KOHDA FACTORY (10/5/93)}

O. Uchida - President

T. Kono - Senior Executive Director

H. Yamada - Engineering and Design

The plant was established in 1972 and currently designs and manufactures Sony's advanced $8 \mathrm{~mm}$ camcorder products. Products include $8 \mathrm{~mm}$ camcorders and tape decks and key components such as tape drums, tape transport mechanisms, and reference tape. The key components manufactured at Kohda are primarily exported to overseas Sony assembly plants. The plant also manufactures some low-volume products such as editors, special effects generators, and color printers. The plant employs 2,040 people including 200 engineers, half of whom are production engineers. The plant has a capacity to produce 550,000 recording drums and 250,000 camcorders per month. Overseas plants primarily do final assembly and manufacture some commodity products like standard quality recording tape. 
The tape drum, transport mechanism, and PCB are key components of the camcorder because they determine the picture quality, reliability, and intelligence of the unit, respectively. Other key components such as the CCD, LCD viewfinder, and ICs are manufactured at other Sony plants. The most advanced production technologies are employed including precision processing, automated assembly, high-density surface mounting, and automatic picture quality adjustment. The plant was ISO 9002 certificated at the time of the JTEC visit; it received ISO 9001 certification in November 1993.

The majority of the operation is automated with Sony FA and precision assembly equipment. According to Sony, the level of automation for various tasks are: $98 \%$ for SMD placement, $100 \%$ for drum manufacture, $98 \%$ for standard tape deck assembly, $71 \%$ for compact tape deck assembly, $100 \%$ for CCD assembly, and $75 \%$ for camera adjustment. The lower level of automation for the most compact tape deck is due to the need for lots of adjustments. Much of the final product assembly that does not require much precision is done manually. Two exceptions are video adjustment and system testing, which is fully automated using a very impressive system.

The SMT factory we visited was producing PCBs for the TR1 camcorder. Each card contains approximately 1400 components. The primary bottleneck in the plant is the flow of materials to the assembly machines, which have to handle up to 100 part types. The CIM system identifies which placement machines are going to run out of parts and notifies an operator approximately 30 minutes in advance. When operators reload the machines, bar code readers verify that the correct parts have been loaded. Only one PWB type at a time is manufactured on any one SMT line. Minor product changeovers take about 15 minutes, but a major product changeover could take two to four hours. Machine instructions are downloaded from a factory CIM system. It appeared that the majority of the SMT assembly time was consumed with the placement of small discrete devices. The engineering manager said that the company was looking at new methods of feeding the components to the placement head that would cut placement time and also looking at the use of thick-film hybrids with integral passive components for higher frequency applications such as HDTV.

The tape drum factory we visited is completely automated and produces the complete tape drum starting from bars of aluminum. The material handling system for the partially manufactured drums resembles vacuum cleaner hoses draped from station to station through which the tape heads roll. During the final assembly steps the recording head must be positioned in a groove in the cylinder with $\pm 1 \mu \mathrm{m}$ accuracy. In order to achieve this, a vision system inspects each drum and measures certain critical dimensions. One of perhaps 100 spacers is placed between the drum and the head that will result in $\pm 5 \mu \mathrm{m}$ placement accuracy of the recording head. The screw that holds the head in place is then tightened under computer control to achieve the final $\pm 1 \mu \mathrm{m}$ accuracy. This simple but elegant solution presumably achieves the necessary accuracy without the expense of machining every head to the final dimensional accuracy. It should be noted that the final assembly step just described, as well as several of the other manufacturing steps, are accomplished using specialized machines built by Sony. 
The assembly of the tape decks is accomplished with over 100 Sony precision assembly robots organized into 6-8 parallel production lines. During the time that JTEC panelists were touring the plant we saw a couple of events where a yellow light alerted an operator to come and assist with some operation. Generally, the operator spent no more than a minute or two before he had the machine back in operation. It appeared that there was approximately one operator per dozen robots in the plant. Our hosts told us that when a robot failure cannot be fixed quickly a new robot may have to be brought in to replace it. During the time a production line is down, all but a few high-precision operations can be replaced by human operators. Failures that take a robot down for an entire shift happen about once every six months.

In the final assembly operation, the tape deck, camera, and PCB are brought together. Once the major subassemblies have been brought together, the camcorders are powered up and focused on a series of images. A fully automated system makes 6-8 adjustments to the picture quality of each camcorder and burns the settings into an onboard PROM. Partially through the process, a robot inserts a tape into the camcorder and tests the record and playback functions. The fully tested and adjusted camcorders then proceed down an assembly line to a series of stations where operators manually perform the final assembly steps including the attachment of flex wiring circuits to the external case. This line produces approximately 1,200 camcorders per shift.

Product and production design for the $8 \mathrm{~mm}$ camcorder products is also located at the Kohda plant. The design center is located in the upper stories of the factory building directly over the production floor. The engineers work in a open space with lots of paper drawings and actual hardware lying around. A glass-walled room contains a mainframe computer and a number of workstations. At the time of the JTEC visit, CADAM, a 2-D mechanical CAD package was in use for the design of the robots and the mechanical assemblies. It is interesting to note that these two operations were going on at adjacent workstations, a sight not likely to be seen in the United States. The engineers rely on the reuse of common components across and within product lines to shorten development time. For example, Sony manufactures a family of tape transport mechanisms that are used in both its camcorders and its Watchman.

\section{SUMMARY}

Sony is a best-of-breed worldwide consumer electronics company. Its leadership appears to be based on a combination of innovative products, precision manufacturing skills, and continuous improvement. Our hosts credit Sony's leadership in the manufacture of highquality, low-cost electromechanical products to its leadership in precision assembly equipment, materials and processes, and factory automation. From what we saw, it certainly appears to be a leader in precision assembly. That leadership is further demonstrated by its ability to market its precision assembly and FA systems to other manufacturers. Sony's focus on in-house production and integration of factory equipment seemed fairly consistent with 
other companies we visited in Japan, but in stark contrast with the direction of leading U.S. electronics companies. While Sony's investments seem justified in areas such as machining the recording head or assembly of the tape transport mechanisms, where the company has succeeded in producing unique and competitive equipment, its investments seem less justified in areas such as surface mount assembly, where numerous companies produce comparable equipment.

According to Sony representatives, "creativity" has always been an important concept at Sony, one of the leaders in introducing new and innovative products to the market. In order to manufacture those products, Sony has been developing new equipment, and that is where its strength lies. It also has a flexible policy that promotes the effective use of existing manufacturing equipment available in the open market.

Like Sony's competency in factory equipment, its strong competencies in materials and processing appear to be a competitive differentiator in the marketplace. Examples like the development of solder paste for very-fine-pitch component assembly, or the exploitation of adhesive bonding for the compact disk optical pickup, seem to demonstrate the value of its process. Few if any U.S. electronics firms have comparable depth in the materials arena.

Sony also recognizes the importance of controlling the manufacturing of its critical components. However, according to Sony representatives, it is not Sony's policy to concentrate manufacturing of key components in Japan. In fact, its corporate policy promotes local manufacturing. This concept is valid for key components as well as products, and thus Sony has many key components plants located within the region of product manufacturing plants on a worldwide basis.

Sony, like other Japanese companies the JTEC team visited, seems almost obsessed with the use of automation to increase productivity and quality. The only tasks being done by humans were those that did not require much precision or perhaps were too expensive to automate, such as the final assembly of the camcorder case.

Our hosts seem to recognize the importance of electronic packaging as a competitive differentiator. They listed the PCB as a key component of both the camcorder and the compact disk player. Sony seems to be pushing surface mount assembly to its limits through incremental refinements rather than any revolutionary technology. Based on our observations, one of the biggest drivers for a change in packaging technology at Sony is reducing the number of discrete components needing assembly on PWBs. While digitization of the electronics and increased IC integration will certainly help, a substrate technology with integral passive components would drastically reduce part count and provide a significant area savings. 
Site:

TDK Corporation

\section{3-1, Nihonbashi, 1-chome, Chuo-ku Tokyo 103, Japan}

Date Visited:

October 7, 1993

Report Author:

G. Meieran

\section{ATTENDEES}

JTEC:
W. Boulton
G. Harman
G. Meieran
R. Shelton

\section{HOSTS:}

Fumio Uchikoba

Kenichi Aoshima

Noboru Yamaki

Akira Okamoto

Mitsunobu Goto

Akira Fukuno

Tadashi Mitsui

Kouichi Yajima

Takashi Horiuchi

Tatsushiro Ochiai
Researcher, Materials Research Center, Narita

Manager, Corporate Planning Office

Dept. Director, General Affairs, Narita

Manager, Advanced Products Development Ctr.

Manager, Corp. Research and Development Dept.

Senior Researcher, Materials Research Ctr.

Chief Engineer, Ferrite Division

Manager, Materials Development Section, Corporate R\&D

Manager, Production Engineering Dept.

Executive Director, General Manager, Materials

Research Ctr.

\section{BACKGROUND}

The visit to TDK was bimodal; a very interesting and useful morning in which we discussed the TDK packaging and assembly issues, and an afternoon plant tour of the ferrite manufacturing facility in Narita, which was interesting but not particularly pertinent to the packaging and assembly issues. Hence, this site report concentrates only on the morning session, and only mentions two aspects of the afternoon tour that had some pertinence to packaging and assembly. Most of the information discussed below was presented to the visiting JTEC team in the form of two interesting and extremely well-done video tapes; we did not personally see any of the processes or equipment described in these tapes. 
TDK appears to be a very well run company with excellent facilities, top quality people, and excellent technology. It was formed in 1935 by the invention (so we are told) of ferrites. It appears to be a world leader and the world's largest supplier of ferrites, ferroelectrics, and other electronic materials. Its products are used everywhere, such as in floppy and hard disks. As a result of this path, TDK has become very adept at manufacturing passive and active electronic components, and in their assembly into high-quality PC boards. Indeed its manufacturing capabilities in the component area are no less than phenomenal; TDK produces very small parts in huge quantities, using state-of-the-art equipment and processing capabilities. Because there is a need to have equipment available to assemble these small components, TDK makes much of its own equipment, and, as other Japanese companies showed us, it is prepared to sell its assembly equipment to the external market (except for its latest state-of-the-art manufacturing equipment).

The quality of TDK products appears to be very high; design of products and processes is thorough and well done. Video tapes describing all this were among the best $I$ have seen and were convincing. Even at the fairly old ferrite plant, most of the processes are automated; it appears as if yield is good and quality levels are high. However, we had the impression from the ferrite plant visit that TDK is not addressing other manufacturing issues; there was lots of inspection, lots of inventory, and little evidence of motivation to do anything differently.

Since much of TDK's product line consists of old products with very little profit margin, it is moving some of its manufacturing overseas, to China and Malaysia, and has challenged its domestic staff to come up with new, high-value-added products. It will use its current products, but will look to incorporate these into high-value products. In newer lines, such as seen on the video tape, there is little evidence of inspection, and automation appears to be $100 \%$. It was impossible to see what inventory levels were present. The TDK philosophy seems to be, "Good enough is good enough." If something requires automation or special manufacturing processes, fine, the company will develop and provide technology and automation as necessary; otherwise, incremental improvement is satisfactory.

TDK has about 25,000 employees total, about 7,000 of whom are domestic. About $60 \%$ of its manufacturing capability was in Japan at the time of the JTEC visit. Its product line includes ferrites, semiconductors, ceramic components, recording media, metallic products, and a variety of other mostly electronic products.

All that we saw was consistent with TDK's stated company philosophy, "Respecting Originality," with its company motto, "Contribute to Culture and Industry Through Creativity," and with its employee attributes, "Vision, Courage, Reliance."

\section{COMPONENT DESIGN AND MANUFACTURING}

TDK designs and fabricates components such as small transformers, inductors, and capacitors in huge (hundreds of millions of individual pieces) quantities. It also makes hybrids, 
sometimes incorporating passive elements in an active circuit. Consequently, it manufactures a very broad line of products. Indeed, its product line numbers in the range of 140,000 , although it is trying to reduce this to a more manageable level $(30,000$ ?). TDK clearly appears to be competitive with the state of the art, or is setting the standards for state of the art, in the fields in which it competes.

The sizes of the small parts TDK manufactures is staggering, even to those of us in the semiconductor industry, in which "small" refers to line geometry, but the chips may be fairly large. Its smallest capacitors are, for example, smaller than a grain of pepper (one sneeze and 400,000 parts disappear!). Even these tiny objects are made up of many layers of alternating dielectric and metalization, cleverly laid down in sequential sides of a chip to give a ramped staircase effect, in the case of physically small inductors.

The emphasis is on cost and size reduction. TDK seems less interested in integration; indeed it seems to be the opposite of a company such as Intel, which makes individual chips that integrate many functions and grow larger as a result of integration; TDK wants to make things as individual components and as small and inexpensive as possible. As a result, it has developed a line of assembly equipment that can handle its small and exceedingly wide line of products. This line of equipment is extremely sophisticated, very precise, and totally automates assembly of PC boards; operators can barely see, much less manually handle, TDK's line of small components. The company's equipment appears to be a decade ahead of anything comparable in the United States.

\section{Customer Focus}

TDK might be expected to be a leader in high-temperature superconductors, resulting from its extensive expertise in ferroelectric device technology. But a technical as well as business perspective arose when superconductors were discussed during the JTEC visit. On the one hand, TDK spent several years and lots of money looking at high-temperature superconductors; however, there were several technical problems that suggested that it need not bother, and work on these materials has ceased. Even more important, our hosts stated that even if all the technical problems were solved (materials synthesis, defects, hysterisis, whatever), the devices would still need to be operated below room temperature, so TDK would likely not get involved. The customer base would not be expected to want to use cooled packages, and since TDK makes products for its customers, it is not likely to get reinvolved. In this sense, TDK looks at technology to help develop markets, but, clearly the market rules, not the technology.

TDK's ceramic substrates are quite thin, say $\sim 5 \mu \mathrm{m}$, and it has solved the cracking problems normally associated with such thin brittle layers. It then builds up 70 or 100 layers, making these small, 1 pf capacitors. It has solved cracking problems by carefully selecting metalization materials (e.g., nickel), closely matching the thermal expansion coefficients of the materials, and firing at relatively low temperatures. 


\section{Assembly Automation Equipment}

Initially, equipment was developed in-house to handle only TDK products, under the assumption that the company could get a better lock on the market this way. People who bought their equipment to assemble some TDK products would find that they could only use it on TDK product lines. This strategy back-fired. It was too focused on TDK product lines, and the competition from companies such as Matsushita, which offered a more "open architecture," caused management to change this strategy. Their present line of equipment, made by a company called Avimount, accounts for 7\% of TDK's business.

\section{Cost Basis}

TDK has calculated that labor costs in Japan are on the order of two seconds per yen. Since a multilayer capacitor costs about one yen, it is impossible to inspect products. Hence, TDK has adopted the philosophy of zero defects. Indeed, current figures show a defect rate on the level of 1 to 10 PPB. On assembled products, there is a defect level of 10 to 100 PPM. Clearly, TDK drives all non-value-added costs out of the manufacturing process; U.S. companies might invest in inspection and testing, while TDK invests in process improvement.

TDK is ISO certified, but only because of U.S. customers. There appears to be no great drive in Japan for standards as there are in the United States.

\section{Technology}

Our hosts showed us an interesting expert system, of which they seemed quite proud. This is a system that designs products by having a customer choose magnetic properties, and the expert system provides the details of how to make the product, e.g., composition, firing conditions, etc. Or the customer can choose a composition for the three-dimensional phase diagram, and the magnetic properties and appropriate processing conditions pop out. This is a neat piece of software, with some excellent graphics, and it appears to be in use.

TDK has an interesting way of making rare-earth iron magnets. It fires (sinters) magnetic bodies made from fine powders with intentionally lower oxygen content in order to get rid of nonmagnetic rare earth oxide impurities. It has introduced an hydrogen absorption and desorption process to ingots so that the ingots become brittle. Since brittle ingots need less impact for fine pulverization, they can prepare fine powder by applying lower oxygen content - a neat way to use a failure mechanism to help solve a problem and simplify a process.

The JTEC team got some idea of the persistence of Japanese companies in pursuing worthwhile ideas and technology, and the inverse, the rapid discarding of even good ideas that do not fit their marketing molds. At Narita, we saw a (new then) green tape line for metalized ceramics that TDK had been pursuing for seven years and was only then being readied for mass production. This line is for glass-ceramic composites, with a low $\left(\sim 900^{\circ} \mathrm{C}\right)$ firing temperature. The material is low-cost and strong, but does not have the thermal 
conductance of pure ceramics such as alumina. But TDK sees a market and is going to start proliferating the technology in the near future.

This is to be contrasted with the rapid elimination of the high- $\mathrm{T}_{\mathrm{c}}$ superconductor program, which simply did not meet TDK's customer profile, even though it seems to have totally appropriate technology and expertise, and the technology seems to have promise for some markets.

Indeed, this seems to be an area of some contention; how does a company like TDK take advantage of new opportunities? TDK is excellent in technology, but seems to be less strong in developing new markets that may be a bit out of the path of its existing markets.

\section{SUMMARY}

The impressive features about TDK are its technology for mass producing a large variety of very small, high-quality products. As a consequence, it has developed a very strong customer consciousness and a wealth of supporting tools (such as assembly equipment for mounting these small parts). It has a strong company focus on producing quality products that require minimal inspection, on satisfying the customer with the range of products it produces, on maintaining a product line compatible with its technological expertise, and on persisting until the technology problems associated with its product lines are resolved.

Any new products must meet the above criteria. As a result, TDK is a very strong force in Japanese electronics manufacturing and has an impressive track record ranging from innovation and invention (of ferrites) to implementation and marketing. Its electronic products line is broad as well as deep, and is state-of-the-art. Whether or not TDK will be as strong a force in marketing assembly equipment remains to be seen, but there is little doubt it is capable of strongly entering this market. 
APPENDIX D. SPONSORS OF THE JTEC STUDY ON ELECTRONIC PACKAGING IN JAPAN

National Science Foundation

Paul Herer

Linton Salmon

Advanced Research Projects Agency

Lance Glasser

Nick Naclerio

National Aeronautics and Space Administration

John Evans

Jillian Evans

Phil Barela

Department of Commerce

Phyllis Genther-Yoshida

Tom Kusuda

George Harman 


\section{APPENDIX E. ATTENDEES AT THE INDUSTRIAL REPRESENTATIVES MEETING ON APRIL 19, 1993}

Lisa Anklewich

W.R. Boulton

Mung Chen

Gerry Dillman

John L. Evans

Edward Hakim

George Harman

Jeffrey Hawthorne

Kim Hyland

Richard Jaeger

Mike Kelly

Bruce Kramer

John Kukowski

Judee Mussehl-Aziz

Nick Naclerio

Luu Nguyen

Don Orr

Mike Pecht

John Peeples

Gordon Roberts

Linton Salmon

Mike Snyder

Melissa Timmons

Nicholas Vadala

E. Jan Vardaman

Daniel Ward

Nancy Watts
Ford

Auburn University

Intel

IBM

Chrysler

Army Research Lab

NIST

Motorola

Apple

Alabama Microelectronics S\&T Center

Georgia Tech

NSF

Rochester Institute of Technology

International Trade Administration

ARPA

National Semiconductor

MCC

University of Maryland

NCR

AT\&T

NSF

Universal

Hayes Microcomputer Products

Digital Equipment Company

TechSearch International

Delco Electronic

Hayes Microcomputer Products 
APPENDIX F. GLOSSARY

ACA

$\mathrm{AD}$

AGV

AI

AMLCD

ASIC

ASIM

AV

AXPC

B-PGA

BGA

$\mathrm{CD}$

CD-ROM

C-PGA

CCL

CFC

CAD

CAE

CAM

CIM

CISC

COB

$\mathrm{COF}$

CTE

CRT

DCC

DFX
Anisotropic Adhesive Connection

Active Device

Automated Guided Vehicle

Artificial Intelligence

Active Matrix Liquid Crystal Display

Application-Specific Integrated Circuit

Application-Specific Integrated Module

Audiovisual

A UNIX operating system unique to Japan

Bumped Pin Grid Array

Ball Grid Array

Compact Disk

Compact Disk Read Only Memory

Ceramic Pin Grid Array

Copper Clad Laminate

Chlorofluorocarbon

Computer-Assisted Design

Computer-Assisted Engineering

Computer-Assisted Manufacturing

Computer-Integrated Manufacturing

Complex Instruction Set Chip

Chip On Board

Chip on Flex Board

Coefficient of Thermal Expansion

Cathode-Ray Tube

Digital Compact Cassette

Design For Excellence 
DIP

DRAM

ECU

EMI

FA

FMS

FOB

FOG

FPQFP

GaAs

HDA

HDD

HDTV

HF

HIC

IC

I/O

IR

ISDN

ISO $(9000$, etc. $)$

KGA

KGD

LCD

LGA

LSI

LTCC

MC

MCM

MCM-C
Dual Inline Package

Dynamic Random Access Memory

Electronic Control Unit

Electromagnetic Interference

Factory Automation

Flexible Manufacturing System

Film On Board

Film On Glass

Fine Pitch Quad Flat Package

Gallium Arsenide

Hard Disk Assembly

Hard Disk Drive

High Definition Television

High Frequency

Hybrid Integrated Circuit

Integrated Circuit

Input/Output

Infrared

Integrated Service Digital Network

International Standards Organization standards

Known Good Assembly

Known Good Die

Liquid Crystal Display

Land Grid Array

Large-Scale Integration

Low-Temperature Ceramic Carrier/Component

Molding Compound

Multichip Module

Multichip Module-Ceramic 
MCM-D

MCM-L

MD

MLC

MOCVD

OA

PA

PC

PCA

PCB

PCMCIA

PDA

PDIP

PEM

PGA

PLCC

PPB

PPM

PQFP

PTH

PWB

QA

QC

QCD

QFJ

QFP

QML

QPL

QSSOP
Multichip Module-thin film Dielectric

Multichip Module-Laminate

Mini Disk

Multilayer Ceramic

Metal Oxide Chemical Vapor Deposition

Office Automation

Personl Assistant

Personal Computer; also, Printed Circuit

Printed Circuit Assembly

Printed Circuit Board

Personal Computer Memory Card Industry Association (card standard)

Personal Digital Assistant

Plastic Dual Inline Package

Plastic Epoxy Molded

Pin Grid Array

Plastic Leaded Chip Carrier

Parts Per Billion

Parts Per Million

Plastic Quad Flat Package

Pin Through hole

Printed Wiring Board

Quality Assurance

Quality Control

Quality, Cost, Delivery

Quad Flat J-type (package)

Quad Flat Package

Qualified Manufacturing List

Qualified Parts List

Quartersize Small Outline Package 


\begin{tabular}{|c|c|}
\hline $\mathrm{RF}$ & Radio Frequency \\
\hline SBB & Stud Bump Bond \\
\hline SEM & Scanning Electron Microscope \\
\hline $\mathrm{SD}$ & Structural Device \\
\hline SDIP & Shrink Dual Inline Processing \\
\hline SIA & Semiconductor Industry Association \\
\hline SIP & Small Inline Package \\
\hline SLC & (IBM's) Surface Laminar Circuit \\
\hline SM & Surface Mount \\
\hline SMD & Surfact Mount Device \\
\hline SMT & Surface Mount Technology \\
\hline SOJ & Small Outline J-leaded (package) \\
\hline SOP & Small Outline Package \\
\hline $\mathrm{SPC}$ & Statistical Process Control \\
\hline SQFP & Shrink Quad Flat Package \\
\hline SQC & Statistical Quality Control \\
\hline SSOP & Shrink Small-Outline Package \\
\hline STD & Strategic Technology Domain \\
\hline STN & Super Twisted Nematic (type of LCD) \\
\hline TAB & Tape Automated Bonding \\
\hline TCE & Thermal Coefficient of Expansion \\
\hline TCP & Tape Carrier Package \\
\hline TFMCM & Thin Film Multichip modules \\
\hline TFT & Thin Film Transfer \\
\hline TMA & Thermal Mechanical Analysis \\
\hline TPM & Total Preventive Maintenance \\
\hline TQC & Total Quality Control \\
\hline TQFP & Thin Quad Flat Package \\
\hline TQM & Total Quality Management \\
\hline
\end{tabular}


TSOP

TSSOP

TTQFP

ULSI

$\mathrm{V}_{\mathrm{cc}}$

$\mathrm{V}_{\mathrm{dd}}$

VCR

VHS

VLSI

VSOP

VSQFP

VTR

$\mathrm{ZD}$
Thin Small Outline Package

Thin Sealed Small Outline Package

Thin, Thin Quad Flat Package

Ultra Large Scale Integration

Cathode-Cathode Voltage

Drain Voltage

Video Cassette Recorder

Standard for VCRs initiated by Matsushita

Very Large Scale Integration

Very Small Outline Package

Very Small Quad Flat Package

Video Tape Recorder

Zero Defects 